UNIVERSIDADE DE SÃO PAULO

INSTITUTO DE GEOCIENCIAS

\title{
PALINOLOGIA E BIOESTRATIGRAFIA DO SUBGRUPO ITARARÉ EM ARAÇOIABA DA SERRA (WESTPHALIANO, BACIA DO PARANÁ), ESTADO DE SÃO PAULO, BRASIL
}

\author{
Paulo Alves de Souza
}

Orientador: Prof. Dr. Setembrino Petri

DISSERTAÇÃO DE MESTRADO

Programa de Pós-Graduação em Geologia Sedimentar

SĀO PAULO

1996 
UNIVERSIDADE DE SÃO PAULO

INSTITUTO DE GEOCIENCIAS

\section{PALINOLOGIA E BIOESTRATIGRAFIA DO SUBGRUPO ITARARÉ EM ARAÇOIABA DA SERRA (WESTPHALIANO, BACIA DO PARANÁ), ESTADO DE SÃO PAULO, BRASIL}

Paulo Alves de Souza

Orientador: Prof. Dr. Setembrino Petri

DISSERTAÇÃO DE MESTRADO

COMISSÃO JULGADORA

nome

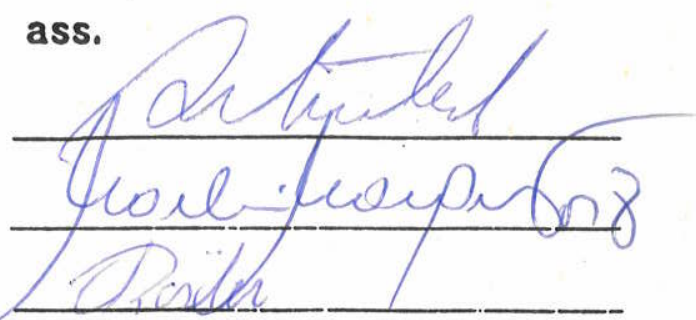

SÃO PAULO

1996 


\section{UNIVERSIDADE DE SÃO PAULO \\ INSTITUTO DE GEOCIENCIAS}

\section{PALINOLOGIA E BIOESTRATIGRAFIA DO SUBGRUPO ITARARÉ EM ARAÇOIABA DA SERRA (WESTPHALIANO, BACIA DO PARANÁ), ESTADO DE SÃO PAULO, BRASIL}

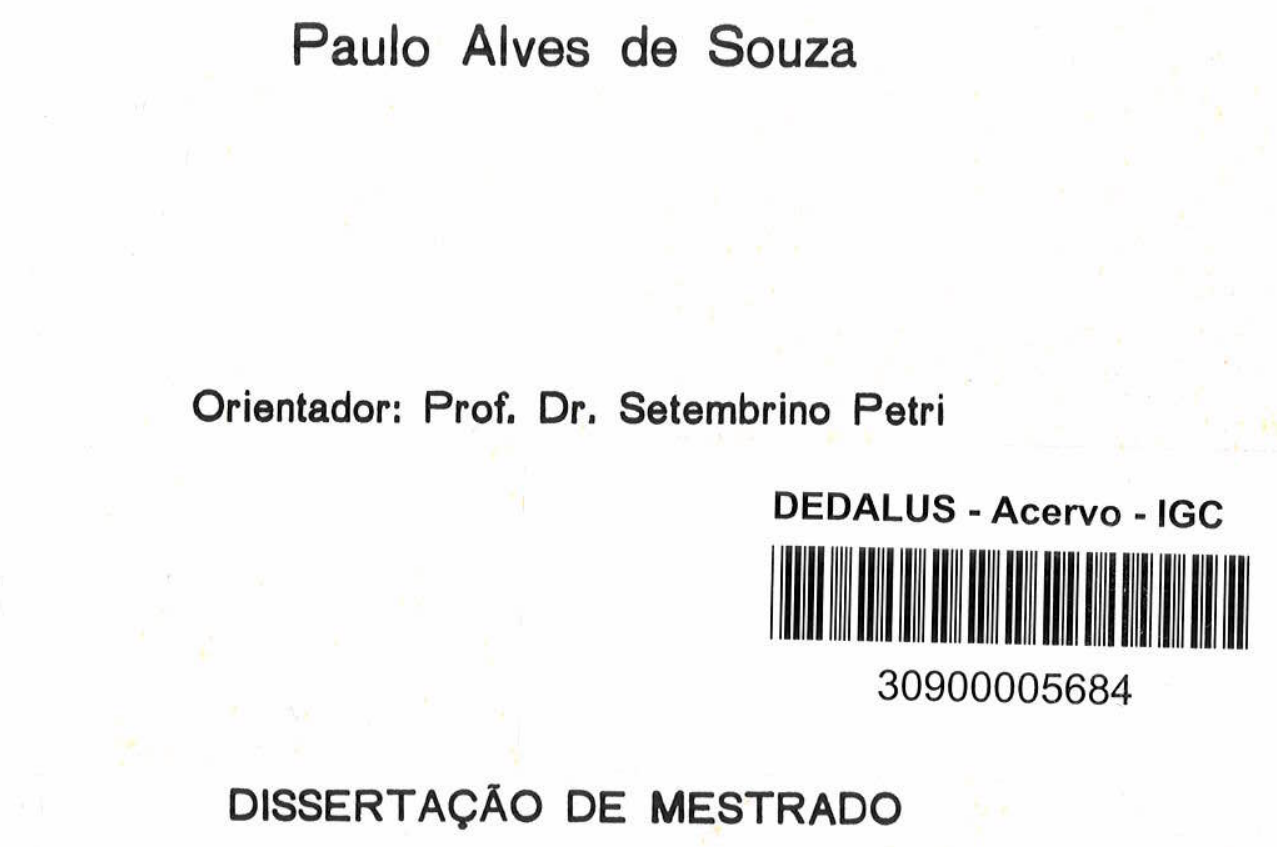

Programa de Pós-Graduação em Geologia Sedimentar

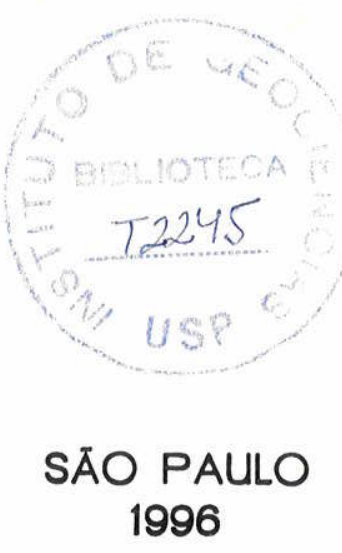




\section{ERRATA}

da Dissertação de Miestrado de Paulo Alves de Souza: "Palinologia e bioestratigrafia do Subgrupo Itararé em Araçoiaba da Serra (Westphaliano, Bacia do Paraná), Estado de São Paulo, Brasil" defendida no IG-USP em 29.02.1996.

\begin{tabular}{|c|c|c|c|}
\hline pág & linha & onde se lê & substituir por \\
\hline 05 & 09 & referente-se & refere-se \\
\hline 09 & penúltima & corelações & correlaçőes \\
\hline 10 & 05 & admostrados & amostrados \\
\hline 11 & 10 & flurorídrico & fluorídrico \\
\hline 14 & 06 & heterogeineidade & heterogeneidade \\
\hline 17 & 14 & conjuto & conjunto \\
\hline 20 & 10 & Hotolândia & Hortolândia \\
\hline 23 & 24 & frqüência & freqüência \\
\hline 27 & 24 & Palinozona & Palinozonas \\
\hline \multirow[t]{2}{*}{29} & 20 & goiraiensis & goraiensis \\
\hline & 26 & Virkkiae & virkkiae \\
\hline \multirow[t]{2}{*}{46} & 6 & esclusivamente & exclusivamente \\
\hline & penúltima & aqueles & aquelas \\
\hline \multirow[t]{2}{*}{51} & 18 & pseudopaliatus & pseudopalliatus \\
\hline & antepenúltima & formas & forma \\
\hline 52 & 11 & vermiculados & vermiculadas \\
\hline 53 & 13 & melhor & melhores \\
\hline \multirow[t]{3}{*}{62} & 14 & tyicus & typicus \\
\hline & 18 & denifida & definida \\
\hline & 18 & atingido & atingindo \\
\hline 64 & 7 & (Azcuy, 1975) Argentina & (Azcuy, 1975), Argentina \\
\hline \multirow[t]{2}{*}{65} & 16 & stratus & stratum \\
\hline & penúltima & ;e & é \\
\hline \multirow[t]{2}{*}{66} & 04 & descreveu & descreveu \\
\hline & 04 & face & 0 \\
\hline 67 & 12 & V. sp. 2, aqui descrita, & V. sp. 2, verificada, porém năo descrita, \\
\hline 73 & 24 & consituindo & constituindo \\
\hline 78 & penúltima & Kremp & Kemp \\
\hline \multirow[t]{2}{*}{83} & 12 & Penssilvania & Pennsylvania \\
\hline & 15 & dintinto & distinto \\
\hline 85 & última & Potonié \& Sah,. 1960; & Potonié \& Sah, 1960, \\
\hline 89 & 12 & corpo central se & corpo central e se \\
\hline 92 & 3 & est. I,, fig. 7 & est. I, fig. 7 \\
\hline 98 & última & subequtoriais & subequatoriais \\
\hline 99 & 14 & equtorial & equatorial \\
\hline 102 & 9 & Torunaisiano & Tournaisiano \\
\hline 108 & 17 & Gametro & Gamerro \\
\hline 111 & 6 & destes útlimos. & deste. \\
\hline 114 & 12 & possuindo & possui \\
\hline 124 & 22 & C. inconstans & C. lestai \\
\hline \multirow[t]{2}{*}{125} & 25 & Illimois & Illinois \\
\hline & última & Pensilvania & Pennsylvania \\
\hline \multirow[t]{2}{*}{126} & 10 & Apiculiretusispora, & Apiculiretusispora sp., \\
\hline & $17 / 18$ & Vallatisporites ciliaris, ... Raistrickia & grafar todas as espécies e gêneros em itálico \\
\hline \multirow[t]{2}{*}{130} & 11 & teriam & tivessem \\
\hline & última & que o intervalo $\mathrm{G}$ & que aqueles do intervalo $\mathrm{G}$ \\
\hline \multirow[t]{2}{*}{131} & 16 & tão antigos mais antigos. & tão antigos. \\
\hline & 25 & classifcou & classificou \\
\hline \multirow[t]{2}{*}{135} & 7 & genese & gênese \\
\hline & 16 & estabelecendo até 5 & estabelecendo 5 \\
\hline 147 & 7 & da dos eventos & dos eventos \\
\hline \multirow[t]{2}{*}{153} & 3 & execelente & excelente \\
\hline & 19 & consideram & consideraram \\
\hline 154 & 16 & năo o foram & năo as foram \\
\hline 155 & 13 & disperçắo & dispersão \\
\hline \multirow[t]{2}{*}{162} & 11 & pantanos & pantanosos \\
\hline & $12 / 13$ & vegetação do tipo gimnospérmicos & vegetação gimnospérmica \\
\hline 172 & 14 & regionalizado & regionalizados \\
\hline
\end{tabular}

acrescentar no final da página 171, após camadas:

mais antigas no que se refere ao Carbonifero, é possivel assegurar que esta ocorrência é a mais antiga da Bacia do Paraná neste período do tempo geológico. 


\section{ABSTRACT}

Surface and subsurface (Geomater borehole) data from south of Araçoiaba da Serra, São Paulo State, contribute to the biostratigraphic and paleoenvironmental analysis of the lower part of the Itararé Subgroup, Paraná basin. One hundred-and-ten taxa were found, related to twenty-six genera of spores, nine of pollen grains and three of microplanktonic elements. Forty-eight species are registered for the first time in the Paraná basin, demonstrating the previous lack of knowledge of this part of the section.

The following taxa position the Geomater sequence and part of the exposed levels in the Westphalian: Granulatisporites varigranifer Menéndez \& Azcuy, 1969; Raistrickia rotunda Azcuy, 1975; Dictyotriletes muricatus (Kosanke) Smith \& Butterworth, 1967; Ahrensisporites cristatus Playford \& Powis, 1979; Ancistrospora inordinata Menéndez \& Azcuy, 1972; Ancistrospora verrucosa Menéndez \& Azcuy, 1972; Florinites guttatus Felix \& Burbridge, 1967; Florinites occultus Habib, 1966; and Florinites sp.

Biostratigraphic analysis indicates that the palynological content is new for the Brazilian part of the Paraná basin. In terms of Gondwana, correlation is best with the oldest Argentinian Carboniferous palinozones and equivalent palynozones in Australia.

The succession in the Geomater borehole is divisible into three informal intervals (lower, middle and upper) delimited by the disappearance and appearance of different taxa.

The taxa verified at $\mathrm{km} \mathrm{122.7,} 123.7$ and 125.8 of the Raposo Tavares highway are correlatable among themselves and with the upper interval of the borehole. Palynomorphs at $\mathrm{km} 118.6$ demonstrated a younger age, contrary to previous lithostratigraphic interpretations.

Among the sporomorphs, the new species Ancistrospora reticulata n. $s p$. is described and another two are transferred to distinct genera: Dictyotriletes pseudopalliatus (Staplin) new comb. and Vallatisporites punctatus (Marques-Toigo) new comb.

In paleoenvironmental terms, the presence of microplanktonic elements referred to Navifusa Combaz, Lange \& Pansart, 1967 indicates a marine influence for the most of the Geomater section and in the studied outcrops as well. 


\section{RESUMO}

Cento e dez táxons, relacionados a vinte e cinco gêneros de esporos, nove de grãos de pólen e três de elementos microplanctônicos, são verificados no poço Geomater e em 4 afloramentos da Rodovia Raposo Tavares, região de Araçoiaba da Serra, Estado de São Paulo, permitindo o estudo e a análise bioestratigráfica de parte da seção basal do Subgrupo Itararé, Bacia do Paraná. Quarenta e oito táxons são noticiados pela primeira vez na bacia, demonstrando o desconhecimento desta parte da seção e a ausência de trabalhos mais profundos desta natureza no Estado de São Paulo.

Os seguintes táxons permitem posicionar a seqüência do poço Geomater e parte dos níveis aflorantes no Westphaliano: Granulatisporites varigranifer Menéndez \& Azcuy, 1969; Raistrickia rotunda Azcuy, 1975; Dictyotriletes muricatus (Kosanke) Smith \& Butterworth, 1967; Ahrensisporites cristatus Playford \& Powis, 1979; Ancistrospora inordinata Menéndez \& Azcuy, 1972; Ancistrospora verrucosa Menéndez \& Azcuy, 1972; Florinites guttatus Felix \& Burbridge, 1967; Florinites occultus Habib, 1966 e Florinites sp.

A análise bioestratigráfica indica a correlação, inédita para a porção brasileira da Bacia do Paraná até agora, com as palinozonas mais antigas do Carbonífero da Argentina e equivalentes na Austrália, cujas sequiências são mais completas.

A sequêencia palinológica do poço Geomater é dividida em três intervalos informais: inferior, intermediário e superior, delimitados pelo aparecimento e desaparecimento de táxons selecionados.

Os níveis aflorantes da Rodovia Raposo Tavares dos km 122,7, 123,7 e 125,8 são correlacionados bioestratigraficamente entre sí e com o intervalo superior do poço. Já

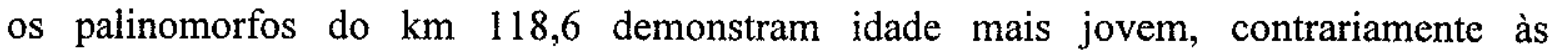
interpretações litoestratigráficas prévias. 
Dentre os esporomorfos, uma espécie nova é descrita: Ancistrospora reticulata sp. n. e duas são relocadas a gêneros distintos: Dictyotriletes pseudopalliatus (Staplin) comb. nov. e Vallatisporites punctatus (Marques-Toigo) comb. nov.

É marcante a presença de elementos microplanctônicos relacionados ao gênero Navifusa Combaz, Lange \& Pansart, 1967, que registra influência marinha na maior parte do poço Geomater e nos níveis aflorantes. 
ÍNDICE

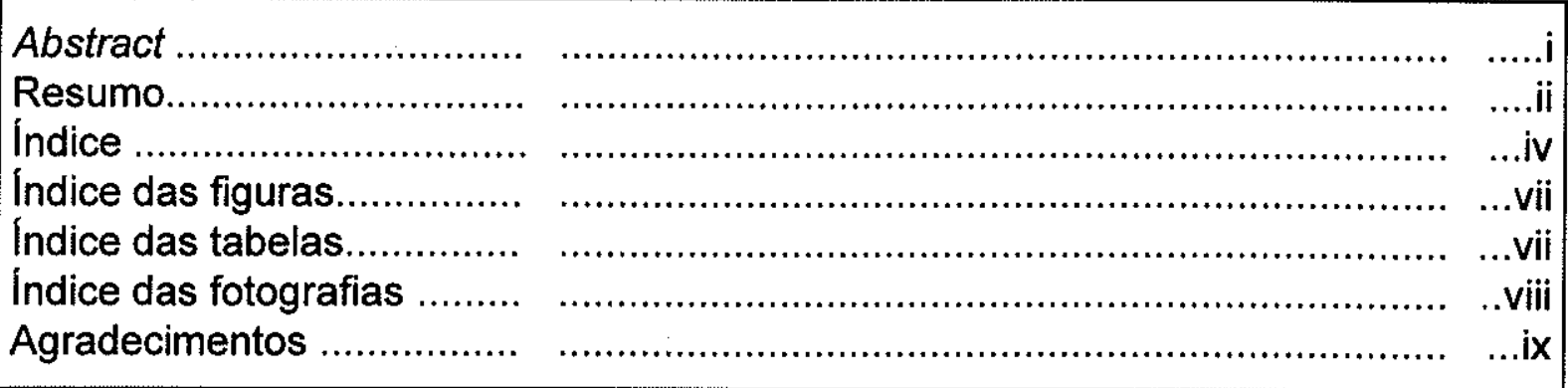

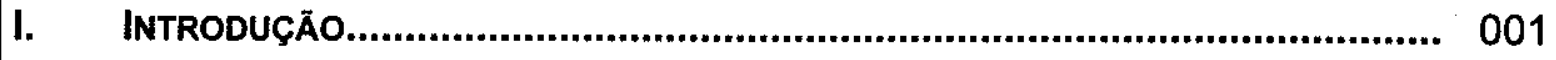

II OBJETIVOS E JUSTITIFICATIVAS......................................................... 003

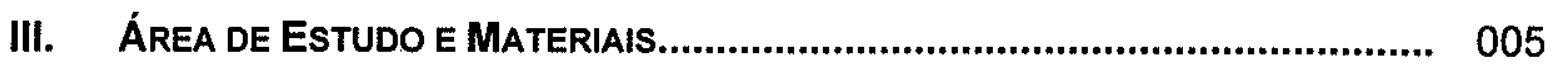

1. Localização e acessos........................................................... 005

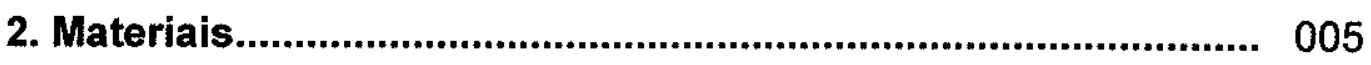

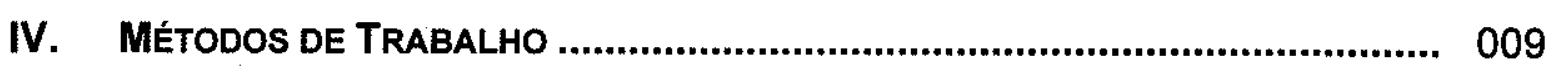

1. Trabalhos de campo e delimitação da área de estudos......... 009

2. Estudos prévios da bioestratigrafia .................................... 009

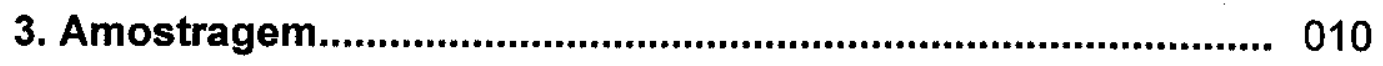

4. Processamento das amostras.............................................. 010

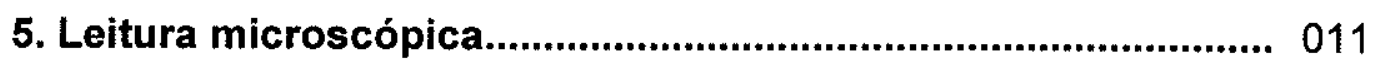

6. Fotomicrografias........................................................... 012

7. Análise quantitativa.......................................................... 012

8. Estudo sistemático.............................................................. 013

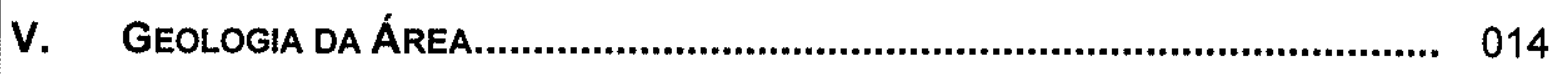

1. Considerações Gerais..................................................... 014

2. Trabalhos prévios na área................................................. 015 
3. Descrição geológica do poço Geomater.................................... 018

VI. Palinoestratigrafia do Subgrupo Itararé....................................... 020

1. Considerações gerais.............................................................. 020

2. Zoneamentos palinoestratigráficos do Paleozóico Superior na Bacia do Paraná....................................................................... 021

3. Correlação dos zoneamentos................................................... 030

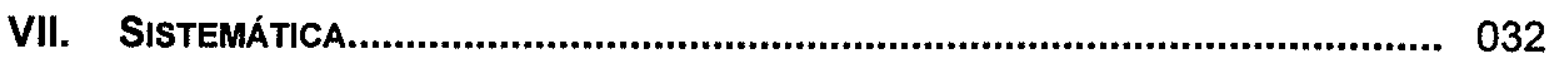

VIII. ANÁLISE PALINOESTRATIGRÁfICA ....................................................... 122

1. Considerações gerais................................................................ 122

2. Análise bioestratigráfica do poço Geomater............................. 124

1. Caracterização de intervalos................................................. 126

2. Comparações com esquemas da Bacia do Paraná

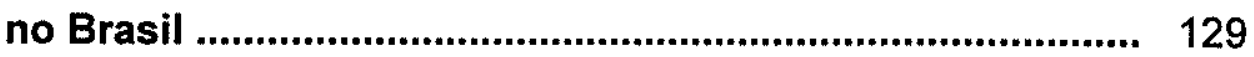

3. Comparações com esquemas de outras regiões gondvânicas................................................................................ 132

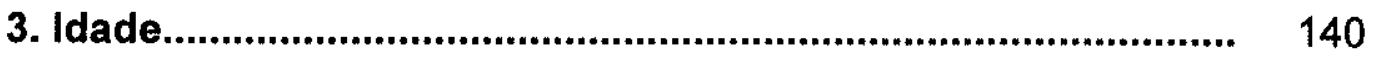

IX. ANÁlise Dos Dados De SUPERfícIe …................................................ 141

1. Descrição dos afloramentos ...................................................... 141

2. Dados e resultados palinológicos ............................................... 142

3. Relações com informações litofaciológicas prévias ............... 144

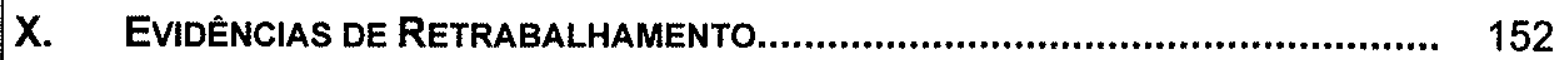

1. Considerações gerais............................................................... 152

2. Critérios de reconhecimento das formas retrabalhadas......... 153

3. Aspectos geológicos/sedimentares......................................... 155 
4. Registros prévios de retrabalhamento do Subgrupo Itararé .. 156

5. Principais conclusões............................................................... 157

XI. Considerações Paleoambientais.................................................... 160

1. Considerações gerais ....................................................... 160

2. Análise dos dados .......................................................... 163

XII. CONCLUSÖES................................................................................ 171

1. Palinologia...................................................................... 171

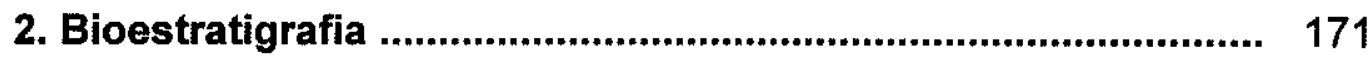

3. Idades ......................................................................................... 173

4. Paleoambiente ................................................................. 174

5. Litoestratigrafia ............................................................. 174

XIII. ConsideraÇÖES FINAIS................................................................ 176

XIV. REFERÊNCIAS BIBLIOGRÁFICAS........................................................ 177 


\section{ÍNDICE DAS FIGURAS}

Figura 01 - Localização da área de estudos (informações geológicas retiradas a partir de Massoli, 1991)

Figura 02 - Seção do trecho da Rodovia Raposo Tavares entre Sorocaba e Itapetininga, com localização dos afloramentos estudados (modificado de Massoli, 1991)

Figura 03 - Perfil do poço Geomater, com representação dos níveis amostrados palinologicamente

Figura 04 - Posicionamento bioestratigráfico das principais ocorrências fossiliferas do Subgrupo Itararé na Bacia do Paraná, conforme Petri \& Souza (1993 -modificado)

Figura 05 - Explanação diagramática dos termos usados nas expressões das dimensões dos grãos de pólen monossacados com simetria radial $(5 a)$, arredondados $(5 b)$ e bissacados $(5 c)$.

Figura 06 - Perfil esquemático do afloramento do $\mathrm{km} \mathrm{118,6} \mathrm{da} \mathrm{Rodovia}$ Raposo Tavares, com indicação do nível amostrado palinologicamente

\section{ÍNDICE DAS TABELAS}

Tabela 1 - Dimensões das espécies do gênero Florinites (Schopf, Wilson \& Bentall) Millay \& Taylor, 1974

Tabela 2 - Dimensões das espécies do gênero Cannanoropollis Potonié \& Sah, 1960

Tabela 3 -

Dimensões das espécies do gênero Plicatipollenites Lele, 1964 ..

Tabela 4 -

Dimensões das espécies do gênero Potonieisporites (Bharadwaj)

Bharadwaj, 1964

Tabela 5 - Dimensões das espécies do gênero Caheniasaccites (Bose \& Kar) Gutierrez, 1993

Tabela 6 - Dimensões das espécies do gênero Striomonosaccites (Bharadwaj) Hart, 1965

Tabela 7 - Dimensões das espécies do gênero Limitisporites (Leschik) Schaarschmidt, 1963

Tabela 8 - Dimensões das espécies do gênero Protohaploxypinus (Samoilovich) Hart, 1964

Tabela 9 - Dimensões das espécies do gênero Striatoabieites (Sedova) Hart, 1964 
Tabela 10- Distribuição de alguns táxons selecionados do poço Geomater ...

Tabela 11- Correlação da seqüência estudada com os principais zoneamentos do Paleozóico Superior da Bacia do Paraná e de outras áreas gondvânicas

Tabela 12- Dados palinológicos dos afloramentos entre os quilômetros 118,6 e 165 da Rodovia Raposo Tavares

Tabela 13- Síntese dos dados litoestratigráficos dos afloramentos na Rodovia Raposo Tavares segundo vários autores e dos resultados bioestratigráficos obtidos no presente trabalho.

Tabela 14- Táxons retrabalhados e registros prévios

Tabela 15- Freqüência dos principais morfogrupos presentes no poço Geomater .

Tabela 16- Representação quantitativa dos principais morfogrupos no poço Geomater

Tabela 17- Afinidades botânicas e dados paleoambientais (conforme Remy, 1975 e Azcuy, 1978) dos principais gêneros de esporomorfos estudados

Tabela 18- Informações sobre a localização dos táxons e lâminas no texto e na coleção científica do DPE-IG-USP

\section{ÍNDICE DAS FOTOGRAFIAS}

Foto 1 - Vista geral do afloramento do $\mathrm{km} \mathrm{118,6}$ da Rodovia Raposo Tavares

Foto 2 - Detalhe do afloramento do km 118,6 da Rodovia Raposo Tavares, com indicação da amostragem palinológica

Foto 3 - Vista geral do afloramento do $\mathrm{km} \mathrm{122,7}$ da Rodovia Raposo Tavares ..................................................................................149

Foto 4 - Detalhe dos níveis de concreção e amostragem palinológica do afloramento do km 122,7 da Rodovia Raposo Tavares

Foto 5 - Vista geral do afloramento do km 123,7 da Rodovia Raposo Tavares ...................................................................................150

Foto 6 - Detalhe do diamictito aflorante do $\mathrm{km} \mathrm{123,7}$ da Rodovia Raposo Tavares

Foto 7 - Afloramento do km 125,8 da Rodovia Raposo Tavares, com indicação dos niveis amostrados palinologicamente

Foto 8 - Detalhe do afloramento do km 125,8 da Rodovia Raposo Tavares, com concreções piritosas 


\section{AGRADECIMENTOS}

Ao Instituto Geológico da Secretaria do Meio Ambiente do Estado de São Paulo e ao Instituto de Geociências da Universidade de São Paulo, através do Programa de Pós-Graduação em Geologia Sedimentar, pela infraestrutura e liberação dos recursos necessários para o desenvolvimento deste trabalho.

Ao Conselho Nacional de Pesquisa (CNPq) e à Coordenação de Aperfeiçoamento de Pessoal de Nível Superior (CAPES) pela concessão de bolsas de estudos.

À Universidade de Guarulhos pela liberação de equipamento para a execução de fotomicrografias.

Ao Prof. Dr. Murilo Rodolfo de Lima (in memorian) pela iniciação na Paleontologia, pela orientação, pela amizade e pelo constante estímulo à prática da ciência e da vida, minha sincera e profunda gratidão e reconhecimento.

Ao Prof. Dr. Setembrino Petri pela continuidade da orientação, pela amizade e disposição incondicional, meus sinceros agradecimentos.

Ao amigo Prof. Dr. Antonio Roberto Saad (IGCE-UNESP) meus sinceros agradecimentos pelo auxílio, amizade e estímulo nas várias etapas do projeto.

Ao Prof. Dr. Paulo Roberto dos Santos, Prof. Dr. Oscar Rösler, Prof ${ }^{a}$. Dr ${ }^{a}$. Mary E. C. Bernardes de Oliveira (IG-USP) e à Prof ${ }^{a}$. Dr ${ }^{a}$. Maria Judite Garcia (UnG), meus sinceros agradecimentos pelas valiosas sugestões e pelo constante estímulo recebido.

Ao Prof. Dr. Rodolfo Dino (CENPES-PETROBRÁS S.A.) pelo processamento da maioria das amostras estudadas, pela leitura crítica do texto e orientação na sistemática.

Ao Prof. Dr. Carlos L. Azcuy (Universidade de Buenos Aires), Prof. Dr. JeanPierre Ybert (ORSTOM/UERJ) e ao geol. Roberto Ferreira Daemon (NEXPARPETROBRÁS S.A.), pela orientação no estudo sistemático e pelas valiosas sugestões.

À Prof ${ }^{a}$. Dr ${ }^{a}$. Marleni Marques-Toigo (UFRGS) pela leitura crítica do texto, orientação na sistemática e sugestões apresentadas. 
Ao Prof. Dr. Thomas Rich Fairchild (IG-USP) pelas valiosas sugestões e auxílio na confecção do Abstract, ao Prof. Dr. Fernando Cilento Fittipaldi (IG-SMA) pela revisão da sistemática e ao Prof. Dr. Cláudio Riccomini (IG-USP) pelo apoio e sugestões apresentadas.

Aos amigos geol. Fábio Shozo Harada, Prof. Francisco Pinheiro de Lima Filho (UFRN) e Prof. Roberto Iannuzzi (UFRGS) pela colaboração nos trabalhos de campo.

À amiga Ms. Elizete Domingues Salvador pela amizade e constante apoio. À Ms. Miriam Chieko Shinzato, Ms. Rita Parisi Conde, Andréa Amarante, Ms. Rosely A. Linguori Imbernon, Fátima Rabelo Praxedes Leite, Ms. Sandra de Fátima Oliveira, Carla Cristina Campos, Patrícia de Souza Cristalli, Ms. Fernando Mancini, Dr. Wilson Luiz Lanzarini, Prof ${ }^{\mathrm{a}}$. Dr ${ }^{\mathrm{a}}$. Ana Maria Góes, Ms. Frésia T. Riccardi Branco, Ms. Luis Eduardo Anelli, Jesús Yanina Rodrígues, Ana Lúcia Gesicki, Ms. Paulo Cesar Boggiani, Prof ${ }^{\mathrm{a}}$. Ana Flora Mandarim-de-Lacerda, Maria da Glória M. Garcia e Ms. Alcina M. F. Barreto, amigos e colegas da Pós-Graduação do IG-USP, pelo companherismo.

Ao Percy Corrêa Vieira, Liana Maria Moretti, Mariana E. Mendes, Maria das Graças P. Barbieri, Zenilda S. S. Nascimento, Maria A. de O. Quadrado (IG-SMA), Maria Lúcia Cicconi, Dalton Machado da Silva, Ivani A. da Silva, Claudionor Barboza (IG-USP) e à Yara Cristina Passarelli pelo apoio e participação nos trabalhos técnicos.

À amiga biol. Sílvia Aparecida Marasco pela amizade, estímulo e apoio nos trabalhos de campo.

Aos amigos geol. Claúdia Regina Passarelli, geol. Annabel Pérez Aguilar e Ms. Luis Fernando Uribe Lozano pelo constante estímulo, apoio, sugestões e companheirismo durante os vários anos de amizade.

Agradecimentos especiais são feitos à minha mãe, Josefa Barbosa de Souza, à Solange Alves de Souza e ao Mauro Panaia, pelo apoio e por me manterem acreditando na vida. 


\section{INTRODUÇÃO}

O estabelecimento de um esquema cronológico que ordene os eventos geológicos do Paleozóico Superior das bacias gondvânicas é sempre dificultado pela natureza glacial de parte dessa seqüência e, por isso, pela restrita biota registrada que pôde sobreviver em condições físicas rigorosas. Faunas marinhas que demonstram contemporaneidade com os depósitos glaciais são relativamente raras nestes sedimentos e, por vezes, refletem associações endêmicas, fatores que dificultam sua utilização na cronologia dos eventos e suas correlações.

Comumente, os depósitos glaciais e rochas associadas contém esporos e grãos de pólen que são o testemunho da vegetação existente nos ambientes marginais à área glaciada ou em fases de retração do gelo, quando então as condições climáticas tornavam-se mais amenas.

É nesse contexto que estão incluídos os depósitos sedimentares do Subgrupo Itararé, unidade que representa, na Bacia do Paraná, em parte, a influência glacial a que estava submetida extensa área do Gondvana durante longo intervalo de tempo no Neopaleozóico.

Como ressaltado por Lima \& Sundaram (1982), os grãos de pólen e esporos são, na Bacia do Paraná, os únicos elementos que podem fornecer um esquema bioestratigráfico mais completo para a seqüência em questão. Isto se dá, geralmente, por serem encontrados em abundância e com ampla distribuição geográfica. Assim, esta tem sido a principal utilização dos palinomorfos nesta bacia, para a datação dos niveis onde ocorrem e por apresentarem subsídios para a interpretação paleoambiental, paleoclimática e paleogeográfica.

O tratamento dos dados palinológicos tem fornecido, nos últimos anos, alguns ensaios de zoneamentos palinoestratigráficos, de caráter local e regional. Neste último caso, aquele realizado por Daemon \& Quadros (1970) representa, sem dúvida, a maior contribuição bioestratigráfica do Paleozóico Superior brasileiro, dada a espessura do pacote e a abrangência geográfica envolvida. 
Recentemente têm sido realizados alguns trabalhos de cunho mais local, cujos resultados demonstram algumas divergências e modificações com relação ao trabalho de Daemon \& Quadros (1970). Em sua grande parte, detalhando melhor alguns dos intervalos estabelecidos (e.g. Daemon \& Marques-Toigo, 1991) ou propondo o estabelecimento de outros intervalos antes não verificados (e.g. Lima et al., 1983).

Outros problemas são constatados quando os resultados palinológicos são confrontados com aqueles oriúndos da paleoflora dos diversos afloramentos conhecidos que, mesmo distantes geograficamente, propiciaram a elaboração de alguns zoneamentos tafoflorísticos formais (Rösler, 1978) ou não-formais (Millan, 1987).

A complexidade das relações espaciais, a diversidade dos litotipos e a ausência de camadas-guias no Subgrupo Itararé exigem estudos integrados dos dados bioestratigráficos e dos levantamentos de campo desta unidade, objetivando o estabelecimento de sua evolução geológica. Neste sentido, o trabalho de Saad (1977) mostrou-se como ponto de partida.

Os últimos trabalhos palinológicos realizados no Subgrupo Itararé têm demonstrado que a sua seqüência no Estado de São Paulo contem os sedimentos mais antigos (Souza et al., 1990; 1993a) e possivelmente os mais novos (Souza et al., 1993b) em termos de sua distribuição na Bacia do Paraná.

Estudos realizados na mesma unidade nos estados do sul da bacia, demonstram que lá o intervalo de tempo da sua sedimentação é mais curto, com idades sakmarianas a artinskianas (Daemon, 1981; Marques-Toigo, 1988).

A análise destes trabalhos e mesmo do mapa de isópacas do intervalo $\mathrm{G}$ de Daemon \& Quadros (1970) confirma a indicação da maior antiguidade dos sedimentos do Subgrupo Itararé na porção nordeste da bacia nos estados do Paraná e São Paulo. Dessa forma, o desenvolvimento de estudos mais locais a partir dessa região parece ser necessário, podendo contribuir, significativamente, na resolução de alguns problemas e na confirmação de algumas hipóteses de ordem bioestratigráfica e geológica. 


\section{OBJETIVOS E JUSTIFICATIVAS}

O desenvolvimento do presente trabalho, apenso ao projeto "Palinologia, bioestratigrafia e paleogeografia do Subgrupo Itararé (Neopaleozóico da Bacia do Paraná) na região de Araçoiaba da Serra, Estado de São Paulo", vinculado ao Instituto Geológico da Secretaria do Meio Ambiente do Estado de São Paulo (IG-SMA), objetiva, fundamentalmente:

- a análise sistemática dos táxons presentes na área de estudo, em superfície e subsuperfície e, dessa forma, contribuir para o conhecimento palinológico do Paleozóico Superior da Bacia do Paraná, cujos trabalhos, principalmente com relação ao Estado de São Paulo, são carentes de análise sistemática mais profunda e atualizada;

- a análise e a correlação bioestratigráfica, a partir dos táxons identificados, visando o melhor detalhamento e o aperfeiçoamento do arcabouço palinoestratigráfico da unidade e da Bacia do Paraná;

- a comparação e, sempre que possível, a correlação dos níveis sedimentares estudados com outros já descritos na unidade, com base no seu conteúdo palinológico;

- fornecer subsídios para melhor determinação paleoecológica e paleoambiental, a partir do estudo das paleofloras representadas. 
Estes estudos tornam-se necessários levando-se em consideração:

- a disponibilidade de dados paleontológicos e geológicos: sejam os testemunhos de sondagem do poço de pesquisa realizado pelo IG-SMA para captação de água na área ou os dados dos afloramentos já conhecidos na Rodovia Raposo Tavares e outros inéditos;

- a hipótese de que é nessa região que se encontram os registros mais antigos do Subgrupo Itararé no Estado de São Paulo, preliminarmente noticiada por Souza (1994) e Souza \& Lima (1994), denotada pelo mapa de isópacas do intervalo G de Daemon \& Quadros (1970), ou pela existência de um pacote de sedimentos maior que 200 m abaixo do nível datado como "Pré-G" por Lima et al. (1983) e ainda, mais a sul, a idade westphaliana reconhecida por Souza et al. (1990, 1993a) no carvão de Buri;

- os sedimentos presentes no poço Geomater, selecionados para estudo, estão assentados diretamente sobre o embasamento, representando, pelo menos localmente, o registro mais antigo do Subgrupo Itararé. 


\section{III. ÁREA DE ESTUDO E MATERIAIS}

\section{III.1 Localização e acessos}

A área de estudo localiza-se no sudeste do Estado de São Paulo, município de Araçoiaba da Serra, sudoeste de Sorocaba, totalmente enquadrada na folha de Salto de Pirapora do IBGE, em escala 1:50.000 (Figura 01).

O acesso se faz, a partir da capital do Estado, pela Rodovia Raposo Tavares (SP-270), logo após o trevo de Araçoiaba da Serra/Araçoiabinha. Com melhores condições de tráfego, pode-se utilizar a Rodovia Castelo Branco, até o km 78, seguindo pela Rodovia José Ermírio de Morais (Castelinho) até Sorocaba, com ligação à Rodovia Raposo Tavares.

\section{III.2 Materiais}

A amostragem de superfície referente-se aos afloramentos da Rodovia Raposo Tavares dos quilômetros 118,6, 122,7, 123,7 e 125,8, como assinalado nas figuras 1 e 2, os quais, dentre todos aqueles estudados em área de maior abrangência, foram os únicos, cujas amostras demonstraram potencialidade palinológica.

O material de subsuperfície é relativo aos testemunhos de sondagem do poço Geomater, perfurado pelo Instituto Geológico - SMA para captação de água (AIG-85) a aproximadamente $2,75 \mathrm{~km}$ a sul da Rodovia Raposo Tavares, na altura do km 122,5, com cooordenadas UTM 231,60 KmE e 7392,80 KmN. Atualmente, situado na propriedade Haras Djérid, antiga Geomater Produtora Rural Ltda.

Deste poço, cujo estudo litofaciológico foi realizado por Massoli (1991), foram estudadas 35 amostras de níveis estratigráficos distintos, das quais 26 forneceram amostragem palinológica abundante, 7 forneceram amostragem palinologicamente escassa $(4,6 ; 14 ; 19,5 ; 43,5 ; 51 ; 55$ e $57 \mathrm{~m})$ e 2 se mostraram 
estéreis (18,0 e 20,5 m). A abundância e escassez foram determinadas conforme critério adotado na análise quantitativa.

As informações geológicas, bem como o posicionamento dos niveis amostrados no poço Geomater, estão representados na Figura 03.

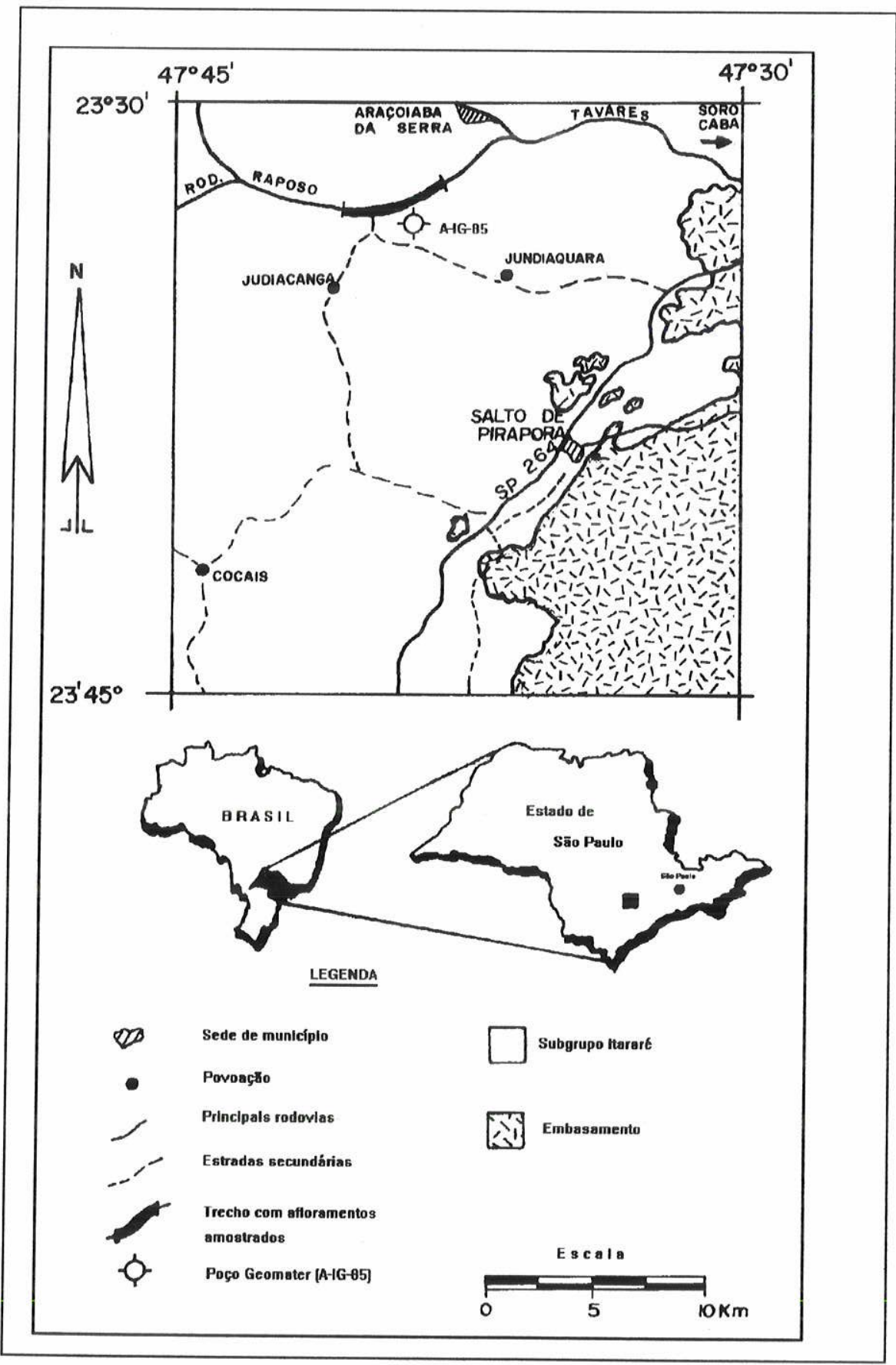

Figura 01 - Localização da área de estudos (informações geológicas retiradas de Massoli, 1991) 


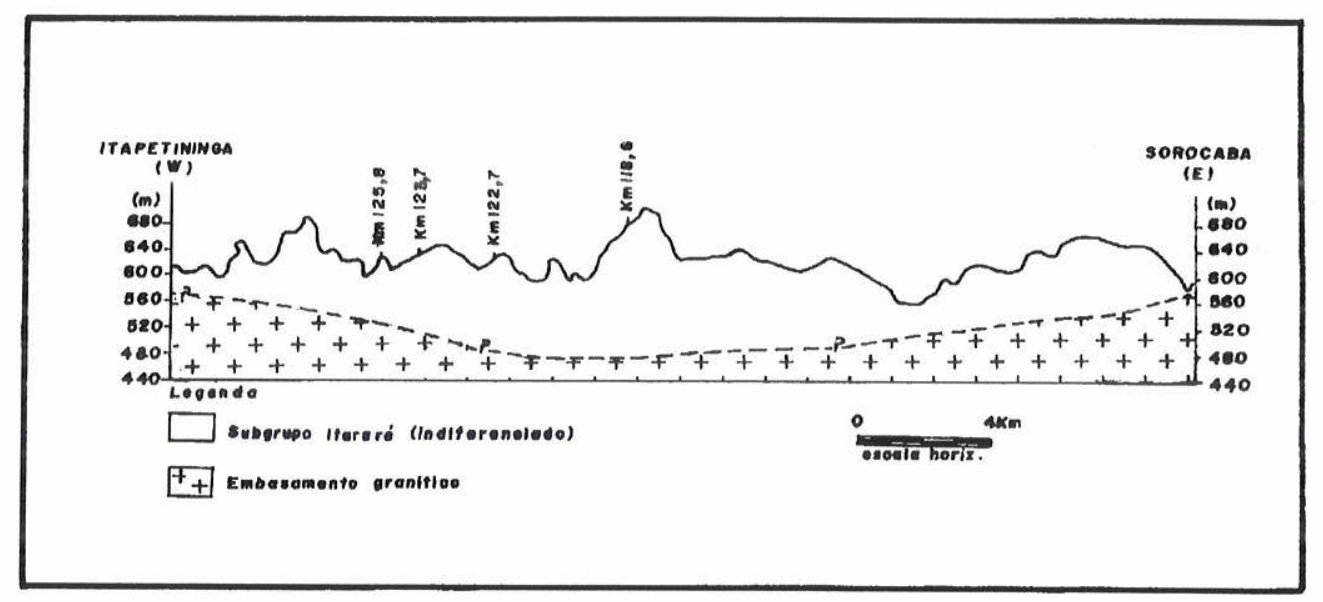

Figura 02 - Seção do trecho da Rodovia Raposo Tavares entre Sorocaba e Itapetininga, com localização dos afloramentos estudados (modificado de Massoli, 1991). 


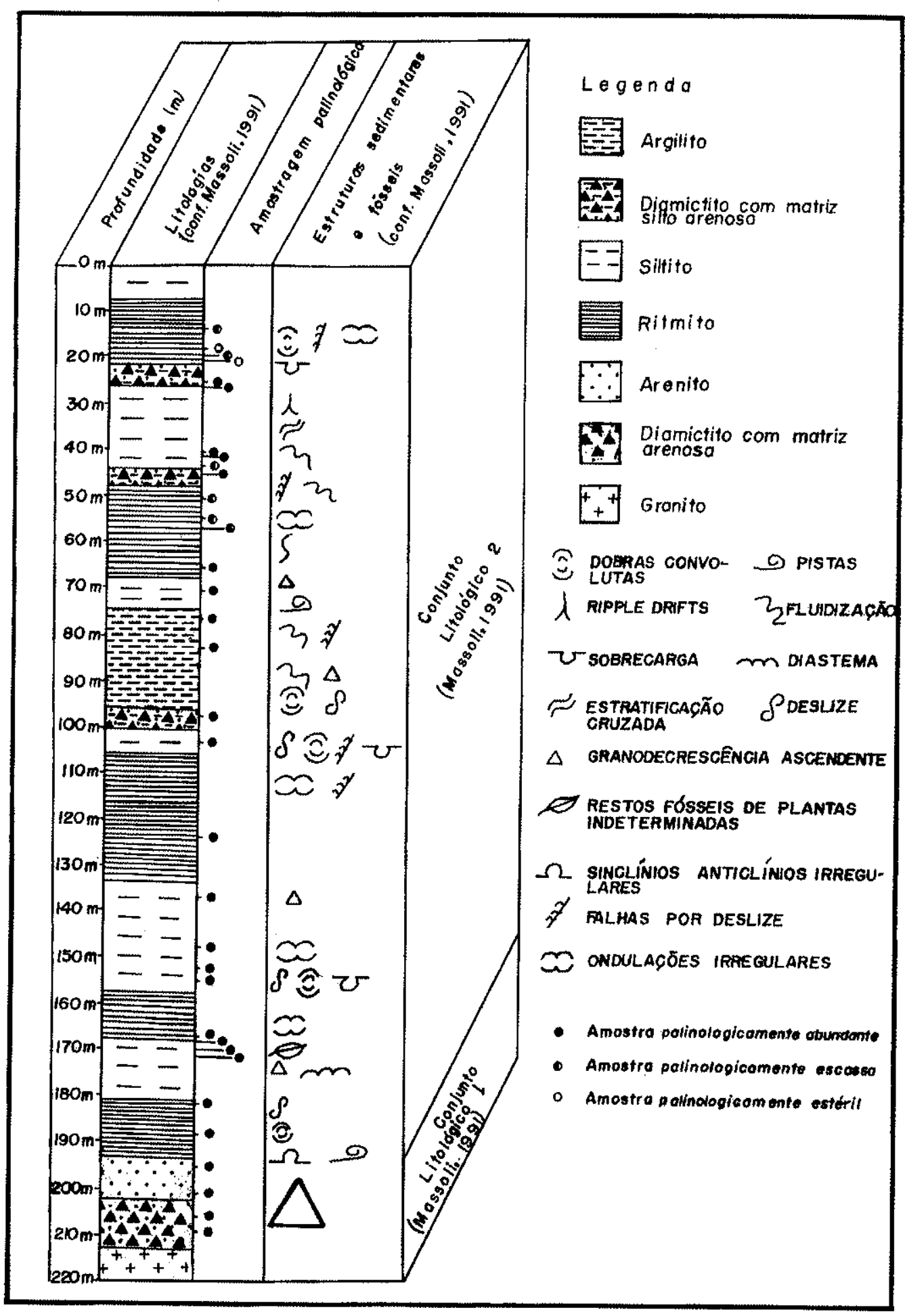

Figura 03 - Perfil do poço Geomater, com representação dos niveis amostrados palinologicamente. 


\section{MÉTODOS DE TRABALHO}

\section{IV.1 Trabalhos de campo e delimitação da área de estudos}

A área selecionada para o trabalho foi estudada previamente à seleção da amostragem palinológica para se detectar os problemas geológicos envolvidos, conforme os trabalhos realizados na área (Frakes \& Figueiredo-Filho, 1967; Saad, 1977; Instituto Geológico, 1990; Massoli, 1991) e a sua potencialidade em termos palinológicos. Para tanto, foi realizada uma etapa de campo preliminar visando o reconhecimento dos principais litotipos presentes

A segunda etapa de campo objetivou a coleta sistemática de amostras ao longo das estradas que continham melhores exposições e atravessavam maior número de litologias. Neste sentido, foram coletadas amostras ao longo de 4 estradas, sendo que destas, apenas o trecho da Rodovia Raposo Tavares mostrou potencial para o estudo.

\section{IV.2 Estudos prévios da bioestratigrafia}

A adequada compreensão da bioestratigrafia e, em particular da Paleontologia do Subgrupo Itararé na Bacia do Paraná, fez-se necessária para fundamentar o presente trabalho. Neste sentido, foram pesquisados os principais trabalhos sobre o tema, procurando-se detectar o estado da arte de seu conhecimento e seus problemas de ordem bioestratigráfica.

Mais especifico ao tema do trabalho, foi realizada uma pesquisa sobre as principais unidades palinoestratigráficas, formais ou não, estabelecidas para a Bacia do Paraná e as suas corelações com os principais zoneamentos de outras áreas gondvânicas. 


\section{IV.3 Amostragem}

Amostragem de superfície

As lâminas selecionadas para estudo, provenientes dos 4 afloramentos, são: 1 do km 118,6; 3 do km 122,7; 1 do km 123,7 e 3 do km 125,8. Os níveis de coleta, em cada afloramento, receberam codificação expedita de campo, conforme pode se observar nas fotografias que compõem o capítulo IX.

Vale destacar que outros afloramentos foram devidamente admostrados, dentro do trecho selecionado. No entanto, se mostraram estéreis palinologicamente.

Amostragem de subsuperfície

A amostragem de subsuperfície foi feita inicialmente pelo Prof. Dr. Setembrino Petri, que selecionou um total de 26 amostras de níveis distintos. Posteriormente, objetivando adensar mais a malha de amostragem, o presente autor selecionou mais 9 amostras, perfazendo um total de 35 níveis amostrados.

\section{IV.4 Processamento das amostras}

O material selecionado para estudos palinológicos foi processado conforme tratamento habitual para amostras do Paleozóico, procurando-se abranger os principais métodos que constam na literatura, como mencionados por Moore \& Webb (1978) e aqueles adotados nos trabalhos de pesquisadores brasileiros (Quadros \& Mello, 1987).

As amostras de subsuperfície selecionadas na primeira etapa foram processadas pelo Prof. Dr. Rodolfo Dino no CENPES-PETROBRÁS, seguindo as mesmas técnicas. Aquelas selecionadas na segunda etapa e as provenientes dos afloramentos foram processadas, por este autor, no Laboratório de Palinologia do Departamento de Paleontologia e Estratigrafia do Instituto de Geociências da USP. 
O tratamento físico-químico utilizado, usualmente denominado de maceração, cujo método varia em função da natureza química da rocha e objetiva a eliminação dos componentes minerais e orgânicos que não palinomorfos, constitui-se conforme as seguinte etapas:

- trituração da rocha em almofariz;

- peneiramento (fração menor que $2 \mathrm{~mm}$ ), homogeneização e pesagem de até 30 g/amostra;

- maceração com ácido clorídrico, no caso das amostras carbonáticas, até a eliminação dos componentes minerais carbonáticos, sob teste visual;

- maceração com ácido flurorídrico durante $24 \mathrm{~h}$, para a eliminação dos componentes silicáticos;

- maceração com ácido clorídrico, à quente $\left(T<65^{\circ} \mathrm{C}\right)$, para a eliminação dos fluorsilicatos/sílica-gel formados;

Após cada processo de maceração a amostra foi lavada com água destilada até a eliminação do componente ácido adicionado.

Após a maceração, a amostra foi peneirada $(\sim 10-225 \mu \mathrm{m})$ procurando-se concentrar o material, resíduo palinológico, sendo em seguida conservado em cápsulas de vidro devidamente codificadas.

As lâminas foram montadas a partir da colagem do resíduo em lamínulas com Cellosize e da colagem destas em lâminas com Entellan. Para cada nível amostrado, tanto de superfície como de subsuperfície, foram confeccionadas 2 lâminas de estudo, lâminas a e e $\underline{b}$, depositadas na coleção científica do Instituto de Geociências da USP, com codificação entre GP/4E-1335 a 1424.

\section{IV.5 Leitura microscópica}

As lâminas confeccionadas foram analisadas no microscópio óptico Carl Zeiss do Laboratório de Óptica do Departamento de Paleontologia e Estratigrafia do 


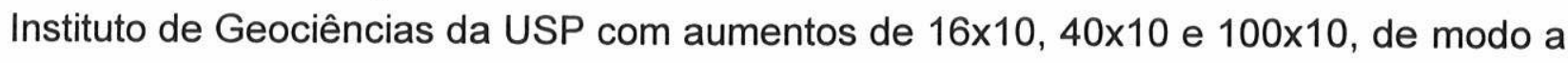
identificar os diferentes táxons presentes em cada uma, elaborando-se, para cada nível, uma lista destes e selecionando-se as melhores formas para fotomicrografias.

\section{IV.6 Fotomicrografias}

$\mathrm{Na}$ realização de fotomicrografias foram utilizados, inicialmente, os equipamentos da Universidade Guarulhos e do Instituto Geológico-SMA, para se registrar, preliminarmente, as diferentes formas observadas.

As formas selecionadas para ilustrarem as estampas foram fotografadas no fotomicroscópio Carl Zeiss do Departamento de Mineralogia e Petrografia do IG-USP e na UnG, em filme colorido Ektar 24 Asa.

\section{IV.7 Análise quantitativa}

Na determinação do percentual dos morfogrupos, foram contados todos os palinomorfos presentes em cada lâmina, procurando-se dispor de um mínimo de 200 formas, quando então eram consideradas "palinologicamente abundantes". Aquelas lâminas com pouca representatividade quantitativa, menos de 200 formas contadas, foram consideradas "palinologicamente escassas", sem aproveitamento nas interpretações de caráter paleoecológico e paleoambiental.

Os palinomorfos foram divididos em morfogrupos, como comumente utilizados na literatura, quais sejam: esporos triletes lisos (TL), apiculados (TA), zonados/cingulados/ cingulizonados

(TC/TZ/TCZ), murornados/auriculados/monopseudossacados (TM/TR/TMS), grãos de pólen monossacados lisos $(M L)$, estriados $(M E)$, bissacados lisos (BL), estriados $(B E)$ e elementos microplanctônicos. Os esporos muronados/auriculados e monopseudossacados foram agrupados devido a sua baixa representatividade. $\mathrm{O}$ 
mesmo ocorreu com os esporos da Suprasubturma Laminatitriletes, devido à afinidade em comum desses grupos.

Dessa forma, foram estabelecidas tabelas de percentagens de cada um destes grupos no material do poço Geomater. Os níveis de superfície foram considerados palinologicamente escassos, não podendo ser constituídas as relações percentuais dos morfogrupos presentes e impedindo seu uso, com maior detalhe, nas considerações paleoambientais.

Vale esclarecer que esta classificação "palinologicamente abundante/escassa" tem efeito somente sob o aspecto quantitativo, sem implicações na potencialidade e uso bioestratigráfico.

\section{IV.8 Estudo sistemático}

Os táxons reconhecidos em cada lâmina foram estudados sistematicamente pela comparação com formas reconhecidas no Brasil, em outras bacias gondvânicas, ou do Paleozóico Superior do Hemisfério Norte.

$\mathrm{Na}$ descrição de cada gênero, procurou-se ressaltar com uma pequena observação, sempre que possível e necessário, as principais características diagnósticas do gênero e as últimas modificações propostas, de acordo com a literatura disponivel. 


\section{GEOLOGIA DA ÁREA}

\section{V.1 Considerações Gerais}

Conhecidos e estudados desde o século passado, os sedimentos do Subgrupo Itararé, cuja origem glacial foi inicialmente reconhecida por Derby (1883; 1888; 1889 apud Rocha-Campos, 1967), receberam várias designações e foram agrupados em várias categorias dentro da hierarquia da nomenclatura litoestratigráfica. Isto reflete as variações dos processos deposicionais que deram origem a unidade, resultando em notável heterogeineidade de associações litofaciológicas ao longo da bacia, levando-a a ser dividida e subdividida de várias formas. Um estudo mais completo abordando as diferentes concepções e as várias divisões estratigráficas propostas para a unidade foi realizado por Rocha-Campos (1967), parcialmente atualizado por Massoli (1991).

A diversidade de seus litotipos, a ausência de camadas guias com expressão regional e a rápida variação de fácies, tanto na horizontal como na vertical, foram os principais obstáculos que impediram a utilização das várias proposições de nomenclatura de forma generalizada. Estas passaram a se constituir em designações de caráter local, aumentando, com isso, a proliferação de termos e a complexidade do estudo desta unidade.

Neste trabalho seguiu-se a designação litoestratigráfica adotada por Petri (1964), aceita por grande parte dos pesquisadores da área e segundo a qual as rochas do Paleozóico Superior da Bacia do Paraná no Estado de São Paulo relacionadas à atividade glacial seriam relativas ao "Subgrupo Itararé".

Importantes observações destacando as dificuldades na distinção entre os vários tipos de depósitos glaciais foram feitas por Caetano-Chang (1984) e Santos (1987), sendo que a primeira autora destacou como errônea a idéia de que toda a sedimentação do Subgrupo Itararé seria glacial. Segundo a mesma, a existência de 
glaciação durante o tempo Itararé e a complexidade do registro desses sedimentos são fatos inquestionáveis devido à presença de inúmeras feições glaciais (e.g. pavimentos de clastos estriados, Rocha Campos et al., 1976). No entanto, este regime não pode ser considerado como responsável direto pela deposição de todo o registro da unidade, tendo, os depósitos de origens lacustre, fluvial, paludal e marinho, recebido melhor definição sobre suas origens e processos associados, somente a partir da década de 70 .

Com relação ao Subgrupo Itararé no Estado de São Paulo, foi a partir do trabalho de Saad (1977), Soares et al. (1977) e Santos (1979) que foram iniciadas análises mais pormenorizadas de suas fácies e sistemas deposicionais, com ensaios de correlações estratigráficas e tentativas de reconstituição paleogeográfica.

Sem se preocuparem com designações estratigráficas formais para os níveis estudados, vários autores passaram então a reconhecer conjuntos litoestratigráficos ou associações faciológicas, denominadas com símbolos alfanuméricos (e.g. Caetano-Chang, 1984; Souza-Filho, 1986; entre outros). Mais recentemente, foram propostas novas subdivisões formais para a seqüência sedimentar abrangendo o Subgrupo Itararé, seja em nível de bacia (França \& Potter, 1988) ou mais localmente (Stevaux et al., 1987).

\section{V.2 Trabalhos prévios na área}

Diferentemente de outras áreas do Estado de São Paulo, como as regiões de Itu, Campinas e Cerquilho, nas quais o potencial mineral do Subgrupo Itararé (águas subterrâneas; pedras ornamentais/revestimento; construção civil; carvão) propiciou o desenvolvimento de vários estudos e pesquisas, a área abrangida pelo presente trabalho é carente de estudos mais detalhados. Cabe aqui destacar, no entanto, aqueles trabalhos que abordaram os aspectos geológicos da região, na tentativa de seu entendimento e, na maior parte destes, de seu empilhamento litoestratigráfico. 
A partir da observação de Leinz (1937), que aventou a idéia de ciclos interglaciais associados a avanços ou retiradas dos gelos no sítio deposicional, no contexto da glaciação do Paleozóico Superior, Frakes \& Figueiredo-Filho (1967) reconheceram, pelo menos, três destes ciclos nas seções geológicas levantadas na Rodovia Raposo Tavares, entre os quilômetros 103 e 157. Segundo estes autores, em muitos dos casos os ciclos estão incompletos, refletindo a erosão que precederia a deposição de cada novo ciclo, evidenciada por irregularidades na base de alguns diamictitos.

Estes autores elaboraram um modelo a partir dos dados levantados, no qual os diamictitos representariam morenas basais depositadas diretamente a partir do gelo. Alguns destes depósitos seriam posteriormente envolvidos em processos de movimento de massa e redepositados. Sedimentos arenosos e outros mais finos, argilas e folhelhos, refletiriam retrabalhamento subaquoso, a partir da fusão do gelo. Processos subaéreos seriam os responsáveis pela deposição das fases finais em cada ciclo, nos quais muitos dos materiais depositados poderiam ser derivados do retrabalhamento de depósitos mais antigos ou recém depositados, que repousavam próximos à área fonte.

A partir do estudo de 7 perfis geológicos transversais à faixa de afloramento do Grupo Tubarão no Estado de São Paulo, Saad (1977) elaborou uma subdivisão litoestratigráfica informal para o Grupo Tubarão, designando, para a seqüência do Subgrupo Itararé, os conjuntos litoestratigráficos A, B, C, D, da base para o topo, e o conjunto litoestratigráfico $E$, topo da seqüência, para a Formação Tatuí. Segundo esse autor, as seqüências litológicas que se repetem no ciclo sedimentar, sob um aspecto mais local, como aquelas descritas por Leinz (1937) e Frakes \& Figueiredo Filho (1967), se constituiriam em reflexos de fenômenos epirogenéticos regionais, de caráter isostático, ligados à evolução da glaciação. Com base no empilhamento estratigráfico proposto, o autor elaborou um modelo tectono-sedimentar para as unidades, que envolveria, pelo menos, quatro fases distintas.

A primeira fase abrangeria desde a época pré-deposicional do conjunto $A$ até o final da deposição do conjunto $B$ e corresponderia ao início da sedimentação do Subgrupo Itararé sobre um embasamento de topografia irregular, envolvendo regiões 
internas da bacia, deprimidas (de orientação geral SE-NO) e elevadas, até a margem atual da bacia.

A maior percentagem de clásticos finos e o registro de intercalações marinhas no conjunto $B$, seriam as principais evidências de relativa calma tectônica alcançada pela "sub-bacia", após a deposição do conjunto A.

A segunda fase, que abrangeria parte do conjunto C seria caracterizada pelo recrudescimento das condições tectônicas, com um levantamento gradual da borda nordeste da bacia, cujo reflexo sedimentar seria o predomínio da associação de diamictitos com clásticos grossos ou clásticos finos. $\mathrm{O}$ conjunto $\mathrm{D}$, correspondente à parte superior do Subgrupo Itararé, seria reflexo da $3^{3}$ fase tectono-sedimentar caracterizada pelo predomínio de sedimentação continental na região nordeste da bacia, gradando, em direção ao sul do Estado, para condições com maior influência marinha. Condições de calmaria tectônica, com sedimentação extremamente fina, caracterizaria a última fase, constituindo o conjuto $\mathrm{E}$, equivalente à Formação Tatuí.

Com a deposição desses 5 conjuntos litoestratigráficos, foram relacionados os registros de 3 microfloras, caracterizadas pela presença de grãos de pólen, esporos e elementos microplanctônicos, distribuídos em percentagens distintas em cada uma, refletindo mudanças de ambientes e o aparecimento/desaparecimento de táxons. Da mais antiga para a mais jovem, a Microflora I corresponderia aos conjuntos $\mathrm{A}$ e $\mathrm{B}$, a Microflora II ao conjunto C e a Microflora III ao conjunto D. Maiores detalhamentos sobre esse zoneamento bioestratigráfico informal são fornecidos no próximo capítulo.

Com referência ao perfil confeccionado ao longo da Rodovia Raposo Tavares por Saad (1977), dos quatro conjuntos equivalentes ao Subgrupo Itararé, provavelmente, apenas os conjuntos B e C corresponderiam ao trecho ora estudado, abrangendo as Microfloras I e II.

Na mesma área do presente trabalho, Massoli (1991) desenvolveu um estudo, apenso a um projeto da Secretaria do Meio Ambiente do Estado de São Paulo (Instituto Geológico, 1990), no qual o Subgrupo Itararé foi dividido, informalmente, em 4 conjuntos litológicos, designados, da base para o topo, de conjunto 1, 2, 3 e 4 . Segundo esse autor, o conjunto 1, que ocorre sobre o embasamento, é caracterizado essencialmente por diamictitos maciços, de matriz arenosa, originados pelo 
retrabalhamento de depósitos glaciais por água de degelo. Este conjunto representaria a deposição mais antiga da unidade, que teria ocorrido em calhas do embasamento. Condições subaquáticas, associadas à deglaciação, seriam responsáveis pela deposição do conjunto 2, caracterizado pela predominância de clásticos essencialmente finos. É no topo deste conjunto que Massoli (1991) posiciona a ocorrência fossilífera de Araçoiaba da Serra (Lima et al., 1976; 1983), que constituiria a primeira ingressão marinha verificada na área. Os depósitos dos conjuntos 3 e 4 , essencialmente compostos de arenitos e siltitos, respectivamente, teriam sido originados pelo retrabalhamento dos sedimentos glaciais por águas de degelo.

Nesse contexto, estaria implícita a existência de sedimentos mais antigos que aqueles datados por Lima et al. (1976; 1983), já que é no topo do conjunto 2 que Massoli (1991) posiciona a ocorrência fossilifera do Km 122,5. Como observado nos trabalhos de Saad (1977), Caetano-Chang (1984) e Massoli (1991), muitos dos depósitos basais do Subgrupo Itararé poderiam significar o resultado do retrabalhamento de sedimentos mais antigos, gerados pela própria glaciação (Frakes \& Figueiredo-Filho, 1967) ou até mesmo outros de idade devoniana (Caetano-Chang, 1984) e carbonífera inferior (Diniz, 1985; Santos, 1987).

\section{V.3 Descrição geológica do poço Geomater}

O poço Geomater, cadastrado no IG-SMA sob a designação A-IG-85, foi detalhadamente estudado por Massoli (1991), do qual são extraídos os dados geológicos, aqui sintetizados na Figura 03.

O poço, que atravessa cerca de $212 \mathrm{~m}$ de sedimentos do Subgrupo Itararé próximo da borda atual da bacia, atinge o embasamento cristalino, representado por um epidosito cinza-escuro de granulação fina.

Das 4 unidades litológicas reconhecidas por Massoli (1991) na folha de Salto de Pirapora, apenas 2 estariam presentes na seqüência do poço.

O Conjunto Litoestratigráfico 1 , com cerca de $15 \mathrm{~m}$ de espessura, é composto por arenitos de granulação variada e diamictitos maciços. 
O Conjunto Litoestratigráfico 2, que atinge cerca de $200 \mathrm{~m}$ de espessura, sobrepondo concordantemente o conjunto 1, apresenta granodecrescência ascendente de arenito muito fino a siltito arenoso. Este conjunto é composto, essencialmente, por sedimentos clásticos finos, destacando-se os ritmitos, argilitos e siltitos, com 2 intercalações de diamictitos maciços ou estratificados. As estruturas sedimentares presentes são de deformação, com dobras irregulares atribuídas a escorregamentos subaquáticos, dobras convolutas e estruturas de sobrecarga, além de falhas com rejeitos milimétricos.

Massoli (1991) identificou diastemas na porção inferior do Conjunto Litoestratigráfico 2, sugerindo serem produtos da ação erosiva de fortes correntezas. É comum, segundo este autor, a ocorrência de fragmentos das rochas subjacentes redepositados, segundo aquele autor, após curto transporte sedimentar.

Além de pistas fósseis ocorrentes na porção basal, restos de plantas foram também verificados neste conjunto, normalmente associados a arenitos muitos finos.

Durante a $1^{a}$ etapa de campo deste trabalho foi verificada a ocorrência de restos de vegetais fósseis em uma estrada vicinal, no afloramento próximo ao ponto 264 do mapeamento realizado pelo Instituto Geológico (1990) em estrada secundária a sul da propriedade "Pró-Vida".

Esses restos vegetais correspondem a pequenos fragmentos de caules carbonizados, com extremidades angulosas, preservados em matriz arenosa fina. Estudos mais detalhados são ainda necessários para a sua melhor caracterização, embora sua preservação não seja muito boa. 


\section{PALINOESTRATIGRAFIA DO SUBGRUPO ITARARÉ}

\section{VI.1 Considerações gerais}

O Subgrupo Itararé já foi objeto de estudo de vários autores que tentaram, a partir de dados pontuais de alguns afloramentos ou do conjunto destes, posicionar bioestratigraficamente as diversas assembléias fossiliferas ocorrentes (e.g. Daemon, 1974a). Dessa forma, foram gerados vários ensaios de empilhamento estratigráfico que, embora apresentem particularidades divergentes, fornecem, geralmente a partir dos dados de afloramentos, onde são mais comuns as associações fósseis, um arcabouço fundamental para o estudo da unidade.

Várias são as ocorrências fossilíferas de fauna e flora no Estado de São Paulo, sendo a mais expressiva a de Capivari e subordinadamente, as de Araçoiaba da Serra, Hotolândia e Itaporanga, em termos de invertebrados e as de Buri, Monte Mor e Cerquilho, em termos paleobotânicos (macro e microflora).

Recentemente, Petri \& Souza (1993) analisaram os dados bioestratigráficos do Subgrupo Itararé gerados, na sua maior parte, posteriormente ao trabalho de Rocha-Campos \& Rösler (1978), sintetizando-os na sua fig. 01, aqui reproduzida (Figura 04). Neste trabalho, é possível detectar a grande contribuição dada pelos macrofósseis vegetais e pelos palinomorfos, embora nem sempre tenham conduzido aos mesmos resultados. Estes autores ressaltaram ainda a necessidade da elaboração de zoneamentos num status formal, reconhecendo, no entanto, as dificuldades de sua elaboração e os avanços conseguidos a partir do zoneamento de Daemon \& Quadros (1970). 


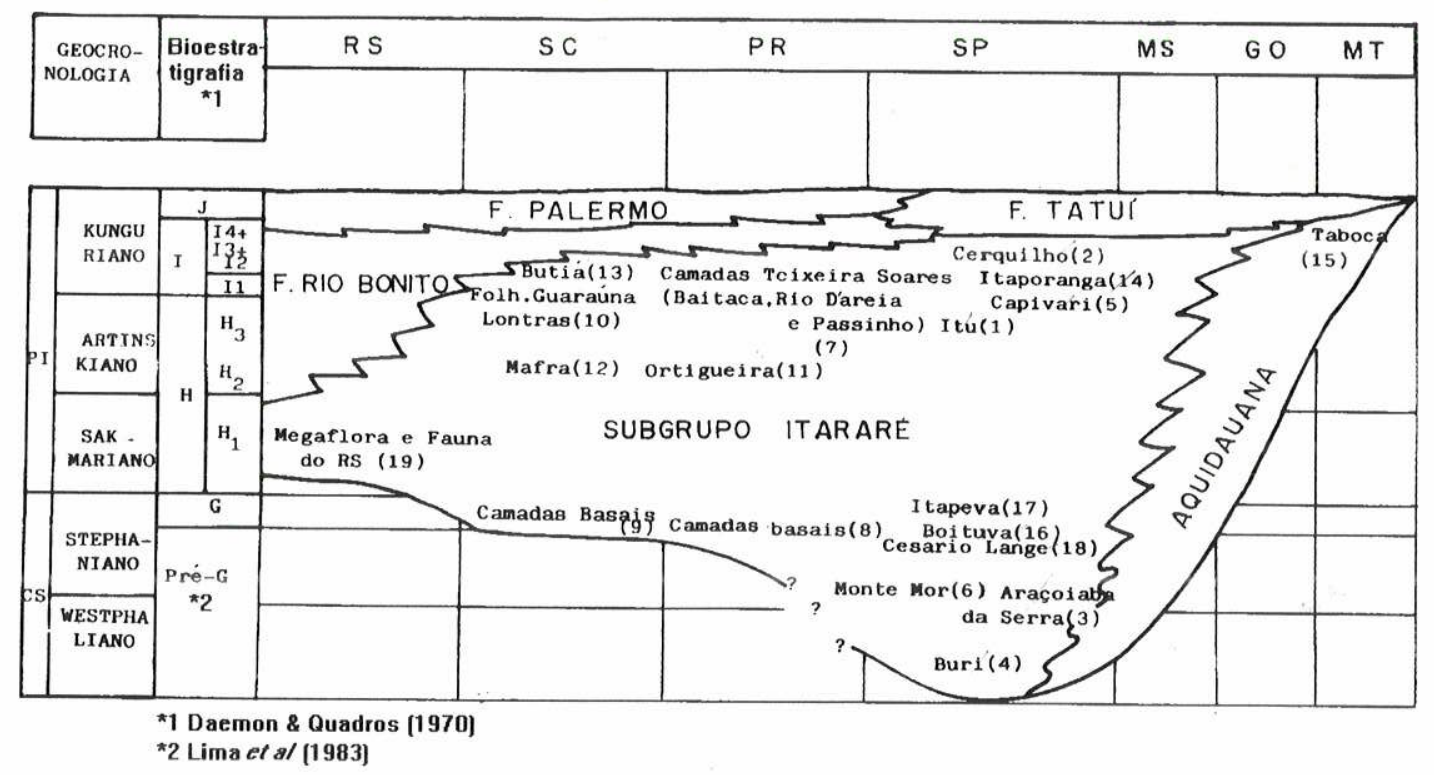

Figura 04 - Posicionamento bioestratigráfico das principais ocorrências fossilíferas do Subgrupo Itararé na Bacia do Paraná, conforme Petri \& Souza (1993 -modificado).

\section{VI.2 Zoneamentos palinoestratigráficos do Paleozóico Superior na Bacia do Paraná}

Várias zonas palinológicas têm sido estabelecidas por órgãos de pesquisa e de exploração, de abrangência local ou regional, mostrando-se úteis para a correlação das unidades sedimentares de faciologia variada. As zonas criadas formam, em seu conjunto, verdadeiros arcabouços bioestratigráficos que oferecem subsídios para a comparação das associações e conseqüentemente dos distintos níveis estratigráficos à longas distâncias. 
Nos trabalhos de Kemp (1975), Kemp et al. (1977), Archangelsky et al. (1980), Balme (1980), Truswell (1980) e Lima \& Sundaram (1982) pode-se encontrar ampla discussão sobre o quadro palinoestratigráfico existente para algumas partes do Eogondvana.

Vários zoneamentos palinológicos foram efetuados para o Paleozóico Superior da Bacia do Paraná, a maioria envolvendo os níveis do Subgrupo Itararé no Estado de São Paulo. Enquanto que os trabalhos de Daemon (1966) e Marques-Toigo (1988, 1991) se restringem ao estados do sul da bacia no país, os trabalhos de Bharadwaj et al. (1976), Saad (1977), Arai (1980) e Sundaram (1980, 1987) são referentes às suas partes mais setentrionais. Somente o trabalho de Daemon \& Quadros (1970) possui caráter mais amplo, abrangendo, basicamente, todo o Paleozóico Superior da bacia.

Estes zoneamentos são apresentados sucintamente a seguir, procurando-se realçar suas principais características.

O primeiro zoneamento palinoestratigráfico efetuado para a Bacia do Paraná foi o de Daemon (1966). Nele, o autor analisou a distribuição dos grãos de pólen monossacados, bissacados e monoletes na seqüência envolvendo desde o Subgrupo Itararé até a Formação Teresina, a partir de 3 furos realizados pela PETROBRÁS S.A. em Santa Catarina (Barra Nova, Canoinhas e Caçador) e 1 no Paraná (União da Vitória).

A partir da seleção de 46 gêneros reconhecidos, codificados com numeração arábica, realizou então um zoneamento palinológico preliminar, distinguindo 3 zonas principais, 2 das quais ainda subdivididas em subzonas. A unidade mais antiga, Zona P3 é caracterizada pela alta freqüência de espécies do gênero Florinites, além de outros monossacados, como Vestigisporites e Vesicaspora. Corresponde, em termos litoestratigráficos, à parte inferior-média do Subgrupo Itararé. A unidade intermediária, Zona P2, que abrange a porção superior do Subgrupo Itararé e a inferior-média da Formação Rio Bonito, caracteriza-se pelo aparecimento de grande números de táxons, destacando-se Vestigisporites e Nukoisporites, bem como Limitisporites e Vittatina. É subdividida em 4 subzonas, P2a, P2b, P2c e P2d, marcadas pelo aparecimento e desaparecimento de táxons selecionados. A unidade 
mais nova, Zona $\mathrm{P} 1$, abrange a seqüência superior do pacote, desde a porção superior da Formação Rio Bonito até a Formação Teresina. Foi subdividida em 2 subzonas, P1a e P1b, cujo limite corresponde à passagem da Formação Palermo e Irati. Caracteriza-se pela predominância dos grãos de pólen bissacados, com os últimos monossacados presentes até a subzona $\mathrm{P} 1 \mathrm{~b}$.

O mais abrangente e utilizado esquema palinoestratigráfico efetuado para a Bacia do Paraná é, sem dúvida, o de Daemon \& Quadros (1970). Com base na distribuição de 40 espécies selecionadas de grãos de pólen sacados, monoletes e monocolpados, além de representantes de Tasmanales, em 31 poços exploratórios da PETROBRÁS S.A. e 13 afloramentos, os autores propuseram a divisão do Paleozóico Superior da Bacia do Paraná em 6 intervalos, designados pelas letras G, H. I, J, K e L. Constituem-se em intervalos de concorrência de táxons, caracterizados por associações palinológicas distintas nos diversos níveis bioestratigráficos estabelecidos. Alguns destes intervalos foram subdividos, por sua vez, em subintervalos, a saber: $H_{1}$, $\mathrm{H}_{2}$ e $\mathrm{H}_{3} ; I_{1}, \mathrm{I}_{2}+\mathrm{I}_{3}+\mathrm{I}_{4} ; L_{1}, L_{2}$ e $L_{3}$.

De acordo com esse esquema, grãos de pólen monossacados dominam até o subintervalo $\mathrm{H}_{2}$, destacando-se os gêneros Potonieisporites, Plicatipollenites e Virkkipollenites. As formas bissacadas estriadas são raras nos intervalos $G, H_{1}$ e $H_{2}$, onde ocorre o gênero Protohaploxypinus (P-486). A partir do subintervalo $\mathrm{H}_{3}$ as formas bissacadas estriadas tornam-se mais freqüêntes e diversificadas, ocorrendo notadamente o aparecimento do gênero Vittatina. Nos intervalos I e J os grãos de pólen monossacados e bissacados são registrados com a mesma freqüência, sendo comuns formas do gênero Vittatina. No topo do intervalo J o gênero Plicatipollenites, muito comum nos intevalos anteriores, diminui em frqüência, tornando-se então ausente na base do intervalo L. A partir do intervalo J, os grãos de pólen bissacados estriados passam a dominar na coluna, sendo raros os monossacados e marcante a presença de Lueckisporites virkkiae, imprimindo importante característica aos intervalos $\mathrm{J}$ e $\mathrm{K}$, cujo limite é considerado datum bioestratigráfico para a bacia.

Comparando as formas reconhecidas e utilizadas como guias bioestratigráficos com outras registradas em outras regiões gondvânicas e do Hemisfério Norte, Daemon \& Quadros (1970) admitiram o seguinte posicionamento 
cronológico aos intervalos estabelecidos: Stephaniano C a Sakmariano ao intervalo G$\mathrm{H}_{1}$; Artinskiano aos subintervalos $\mathrm{H}_{2}-\mathrm{H}_{3}$; Kunguriano aos intervalos I e J; e, Kazaniano aos intervalos $\mathrm{K}$ e $\mathrm{L}$.

De maneira geral, os autores observaram que abaixo do datum estabelecido, os intervalos bioestratigráficos se comportam de maneira irregular, correspondendo à fase de ajustamento da bacia. Acima do datum, concluiram por constância mais acentuada no registro, dado o melhor paralelismo dos limites dos intervalos.

O intervalo $G$ não foi verificado em todos os poços estudados. Suas isópacas mostram maiores espessuras na região norte e sudeste da bacia, a partir do norte do Estado do Paraná onde, provavelmente, teria iniciado a deposição de seus sedimentos, transgredindo somente no intervalo $\mathrm{H}_{1}$ no Estado de Santa Catarina e $\mathrm{I}_{1}$, no Estado do Rio Grande do Sul.

As camadas da parte superior do Subgrupo Itararé seriam em muitos locais, sincrônicas com aquelas da Formação Rio Bonito. Esta última, vale notar, transgride o datum (limite $\mathrm{J} / \mathrm{K}$ ) de modo indiscriminado, demonstrando a recorrência de suas litologias no tempo.

A operacionalidade do trabalho, seu valor e contribuição são incontestáveis. No entanto, várias são as dificuldades que surgem quando de sua utilizacão, sobretudo nos trabalhos de cunho mais local. Aproximadamente $50 \%$ das comparações de formas para a atribuição cronológica foi baseada em trabalhos de materiais do Hemisfério Norte. O trabalho mostra, atualmente, algumas divergências, como por exemplo o aparecimento do gênero Vittatina, apontado por aqueles autores a partir do Artinskiano, tendo, no entanto, sido registrado no Sakmariano por vários autores (Marques-Toigo, 1988; Broutin et al., 1990; Fasolo \& Vergel, 1993), ainda que Barss (1972, apud Kemp, 1975) tenha suspeitado de seu aparecimento já no Carbonífero Superior.

Górecka \& Górecka-Nowak (1990) assinalaram seu registro a partir do Stephaniano A na Polônia, enquanto Vergel (1993) na porção superior da Palinozona Potonieisporites-Lundbladispora da Bacia Chacoparanaense, correspondente ao Stephaniano. 
A partir da observação desses dados, torna-se clara a necessidade de reavaliação das atribuições cronológicas, bem como melhor definição sistemática para os táxons utilizados, tendo também em vista que a grande maioria das formas reconhecidas por Daemon \& Quadros (1970) receberam, como também em Daemon (1966), numeração de caráter operacional.

A partir do estudo de 45 gêneros incluindo 66 espécies de 12 amostras provenientes de seções das seqüências das bacias do Paraná e Parnaíba, Bharadwaj et al. (1976) registraram a ocorrência de 4 assembléias de esporomorfos na Bacia do Paraná (zonas de associação $A, B, C$ e D) e 3 na Bacia do Maranhão (zonas de associação A, B e C), correlacionando-as entre sí, com a proposição de 6 intervalos bioestratigráficos distintos, alguns dos quais comuns em ambas as bacias. Da mais antiga para a mais jovem, receberam designação numérica de 1 a 6 .

Os problemas na utilização deste zoneamento são inúmeros, devidos, principalmente, à pouca representatividade da amostragem, a não correlação com o zoneamento de Daemon \& Quadros (1970), relativamente mais abrangente e à não especificação das proveniências das amostras.

Com base nos resultados palinológicos de 70 amostras provenientes de 8 perfis estratigráficos realizados transversalmente à faixa de afloramentos do Subgrupo Itararé no Estado de São Paulo, Saad (1977) reconheceu 3 assembléias microflorísticas distintas, caracterizadas pela composição qualitativa e quantitativa de gêneros de algas, esporos e grãos de pólen.

As 3 assembléias, que receberam a designação informal de Microflora I, II e III, da mais antiga para a mais nova, caracterizariam, conforme aquele autor, intervalos provavelmente correspondentes a zonas de associação.

A Microflora I, correspondente aos conjuntos litológicos A e B e ao intervalo G- $\mathrm{H}_{1}$ de Daemon \& Quadros (1970) é caracterizada pela predominância de esporos (até $80 \%$ ), com quantidades subsidiárias de grãos de pólen monossacados (20\%), monocolpados (2-3\%), bissacados lisos e estriados (até cerca de 3\%). Grande parte dos componentes desta microflora alcançam niveis superiores, até a Microflora II; portanto, seu aspecto marcante parece ser o quantitativo, destacando-se a baixíssima 
freqüência de grãos de pólen estriados, a alta freqüência de esporos e subordinadamente de monossacados.

As microfloras que se sucedem são equivalentes ao intervalo $\mathrm{H}_{2}-\mathrm{I}_{4}$ de Daemon \& Quadros (1970). A Microflora II, correspondente ao conjunto litológico C, é mais diversificada, com o aparecimento de alguns esporos dos gêneros Punctatisporites, Retusotriletes, Acanthotriletes e grãos de pólen estriados dos gêneros Protohaploxypinus, Taeniaesporites e Cycadopites. O gênero Virkkipollenites, presente na Microflora I, desaparece na porção basal do intervalo que caracteriza a Microflora II. Nesta, nota-se pequeno decréscimo na freqüência de esporos e acréscimo de grãos de pólen bissacados lisos e estriados, cujas percentagens médias ultrapassam 10\%. Limitados a este intervalo estão os gêneros Verrucososporites, Microbaculispora, Pustulatisporites, Brochotriletes, Striatoabieites e Alisporites.

A assembléia mais jovem, Microflora III, correspondente ao conjunto litológico D, apresenta decréscimo na freqüência dos esporos e por outro lado, aumento na participação dos grãos de pólen estriados, presentes em cerca de $30 \%$. A mesma relação se dá também entre os grãos de pólen monossacados, que baixam ligeiramente em freqüência e os monocolpados, que atingem cerca de 4\%. Nestas, é marcante a presença restrita de Hamiapollenittes, Cyclogranisporites e Lycospora, além de algas do tipo Tasmanites na associacão, que chegam à percentagem de $5 \%$.

A idade atribuída às microfloras, conforme Saad (1977), corresponde ao intervalo Carbonífero Superior-Permiano Inferior e os dados bioestratigráficos indicam que em um caso, entre os conjuntos B e C, o limite entre os conjuntos litológicos coincide, aproximadamente, com o limite entre as microfloras estabelecidas.

Arai (1980) reconheceu 42 gêneros de esporomorfos em um total de 65 amostras procedentes de vários afloramentos da seqüência paleozóica superior da Bacia do Paraná nos estados de São Paulo, Paraná e Santa Catarina.

A grande contribuição neste trabalho é dada, conforme o autor, pelos grãos de pólen estriados. De uma maneira geral, conforme o autor, os Striatiti são raros nos estratos basais estudados e em alguns casos ausentes (Cesário Lange, Capivari e Buri). Progressivamente, subindo na coluna estratigráfica, aumentam em percentagem nas assembléias. Este acréscimo é acompanhado pelo decréscimo de esporos triletes, 
notadamente os zonados do tipo Vallatisporites. Qualitativamente, formas estriadas de contorno haploxylonóide simples, que dominam nas porções basais, cedem lugar a formas do tipo Vittatina e outras com contorno diploxilonóide como Taeniaesporites, Striatopodocarpites e Striatoabieites.

Assim, Arai (1980) propôs então a subdivisão da coluna em 6 unidades bioestratigráficas designadas informalmente de "Fases". A Fase Pré-Striatiti, mais inferior na coluna, é caracterizada pela ausência de grãos de pólen estriados, alta freqüência de monossacados, dos quais Potonieisporites e Vestigisporites são mais relevantes e pela abundância de Vallatisporites. A seguinte, Fase Protohaploxypinus, é caracterizada pela presença de grãos de pólen estriados, sobretudo do gênero que the dá o nome, ainda subordinados aos esporos triletes e grãos de pólen monossacados presentes na fase anterior. Na fase seguinte, Vittatina I, ocorre um equilíbrio na percentagem de grãos de pólen estriados e monossacados, com a presença do gênero Vittatina. Este gênero ultrapassa $50 \%$ na Fase Vittatina II, chegando, em alguns casos, a revelar freqüências superiores a $90 \%$. Grãos de pólen estriados de contorno diploxylonóide, com sacos bem desenvolvidos, são característicos da Fase Striatiti Superior, cuja base é marcada pelo aparecimento dos gêneros Taeniaesporites, Striatopodocarpites e Striatoabieites. A Fase Lueckisporites, superior na sequência, caracteriza-se pela constatação do gênero que the dá o nome e pela predominância absoluta de grãos de pólen estriados, com presença subordinada de bissacados lisos.

Com base no estudo palinológico de 10 amostras do Subgrupo Itararé no Estado de São Paulo (Buri e Cesário Lange) e da Formação Rio Bonito nos estados do Paraná e Santa Catarina, Sundaram (1980) reconheceu 2 assembléia palinológicas distintas, designadas informalmente de Palinozona A e B. A mais antiga, Palinozona A, observada nas amostras do Subgrupo Itararé, é dominada pelos esporos triletes, especialmente formas cinguladas e zonadas, representadas pelos gêneros Vallatisporites, Kraeuselisporites, Cingulatisporites, Cirratriradites, Acanthotriletes, entre outros, que perfazem até $70-80 \%$ da assembléia. Os grãos de pólen monossacados, em torno de $20 \%$, são representados por Cannanoropollis, Plicatipollenites e Parasaccites. A Palinozona B, observada nas amostras da Formação Rio Bonito, apresenta grande quantidade de grãos bissacados, que chegam a 60-65\%, 
enquanto que os esporos triletes não ultrapassam $20 \%$. Os bissacados mais comuns nesta assembléia são Scheuringipollenites, Platysaccus, Faunipollenites e, entre os estriados, Striatopodocarpites, Protohaploxypinus e Vittatina.

Comparando o conteúdo microflorístico das 2 palinozonas com outras assembléias gondvânicas, Sundaram (1980) só encontrou correspondência da Palinozona A nas bacias vizinhas da América do Sul, Paganzo e Chaco-Paraná; enquanto que a Palinozona B teria grande semelhança com palinozonas encontradas em outras bacias gondvânicas.

A última tentativa de zoneamento palinoestratigráfico para o Subgrupo Itararé no Estado de São Paulo foi realizada por Sundaram (1987), com base nas amostras coletadas ao longo das seções estratigráficas descritas por Saad (1977). Embora a distribuição das amostras férteis tenha sido irregular ao longo das seções e a distribuição dos palinomorfos na parte basal da seqüência amostrada não pudesse ser estabelecida completamente em nenhuma das seções, o autor reconheceu 3 intervalos que corresponderiam a zonas de associações, informalmente designadas, da mais antiga, Palinozonas $\mathrm{A}, \mathrm{B}$ e $\mathrm{C}$.

A Palinozona $\mathrm{A}$, corresponde à metade inferior do Subgrupo Itararé e teria como formas características, por ocorrerem somente nela: Cirratriradites saturni, Cirratriradites megaspinosus, Densosporites annulatus e Laevigatosporites desmoinenses. Esses elementos, que mundialmente ocorreriam no Carbonífero Inferior (Sundaram, 1987), dariam uma conotação de antiguidade à seqüência. Correspondente à parte média do Subgrupo Itararé, a Palinozona $\mathrm{B}$, se caracterizaria pela presença de Punctatisporites ( $P$. gretensis forma minor, $P$. minutus, $P$. gretensis), Cyclogranisporites minutus, Apiculatisporis levis, A. spinosaetosus, Microbaculispora tentula e Horriditriletes curvibaculosus. A Palinozona C, correspondente à metade superior da unidade, teria como elementos característicos Striomonosaccites ovatus, Protohaploxypinus chaloneri, P. jacobii, Vittatina vittifera, Cycadopites follicularis e Marsupipollenites striattus.

Os grãos de pólen monossacados apareceriam apenas a partir da Palinozona C, juntamente com grãos de pólen bissacados e estriados, o que levou o autor a aventar a hipótese da reunião das Palinozonas A e B. Contudo, correlacionou a 
Palinozona A com aquelas mais primitivas do Eogondvana, a saber, "Stage" 1 (Evans, 1969), Unidade I (Kemp et al., 1977), Zona de Ancistrospora (Azcuy \& Jelin, 1980) e na Bacia do Paraná, ao intervalo G de Daemon \& Quadros (1970) ou relativo à idade PréG sugerida por Lima et al. (1983). As palinozonas conseguintes seriam relativas ao intervalo $\mathrm{H}_{1}+\mathrm{H}_{2}$ e $\mathrm{H}_{3}+\mathrm{I}_{1} \mathrm{I}_{4}$ de Daemon \& Quadros (1970), respectivamente.

Marques-Toigo (1988, 1991) propôs um zoneamento bioestratigráfico a partir do estudo das associações microflorísticas dos principais níveis de carvão de superfície e subsuperfície do Estado do Rio Grande do Sul e sul do Estado de Santa Catarina. A seqüência estratigráfica envolvida compreende desde o Subgrupo Itararé até a Formação Irati.

Baseada nas distribuições verticais e laterais dos grãos de pólen monossacados, bissacados e estriados, bem como sua abundância relativa, a autora dividiu a seqüência em 2 zonas de intervalo, chamadas de Zona Cannanoropollis korbaensis e Zona Lueckisporites virkkiae, cujas características são colocadas a seguir.

-Zona Cannanoropollis korbaensis: definida pela distribuição da espécie que Ihe dá o nome e, na sua ausência, por Potonieisporites simplex, de igual range, ou ainda pelos níveis de extinção de Limitisporites vesiculosus e Hamiapollenites karroensis. É subdividida em 3 subzonas de intervalo: (1) Subzona Protohaploxypinus goiraiensis: correspondente litoestratigraficamente ao Subgrupo Itararé naqueles estados e à base da Formação Rio Bonito, com idade posicionada entre o Sakmariano e o Artinskiano; (2) Subzona Caheniasaccites ovatus: correspondente à parte média da Formação Rio Bonito, com idade situada entre o Artinskiano e o Kunguriano; (3) Subzona Hamiapollenites karroensis: correspondente ao topo da Formação Rio Bonito, de idade kunguriana.

-Zona Lueckisporites Virkkiae: definida pela distribuição de Lueckisporites virkkiae ou, na sua ausência, por Marsupipollenites trirradiatus, Staurosaccites cordubensis, Striatopodocarpites pantii, Lunatisporites variesectus e Protohaploxypinus perfectus, de igual range. É correspondente às formações Palermo e Irati, com idade atribuída entre o Kazaniano e o Tatariano, Permiano Superior. 
Mais recentemente, Daemon \& Marques-Toigo (1991) tentaram a integração dos trabalhos de Daemon \& Quadros (1970) e Marques-Toigo $(1988,1991)$ propondo a criação da Zona Potonieisporites novicus, mais antiga que a Zona Cannanoropollis korbaensis e correspondente aos intervalos $\mathrm{G}-\mathrm{H}_{1}$ de Daemon \& Quadros (1970). Neste trabalho se confirma a ausência do registro sedimentar e microflorístico pré $\mathrm{H}_{2}$ nos estados do Rio Grande do Sul e sul de Santa Catarina, como postulado por Daemon (1981). Estes autores redesignaram ainda a Zona Cannanoropollis korbaensis como Zona Vittatina, mantendo a definição da Zona conforme Marques-Toigo (1988, 1991). A subzona Protohaploxypinus goraiensis foi redefinida como ProtohaploxypinusLimitisporites, correspondendo aos intervalos $\mathrm{H}_{2}$ e $\mathrm{H}_{3}$ de Daemon \& Quadros (1970). A subzona Caheniasaccites ovatus permaneceria como tal, correspondendo ao intervalo $\mathrm{H}_{4}-\mathrm{I}$ e a subzona Hamiapollenites karroensis passou a se denominar subzona Marsupipollenites, correspondendo, por sua vez, ao intervalo J.

\section{VI.3 Correlação dos zoneamentos}

$\mathrm{Na}$ análise dos zoneamentos bioestratigráficos foram verificados alguns problemas que refletem, por um lado, a precariedade dos dados palinológicos e por outro, a ausência de bons elementos marcadores, de correlação mais geral.

As bases de correlação do zoneamento de Bharadwaj et al. (1976) com outros de maior abrangência são insatisfatórias, tendo em vista a amostragem reduzida, sendo arriscada qualquer correlação, como a que realizaram Lima \& Sundaram (1982).

A assembléia "Pré-Striatiti" estabelecida por Arai (1980) foi correlacionada, pelo autor proponente, com o intervalo G de Daemon \& Quadros (1970). Como essa assembléia foi caracterizada pela ausência de grãos de pólen estriados, a correlação com intervalo $\mathrm{G}$ é indevida, tendo em vista que este tipo de grão já é presente neste intervalo. 
Alguns problemas são verificados também quanto às atribuições de idades aos intervalos, podendo aumentar substancialmente os problemas de ordem bioestratigráfica.

As diferenças paleoclimáticas e ambientais devem ser levadas em consideração na correlação de assembléias de regiões distintas, com atenção aumentada quanto maior for o distanciamento destas. Pode-se, facilmente, estar comparando climas de diferentes regiões e não, necessariamente, os níveis litoestratigráficos ou zonas bioestratigráficas, como destacou Sundaram (1987).

Hipóteses sobre o comportamento paleobiogeográfico das floras paleozóicas da América do Sul já foram levantadas por lannuzzi \& Rösler (1993), indicando a necessidade de estudos baseados em maior número de táxons, de modo a suprimir problemas causados pelos endemismos e migrações.

Pelos motivos discutidos, não é reproduzido aqui qualquer quadro de correlação com todas as palinozonas estabelecidas na Bacia do Paraná. Neste sentido, é dado destaque apenas àqueles zoneamentos de caráter mais amplo, relativos aos trabalhos de Daemon \& Quadros (1970), Marques-Toigo (1988) e Daemon \& Marques-Toigo (1991). Somente no capitulo VIII estes esquemas são devidamente comparados e correlacionados, enfatizando-se suas relações com o trabalho realizado. Vale ressaltar que o trabalho de Daemon \& Marques-Toigo (1991) já sofreu modificações, conforme apresentado pelo primeiro autor na "Mesa Redonda do Paleozóico Superior" que ocorreu durante o $2^{\circ}$ Simpósio sobre Cronoestratigrafia da Bacia do Paraná (27-29.09.95, ILEA-UFRGS, Porto Alegre, RS), já parcialmente utilizado por Milani et al. (1994). De maneira geral, as mudanças ainda são preliminares, carentes de formalização. 


\section{SISTEMÁTICA}

São apresentados 110 táxons de palinomorfos dos níveis de superfície e subsuperfície (poço Geomater). Destes, 65 são referentes a espécies de esporos, relativas a 26 gêneros, além de 3 esporos indeterminados; 42 espécies de grãos de pólen, relativas a 9 gêneros; e, 3 espécies de elementos microplanctônicos, relativas a 2 gêneros.

A análise permitiu a proposição de uma nova espécie de esporo, bem como a relocação de 2 espécies em outros gêneros.

$\mathrm{Na}$ classificação dos esporomorfos foi utilizado o sistema proposto por Potonié (1970), que os divide em Proximegerminantes (esporos) e Variegerminantes (grãos de pólen), além das subdivisões inferiores como as propostas por Cookson (1947), Erdtman (1947), Potonié \& Kremp (1954), Leschik (1955), Potonié (1956, 1958), Dybová \& Jachowicz (1957), Neves (1961), Bharadwaj (1962), Dettman (1963), Richardson (1965) e Smith \& Butterworth (1967), reunidas a partir do esquema proposto por Potonié (1970), amplamente utilizado em nível mundial no agrupamento dos esporos e grãos de pólen do Paleozóico.

Os aspectos relacionados à terminologia palinológica empregada para os esporomorfos do Paleozóico mundial não estão muito bem estabelecidos. Vários autores ao descreverem as formas de esporos e grãos de pólen utilizam termos distintos para as mesmas estruturas ou componentes morfológicos.

Neste trabalho, face à dificuldade encontrada na uniformização de alguns termos, eles são tratados, geralmente, como nas descrições originais de cada táxon; o que, embora possa suscitar a proliferação de termos, visa, sobretudo, evitar a sua utilização indevida. 


\author{
Anteturma Proximegerminantes Potonié, 1970 \\ Turma TRILETES (Reinsch) Dettman, 1963 \\ Suprasubturma ACAVATITRILETES (Lüber) Dettman, 1963 \\ Subturma AZONOLETES (Lüber) Dettman, 1963 \\ Infraturma LAEVIGATI (Bennié \& Kidston) Potonié, 1956
}

Gênero Punctatisporites (Ibrahim) Potonié \& Kremp, 1954

Espécie-tipo: Punctatisporites punctatus Ibrahim, 1933

Afinidade botânica: PTERIDOPHYTA-FILICOPSIDA (Potonié \& Kremp, 1956; Eggert \& Taylor, 1966; Andrews et al., 1970; Courvoisier \& Phillips, 1975).

Neste gênero são incluídos esporos de contorno equatorial circular a subcircular, com exina não ornamentada, apresentando punctação, infrareticulação ou infragranulação, que não se projeta em sua margem e raios da marca trilete maiores que metade do raio do esporo.

Punctatisporites gretensis Balme \& Hennelly, 1956

Est. 1, fig. 1

Diagnose: Balme \& Hennelly [1956. Australian Journal of Botany, Melbourne, 4(3):240-250]

Locus/stratum typicus: Hebburn $n^{0} 2$ Collieri, Greta Coal Measures, Permiano, New South Wales, Autrália.

Descrição: esporo radial trilete de contorno e margem equatorial subcircular a circular lisa. Exina fina $(1,5 \mu \mathrm{m})$, inframicropunctada. Laesuras retas e finas, alcançando $2 / 3$ do raio.

Dimensões: diâmetro equatorial (deq): 38(56)73 $\mu \mathrm{m}$ (15 exemplares).

Ocorrência (no presente trabalho): espécie muito comum, registrada em todos os níveis de superfície/subsuperfície.

Distribuição biocronoestratigráfica: bastante comum nas bacias gondvânicas, distribuindose na Bacia do Paraná, no Subgrupo Itararé (Pons, 1976a: est. I, fig. 1; Sundaram, 1987: est. I, fig. 11; Dias, 1993a: est. 1, fig. 1) e Formação Rio Bonito (Ybert, 1975: est. 1, figs. 
16 a 18) e em estratos mais jovens abrangidos pela Zona Cannanoropollis korbaensis e Lueckisporites virkkiae (Marques-Toigo, 1988).

Comentários/observações: Hart (1965) separou as espécies de $P$. gretensis Balme \& Hennelly, 1956 que mediam entre 45(62)114 $\mu \mathrm{m}$ em $P$. gretensis forma minor. Como apontado por Ottone (1991), é difícil e não recomendado a separação desta espécie levando-se em consideração suas diferenças de tamanho, que podem refletir variações na mesma espécie. Desta forma, várias dessas espécies registradas na Bacia do Paraná devem ser melhor atribuídas a $P$. gretensis Balme \& Hennelly, 1956, não se considerando os critérios de Hart (1965).

\section{Punctatisporites foveolatus Bose \& Maheswari, 1969}

Est. 1, fig. 2

Diagnose: Bose \& Maheswari (1969. Annales du Musée Royal de L'Africa Centrale, Tervuren, Série IN $8^{0}$, Sciences Geologiques, $n^{0} 63 ;$ p. 14-15, est. I, fig. 18-20, text-fig. 6)

Locus/Stratum typicus: carvão de Lukuga, próxima ao Rio Kibamba, Congo.

Descrição: esporo radial trilete, de contorno equatorial e margem subcircular lisa. Exina fina $(1,5-2,0 \mu \mathrm{m})$, finamente punctada na região inter-radial proximal, ao redor da laesura; finamente infrapunctada fora da área de contato. Raios da laesura ligeiramente ondulados e espessados, estendendo-se até $2 / 3$ do raio.

Dimensões: deq: 44-81 $\mu \mathrm{m}$ (10 exemplares).

Ocorrência: 168; 170 e 201 m (poço).

Distribuição biocronoestratigráfica: forma registrada no carvão de Buri, posicionado no Westphaliano da Bacia do Paraná (Souza et al., 1993a: est. I, fig. 3).

Comentários/comparação: os exemplares aqui descritos são atribuídos a esta espécie pelo tipo e distribuição da infraestrutura da exina. O nome atribuído a esta espécie pelos autores proponentes é indevido, visto que este gênero não inclui espécies com fovéolos e neste caso não se trata deste tipo de elemento escultural. Maheswari \& Bose (1969) se referem à estrutura da exina na área de contato como "almost foveolate" (sic), não caracterizando assim verdadeiros fovéolos, típicos das espécies do gênero Foveosporites Balme, 1957, em que se distribuem nas faces proximal e distal. 


\section{Punctatisporites solidus Hacquebard, 1957}

Est. 1, fig. 3

Diagnose: Hacquebard [1957. Micropaleontology, New York, 3(4):301-324; p. 308, est. 1, fig. 13]

Locus/Stratum typicus: West Gore Sample, Grupo Horton, Mississipiano da Nova Scotia, Canadá.

Descrição: esporo radial trilete de contorno e margem equatorial subcircular a circular lisa. Exina fina $(2-2,5 \mu \mathrm{m})$, infrapunctada. Laesuras retas e finas, alcançando $4 / 5$ do raio.

Dimensões: deq: 49-55 $\mu \mathrm{m}$ (2 exemplares).

Ocorrência: 167 e 171,3 m (poço).

Distribuição biocronoestratigráfica: espécie retrabalhada, assinalada entre o Devoniano Médio e o Carbonífero Inferior (Hacquebard, 1957; Playford \& McGregor, 1993: est. 8, fig. 10-11).

Comentários/comparação: forma registrada pela primeira vez na Bacia do Paraná; assemelha-se muito com a descrita originalmente, principalmente pela presença do limbo marginal ("limbus-like" sensu Hacquebard, 1957:308), que a separa das demais espécies do gênero.

\section{Gênero Calamospora Schopf, Wilson \& Bentall, 1944}

Espécie-tipo: Calamospora hartungiana Schopf, Wilson \& Bentall, 1944

Afinidade botânica: PTERIDOPHYTA-SPHENOPHYTA (Kosanke, 1950; Potonié \& Kremp, 1954; Courvousier \& Phillips, 1975).

Estão reunidos neste gênero, micrósporos e megásporos lisos, com raios da laesura pequenos, não ultrapassando metade do raio do esporo, com tênue marca de contato; dobras secundárias são muito comuns. A definição de suas espécies tem sido feita com base no desenvolvimento da laesura, presença e diferenciação das áreas de contato, natureza e extensão das dobras e espessura da exina, conforme apontam Smith \& Butterworth (1967:131). 


\section{Calamospora hartungiana Schopf, Wilson \& Bentall, 1944}

Est. 1, fig. 4

Diagnose: Schopf et al. (1944. State Geological Survey of Illinois, Urbana, Report of Investigations 91, 66 p. 3 est.; p. 51 , fig. 1)

Locus/stratum typicus: Carvão Macoupin, Rio Salt Fork of Vermilion, Vermilion County, Illinois, EUA.

Descrição: esporo radial trilete, de contorno equatorial subcircular. Exina fina $(1,0 \mu \mathrm{m})$, lisa, geralmente corroída, o que the confere aspecto granulado. Dobras distribuídas aleatoriamente e densamente sobre toda a exina, com grandes dimensões (máx. $5 \mu \mathrm{m}$ de alt. $\times 45 \mu \mathrm{m}$ de compr.). Laesura não visível.

Dimensões: deq: 80-110 $\mu \mathrm{m}$ (16 exemplares).

Ocorrência: 25,$5 ; 26,5 ; 41 ; 41,3 ; 45 ; 71 ; 77 ; 83 ; 98 ; 103,5 ; 124 ; 137 ; 155 ; 167 ; 168 ; 170 ; 171,3$; 182; 188,5; 195; 206 e 209 m (poço).

Comentários/comparações: assemelha-se muito com as espécies ilustradas por Barss (1967: est. XVIII, fig. 2) do Westphaliano B do Canadá, Césari (1985: est. II, fig. 1) na Formação Tupé e Ottone \& Azcuy (1989: est. I, fig. 1) na Formação Guadancol, Carbonífero MédioSuperior, Argentina.

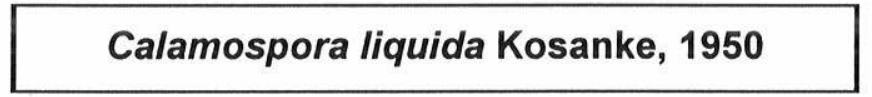

Est. 1, fig. 5

Diagnose: Kosanke (1950. State Geological Survey of Illinois, Urbana, Bull. 74, 128 p.; p. 41, est. 9, fig. 1)

Locus/stratum typicus: Pennsylvaniano de Illinois, EUA.

Descrição: esporo radial trilete, de contorno equatorial subcircular. Exina fina $(1,0 \mu \mathrm{m})$ e lisa. Raios da laesura retos, atingindo até $2 / 3$ do raio do esporo. Com pregueamento acentuado na zona marginal.

Dimensões: deq: 47-68 $\mu \mathrm{m}$ (9 exemplares).

Ocorrência: 25,5;103,5; 124; 137; 148; 171,3; 167; 188,5 e 209 m (poço). 
Distribuição biocronoestratigráfica: muito comum no Subgrupo Itararé nos estados do sul do Brasil na Bacia do Paraná (Marques-Toigo, 1988: est. I, fig. 2; Dias, 1993a: est. 1, fig. 8).

Comentários/comparações: não noticiada, até o momento, no Estado de São Paulo, esta espécie difere das outras do gênero pelo caráter mais fino e "limpo" da exina, além do pregueamento conspícuo na zona marginal. Com relação a C. smileyana Menéndez, 1965, o próprio autor proponente a diferenciou de C. liquida Kosanke, 1950 observando as menores dimensões do diâmetro equatorial desta última, que não ultrapassam, como no presente caso, $94 \mu \mathrm{m}$.

\section{Calamospora sp.}

Est. 1, fig. 6

Descrição: esporo radial trilete, de contorno equatorial subcircular. Exina fina $(<1,0 \mu \mathrm{m})$ e lisa, com algumas dobras/compressões arcuadas. Raios da laesura levemente sinuosos e altos $(2,0 \mu \mathrm{m})$.

Dimensões: deq: 68-71 $\mu \mathrm{m}$ (15 exemplares).

Ocorrência: freqüente em todo o poço e afloramentos.

Comentários/comparações: esta espécie ocorre geralmente não muito bem preservada no material estudado, o que dificulta a sua melhor atribuição sistemática.

Gênero Retusotriletes (Naumova) Streel, 1964

Espécie-tipo: Retusotriletes simplex Naumova, 1953

Afinidade botânica: PTERIDOPHYTA-PSILOPHYTA (Azcuy, 1978).

Retusotriletes simplex Naumova, 1953

Est. 1, fig. 7

Diagnose: Naumova (1953. Trav. Inst. Sci. Geol. Akad. Nauk. SSSR, Moscou, 143:1-154; p. 18, est. 2, fig. 9) 
Locus/stratum typicus: região de Kaluga, Devoniano Médio, ex-URSS.

Descrição: esporo radial trilete, de contorno circular a subcircular. Exina fina (1-1,5 $\mu \mathrm{m})$ e lisa. Raios da laesura retos, bem marcados, até $4 / 5$ do raio, onde se prolongam em curvatura na margem equatorial, destacando a área de contato.

Dimensões: deq: $24-34 \mu \mathrm{m}$ (7 exemplares).

Ocorrência: 25,5; 148 e 201 m (poço).

Distribuição biocronoestratigráfica: espécie muito comum no Subgrupo Itararé (Dias, 1993a: est. 1, fig. 12) e Formação Rio Bonito (Ybert, 1975: est. 1, fig. 19; Dias-Fabrício, 1981: est. 1, fig. 9) na Bacia do Paraná e no Paleozóico Superior em nível mundial.

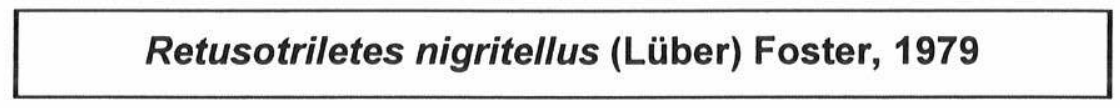

Est. 1, fig. 10

Diagnose: Foster (1979. Geological Survey of Queensland, Brisbane, Publ. Esp. 372; p. 30, est. 1, fig. 7 e 16).

Locus/stratum tipicus: Bacia de Kusnetz, Permiano de Erynakova, ex-URSS (Lüber \& Waltz, 1941 apud Foster, 1979).

Descrição: esporo radial trilete de contorno equatorial circular. Exina fina $(1,0 \mu \mathrm{m})$; raios da laesura retos, alcançando de $1 / 3$ a $1 / 2$ do raio do esporo. Área de contato nítida com escurecimento na região inter-radial polar e curvatura dos raios da laesura.

Dimensões: deq: $32-49 \mu \mathrm{m}$ (12 exemplares).

Ocorrência: 57; 77; 83; 103,5; 148; 152,5; 155; 167; 168; 170; 182 e 209 m (poço).

Distribuição biocronoestratigráfica: espécie muito comum nos estratos do Subgrupo Itararé (Marques-Toigo, 1988: est. I, fig. 5; Dias, 1993a: est. 1, fig. 12) e Formação Rio Bonito (Ybert, 1975: est. 1, fig. 14; Dias-Fabrício, 1981: est. 1, fig. 9), estendendo-se, pelo menos, até a Formação Palermo (Leipnitz, 1981: est. I, fig. 22) na Bacia do Paraná, sendo comumente referenciada como Calamospora nigritella (Lüber \& Waltz) Hart, 1965. Assim como Foster (1979), Azcuy (1995, comunicação pessoal) não concorda com a relocação dada a esta espécie por Hart (1965), sendo mais correta sua atribuição ao gênero Retusotriletes (Naumova) Streel, 1964 devido, principalmente, à área de contato ressaltada, característica diagnóstica deste último gênero. 


\section{Retusotriletes baculiferus Ybert, 1975}

Est. 1, fig. 9

Diagnose: Ybert (1975. Pesquisas, Porto Alegre, 5:181-226; p. 186, est. 1, fig. 21 a 23)

Locus/stratum typicus: afloramento Rio Jaguarão, Formação Rio Bonito, Permiano Inferior, Rio Grande do Sul.

Descrição: esporo radial trilete, de contorno subcircular. Exina fina $(1,0 \mu \mathrm{m})$, com alguns pequenos cones mal distribuídos na superfície que, quando na margem, dão a esta contorno irregular. Raios da laesura retos, finos até próximo à margem, onde se prolongam em curvatura na margem equatorial, destacando a área de contato.

Dimensões: deq: $44-46 \mu \mathrm{m}$; cones: $2,0 \mu \mathrm{m}$ alt. x 1,5 $\mu \mathrm{m}$ base (7 exemplares).

Ocorrência: 45; 152,5; 155 e 188,5 m (poço).

Distribuição biocronoestratigráfica: muito comum no Subgrupo Itararé (Marques-Toigo, 1988: est. 1, fig. 11) e Formação Rio Bonito (Dias-Fabrício, 1981: est. 1, fig. 11) na Bacia do Paraná.

Comentários/comparações: Souza et al. (1993a: est. I, fig. 6) ilustraram um exemplar semelhante a esta espécie no carvão de Buri, atribuindo-a, indevidamente, como Apiculatisporites sp.

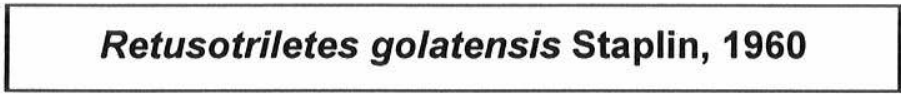

Est. 1, fig. 8

Diagnose: Staplin (1960. Palaeontographica, Sttutgart, Abt. B, 107:1-40, 8 est.; p. 22, est. 4, fig. 21 a 23)

Locus/stratum typicus: Formação Golata, Mississipiano Superior, Alberta, Canadá.

Descrição: esporo radial trilete de contorno equatorial subcircular. Exina fina $(1,0 \mu \mathrm{m})$, microgranulada. Raios da laesura finos e retos, até a região subequatorial, onde curvamse, ressaltando a área de contato.

Dimensões: $24-28 \mu \mathrm{m}$ (7 exemplares).

Ocorrência: 26,5; 41; 103,5; 137; 206 e 209 m (poço). 
Distribuição biocronoestratigráfica: espécie assinalada no Subgrupo Itararé (MarquesToigo: est. I, fig. 9; Dias, 1993a: est. 1, fig. 13) e Formação Rio Bonito (Ybert, 1975: est. 1, fig. 20) na Bacia do Paraná.

Comentários/comparações: difere de R. simplex Naumova, 1953 por esta apresentar granulação na exina.

\section{Retusotriletes sp. 1}

Est. 1, fig. 11

Descrição: esporo radial trilete liso, microgranulado (alt. $<0,5 \mu \mathrm{m}$ ) de contorno equatorial arredondado e margem lisa. Raios da laesura finos e retos, alcançando $3 / 4$ do raio do esporo, prolongando-se em curvatura, destacando a área de contato.

Dimensões: 52(62)68 $\mu \mathrm{m}$ (7 exemplares).

Ocorrência: 25,5; 41; 77 e 103,5 m (poço) e km 125,8.

Comentários/comparações: as dimensões mais elevadas e a ausência de elementos ornamentais distinguem as formas aqui assinaladas daquelas comumente registradas na Bacia do Paraná. R. sp. 2, aqui assinalada, possui área de contato melhor definida.

\section{Retusotriletes sp. 2}

Est. 1, fig. 12

Descrição: esporo radial trilete, de contorno equatorial subcircular. Exina fina $(1,0 \mu \mathrm{m})$ e lisa. Raios da laesura retos, finos, distintos, até $4 / 5$ do raio do esporo, onde se curvam, destacando a área de contato.

Dimensões: deq: $58 \mu \mathrm{m}$ (1 exemplar).

Ocorrência: 170 m (poço).

Comentários/comparações: esta espécie é muito semelhante a $R$. obliteratus Chibrikova, 1962, comum no Devoniano do Canadá, não sendo a ela atribuída devido a não disponibilidade de sua diagnose. 


\section{Retusotriletes sp. 3}

Est. 1, fig. 13

Descrição: esporo radial trilete, de contorno subcircular. Exina fina $(1,5 \mu \mathrm{m})$, infrapunctada. Raios da laesura retos, bem marcados, alcançando até 3/5 do raio. Área de contato bem definida, escura, com distanciamento da margem em cerca de $10 \mu \mathrm{m}$.

Dimensões: deq: $52 \mu \mathrm{m}$ (1 exemplar).

Ocorrência: 45 m (poço).

Distribuição biocronoestratigráfica: Higgs (1975: est. 1, fig. 9 e 13) e Clayton et al. (1977: est. 6, fig. 4) ilustraram espécies semelhantes, -Retusotriletes sp. A, com distribuição entre o Devoniano Superior e o Carbonífero europeus. Segundo Azcuy (1995, comunicação pessoal), esta espécie é comum também na Formação Ambo, Carbonífero Inferior do Peru.

Comentários/comparações: espécie considerada retrabalhada, sendo registrado apenas 1 exemplar.

Infraturma APICULATI (Bennié \& Kidston) Potonié, 1956

Subinfraturma GRANULATI Dybová \& Jachowicz, 1957

Gênero Cyclogranisporites Potonié \& Kremp, 1954

Espécie-tipo: Cyclogranisporites leopoldi (Kremp) Potonié \& Kremp, 1954

Afinidade botânica: PTERIDOPHYTA-FILICOPSIDA (Potonié \& Kremp, 1956; Laveine, 1969).

Cyclogranisporites parvigranulosus (Leschik) Ybert, 1975

Est. 1, fig. 14

Diagnose: Ybert (1975. Pesquisas, Porto Alegre, 5:181-226; p. 187, fig. 30).

Locus/stratum typicus: Carbonífero da ex-URSS. 
Descrição: esporo radial trilete liso, de contorno equatorial subcircular. Raios da laesura finos, levemente sinuosos, alcançando $2 / 3$ a $3 / 4$ do raio do esporo. Exina fina $(\sim 1,5 \mu \mathrm{m})$, densamente e finamente infragranulada, com algumas dobras arcuadas periféricas.

Dimensões: 53-60 $\mu \mathrm{m}$ (3 exemplares).

Ocorrência: 103,5 e 152,5 m (poço).

Distribuição biocronoestratigráfica: também assinalada no carvão de Candiota-Hulha Negra, Formação Rio Bonito (Ybert, 1975: est. 1, fig. 30), Bacia do Paraná.

Comentários/comparações: Cyclogranisporites flexuosus Playford, 1964 possui lábios espessados na laesura $(\sim 3 \mu \mathrm{m})$ e exina mais grossa $(3-5,5 \mu \mathrm{m})$. C. gondwanensis Bharadwaj \& Salujha, 1964 e C. minutus Bharadwaj, 1957 têm dimensões bem menores. C. lasius (Waltz) Playford, 1962, descrita no Carbonífero Inferior de Spitsbergen, possui as mesmas características diagnósticas desta espécie, podendo tratar-se de sinonímia.

Gênero Granulatisporites (Ibrahim) Potonié \& Kremp, 1954

Espécie-tipo: Granulatisporites granulatus Ibrahim, 1933

Afinidade botânica: PTERIDOPHYTA-FILICOPSIDA (Potonié \& Kremp, 1956; Grauvogel-Stamm \& Doubinger, 1975; Millay \& Taylor, 1982).

\section{Granulatisporites varigranifer Menéndez \& Azcuy, 1969}

Est. 1, fig. 15

Diagnose: Menéndez \& Azcuy [1969. Ameghiniana, Buenos Aires, VI(2):77-97; est. 3, fig. 3)

Locus/stratum typicus: Formação Lagares, Namuriano, Bacia de Paganzo, Argentina.

Descrição: esporo radial trilete de contorno equatorial triangular, com bordas inter-radiais retas e vértices amplamente arredondados. Margem irregular, devido às projeções dos elementos esculturais. Raios da laesura finos e retos, alcançando $2 / 3$ do raio do esporo. Exina fina $(0,5 \mu \mathrm{m})$, ornamentada por pequenos grânulos, cuja altura varia entre $0,2-1 \mu$ $\mathrm{m}$ de alt. $\times 0,2-1,5 \mu \mathrm{m}$ de base, separados com distanciamento oscilando entre 1 a $2 \mathrm{x}$ a medida de sua base. 
Dimensões: Deq: 28-38 $\mu \mathrm{m}$ (9 exemplares).

Ocorrência: 4,6; 41,3; 77; 98; 152,5; 195 e 209 m (poço).

Comentários/comparações: Azcuy (1975a) apresentou exemplares muito semelhantes aos aqui descritos; porém, com medidas maiores no diâmetro equatorial (39-50 $\mu \mathrm{m})$.

\section{Granulatisporites triconvexus Staplin, 1960}

Est. 1, fig. 16

Diagnose: Staplin (1960. Palaeontographica, Sttutgart, Abt. B, 107:1-40, 8 est.; p. 15, est. 3, fig. 1112)

Locus/stratum typicus: Formação Golata, Mississipiano Superior, Alberta, Canadá.

Descrição: esporo radial trilete, convexamente triangular. Exina fina $(<1,0 \mu \mathrm{m})$, finamente granulada (vista sob imersão em óleo). Raios da laesura levemente sinuosos, com lábios escuros, de até $3 \mu \mathrm{m}$ de largura, que acompanham os raios nos dois lados adjacentes destes.

Dimensões: deq: $42 \mu \mathrm{m}$ (1 exemplar).

Ocorrência: 77 m (poço)

Comentários/comparações: difere de Punctatisporites incomptus Felix \& Burbridge, 1967, por esta apresentar exina finamente granulada, assim observada apenas sob imersão em óleo, como também se refere Staplin (1960:15) na descrição original da espécie.

Subinfraturma VERRUCATI Dybová \& Jachowicz, 1957

Gênero Verrucosisporites (Ibrahim) Smith, 1971

Espécie-tipo: Verrucosisporites verrucosus (Ibrahim) Ibrahim, 1933

Afinidade botânica: PTERIDOPHYTA-FILICOPSIDA (Laveine, 1969, 1971; Millay \& Taylor, 1982). 
Verrucosisporites verrucosus (Ibrahim) Ibrahim, 1933

Est. 1, fig. 17

Diagnose: Potonié \& Kremp [1955. Palaeontographica, Sttutgart, Abt B, 98(1/3), p. 69].

Locus/stratum typicus: Ruhr Coalfield, Agir Seam, Alemanha, topo do Westphaliano B.

Descrição: esporo radial trilete, de contorno equatorial arredondado, com margem irregular devido à projeção dos elementos esculturais. Exina fina $(3,5-4,0 \mu \mathrm{m})$, ornamentada por verrugas, com altura não superior a $2 \mu \mathrm{m}$ com cristas arredondadas. Raios da laesura distintos, retos, alcançando, aproximadamente, 1/3 do raio.

Dimensões: deq: $60-64 \mu \mathrm{m}$; verrugas: $4(5) 6 \mu \mathrm{m}$ base $\mathrm{e}<2,0 \mu \mathrm{m}$ de alt. (3 exemplares)

Ocorrência: 124 e 152,5 m (poço).

Comentários/observações: difere de Verrucosisporites andersonni (Anderson) Backhouse, 1991, pelas menores dimensões e ornamentação mais densa naquela e de Verrucosisporites asprilis Playford \& Helby, 1968 pelas menores dimensões e a exina não ultrapassar $2,5 \mu \mathrm{m}$ de espessura naquela espécie.

\section{Verrucosisporites cf. V. morulatus (Knox) Smith \& Butterworth, 1967}

Est. 1, fig. 18

Diagnose: Smith \& Butterworth (1967. Special Paper in Palaeontology, Londres, vol. 1, 342 p.; p. 151, est. 5, fig. 15-16).

Locus/stratum typicus: Sulphur Seam, Lindsay Colliery, Namuriano A, East Fife Coalfield, Escócia.

Descrição: esporo radial trilete, de contorno equatorial ovalado, com margem irregular devido à projeção dos elementos esculturais. Exina fina $(3-4,0 \mu \mathrm{m})$, ornamentada por verrugas compactas, com ápices arredondados, de base irregular (poligonal/arredondada). Raios da laesura não observados.

Dimensões: deq: 58-62 $\mu \mathrm{m}$; elem. escult.: $2-5 \mu \mathrm{m}$ base e alt. $<1,5 \mu \mathrm{m}$ (3 exemplares)

Ocorrência: 168 e 171,3 m (poço).

Distribuição biocronoestratigráfica: muito comum na Formação Rio Bonito e Subgrupo Itararé nos estados do sul do Brasil. 
Comentários/observações: a forma aqui descrita é semelhante àquelas descritas para o Rio Grande do Sul por Dias-Fabrício (1981: est. 3, fig. 11) e Dias (1993a: est. 3, fig. 1), ainda que suas dimensões sejam maiores.

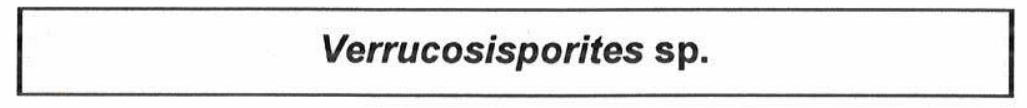

Est. 1, fig. 19

Descrição: esporo radial trilete de contorno equatorial subarredondado a subtriangular. Exina fina $(2,0 \mu \mathrm{m})$, ornamentada por verrugas irregularmente distribuídas, espaçadas entre sí, dando aspecto irregular no contorno marginal. Raios da laesura simples, finos e retos, até próximo à margem equatorial.

Dimensões: deq: $46-72 \mu \mathrm{m}$; elem. escult.: 2(4)5 $\mu \mathrm{m}$ base $\mathrm{x}$ alt. $<2,0 \mu \mathrm{m}$ (7 exemplares).

Ocorrência: 41,3; 45; 167; 170; 195 e 201 m (poço).

Comentários/observações: difere de Verrucosisporites sp. 15806 ( in Barss, 1967: est. V, fig. 20) porque naquela a ornamentação é mais densa; difere de V. nitidus (Naumova) Playford, 1964 pelo caráter mais espaçado dos elementos esculturais desta. V. cf. V. scoticus (Wislow) Neves \& loannides, 1974 possui verrugas mais pronunciadas; V. dejerseyi Playford, 1978 apresenta elementos esculturais variados (verrugas, cones e pilas).

Subinfraturma NODATı Dybová \& Jachowicz, 1957

Gênero Apiculiretusispora (Ibrahim) Potonié \& Kremp, 1954

Espécie-tipo: Apiculiretusispora brandtii Strell, 1964

Apiculiretusispora sp.

Est. 2, fig. 1

Descrição: esporo radial trilete de contorno equatorial subcircular. Exina fina $(<1,0 \mu \mathrm{m})$, ornamentada por cones e grânulos, irregularmente distribuídos, que dão aspecto 
irregular à margem. Raios da laesura finos e retos, alcançando a margem, onde se curvam irregularmente.

Dimensões: deq: $34-38 \mu \mathrm{m}$; elementos esculturais: $1,5 \mu \mathrm{m}$ base $\times 1,0 \mu \mathrm{m}$ alt (4 exemplares).

Ocorrência: 152,5; 201 e 206 m (poço).

Comentários/observações: difere de Apiculiretusispora tuberculata Azcuy, 1975 porque naquela a ornamentação se distribui, quase que esclusivamente, sobre a face distal.

\section{Gênero Spinozonotriletes Hacquebard, 1957}

Espécie-tipo: Spinozonotriletes uncatus Hacquebard, 1957

\section{Spinozonotriletes conspicuus Playford, 1964}

\section{Est. 2, fig. 2}

Diagnose: Playford (1964. Geological Survey of Canadá, Ottawa, Bull. 107, 47 p., 11 est.; p. 22-23, est. $V$, fig. 3-4)

Locus/stratum typicus: Grupo Horton, Mississipiano, Nova Scotia, Canadá.

Descrição: Esporo radial trilete de contorno equatorial subcircular a subtriangular. Intexina, "mesosporoid" (sensu Playford, 1964:22) ou "corpo central" (sensu Hacquebard, 1957:315) de espessura fina $(2-3 \mu \mathrm{m})$, cujos raios da laesura, finos e retos, alcançam a margem equatorial. Superfície finamente infrapunctada, esculturada por espinhos irregularmente espaçados $(2-10 \mu \mathrm{m})$, com 4-6 $\mu \mathrm{m}$ de base e até $7 \mu \mathrm{m}$ de altura, nas faces distal e proximal. Exoexina ("perispore" sensu Hacquebard, 1957:315) contendo os mesmos elementos esculturais e pequenos cones, com $2 \mu \mathrm{m}$ de base e 1-2 $\mu \mathrm{m}$ de altura, que se distribuem mais regularmente nas margens.

Dimensões: Deq: 60-70 $\mu \mathrm{m}$ (sem elementos esculturais); cc (corpo central): $56 \mu \mathrm{m}$ (3 exemplares).

Ocorrência: 152,5; 155 e 167 m (poço).

Comentários/comparações: espécie considerada como retrabalhada; as formas aqui atribuídas a esta espécie possuem dimensões ligeiramente maiores do que aqueles descritas originalmente por Playford (1964). No entanto, têm semelhança em seus 
principais caracteres, principalmente quanto à natureza e distribuição dos elementos esculturais.

Subinfraturma BACULATI Dybová \& Jachowicz, 1957

\section{Gênero Raistrickia (Schopf, Wilson \& Bentall) Potonié \& Kremp, 1954}

Espécie-tipo: Raistrickia grovensis Schopf, Wilson \& Bentall, 1944

Afinidade botânica: PTERIDOPHYTA-FILICOPSIDA (Potonié \& Kremp, 1956; Eggert \& Taylor, 1966; Laveine, 1969; Andrews et al., 1970; Grauvogel-Stamm \& Doubinger, 1975).

\section{Raistrickia rotunda Azcuy, 1975}

Est. 2, fig. 3

Diagnose: Azcuy [1975. Ameghiniana, Buenos Aires, XII(1):1-69, p. 60-62, est. XVII, fig. 110-113 e est. XVIII, fig. 8]

Locus/stratum typicus: Membro Estratos Carbonosos, Formação Malazán, NamurianoWestphaliano, Bacia de Paganzo, Argentina.

Descrição: esporo radial trilete de contorno subcircular a subtriangular, com margem irregular devido à projeção dos elementos esculturais. Exina fina $(2-2,5 \mu \mathrm{m})$, ornamentada por báculas e pilas com ápices arredondados e raramente angulares, irregularmente distribuídos e de dimensões variadas.

Dimensões: deq: 44-62 $\mu \mathrm{m}$; elem. escult.: $4 \mu \mathrm{m}$ base $\times 4-6,0 \mu \mathrm{m}$ de alt. ( 6 exemplares).

Ocorrência: 98; 103,5; 124; 152,5; 167 e 168 m (poço).

Comentários/comparação: os exemplares se enquandram na descrição original da espécie, distinguindo-se de $R$. densa Menéndez, 1965 porque naquela a ornamentação é constituída predominantemente por cones. Souza et al. (1993a: est. 1, fig. 10-12) também reconheceram esta espécie no carvão de Buri, Westphaliano da Bacia do Paraná. 
Raistrickia sp.

Est. 2, fig. 4

Descrição: esporo radial trilete de contorno circular a subcircular, com margem irregular devido à projeção dos elementos esculturais. Exina fina $(2-2,5 \mu \mathrm{m})$, ornamentada por pilas e clavas, irregularmente distribuídas. Raios da laesura não visiveis devido à forte ornamentação.

Dimensões: deq: 45-65 $\mu \mathrm{m}$; elem. escult.: 4-8 $\mu \mathrm{m}$ base $\times$ 4-8 $\mu \mathrm{m}$ de alt. (3 exemplares).

Ocorrência: 152,5 e 155 m (poço).

Comentários/comparação: difere das demais espécies do gênero pela irregularidade do tamanho e distribuição dos elementos ornamentais.

Subinfraturma PSEUdocingulatI Neves, 1961

(originalmente proposta como "Séries")

Gênero Secarisporites Neves, 1961

Espécie-tipo: Secarisporites lobatus Neves, 1961

Secarisporites cf. S. lobatus Neves, 1961

Est. 2, fig. 5

Diagnose: Neves [1961. Palaeontology, Londres, 4(2):247-279; p. 261-262, text-fig. 2]

Locus/stratum typicus: Folhelhos marinhos com Gastrioceras cancellatum Derbyshire, Namuriano, Inglaterra.

Descrição: esporo radial trilete de contorno subtriangular, com margem irregular devido à projeção dos elementos esculturais. Raios da laesura nítidos, simples e retos até próximo à margem equatorial. Elementos ornamentais constituídos de báculas de forma lobada e tamanho variado. 
Dimensões: deq: $70 \mu \mathrm{m}$; elem. escult.: $8 \mu \mathrm{m}$ base $x>10,0 \mu \mathrm{m}$ de larg. (1 exemplar).

Ocorrência: 152,5 m (poço).

Comentários/comparação: difere das espécies do gênero Raistrickia (S. W. \& B.) Potonié \& Kremp, 1954 visto que naquele gênero os elementos esculturais são de dimensões mais reduzidas e, como característico nas espécies do gênero Secarisporites Neves, 1961, as margens são lobadas, como aqui observado.

\section{Secarisporites sp.}

Est. 2, fig. 6

Descrição: esporo radial trilete de contorno equatorial subtriangular. Exina fina $(2,0 \mu \mathrm{m})$, densamente ornamentada por báculas com topos arredondados e elementos lobados. $\mathrm{Na}$ margem, os elementos lobados estão dispostos mais continuamente, dando aspecto cingulado ao esporo. Raios da laesura finos e retos, alcançando a margem equatorial.

Dimensões: deq: $40 \mu \mathrm{m}$; elem. escult.: $3,0 \mu \mathrm{m}$ base $\times 5,0 \mu \mathrm{m}$ de alt. (1 exemplar).

Ocorrência: 167 m (poço).

Comentários/comparação: esta forma é muito semelhante a S. crenatus Peppers, 1964. No entanto, a disposição mais irregular dos elementos ornamentais desta espécie impede seu enquadramento nessa espécie.

Infraturma MURORnATI Potonié \& Kremp, 1954

Gênero Dictyotriletes (Naumova) Smith \& Butterworth, 1967

Espécie-tipo: Dictyotriletes bireticulatus (Ibrahim) Potonié \& Kremp, 1954

Afinidade botânica: PTERIDOPHYTA (?)-PTEROPSIDA (Hamer \& Rothwell, 1983). 


\section{Dictyotriletes muricatus (Kosanke) Smith \& Butterworth, 1967}

Est. 2, fig. 7

Diagnose: Smith \& Butterworth (1967. Special Paper in Palaeontology, Londres, Vol. 1, 342 p.; p. 197-198, est. II, fig. 25-26)

Locus/stratum typicus: carvão La Salle, Bureau County, parte superior do Grupo McLeansboro, Westphaliano A-C, Illinois, EUA.

Descrição: esporo trilete de contorno equatorial subcircular. Raios da laesura medindo de $2 / 3$ a 3/3 do raio do esporo. Exina fina $(2-2,5 \mu \mathrm{m})$ com muri estendendo-se até $12 \mu \mathrm{m}$ além do corpo central, com $4 \mu \mathrm{m}$ de largura, cobrindo todo o corpo central do esporo.

Dimensões: deq: 70-75 $\mu \mathrm{m}$ (5 exemplares).

Ocorrência: 167; 168; 170 e 182 m (poço).

Distribuição biocronoestratigráfica: assinalada entre o Westphaliano A a C da Grã-Bretanha (Smith \& Butterworth, 1967) e Carbonifero Superior de Illinois (Kosanke, 1950).

Comentários/comparações: difere de Dictyotriletes bireticulatus (Ibrahim) Smith \& Butterworth, 1967 pelo padrão mais regular da reticulação desta espécie e de $D$. densoreticulatus Potonié \& Kremp, 1954 pela maior espessura dos muri naquela espécie.

Dictyotriletes pseudopalliatus (Staplin) comb. nov.

Est. 2, fig. 8

Sinonímia:

Reticulatisporites pseudopalliatus Staplin, 1960 in Staplin (1960: p. 13, est. 2, fig. 24)

Reticulatisporites pseudopalliatus Staplin, 1960 in Ybert (1975:est. 2, fig. 47-48)

Reticulatisporites pseudopalliatus Staplin, 1960 in Dias-Fabrício (1981: est. II, fig. 14)

Reticulatisporites pseudopalliatus Staplin, 1960 in Marques-Toigo (1988: est. 3, fig. 8)

Reticulatisporites pseudopalliatus Staplin, 1960 in Dias (1993a: est.3, fig. 6)

Reticulatisporites pseudopalliatus Staplin, 1960 in Cesari et al. (1995: est. II, fig. 13)

Locus/stratum typicus: Formação Golata, Mississipiano Superior, Alberta, Canadá.

Nova diagnose: esporo radial trilete de contorno equatorial circular a subcircular; reticulado, com muri de 1,0-2,0 $\mu \mathrm{m}$ de largura e 3-10 $\mu \mathrm{m}$ de altura, com lúminas de disposição 
poligonal, finamente granulada, de até $13 \mu \mathrm{m}$ de largura. Raios da laesura simples, extendendo-se até $2 / 3$ do raio total. Diâmetro equatorial entre 40-70 $\mu \mathrm{m}$.

Descrição: esporo trilete de contorno equatorial subcircular. Raios da laesura finos, não ultrapassando $2 / 3$ do raio do esporo. Exina ornamentada por reticulação de caráter irregular, com muri de até $2 \mu \mathrm{m}$ de largura e $5 \mu \mathrm{m}$ de altura. Lúmina finamente granulada, de padrão irregular, com até $13 \mu \mathrm{m}$ de largura.

Dimensões: deq: 50(55)60 $\mu \mathrm{m}$ (7 exemplares).

Ocorrência: 77; 137; 152,5; 201; 206 e 209 m (poço) e Afloramento km 122,7.

Distribuição biocronoestratigráfica: espécie assinalada desde o Mississipiano Superior (Staplin, 1960) até o Permiano Inferior (Ybert, 1975).

Comentários/observações: Smith \& Butterworth (1967) realizaram uma emenda na diagnose de Potonié \& Kremp (1954) do gênero Dictyotriletes, de modo a incluir neste algumas espécies atribuídas a Reticulatisporites, pela verificação de um cíngulo na espécie-tipo deste último gênero, Reticulatisporites reticulatus (Ibrahim) Ibrahim, 1933. Desta forma, aquelas espécies de esporo radial trilete reticulado, com muri projetando-se na margem equatorial e lumina regular a variável foram incluídas em Dictyotriletes, enquanto que aquelas providas de cíngulo, em Reticulatisporites. Azcuy et al. (1982) já haviam comparado Dictyotriletes sp. (sua fig. II, est. 3) com Reticulatisporites pseudopaliatus Staplin, 1960, destacando que, algumas espécies descritas na América do Sul, como aquelas ilustradas por Dias-Fabrício (1980: est. 2, fig. 14 apud Azcuy et al., 1982) e Ybert (1975: est. 2, fig. 47-48) teriam melhor enquadramento no gênero Dictyotriletes, devido à falta de cíngulo, conforme emenda ao gênero Reticulatisporites realizada por Neves (1964, apud Azcuy et al., 1982). Esta espécie é muito semelhante a $D$. equigranulatus Nevile, 1968, pela forma e disposição dos muri, diferindo, no entanto, pela granulação, presente naquela espécie.

\section{Dictyotriletes sp.}

Est. 2, fig. 9

Descrição: esporo trilete de contorno equatorial subcircular. Raios da laesura alcançando metade do raio do esporo. Corpo central subcircular, esculturado com muri de até $5 \mu \mathrm{m}$ de espessura e $8 \mu \mathrm{m}$ de altura, onde se desenvolvem luminas de formas irregular, de até $23 \mu \mathrm{m}$.

Dimensões: Deq: 52-60 $\mu \mathrm{m}$, incluindo altura dos muri (3 exemplares). 
Ocorrência: 201 e 206 m (poço).

Distribuição biocronoestratigráfica: Césari (1985: est. 3, fig. 2) ilustrou forma semelhante na Formação Tupé, Argentina.

\section{Gênero Convolutispora Hoffmeister, Staplin \& Malloy, 1955}

Espécie-tipo: Convolutispora florida Hoffmeister, Staplin \& Malloy, 1955

Afinidade botânica: PTERIDOPHYTA-FILICOPSIDA (Laveine, 1969).

\section{Convolutispora sp.}

Est. 2, fig. 10

Descrição: esporo trilete de contorno equatorial subcircular. Raios da laesura nítidos, alcançando pouco mais que $2 / 3$ do raio do esporo. Fortemente ornamentado por cristas (muri) irregulares, vermiculados, que dão contorno irregular à margem. Cristas com pequenas espessuras $(1,5-2,0 \mu \mathrm{m})$ e alturas $(2-2,5 \mu \mathrm{m})$, dispondo-se com um padrão de vermiculação médio.

Dimensões: Deq: $46-48 \mu \mathrm{m}$ (3 exemplares).

Ocorrência: 171,3 e 201 m (poço).

Comentários/comparações: distingue-se de Convolutispora muriornata Menéndez, 1965 pela ausência de grânulos e espinhos nos muri e por estes últimos serem mais grossos naquela espécie, além das dimensões menores.

Gênero Murospora Somers, 1952

Espécie-tipo: Murospora kosankei Somers, 1952

Afinidade botânica: sem referências. 


\section{Murospora sp.}

Est. 2, fig. 11

Descrição: esporo radial trilete, convexamente triangular. Raios da laesura finos e retos, bordejados por um par de "torus" que se prolongam até a margem equatorial, formando um pseudocíngulo. Exina fina $(\sim 1-1,5 \mu \mathrm{m})$ e lisa.

Dimensões: deq: $46-52 \mu \mathrm{m}$ (4 exemplares).

Ocorrência: 45, 137 e 152,5 m (poço).

Comentários/comparação: difere de Leiotriletes ornatus Ischenko, 1956 pela aparência cingulada destas formas. Foster (1979: est. 2, fig. 12) identificou uma espécie muito semelhante, Retusotriletes sp. A que, conforme aquele autor, também apresenta área de contato melhor definida pela curvatura dos raios da laesura, caráter não observado nas espécies aqui estudadas. Murospora torifera Ybert, 1975 possui um par de "torus" que acompanha a laesura e cíngulo melhor definidos e mais espessos.

\section{Gênero Emphanisporites McGregor, 1961}

Espécie tipo: Emphanisporites rotatus McGregor, 1961

Afinidade botânica: PTERIDOPHYTA-PSILOPHYTA (McGregor, 1961).

\section{Emphanisporites rotatus McGregor, 1961}

Est. 2, fig. 12

Diagnose: McGregor (1961. Geological Survey of Canadá, Bull. 76, 15 p.; p. 3, est. I, fig. 1-4)

Locus/stratum typicus: Formação Battery Point, Gaspé Península e Formação Sextant, Devoniano Superior, Ontário, Canadá.

Descrição: esporo radial trilete, de contorno equatorial subtriangular a subarredondado. Raios da laesura nítidos, retos, até à margem equatorial. Exina lisa, fina (1,5-2 $\mu \mathrm{m})$. Área de contato bem definida com 3 costelas radiais em cada região inter-radial.

Dimensões: deq: $39 \mu \mathrm{m}$ (1 exemplar).

Ocorrência: 152,5 m (poço). 
Distribuição biocronoestratigráfica: espécie registrada no Devoniano de diversas partes do mundo, como no Devoniano Superior do Saara (Jardiné \& Yapaudjian (1968: est. 1, fig. 3), do Canadá (McGregor, 1961) e Bacia do Paraná (Dino \& Rodrigues, 1995: est. I, fig. 18) e no Carbonífero Inferior da Argentina ( Cesari \& Limarino, 1992: est. I, fig. 3).

Comentários/comparações: espécie considerada como retrabalhada, tendo sido registrado apenas 1 exemplar.

Subturma ZONOTRILETES Waltz, 1935

Infraturma AURICULATI (Schopf) Dettman, 1963

Gênero Ahrensisporites Potonié \& Kremp, 1954

Espécie-tipo: Ahrensisporites guerickei (Horst) Potonié \& Kremp, 1954

Afinidade botânica: desconhecida.

Ahrensisporites cristatus Playford \& Powis, 1979

Est. 2, fig. 15

Diagnose: Playford \& Powis [1979. Pollen et Spores, Paris, XXI(3):371-394; p. 382-385, est II fig. 6, est. III, fig. 1 a 7$]$

Locus/stratum typicus: Formação Grant, Bacia de Canning, Assembléia de Spelaeotriletes yberti, Namuriano/Westphaliano, oeste da Austrália.

Descrição: esporo radial trilete de contorno equatorial triangular, com bordas inter-radiais lisas, levemente convexas e extremidades radiais levemente expandidas, onde se projeta a ornamentação. Raios da laesura retos, alcançando a periferia equatorial, bordeado por fortes lábios ( $5 \mu \mathrm{m}$ de altura). Cristas mais ou menos contínuas e arqueadas (kyrtoma), desenvolvidas entre os ângulos da laesura (na superfície distal), projetando-se nos extremos radiais. Na face distal, entre as cristas, a exina é ornamentada por espinhos e cones $(3 \mu \mathrm{m}$ de base $\mathrm{x}$ até $10 \mu \mathrm{m}$ de altura).

Dimensões: deq: 95-125 $\mu \mathrm{m}$ (6 exemplares).

Ocorrência: 98; 148; 168; 171,3 e 209 m (poço). 
Distribuição biocronoestratigráfica: espécie assinalada na Formação Água Colorada, Bacia de Paganzo e Formação Santa Máxima, Argentina (Azcuy et al., 1982: est. III, fig. 2; Ottone, 1989: est. 5, fig. 1; Limarino et al., 1984 apud Ottone, 1989). A ocorrência desta espécie é restrita ao Carbonífero Médio das bacias gondvânicas.

Comentários/comparações: espécie pela primeira vez noticiada no Paleozóico Superior da Bacia do Paraná. São poucas as espécies atribuídas a este gênero, sendo que, conforme Playford \& Powis (1979:385), nenhuma é comparável a Ahrensisporites cristatus Playford \& Powis, 1979, bem diferenciada das outras pela natureza do kyrtoma, constituído por cristas conadas e arcuadas.

Infraturma CinguLATI (Potonié \& Klaus) Dettman, 1963

Gênero Stenozonotriletes (Naumova) Ischenko, 1952

Espécie-tipo: Stenozonotriletes conformis Naumova, 1953

Afinidade botânica: desconhecida.

\section{Stenozonotriletes perforatus Playford, 1962}

Est. 2, fig. 13

Descrição: Playford [1962. Palaeontology, Londres, 5(3):550-618; p. 607, est. 86, fig. 8-9, text-fig. 5e].

Locus/stratum typicus: Citadellet, Carbonifero Inferior, Spitsbergen.

Descrição: esporo radial trilete cingulizonado liso, de contorno equatorial convexamente subtriangular a subarredondado. Raios da laesura distintos, finos e retos, alcançando $3 / 4$ do raio do corpo do esporo. Corpo central finamente punctado, com contorno acompanhando o contorno geral do grão. Cíngulo liso, de espessura uniforme, relativamente estreito.

Dimensões: deq: 56(59)64; cíng.:4(4,5)5,5m (11 exemplares).

Ocorrência: 25,$5 ; 41,3 ; 45 ; 51 ; 55 ; 66 ; 103,5 ; 137 ; 152,5$ e 155 m (poço) e Afloramento km 125,8 . 
Comentários/comparações: Playford (1962:605) destacou as dificuldades na distinção de algumas das espécies atribuídas a este gênero e de Punctatisporites (Ibrahim) Potonié \& Kremp, 1954, o qual possui exina fina e que em vista polar pode simular um estreito cíngulo. A individualização da área marginal, de modo a formar um cíngulo, e suas proporções, fazem distinção desta espécie com aquelas do gênero Punctatisporites. Conforme a diagnose da espécie, a média da medida do cíngulo é de $4,5 \mu \mathrm{m}$ e do diâmetro equatorial é de $65 \mu \mathrm{m}$, com o cíngulo representando $6,9 \%$ do diâmetro total do esporo. No material aqui observado, essas médias são $4,5 \mu \mathrm{m}$ e $59 \mu \mathrm{m}$, respectivamente, com o cíngulo representando $7,6 \%$ do diâmetro total do esporo. $S$. facilis Ishchenko, 1956 e S. simplex Naumova, 1956 são lisos. S. inductus Ishchenko, 1956 possui margem equatorial denteada. S. spetcandus Naumova, 1953 possui laesura bordejada, com lábios elevados. S. stenozonalis (Waltz) Ishchenko, 1958 possui relação cíngulo/deq total 1:6, evidenciando um cíngulo proporcionalmente mais desenvolvido. Exemplar semelhante também foi descrito por Owens et al. (1977: est. 2, fig. 5) em sedimentos do Carbonífero Inferior (Tournaisiano).

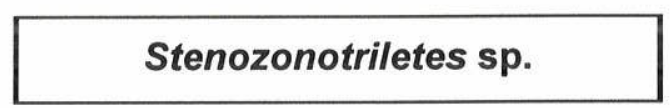

Est. 2, fig. 14

Descrição: esporo radial trilete, de contorno equatorial subtriangular a subarredondado. Exina fina $(2-3 \mu \mathrm{m})$, infrapunctada. Raios da laesura distintos, levemente pronunciados, retos, alcançando as proximidades da margem equatorial. Cíngulo de espessura variada (6-8 $\mu$ m), mais espesso nas regiões inter-radiais.

Dimensões: Deq: 66-78 $\mu \mathrm{m}$ (3 exemplares).

Ocorrência: 152,5 e 168 m (poço).

Comentários/comparações: espécie considerada como retrabalhada. Os exemplares aqui descritos são bastante similares àquela espécie descrita por Playford (1964: est. IX, fig. 9), Stenozonotriletes sp., no Mississipiano do Canadá, com exceção da espessura do cíngulo, que naquela é mais uniforme. 
Suprasubturma LAMINATITRILETES Smith \& Butterworth, 1967

Subturma ZONOLAMINATITRILETES Smith \& Butterworth, 1967

Infraturma CINGULICAVATI Smith \& Butterworth, 1967

\section{Gênero Lundbladispora (Balme) Playford, 1965}

Espécie-tipo: Lundbladispora wilmotti (Balme) Playford, 1965

Afinidade botânica: PTERIDOPHYTA-LYCOPHYTA (Balme, 1963; Marques-Toigo \& Picarelli, 1984).

\section{Lundbladispora riobonitensis Marques-Toigo \& Picarelli, 1984}

Est. 2, fig. 17

Diagnose: Marques-Toigo \& Picarelli (1984. Bol. IG-USP, São Paulo, 15:46-52; p. 48, est. I, fig. 1-3, est. II, fig. 1B, 5 e 6$)$

Locus/stratum typicus: carvão de Iruí, Formação Rio Bonito, Permiano Inferior, Rio Grande do Sul, Brasil.

Descrição: esporo radial trilete cingulizonado, de contorno triangular, lado convexos e vértices arredondados. Face proximal finamente punctada, com aspecto esponjoso; raios da laesura nítidos, sinuosos, até o limite interno da cingulizona. Cíngulo regular em tamanho e espessura, comportando pequenos cones e espinhos (1-1,5 $\mu \mathrm{m}$ de alt.), distribuídos amplamente pela face distal.

Dimensões: deq: 44-68 $\mu \mathrm{m}$; cing.: 5(6)7 $\mu \mathrm{m}$; cc: 30-58 $\mu \mathrm{m}$ (7 exemplares).

Ocorrência: 26,$5 ; 41 ; 41,3 ; 45 ; 71 ; 103,5 ; 137 ; 148 ; 152,5 ; 155 ; 167 ; 167$ e 167 m (poço) e Afloramento $\mathrm{km} \mathrm{123,7.}$

Distribuição biocronoestratigráfica: espécie comumente assinalada no Paleozóico Superior da América do Sul (e.g. Marques-Toigo, 1988: est. IV, fig. 7; Ottone, 1991: est. I, fig. 5).

Comentários/comparações: L. braziliensis Marques-Toigo \& Picarelli, 1984 possui raios da laesura menos pronunciados e ornamentação mais densa. 


\section{Lundbladispora braziliensis (Marques-Toigo \& Pons) Marques-Toigo \& Picarelli, 1984}

Est. 2, fig. 16

Diagnose: Marques-Toigo \& Picarelli (1984. Bol. IG-USP, São Paulo, 15:46-52; p. 46, est. I, fig. 4-6, est. II fig. 1A, 2, 3, 4, 7 e 8 ).

Locus/stratum typicus: carvão de Candiota (RS) e camada Barro Banco (SC), Formação Rio Bonito, Permiano Inferior, Brasil.

Descrição: esporo trilete cingulizonado de contorno equatorial subcircular a convexamente subtriangular. Exina espessa; face proximal lisa a finamente punctada; face distal e cingulizona ornamentadas por esculturas do tipo "echinate", em geral coalescentes, com elementos de até $5 \mu \mathrm{m}$ de diâmetro basal e 3,5 $\mu \mathrm{m}$ de altura. Cíngulo espessado (7-9 $\mu$ m), esculturado equatorialmente por grânulos, pequenos espinhos e verrugas.

Dimensões: deq: $72-84 \mu \mathrm{m}$ (7 exemplares).

Ocorrência: $18 ; 26,5 ; 45 ; 66 ; 71 ; 148 ; 152,5 ; 155 ; 167$ e 171,3 m (poço).

Comentários/comparações: espécie muito comum no Paleozóico Superior das bacias gondvânicas sul-americanas (e.g. Archangelsky \& Gamerro, 1979: est. 4, fig. 7; MarquesToigo, 1988: est. IV, fig. 8; Dias, 1993a: est. 4, fig. 8).

\section{Lundbladispora sp.}

Est. 2, fig. 18

Descrição: esporo radial trilete cingulizonado, de contorno equatorial convexamente triangular. Corpo central nítido; raios da laesura elevados, de até $2 \mu \mathrm{m}$ de largura, atingindo o bordo interno da cingulizona, onde o corpo central se espessa e é mais escuro. Face proximal e distal de aspecto "esponjoso"; cingulizona fina, com limites interno e externo não muito bem definidos, aparentando uma "franja".

Dimensões: deq: 70-82 $\mu \mathrm{m}$; cing.: 8-12 $\mu \mathrm{m}$ (8 exemplares).

Ocorrência: 103,5 e 167 m (poço) e Afloramento km 122,7.

Comentários/comparações: assemelha-se muito a Lycospora sp. T descrita por Jansonius (1962: est. 11, fig. 13-14), no Pennsylvaniano do Canadá, principalmente pelo engrossamento/escurecimento do corpo central na área radial terminal, tendo, no entanto, maiores dimensões e cingulizona mais desenvolvida. 


\section{Gênero Lycospora (Schopf, Wilson \& Bentall) Potonié \& Kremp, 1954}

Espécie-tipo: Lycospora micropapillata (Wilson \& Cöe) Schopf, Wilson \& Bentall, 1944

Afinidade botânica: PTERIDOPHYTA-LYCOPHYTA (Azcuy, 1978).

\section{Lycospora sp. 1}

Est. 3, fig. 1

Descrição: esporo radial trilete zonado, de contorno equatorial subtriangular, lados ligeiramente convexos e vértices arredondados. Corpo central distinto, liso ou finamente granulado, com raios da laesura medindo cerca de $4 / 5$ ou próximo do raio do corpo central. A face distal pode apresentar pequenos cones pouco desenvolvidos e irregularmente distribuídos. A zona é translúcida, de largura regular e aspecto inframicroreticulado.

Dimensões: deq: 33(50)60 $\mu \mathrm{m}$; cc: 30-50 $\mu$; zona: 2-6 $\mu \mathrm{m}$ (8 exemplares).

Ocorrência: 14; 26,5; 41; 45; 66; 83; 182; 188,5; 206 e 209 m (poço) e Afloramento km 122,7.

Comentários/comparações: as formas atribuídas a esta espécie se assemelham muito a Endosporites sp. ilustrada por Barss (1967: est. VI, fig. 4-5), comum no Viseano do Canadá. No entanto, as espécies daquele gênero possuem perina. Barss (1967: est. VI, fig. 1-2) também ilustrou forma muito semelhante, atribuída a ?Lycospora spp (sic).

\section{Lycospora sp. 2}

Est. 3, fig. 2

Descrição: esporo radial trilete zonado, de contorno equatorial subtriangular. Corpo central liso. Raios da laesura estendendo-se até $1 / 2$ a $2 / 3$ do raio do corpo central, sendo este último, na região polar, levemente escurecido. Zona fina, com reticulação conspícua e margem de contorno externo irregular.

Dimensões: deq: $68 \mu \mathrm{m}$; cc: $62 \mu \mathrm{m}$; zona: 3-4,5 $\mu \mathrm{m}$ (1 exemplar).

Ocorrência: 209 m (poço).

Comentários/comparações: o escurecimento da área de contato, na face proximal, distingue esta espécie das demais do gênero. 
Gênero Densosporites (Berry) Butterworth et al., 1964

Espécie-tipo: Densosporites convexis Berry, 1937

Afinidade botânica: PTERIDOPHYTA-LYCOPHYTA (Azcuy, 1978).

\section{Densosporites triangularis Kosanke, 1950}

Est. 3, fig. 3

Diagnose: Kosanke (1950. State Geological Survey of Illinois, Urbana, Bull. 74, 128 p; p. 34, est. 7, fig. 1)

Locus/stratum typicus: Pennsylvaniano de Illinois, EUA.

Descrição: esporo radial trilete cingulado, de contorno equatorial subtriangular. Raios da laesura sinuosos, ligeiramente elevados, estendendo-se até a margem interna do cíngulo. Face proximal do corpo central finamente granulada. Cíngulo proeminente (10$12 \mu \mathrm{m}$ de largura), afinando-se em direção à margem externa, onde é finamente serrado. Na margem interna são comuns pequenos cones (1-2 $\mu \mathrm{m}$ de altura).

Dimensões: Deq: 46-76 $\mu \mathrm{m}$ (8 exemplares).

Ocorrência: 98; 103,5; 148 e 152,5 (poço).

Distribuição biocronoestratigráfica: assinalado entre o Viseano e o Namuriano da GrãBretanha (Smith \& Butterworth, 1967) e nas Palinozonas A e C de Sundaram (1987: est. IV, fig. 11), Stephaniano-Eopermiano.

Comentários/comparações: esta espécie difere de Densosporites anulatus (Loose) Smith \& Butterworth, 1967 pela presença de elementos esculturais na face proximal e no cíngulo e pelas maiores dimensões daquela espécie.

\section{Densosporites sp.}

Est. 3, fig. 4

Descrição: esporo radial trilete cingulado, de contorno equatorial subtriangular. Face proximal finamente granulada. Raios da laesura finos, sinuosos, extendendo-se até a margem externa do corpo central. Cingulizona espessa $(10-14 \mu \mathrm{m})$, mais grossa na margem 
interna, onde apresenta pequenos cones (3-4 $\mu \mathrm{m}$ de altura). Margem externa mais fina, com projeções coniformes e "mamóides".

Dimensões: Deq: 68-72 $\mu \mathrm{m}$ (5 exemplares).

Ocorrência: 152,5; 155; 182 e 201 m (poço).

Comentários/comparações: difere de Densosporites triangularis Kosanke, 1950 pela maior irregularidade do cíngulo na margem equatorial.

\section{Gênero Dentatispora Tiwari, 1964}

Espécie-tipo: Dentatispora indica Tiwari, 1964

Dentatispora cf. D. indica Tiwari, 1964

Est. 4, fig. 4

Diagnose: Tiwari [1964. The Palaeobotanist, Lucknow, 13(2):168-214; p. 250-251, est. 1, fig. 1-2]

Locus/stratum typicus: Korba Coalfield, Índia, Barakar Stage.

Descrição: esporo trilete de contorno equatorial triangular, com lados convexos e vértices arredondados. Corpo central distinto, fino, subtriangular. Raios da laesura finos, levemente sinuosos, chegando até a margem equatorial. Cingulizona bem desenvolvida, espessa na margem externa, com contorno caracteristicamente denteado ou arqueado. Elementos esculturais pouco distribuídos na superfície distal, constituídos por espinhos e cones. Face proximal do corpo central ponteada, com elementos espiniformes em sua margem.

Dimensões: deq: 52-74 $\mu \mathrm{m}$; cc: 30-56 $\mu \mathrm{m}$; cing.: 8(12)15 $\mu \mathrm{m}$; elem. escult. 4-5 $\mu \mathrm{m}$ alt. x $5 \mu \mathrm{m}$ base (3 exemplares).

Ocorrência: $57 ; 182$ e 188,5 m (poço).

Comentários/comparações: as formas aqui atribuídas se assemelham muito com aquelas descritas originalmente por Tiwari (1964), sendo a primeira referência desta espécie na Bacia do Paraná. 


\section{Gênero Vallatisporites Hacquebard, 1957}

Espécie-tipo: Vallatisporites vallatus Hacquebard, 1957

Afinidade botânica: PTERIDOPHYTA-LYCOPHYTA (Azcuy, 1978; Taylor, 1981).

Azcuy (1975b) destacou os caracteres diagnósticos mais distintivos do gênero: a) separação da endexina e exoexina, com a formação de um canal característico ao redor do corpo central; b) zona mais larga internamente vacuolada; c) desenvolvimento de um espessamento radial na zona, geralmente na porção média desta; e d) exoexina internamente punteada, onde geralmente se projetam os elementos esculturais mais característicos. Estes aspectos diagnósticos e o tipo de ornamentação são aqui utilizados na identificação das espécies do gênero.

\section{Vallatisporites vallatus Hacquebard, 1957}

Est. 3, fig. 5

Diagnose: Hacquebard [1957. Micropaleontology, New York, 3(4):201-324; p. 312-313, est. 2, fig. 12]

Locus/stratum tyicus: Grupo Horton, amostras de West Gore e Blue Beach, Mississipiano, Canadá.

Descrição: esporo radial trilete zonado, de contorno equatorial subtriangular, com lados convexos e vértices amplamente arredondados. Corpo central distinto, com dobras arqueadas e margem bem denifida. Raios da laesura bem marcados, atingido a margem externa. Corpo central e margem externa da zona separadas por um anel de pequenos vacúolos ou fovéolos. Zona relativamente estreita, ornamentada por pequenos espinhos e verrugas, presentes também na superfície distal do corpo central.

Dimensões: deq: $56-70 \mu \mathrm{m}$; cc: $36-54 \mu \mathrm{m}$; zona: 4-13 $\mu \mathrm{m}$; elem. escult.: até $3 \mu \mathrm{m}$ alt. (10 exemplares).

Ocorrência: 25,5; 26,5; 45; 55; 98; 170; 171, 3; 182; 201 e 206 m (poço).

Distribuição biocronoestratigráfica: muito comum no Carbonifero Superior e Permiano Inferior nos estados do sul do Brasil da Bacia do Paraná, no Subgrupo Itararé (e.g. Sundaram, 1987: est. IV, fig. 4; Dias, 1993a: est. 3, fig. 8) e na Formação Rio Bonito (e.g. Cauduro, 1970: est. V, fig. 43-44; Dias-Fabrício, 1981: est. IV, fig. 6). 
Vallatisporites arcuatus (Marques-Toigo) Archangelsky \& Gamerro, 1979

Est. 3, fig. 6

Diagnose: Archangelsky \& Gamerro [1979. Rev. Esp. de Microp., Madrid, 11(3):417-478; p. 430-432, est. III, fig. 8-9]

Locus/stratum typicus: Passo de las Bochas, Formação San Gregório, Permiano Inferior, Uruguai.

Descrição: esporo radial trilete zonado, de contorno equatorial subtriangular, lados convexos e vértices arredondados. Corpo central (intexina) proximamente ligado à exoexina, subtriangular, face proximal finamente granulada e face distal ornamentada com pequenas verrugas de até $2 \mu \mathrm{m}$ de base. Raios da laesura sinuosos, ligeiramente elevados, até à margem do corpo central. Zona ampla, margem interna com engrossamentos radiais em forma de arcos que se unem lateralmente; margem externa mais grossa, com cones e projeções espiniformes (até $3 \mu \mathrm{m}$ de altura), ressaltados no contorno equatorial.

Dimensões: deq: 48-60 $\mu \mathrm{m}$; cc: 28-34 $\mu \mathrm{m}$; zona: 8-15 $\mu \mathrm{m}$ (7 exemplares).

Ocorrência: 41; 66; 170 e 206 m (poço) e Afloramento km 118,6.

Distribuição biocronoestratigráfica: muito comum no Paleozóico Superior da Bacia do Paraná, já tendo sido registrada no Subgrupo Itararé (Marques-Toigo, 1974: est. I, fig. 67; Sundaram, 1987: est. IV, fig. 1; Dias, 1993a: est. 3, fig. 9), Formação San Gregório (Beri, 1988: fig. 9a), Uruguai, e Formação Rio Bonito (Dias-Fabrício, 1981: est. 5, fig. 5).

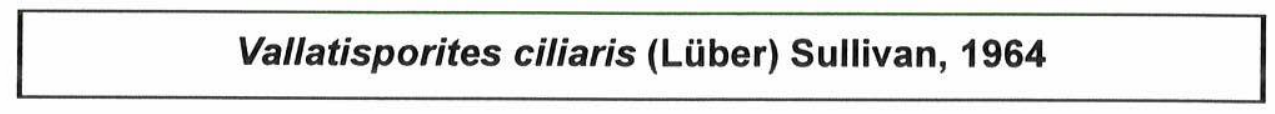

Est. 3, fig. 7

Diagnose: Sullivan [1964. Palaeontology, Londres, 7(3):351-392; p. 370-371, est. 59, fig. 14-15, textfig. 3]

Locus/stratum typicus: Arenito Drybrook, Bacia Forest of Dean, Gloucestershire, Carbonifero Inferior a Westphaliano, Reino Unido.

Descrição: esporo radial trilete zonado, de contorno equatorial convexamente triangular. Corpo central liso, bem definido, subtriangular. Raios da laesura nítidos, levemente sinuosos, alcançando a margem externa da zona. Face proximal finamente infrapunctada. Elementos ornamentais na face distal constituidos por espinhos e cones, 
bem espaçados, de até $4 \mu \mathrm{m}$ de altura. Zona com engrossamento radial, separando a margem interna, vacuolada e mais clara que a margem externa, esta última mais ornamentada por espinhos e com cones pouco pronunciados.

Dimensões: deq: 50(73)80 $\mu \mathrm{m}$; cc: 38-44(38) $\mu \mathrm{m}$; zona: 12(14)16 $\mu \mathrm{m}$ (12 exemplares)

Ocorrência: 152,5;167 e 209 m (poço).

Distribuição biocronoestratigráfica: assinalada nas formações Tupé (Césari, 1985) e Malazán (Azcuy, 1975b) Argentina.

Comentários/comparações: difere de Vallatisporites spinosus Cauduro, 1970 pela ausência de ornamentação na face proximal do corpo central, se bem que a autora deixa dúvidas sobre essa possibilidade na sua descrição: "central area and cingulum covered with spines which become smaller toward the periphery" (Cauduro, 1970:13). Conforme Playford \& McGregor (1993), várias formas foram atribuídas indevidamente em V. ciliaris (Luber) Sullivan, 1964, tendo, estes autores, separado aquelas espécies descritas a partir do trabalho de Sullivan (1964) e renomeado-as em V. drybrookensis, aceitando como V. ciliaris aquelas que constam nos trabalhos de Pokrovskaya (1966 apud Playford \& McGregor, 1993) e Lüber \& Waltz (1941, apud Playford \& McGregor, 1993). No presente trabalho, mantém-se a proposição de Sullivan (1964) visto V. ciliaris ser uma espécie comum no Paleozóico Superior da América do Sul, ressaltando-se a necessidade de melhor avaliação, conforme a proposição de Playford \& McGregor (1993), de modo a se separar todos os táxons e atribuí-los devidamente.

\section{Vallatisporites banffensis Staplin \& Jansonius, 1964}

Est. 3, fig. 8

Diagnose: Staplin \& Jansonius (1964. Palaeontographica, Sttutgart, Abt. B, 114:95-117, 3 est.; p. 112-113, est. 21 , fig. 7-12. text-fig. 21)

Locus/stratum typicus: Formação Banff, Tournaisiano, Território Nordeste, Canadá.

Descrição: esporo radial trilete zonado de contorno convexamente subtriangular. Raios da laesura nítidos, sinuosos, alcançando a margem externa da zona. Face proximal do corpo central lisa a infrapunctada. Face distal granulosa a finamente verrucosa $(1,5-2 \mu \mathrm{m}$ de base). Zona ampla e regular. $\mathrm{Na}$ base da zona se desenvolvem pequenos vacúolos e arcos irregulares de tamanho variável. Margem externa fina. Zona granulada, com raras verrugas, que atingem até $2 \mu \mathrm{m}$ de base.

Dimensões: deq: 58-80 $\mu \mathrm{m}$; cc: 30-50 $\mu \mathrm{m}$; zona: 10-16 $\mu \mathrm{m}$ (8 exemplares). 
Ocorrência: 25,5 m, 26,5 m, 148 m, 170 m e 206 m (poço).

Distribuição biocronoestratigráfica: assinalada desde o Carbonífero Superior (Lima et al., 1983: est. 3, fig. 15; Sundaram, 1987: est. IV, fig. 2) ao Permiano Inferior (Ybert, 1975: est. 2, fig. 59) da Bacia do Paraná.

Comentários/comparações: os caracteres das formas aqui descritas se encaixam perfeitamente na descrição original de Staplin \& Jansonius (1964). No entanto, estes autores assinalaram que as dimensões do diâmetro equatorial não ultrapassam $50 \mu \mathrm{m}$. Como também verificado por Ybert (1975), os exemplares descritos na Bacia do Paraná parecem possuir dimensões maiores, atingindo até $80 \mu \mathrm{m}$ no diâmetro equatorial.

Vallatisporites punctatus (Marques-Toigo) comb. nov.

Est. 3, fig. 9

Sinonímia: Kraeuselisporites punctatus nov. sp. in Marques-Toigo (1974: est. II, fig. 1 e 2)

Diagnose: Marques-Toigo [1974. An. Acad. bras. Ci., Rio de Janeiro, 46(3/4):601-616; p. 605-606, est. II, fig. 1-2]. Permanece como proposto, ampliando-se aqui somente as dimensões estabelecidas.

Locus/stratus typicus: Passo de las Bochas, Formação San Gregório, Permiano Inferior, Uruguai.

Descrição: esporo radial trilete zonado, de contorno equatorial convexamente triangular. Corpo central distinto, face proximal e distal densamente punctada. Raios da laesura finos, levemente sinuosos até à margem interna do corpo central. Zona contínua, apresentando na margem interna uma seqüência de pequenos vacúolos ou ranhuras convolutas. A parte externa da zona é fina, membranosa e lisa.

Dimensões: deq: 68-74 $\mu \mathrm{m}$; cc: $50-60 \mu \mathrm{m}$; zona: 7-11 $\mu \mathrm{m}$ (5 exemplares)

Ocorrência: 124 m e 152,5 m (poço).

Comentários/comparações: pelas mesmas razões que levaram Archangelsky \& Gamerro (1979) a enquadrar Kraeuselisporites arcuatus Marques-Toigo, 1974 no gênero Vallatisporites Hacquebard, 1957, propõe-se aqui a mesma alteração genérica, levandose em consideração, principalmente, que em Kraeuselisporites (Leschik) Jansonius, 1962 a face proximal é lisa e que a presença de vacúlos e cuniculus, conforme descrito por Sullivan (1964:371), ;e diagnóstico de Vallatisporites Hacquebard, 1957. Marques-Toigo (1988: est. IV, fig. 3) reconheceu Kraeuselisporites punctatus Jansonius, 1962 na 
Formação Rio Bonito no sul do país. Difere portanto dos exemplares aqui estudados porque estes apresentam, caracteristicamente, face proximal do corpo central punctada. Podendo, no entanto, conforme diagnose de Marques-Toigo (1974), apresentá-la lisa. Jansonius (1962) descreveu K. punctatus, face que já invalidaria a proposição nominal de Marques-Toigo (1974). Esta última espécie, comum no Triássico Inferior do Canadá, possui face distal escabrada a punctada e face proximal lisa.

\section{Vallatisporites cf. V. spinosus Cauduro, 1970}

Est. 3, fig. 10

Diagnose: Cauduro (1970. Escola de Geologia, Porto Alegre, Publ. Esp. 17, 34 p, 20 est.; p. 12-13, est. $\vee$, fig. 48-50)

Locus/stratum typicus: afloramento de São Sepé, Formação Rio Bonito, Permiano Inferior, Rio Grande do Sul.

Descrição: esporo radial trilete zonado, convexamente triangular. Corpo central nítido; raios da laesura proeminentes, levemente sinuosos, alcançando a porção média da zona. Face proximal punctada a granulada; face distal ornamentada por espinhos bem pronunciados e espaçados. Zona ampla e regular, com engrossamento radial, margem externa lisa; margem interna com pequenas auréolas, ornamentada pelos mesmos tipos de espinhos ocorrentes na face distal, não atingindo, no entanto, o contorno da margem externa.

Dimensões: deq: $69-80 \mu \mathrm{m}$; cc: $34-49 \mu$; zona: 8-18 $\mu \mathrm{m}$; elem. escult.: até $2 \mu \mathrm{m}$ base $\mathrm{x} 3 \mu \mathrm{m}$ de alt. (5 exemplares).

Ocorrência: 41; 41,3; 43,5; 195 e 209 m (poço).

Comentários/comparações: difere de Vallatisporites russoi Archangelsky \& Gamerro (1979) pela presença, naquela espécie, de elementos verrucosos fusionados na face distal e de Vallatisporites ciliaris (Luber) Sullivan, 1964 pela maior densidade da ornamentação naquela espécie. 


\section{Vallatisporites sp.}

Est. 3, fig. 11

Descrição: esporo radial trilete zonado, convexamente triangular. Corpo central circular, distinto, com engrossamento radial na margem externa. Face proximal lisa; raios da laesura nítidos, retos a sinuosos, atingindo a metade da zona. Face distal ornamentada por espinhos e cones de até $4 \mu \mathrm{m}$ de alt e $2 \mu \mathrm{m}$ de diâmetro basal, que ocupam também a zona, diminuindo de tamanho à medida que se aproximam da margem externa. Zona ampla e fina, com engrossamento radial.

Dimensões: deq: 68-76 $\mu \mathrm{m}$; cc: 30-42 $\mu \mathrm{m}$; zona: 13-20 $\mu \mathrm{m}$ (6 exemplares).

Ocorrência: $124 ; 137 ; 152,5 ; 155 ; 167$ e 170 m (poço).

Comentários/comparação: difere das demais espécies do gênero por apresentar corpo central subcircular e de $V$. sp. 2, aqui descrita, pelo contorno equatorial mais nitidamente subtriangular desta e por apresentar face proximal do corpo central lisa.

\section{Gênero Kraeuselisporites (Leschik) Jansonius, 1962}

Espécie-tipo: Kraeuselisporites dentatus Leschik, 1955

Afinidade botânica: desconhecida.

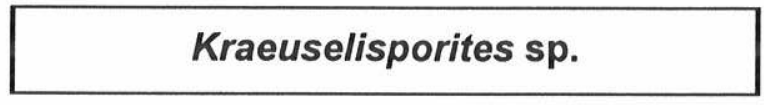

Est. 3, fig. 12

Descrição: esporo radial trilete zonado, convexamente triangular. Raios da laesura nítidos, com lábios se extendendo até à margem interna da zona. Corpo central bem destacado, subtriangular, com face proximal lisa e face distal ornamentada por projeções espiniformes com terminações "mamóides", de base larga (3-5 $\mu \mathrm{m})$ e altura variável (7-9$10 \mu \mathrm{m})$, distribuídos espaçadamente. Zona ampla e regular, translúcida, com alguns elementos ornamentais.

Dimensões: deq: $70 \mu \mathrm{m}$; cc: $48 \mu \mathrm{m}$; zona: 12-15 $\mu \mathrm{m}$ (1 exemplar).

Ocorrência: 167 m (poço). 
Comentários/comparações: o exemplar é comparável a Kraeuselisporites sommeri Cauduro, 1970, diferindo daquela pelo tipo de ornamentação espinhosa com base poligonal, diferentemente do observado aqui. Difere também de K. spinosus Jansonius, 1962 e K. apiculatus Jansonius, 1962, essencialmente pelo tipo de ornamentação verificado nesta, com terminação "mamóide" (Staplin \& Jansonius, 1964:97), muito comum nas espécies do gênero Cristatisporites Potonié \& Kremp, 1954. Vallatisporites galearis Sullivan, 1964 possui elementos ornamentais semelhantes, diferindo deste, no entanto, pela presença, naquela, de uma vacuolação interna na zona.

\section{Gênero Cristatisporites (Potonié \& Kremp) Butterworth et al., 1964}

Espécie-tipo: Cristatisporites indignabundus (Potonié \& Kremp) Staplin \& Jansonius, 1964

Afinidade botânica: PTERIDOPHYTA-LYCOPHYTA (Chaloner, 1962).

A diagnose original do gênero foi emendada posteriomente por Butterworth et al. (1964:1053) e Staplin \& Jansonius (1964), que destacaram as diferenças entre as faces distal e proximal e excluíram do gênero as espécies com um cíngulo radialmente costado ("radially costate cingulum"). Archangelsky \& Gamerro (1979) aceitaram esta modificação, denominando de cingulizona a conjugação de um engrossamento constante (cíngulo) e de uma zona fina na expansão equatorial do esporo, também adotada por Dias (1993a). Entretanto, Sundaram (1987), baseado na definição da Infraturma Cingulicavati Smith \& Butterworth, 1967, destacou que seria possível incluir no gênero todas as formas com cíngulo, zona ou cingulizona. Ententendo que a proposição seguida por Archangelsky \& Gamerro (1979) não contraria a colocação do gênero na Infraturma Cingulicavati, mas que restringe como cingulizonadas as formas cuja expansão equatorial conjugam cíngulo e zona, é esta a idéia aqui aceita. A terminologia adotada nas descrições do gênero Cristatisporites Potonié \& Kremp, 1954 neste trabalho é próxima daquela utilizada por Staplin \& Jansonius (1964:98), diferindo contudo do termo cingulizona como utilizado para o gênero Cingulizonates (Dybová \& Jachowicz) Butterworth, Jansonius, Smith \& Staplin, 1964, que seria referente a uma zona bizonada, na qual a porção mais próxima à intexina seria mais espessa. 
Cristatisporites indignabundus (Potonié \& Kremp) Staplin \& Jansonius, 1964

Est. 3, fig. 13

Diagnose: Staplin \& Jansonius (1964. Palaeontographica, Abt. B, Sttutgart, 114:95-117; p. 108-109, est. 19 , fig. $7-9,12,14$ e 20 )

Locus/stratum typicus: Ruhrgebiet, Westphaliano B-C da Alemanha.

Descrição: esporo trilete cingulizonado de contorno equatorial subtriangular, lados convexos e vértices arredondados. Raios da laesura espessos, ressaltados, atingindo a margem interna da cingulizona. Face proximal lisa ou ponteada. Face distal ornamentada por elementos verrucosos e espiniformes com base de até $4 \mu \mathrm{m}$. Na região equatorial os elementos esculturais são mais abundantes e têm altura mais elevada (até $15 \mu \mathrm{m}$ ), incluindo alguns elementos do tipo mamóide. Cingulizona ampla, com algumas projeções papiliformes curtas (até $4 \mu \mathrm{m}$ de alt.) que, quando na margem, lhe confere contorno irregular.

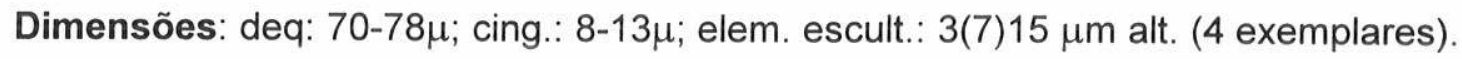

Ocorrência: 41 m, 201 m e 206 m (poço).

Comentários/comparações: estas formas diferem das demais descritas para o gênero neste trabalho, principalmente pela ornamentação variada mais densamente distribuída na região equatorial do corpo central. Ottone (1989: est. 7, fig. 11) descreveu espécie semelhante, Cristatisporites sp. C, diferindo desta pelas dimensões proporcionalmente mais elevadas na relação zona/corpo central daquela.

\section{Cristatisporites inconstans Archangelsky \& Gamerro, 1979}

Est. 3, fig. 14 e 15

Diagnose: Archangelsky \& Gamerro [1979. Rev. Esp. de Microp., Madrid, XI(3):417-478; p. 435, est. V, fig. 1-5]

Locus/stratum typicus: CdO es-1 e Cd CA es-1, perfurações da Bacia Chacoparanaense, Argentina.

Descrição: esporo radial trilete cingulizonado, de contorno equatorial subtriangular, lados convexos e vértices arredondados. Raios da laesura finos, sinuosos a ligeiramente sinuosos e levantados, até o bordo interno da cingulizona, nem sempre alcançando a 
margem externa da mesma. Face proximal finamente granulada, com pequenos espinhos mal distribuídos próximos ao equador. Face distal ornamentada por pequenas verrugas (3-4 $\mu \mathrm{m}$ de base) bem espaçadas. Na margem interna da cingulizona os elementos esculturais passam a ser espiniformes e coalescentes com bases largas. Cingulizona ampla e mais adelgaçada na margem externa, onde se apresenta irregularmente recortada com pequenas projeções espiniformes.

Dimensões: deq: 62(70)78 $\mu \mathrm{m}$; cing.: 8-12 $\mu \mathrm{m}$ (7 exemplares).

Ocorrência: 41 m, 45 m, 182 m, 188,5 m, 195 m e 201 m (poço).

Distribuição biocronoestratigráfica: Zona Potonieisporites-Lundbladispora e Zona Cristatisporites da Bacia Chacoparanaense, Argentina.

Comentários/comparações: a única espécie do gênero com similaridade a esta é $C$. irradiatus Picarelli \& Dias-Fabrício, 1990 (sinonímia de C. solaris Dias-Fabrício, 1981), porém a mesma possui cingulizona ampla, recortada apenas na margem externa.

\section{Cristatisporites rolerii Ottone, 1989}

Est. 3, fig. 17

Diagnose: Ottone (1989. Palaeontographica, Sttutgart, Abt. B, 213:89-148, 12 est.; p. 113, est. 7, fig. 1 e 3)

Locus/stratum typicus: Quebrada (Ravin) El Saltito, Cerros Bayos, Paleozóico Superior, Formação Santa Maxima, Mendonza, Argentina.

Descrição: esporo radial trilete cingulizonado, de contorno equatorial subtriangular, com lados convexos e vértices arredondados. Corpo central subtriangular; raios da laesura finos (1$1,5 \mu \mathrm{m})$, levemente sinuosos, alcançando a margem externa do corpo central. Face proximal finamente granulada/infrapunctada. Face distal contendo esparsas verrugas mameliformes e pequenos cones (base: 4-8 $\mu \mathrm{m}$ ), desenvolvidos até a margem interna da cingulizona. Cíngulizona com 5-10 $\mu \mathrm{m}$ de largura, contendo elementos espiniformes e coniformes, geralmente mucronados.

Dimensões: deq: $58-70 \mu \mathrm{m}$; cc: $42-50 \mu \mathrm{m}$ (3 exemplares).

Ocorrência: 167 e 201 m (poço).

Comentários/comparações: forma inédita na Bacia do Paraná. 


\section{Cristatisporites lestai Archangelsky \& Gamerro, 1979}

Est. 3, fig. 16

Diagnose: Archangelsky \& Gamerro [1979. Rev. Esp. de Microp., Madrid, 11(3):417-478; p. 437438, est. VI, fig. 1-3]

Locus/stratum typicus: Zona Potonieisporites-Lundbladispora, Paleozóico Superior, Prov. de Córdoba, Argentina.

Descrição: esporo radial trilete cingulizonado, de contorno equatorial subtriangular, lados convexos e vértices arredondados. Face proximal com pequenas verrugas esparsas; raios da laesura sinuosos, até a margem externa do corpo central. Cingulizona larga, lisa, com ocasionais vacúolos; margem externa irregular, com saliências espiniformes e papiliformes, ocasionalmente com terminações mamóides. Face distal esculturada por elementos verrucosos e baculosos de base estreita $(4-5 \mu \mathrm{m})$, na maioria das vezes fusionados, que projetam-se no equador.

Dimensões: deq: 72-76 $\mu \mathrm{m}$; cing.: 12-15 $\mu \mathrm{m}$; elem. escult.: 5-12 $\mu \mathrm{m}$ alt. (6 exemplares).

Ocorrência: 55; 167; 182; 188,5 e 201 m (poço).

Distribuição biocronoestratigráfica: assinalado nas Zonas Potonieisporites-Lundbladispora e Cristatisporites da Bacia Chacoparanaense da Argentina, entre o Carbonífero Superior e o Permiano Inferior.

Comentários/comparações: espécie já assinalada no Subgrupo Itararé (Dias, 1993a: est. 4, fig. 7). Difere de C. crassilabratus Archangelsky \& Gamerro, 1979 pela natureza mais homogênea da cingulizona deste e por aquele não apresentar a laesura bem desenvolvida; bem como de C. rolerii Ottone, 1989 pelo caráter da ornamentação mais verrucoso daquela e de C. irradiatus Picarelli \& Dias-Fabrício, 1990 pela ornamentação menos densa na face distal daquela.

Cristatisporites mammillatus Maheswari, 1969

Est. 3, fig. 18

Diagnose: Maheswari [1969. The Palaeobotanist, Lucknow, 15(3):255-280; p. 132-133, est. II, fig. 811] 
Locus/stratum typicus: confluência dos rios Lufupa e Mushyashya, sul de Katanga, Zaire (exCongo Belga), Paleozóico Superior.

Descrição: esporo radial trilete cingulizonado, de contorno convexamente triangular. Corpo central distinto; exina da face proximal granulosa; raios da laesura levemente sinuosos, proeminentes, se extendendo até a cingulizona. Processos espiniformes, verrucosos e em forma de cones são característicos na face distal e na superfície distal e proximal da cingulizona, em alguns casos dando aspecto irregular à margem desta.

Dimensões: deq: 65-80 $\mu \mathrm{m}$; cc:45-55 $\mu \mathrm{m}$; cing.: 6-12 $\mu \mathrm{m}$ (7 exemplares).

Ocorrência: 77; 83; 148; 152,5; 167 e 201 m (poço).

Distribuição biocronoestratigráfica: assinalada no sul de Katanga, Permiano do Zaire (Maheswari, 1969).

Comentários/comparações: os exemplares aqui descritos são ligeiramente maiores do que aqueles descritos por Maheswari (1969), porém, suas feições principais, sobretudo a ornamentação do tipo mameliforme, permitem seu enquadramento na espécie.

\section{Cristatisporites sp.}

Est. 3, fig. 19

Descrição: esporo radial trilete cingulizonado, de contorno convexamente triangular. Corpo central distinto, punctado na face proximal e ornamentado por pequenas verrugas e espinhos na face distal, de até $5 \mu \mathrm{m}$ de alt. Raios da laesura nítidos, levemente proeminentes e sinuosos, atingindo a zona na margem externa. Cingulizona constituída em uma franja de contorno irregular, com processos espiniformes arranjados radialmente.

Dimensões: deq: 58-68 $\mu \mathrm{m}$; cc: $50 \mu \mathrm{m}$; zona: 7-10 $\mu \mathrm{m}$ (3 exemplares).

Ocorrência: 167 e 206 (poço) m.

Comentários/comparações: difere das espécies do gêneros Vallatisporites Hacquebard, 1957 pela natureza da zona, caracterizando uma franja com elementos muito bem projetados. 


\section{Gênero Ancistrospora Menéndez \& Azcuy,1972}

Espécie-tipo: Ancistrospora verrucosa Menéndez \& Azcuy, 1972

Afinidade botânica: PTERIDOPHYTA-LYCOPHYTA (Azcuy, 1978).

Playford (1978) relocou as espécies de Ancistrospora Menéndez \& Azcuy, 1972 ao gênero Cristatisporites (Potonié \& Kremp) Butterworth, Jansonius, Smith \& Staplin, 1964, modificando seus nomes (Cristatisporites inordinatus=Ancistrospora inordinata; C. menendezii=A. verrucosa; $C$. spinosus=A. spinosa).

No entanto, são verificadas algumas diferenças importantes que fazem diferenciar estes dois gêneros:

1) ornamentação na face proximal: as espécies de Ancistrospora apresentam face proximal finamente ponteada a microgranulada, enquanto que as de Cristatisporites apresenta face proximal desde lisa (C. connexus Potonié \& Kremp, 1955), ponteada [C. solaris (Balme) Butterworth et al., 1964], espinhosa (C. crassilabratus Archangelsky \& Gamerro, 1979) a verrucosa (C. lestai Archangelsky \& Gamerro, 1979);

2) ornamentação da exoexina na face distal: nas espécies do gênero Ancistrospora é verificada uma forte ornamentação, com verrugas, espinhos e cones com ápices curvados em forma de ganchos. A fusão basal destes elementos lhe dá aparência vermicular a verrucosa. Nas espécies de Cristatisporites os elementos ornamentais se distribuem isolados na face distal da exoexina, se constituindo em grânulos, elementos verrucosos, espinhosos e "mamóides". A única espécie que possui elementos coalescentes é C. connexus Potonié \& Kremp, 1955, neste caso, se constituindo de cristas interconectadas; e,

3) engrossamento equatorial da exoexina: nas espécies do gênero Ancistrospora este engrossamento é mais notável pela maior fusão dos elementos ornamentais nessa região, consituindo em um engrossamento contínuo, delimitando ambas as faces do esporo. As espécies de Cristatisporites possuem cingulizona geralmente fina a irregular ( $C$. inconstans Archangelsky \& Gamerro, 1979).

Por essas diferenças, consideradas aqui essenciais nas diagnoses dos dois gêneros, não são aceitas as modificações propostas por Playford (1978), validando-se o gênero Ancistrospora como originalmente proposto por Menéndez \& Azcuy (1972), além de incluir neste, mais uma espécie.

Apesar de não ser uma justificativa sistemática, é oportuna a manutenção do referido gênero, já que possui importante valor bioestratigráfico, nomeando uma biozona na Bacia de Paganzo, Argentina. 


\section{Ancistrospora verrucosa Menéndez \& Azcuy, 1972}

Est. 4, fig. 1

Diagnose: Menéndez \& Azcuy [1972. Rev. Esp. de Microp., Madrid, IV(2):157-168; p. 162-163, est. 1 , fig. 1 a 6 , est. 3 , fig. $3-5$, text-fig. 1 e $2 A]$

Locus/stratum typicus: Formação Lagares, Namuriano/Westphaliano, Bacia de Paganzo, Prov. La Rioja, Argentina.

Descrição: esporo radial trilete cingulizonado, de contorno equatorial subtriangular, lados ligeiramente convexos e vértices arredondados. Raios da laesura levemente sinuosos, simples ou acompanhados de lábios pouco elevados (2-3 $\mu \mathrm{m}$ de alt.), extendendo-se até a margem interna do cíngulo. Face proximal microgranulada. Elementos esculturais proeminentes desenvolvidos na face distal e no cíngulo, constituídos de verrugas com base subcircular $(5-8 \mu \mathrm{m})$ e pequena altura $(2-3 \mu \mathrm{m})$, às vezes fusionadas; algumas destas verrugas possuem terminação espinhosa, visível nas margens do cíngulo $(0,5-1,0$ $\mu \mathrm{m})$. Cingulizona ampla $(8-15 \mu \mathrm{m})$ com contato exoexina/intexina bem marcado.

Dimensões: deq: 50(58)70 $\mu$; cíngulo: 5-10 $\mu \mathrm{m}$ (11 exemplares).

Ocorrência: 45; 77; 103,5; 124; 148; 152,5; 155 e 167 m (poço) e Afloramento km 122,7.

Distribuição biocronoestratigráfica: comum no Westphaliano da Bacia de Paganzo, Argentina (Ottone, 1989: est. 6, fig. 8), sendo elemento fundamental da Palinozona de Ancistrospora (Azcuy \& Jelin, 1980).

Comentários/comparações: as características gerais do espécie diferem das outras propostas para o gênero Ancistropora Menéndez \& Azcuy, 1972, pelos diferentes tipos de esculturas. É muito similar àqueles descritos por Playford (1978: est. 10, fig. 3-6), quando então sinonimizou o citado gênero em Cristatisporites Potonié \& Kremp, 1954.

\section{Ancistrospora inordinata Menéndez \& Azcuy, 1972}

Est. 4, fig. 2

Diagnose: Menéndez \& Azcuy [1972. Rev. Esp. de Microp., Madrid, IV(2):157-168; p. 167-168, est. III, fig. 1-2, text-fig. 2C]

Locus/stratum typicus: Formação Lagares, Namuriano/Westphaliano, Bacia de Paganzo, Prov. de La Rioja, Argentina. 
Descrição: esporo radial trilete cingulizonado, de contorno subtriangular a subarredondado. Raios da laesura finos, ligeiramente sinuosos, alcançando a margem interna da cingulizona. Face proximal microgranulada. Face distal e cingulizona ornamentada por espinhos e pequenos cones (3-5 $\mu \mathrm{m}$ de base $\times 2-4 \mu \mathrm{m}$ de alt.) distribuídos irregularmente, que às vezes se fusionam na base. Espinhos bem perceptíveis na margem equatorial. Cingulizona ampla $(8-10 \mu \mathrm{m})$, com contato intexina/exoexina bem marcado.

Dimensões: deq: 60(65)-76 $\mu \mathrm{m}$ (7 exemplares).

Ocorrência: 137; 152,5; 155; 195 e 206 m (poço).

Distribuição biocronoestratigráfica: espécie menos comum, porém característica da Palinozona de Ancistrospora (Azcuy \& Jelin, 1980).

Comentários/comparações: esta espécie possui contorno mais triangular com ângulos mais acentuados que as outras espécies do gênero originalmente locado, além de apresentar maior diversidade de elementos esculturais, com distribuição mais irregular. Ancistrospora inordinata Menéndez \& Azcuy, 1972 ilustrada por Lima et al. (1983: est. III, fig. 11) possui contorno subarredondado, podendo não ser referivel a esta espécie. 0 mesmo ocorre com aquela ilustrada por Souza et al. (1993a: est. 2, fig. 9).

\section{Ancistrospora reticulata sp. $\mathbf{n}$.}

Est. 4 , fig. 3 e 5

Locus/stratum typicus: poço Geomater (A-IG-85), prof. 182 m, Subgrupo Itararé, Araçoiaba da Serra, Estado de São Paulo.

Derivatio nomen: devido ao arranjo reticulado da exoexina na face distal.

Diagnose: esporo radial trilete, de contorno equatorial convexamente triangular. Holótipo medindo $62 \mu \mathrm{m}$. Raios da laesura finos e retos, atingindo a margem interna da cingulizona. Intexina separada da exoexina. Face proximal central lisa ou finamente granulada. Face distal ornamentada por elementos irregulares coalescentes formando cristas, que se ligam ao cíngulo. Subordinadamente apresenta verrugas de base irregular. Cíngulo homogêneo, espesso e com projeções espiniformes/papiliformes na margem externa.

Descrição: esporo radial trilete de contorno equatorial convexamente triangular. Raios da laesura finos e retos atingindo a margem interna da cingulizona. Face proximal central lisa a finamente granulada; face distal com elementos irregulares altos, coalescentes, 
formando cristas, de arranjo e espaçamento irregularmente reticulado, que se ligam ao cíngulo. Subordinamente ocorrem verrugas de base irregular, às vezes coalescentes. Cingulizona homogênea, de margem denteada, com projeções de elementos espiniformes/papiliformes.

Ocorrência: 45; 83; 167; 182 e 201 m (poço).

Holótipo: nível 182 m do poço Geomater; lâmina GP/4E-1412.

Dimensões: • holótipo: deq:62 $\mu \mathrm{m}$; corpo central: $42 \mu \mathrm{m}$; cíngulo: $8 \mu \mathrm{m}$; cristas: $4 \mu \mathrm{m}$ de larg; projeções: 2-3 $\mu \mathrm{m}$; verrugas: $4 \mu \mathrm{m}$ de base. $\bullet$ outros (8 medidos): deq: $54-84 \mu \mathrm{m}$; corpo central: $38-56 \mu \mathrm{m}$; cíngulo: 4-12 $\mu \mathrm{m}$; cristas: $4(5) 6 \mu \mathrm{m}$; projeções: 1,5-4 $\mu \mathrm{m}$ alt.; verrugas: 3-7 $\mu \mathrm{m}$ de base.

Comparações: as espécies do gênero Reticulatisporites (Ibrahim) Neves, 1964 caracterizamse por apresentar ornamentação reticulada, mais simples e homogênea, que se projeta na margem equatorial. Nas espécie aqui descrita ocorre um espessamento da margem equatorial pela fusão dos elementos ornamentais, como nas outras espécies do gênero Ancistrospora. A cingulizona de Cristatisporites é mais heterogênea. No entanto, o cíngulo, diagnóstico desta espécie, é mais heterogêneo, com uma zona de afinamento periférico, além de que não possui elementos verrucosos ou projeções sobre este. Difere das demais espécies do gênero Cristatisporites (Potonié \& Kremp) Butterworth, Jansonius, Smith \& Staplin, 1964 pelo arranjo reticulado irregular da exoexina na face distal. C. connexus Potonié \& Kremp, 1955, descrita no Westphaliano da Alemanha, cujo arranjo dos elementos ornamentais na face distal é conspicuamente reticulado, é relativamente menor $(45-59 \mu \mathrm{m})$ e possui verrugas de grandes dimensões, mais individualizadas em toda a superficie do cíngulo e face distal.

Discussão: o engrossamento equatorial da exoexina é importante caracter morfológico distintivo desta espécie, de natureza semelhante àquela das espécies de Ancistrospora não verificado em C. connexus Potonié \& Kremp, 1955. 
Suprasubturma PSEUDOSACITRILETES Richardson, 1965

Infraturma MONOPSEUDOSACCITI Smith \& Butterworth, 1967

\section{Gênero Spelaeotriletes Neves \& Owens, 1966}

Espécie-tipo: Spelaeotriletes triangulus Neves \& Owens, 1966

Conforme a descrição de Neves \& Owens (1966:342-344), as características principais para o agrupamento dos esporos triletes neste gênero são o contorno triangular a subcircular e exina dividida em intexina e exoexina, ligadas apenas na superfície proximal. A exoexina é lisa a infrapunctada, suportando elementos ornamentais que se fusionam, constituídos por pequenos cones, grãos e verrugas, mais densamente distribuídos na superfície distal. Outros elementos esculturais são característicos em algumas espécies incluídas no gênero, como espinhos e báculas, diagnósticos de Spelaeotriletes yberti (Marques-Toigo) Playford \& Powis, 1979 muito comum no Paleozóico Superior da Bacia do Paraná, notadamente nos estados do sul do Brasil (e.g. Dias, 1993a).

\section{Spelaeotriletes triangulus Neves \& Owens, 1966}

Est. 4, fig. 7

Diagnose: Neves \& Owens [1966. Pollen et Spores, Paris, 8(1/3):337-359; p. 345-6; est. I, fig. 1-3]

Locus/stratum typicus: Carvão Pot Bank, Staffordshire, Namuriano A, Inglaterra.

Descrição: esporo trilete de contorno equatorial subtriangular, lados convexos e vértices arredondados. Exoexina densamente ornamentada por verrugas e cones que se fundem lateralmente. Raios da laesura distintos, desenvolvidos até a margem externa do esporo.

Dimensões: deq: 74-75-100-115 $\mu \mathrm{m}$; cc: $42 \mu \mathrm{m}$; elem escult.: $2,5 \mu \mathrm{m}$ base $\times 3,0 \mu \mathrm{m}$ alt. (4 exemplares).

Ocorrência: 168 e 170 m (poço).

Comentários/comparações: o caráter verrucoso da ornamentação e a fusão lateral de seus elementos separam esta espécie das demais do gênero. Particularmente, difere de Spelaeotriletes yberti (Marques-Toigo) Playford \& Powis, 1979 pelo contorno mais 
francamente subtriangular a triangular e pela natureza mais arredondada dos elementos esculturais desta. A maior densidade da ornamentação da face distal separa esta espécie de Spelaeotriletes arenaceus Neves \& Owens, 1966. O caráter verrucoso da ornamentação e a fusão lateral de seus elementos separam esta espécie das demais do gênero. S. arenaceus Neves \& Owens, 1966 possui maior variedade de elementos ornamentais, constituídos por báculas, verrugas, pilas e cones.

\section{Spelaeotriletes yberti (Marques-Toigo) Playford \& Powis, 1979}

Est. 4, fig. 6

Diagnose: Playford \& Powis [1979. Pollen et Spores, Paris, XXI(3):371-394; p. 388-392, est. IX, fig. 16, est. V, fig. 1-6]

Locus/stratum typicus: Formação San Gregório, Permiano Inferior do Uruguai.

Descrição: esporo radial trilete monopseudossacado, de contorno equatorial convexamente triangular. Raios da laesura grossos (até $5 \mu \mathrm{m}$ ), distribuídos até a margem equatorial, onde delimitam uma fraca curvatura. Face distal ornamentada por pequenos cones e espinhos (até 1,5 $\mu \mathrm{m}$ de alt. e 1-2 $\mu \mathrm{m}$ de diâmetro basal) fracamente distribuídos pela superfície distal e proximal, que ocasionalmente se fusionam, caracter mais nitidamente verificado na margem equatorial. Exoexina ou pseudossaco geralmente associada a dobras que se estendem até a margem equatorial.

Dimensões: deq: $88-135 \mu \mathrm{m}$; cc: $45-70 \mu \mathrm{m}$; elem. escult.: até $3 \mu \mathrm{m}$ de alt. (10 exemplares).

Ocorrência: $71 ; 98 ; 103,5 ; 152,5 ; 155 ; 167 ; 170 ; 171,3 ; 168 ; 182$ e 188,5 m (poço).

Distribuição biocronoestratigráfica: espécie muito comum no Subgrupo Itararé e raramente na Formação Rio Bonito no sul do país.

Comentários/comparações: neste trabalho se mantem a designação nominal da espécie como originalmente proposto por Marques-Toigo (1970), entendendo-se que a derivação do nome é a partir do YBERT ( Prof. Dr. da UFRJ e Orlstom), face ter sido grafada erroneamente como ybertii por diversos autores (e.g. Playford \& Powis, 1978; Kremp et al., 1977). 


\section{Spelaeotriletes sp.}

Est. 4, fig. 9

Descrição: esporo radial trilete monopseudossacado, de contorno equatorial subarredondado. Raios da laesura distintos, levemente sinuosos, chegando a atingir a margem equatorial. Exoexina fina $(2-3 \mu \mathrm{m})$, esculturada na face distal por pequenos espinhos ( $3 \mu \mathrm{m}$ de alt., $\mathrm{x}$ 1-2 $\mu \mathrm{m}$ de base), cones e, menos comumente, grânulos, distribuídos irregularmente, menos comumente fusionados.

Dimensões: deq: 90(110)130 $\mu \mathrm{m}$; cc: $40-60 \mu \mathrm{m}$; elem. escult.: 3-5 $\mu \mathrm{m}$ alt. (9 exemplares).

Ocorrência: $41 ; 77 ; 103,5 ; 137 ; 152,5$ m; 155; 167;168 e 170 m (poço).

Comentários/comparações: o caráter predominantemente espinhoso/em forma de cones da ornamentação e o contorno mais arredondado desta espécie a separa de $S$. yberti (Marques-Toigo) Playford \& Powis, 1979 e de S. triangulus Neves \& Owens, 1966. S. arenaceus Neves \& Owens, 1966 possui contorno equatorial subtriangular e ornamentação mais variada. Os exemplares aqui descritos se assemelham muito com aqueles ilustrados por Coquel \& Moreau-Benoit (1989: est. 1, fig. 2 e 6) atribuídos a Spelaeotriletes sp. A, registrados no Devoniano Superior e Carbonífero Inferior do norte da África.

Gênero Grandispora (Hoffmeister, Staplin \& Malloy) Neves \& Owens, 1966

Espécie-tipo: Grandispora spinosa Hoffmeister, Staplin \& Malloy, 1955

Grandispora brevispinosa Menéndez \& Pöthe de Baldis, 1967

Est. 4, fig. 10

Diagnose: Menéndez \& Pöthe de Baldis (1967. Rev. Palaeob. and Palyn., Amsterdam, 1:167-172; p. 166, est. I, fig. $\mathrm{H}$ )

Locus/stratum typicus: furo de sondagem Picuíba 1, $1222 \mathrm{~m}$, Devoniano, noroeste do Paraguai. 
Descrição: esporo radial trilete monopseudossacado de contorno subtriangular. Corpo central liso com raios da laesura finos, distintos e retos até $4 / 5$ do raio do corpo central. Saco ("blader wall") ornamentado por pequenos espinhos ( $<1 \mu \mathrm{m}$ de alt), apresentando alguns pregueamentos radiais a partir do corpo central até margem externa do saco.

Dimensões: deq: 106-125 $\mu \mathrm{m}$; cc: 73-90 $\mu \mathrm{m}$ (2 exemplares).

Ocorrência: $152,5 \mathrm{~m}$ (poço).

Comentários/comparações: espécie considerada como retrabalhada. Difere de Grandispora echinata Hacquebard, 1957 pela natureza mais conspícua de sua ornamentação.

\section{ESPORO INDETERMINADO 1}

Est. 4, fig. 11

Descrição: esporo radial trilete de contorno equatorial circular. Exina lisa e fina $(2,5-3 \mathrm{~m}) \mathrm{com}$ infrareticulação/infravermiculação muito fina, que the dá aparência esponjosa. Dobras periféricas arcuadas são comuns. Raios da laesura proporcionalmente pouco espessos (4 $\mu \mathrm{m})$, alcançando $2 / 3$ a $3 / 4$ do raio do esporo.

Dimensões: deq: 60(81)110 $\mu \mathrm{m}$ (8 exemplares).

Ocorrência: 103,5 e 137 m (poço) e Afloramento km 125,8.

Comentários/comparações: esta espécie tem caracteres muito semelhantes àqueles presentes em Punctatisporites pavivermiculatus Playford, 1962, principalmente pela infrareticulação/infravermiculação da exina. No entanto, é verificado um "descolamento" da exina na margem equatorial em todas as formas observadas, separando-as deste gênero.

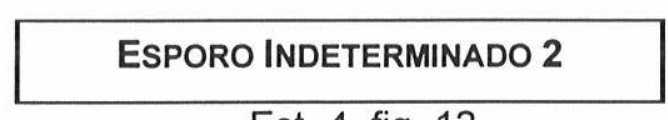

Est. 4, fig. 12

Descrição: esporo radial trilete de contorno triangular, lados ligeiramente convexos. Exina fina e lisa. Raios da laesura distintos, retos, alcançando a margem equatorial. Face distal com dobras semi-circulares, acompanhando a projeção da laesura na face distal. Estas 
dobras, ou arcos, quando se aproximam do centro do esporo apresentam-se mais escuros e, à medida que se aproximam da extremidade radial, tornam-se mais claros e distintos.

Dimensões: deq: 84-104 $\mu \mathrm{m}$ (5 exemplares).

Ocorrência: 98, 124 e 168 m (poço),

Coimentários/comparações: apesar de comum no material estudado, sua preservação não é muito boa, impedindo sua atribuição em nível taxonômico adequado.

\section{ESPORO INDETERMINADO 3}

Est. 4, fig. 8

Descrição: esporo trilete de contorno equatorial triangular, lados levementes convexos e vértices pronunciados. Raios da laesura finos e retos, alcançando a margem equatorial, com cristas mais escuras, proeminentes e triradiadas que acompanham o contorno do esporo, engrossando na porção inter-radial. A exina é lisa e somente nas cristas é ponteada.

Dimensões: deq: $54 \mu \mathrm{m}$ (1 exemplar).

Ocorrência: 167 m (poço).

Distribuição biocronoestratigráfica: assemelha-se muito às espécies do gênero Latipulvinites Peppers, 1964, originalmente assinalado na Bacia de Illinois, EUA, com idade carbonífera superior (Peppers, 1964). No entanto, qualquer posicionamento sistemático mais detalhado é inseguro, tendo em vista que apenas 1 forma foi verificada e que as cristas naquela espécie são mais convexas.

As dimensões dos grãos de pólen estão expressas em tabelas. Para seu melhor entendimento, nas figuras $5 a, 5 b$ e $5 c$ estão demonstradas, esquematicamente, as medidas realizadas. 


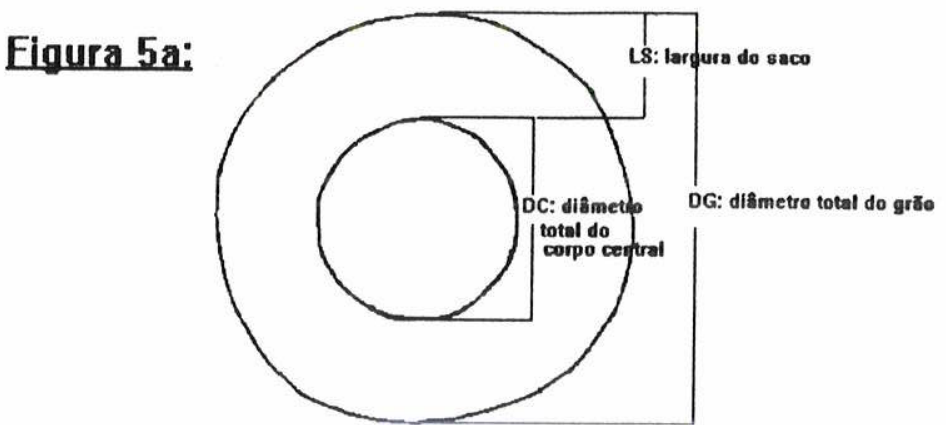

Figura 5b:

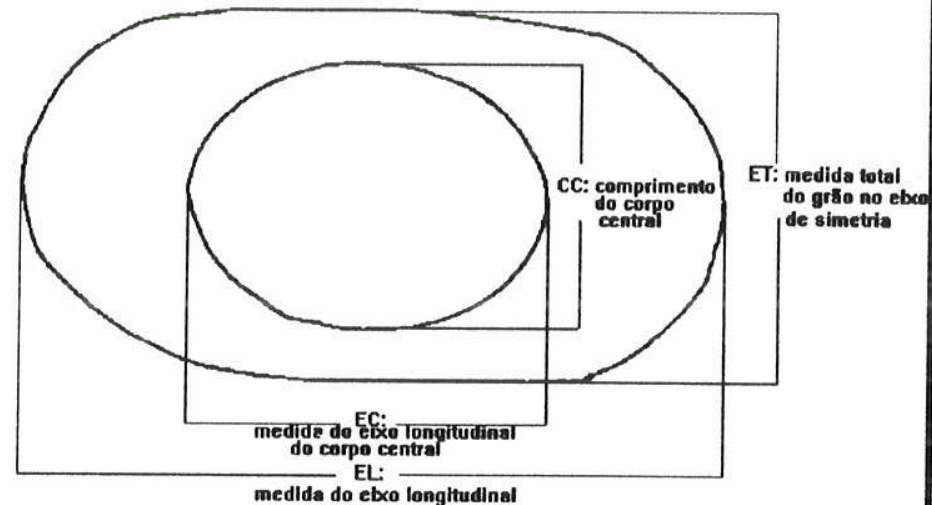

Figura 5c:

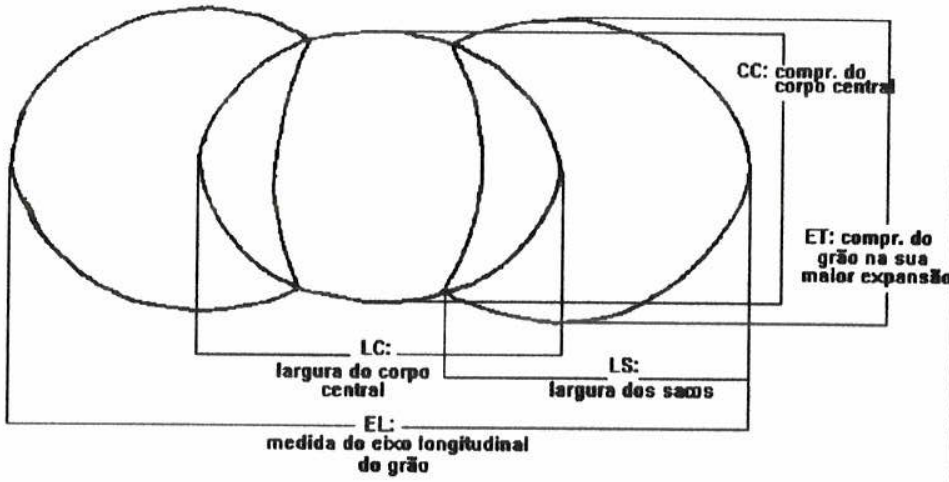

Figura 05 - Explanação diagramática dos termos utilizados nas expressões das dimensões dos grãos de pólen monossacados arredondados (5a), monossacados com simetria bilateral (5b) e bissacados (5c). 
Anteturma VARIEgerminantes Potonié, 1970

Turma SACCITES Erdtmann, 1947

Subturma Monosaccites (Chitaley) Potonié \& Kremp, 1954

Infraturma ALETESACCITES Leschik, 1955

\section{Gênero Florinites (Schopf, Wilson \& Bentall) Millay \& Taylor, 1974}

Espécie-tipo: Florinities antiquus Schopf, Wilson \& Bentall, 1944

Afinidade botânica: CORDAITOPHYTA/CONIFEROPHYTA (Potonié \& Kremp, 1956; Potonié, 1970; Azcuy, 1978).

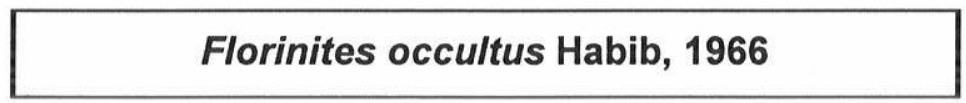

Est. 5, fig. 3

Diagnose: Habib [1966. Palaeontology, Londres, 9(4):629-666; p. 649, est. 108, fig. 4-5]

Locus/stratum typicus: Lower Kittanning Coal Seam, Western Pennsilvania, EUA, Westphaliano D.

Descrição: grão de pólen monossacado de simetria bilateral e contorno longitudinalmente ovalado. Corpo central circular, dintinto, intramicroreticulado. Raios da laesura não visíveis. Saco intrareticulado, de margem lisa, com inserção no corpo central equatorial na face proximal e subequatorial na face distal, de onde se desenvolvem algumas finas pregas radiais.

Dimensões: ver Tabela 1.

Ocorrência: 41,3; 83; 201 e 209 m (poço).

Distribuição biocronoestratigráfica: ocorrente no Carbonífero Superior da Bacia do Amazonas (Marques-Toigo, M. 1995, comunicação pessoal).

Comentários/comparações: difere das espécies do gênero pelas dimensões mais reduzidas e pelo escurecimento do corpo central. 
Est. 5, fig. 1

Diagnose: Felix \& Burbridge [1967. Palaeontology, Londres, 10(3):349-425; p. 409-410, est. 64, fig. 13]

Locus/stratum typicus: Formação Springer, Anadarko Basin, Tournaisiano-Westphaliano B, Oklahoma, EUA.

Descrição: grão de pólen monossacado de simetria bilateral. Marca monolete distinta, alcançando 4/5 do raio do corpo central, ocasionalmente com um terceiro raio conspícuo. Corpo central distinto, arredondado a ovalado, com um padrão de reticulação incipiente, com duas pregas bem desenvolvidas, transversais ao eixo maior do grão. Saco intrareticulado, bem desenvolvido longitudinalmente.

Dimensões: ver Tabela 1.

Ocorrência: 182; 195; 206 e 209 m (poço).

Comentários/comparações: forma inédita na Bacia do Paraná. As formas aqui verificadas são claramente atribuíveis a esta espécie, sobretudo devido ao sistema de pregas e forma do corpo central.

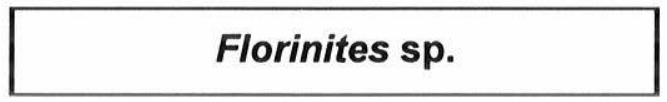

Est. 5, fig. 2

Descrição: grão de pólen monossacado de simetria bilateral e contorno oval a subcircular. Corpo central distinto, intramicroreticulado, de formato romboidal a subretangular. Laesura não visível. Inserção do saco proximalmente no equador e na face distal subequatorial, onde se desenvolve um sistema de pregas de arranjo irregular, compreendendo 3 ou mais pregas. Saco intrareticulado, amplo, de margem lisa.

Dimensões: ver Tabela 1.

Ocorrência: 137; 148;155; 171,3; 188,5; 195 e 206 m (poço).

Distribuição biocronoestratigráfica: Conforme Marques-Toigo, M. \& Daemon, R. F. (1995, comunicação pessoal) esta forma é comum nos estratos do Carbonífero Superior da Bacia do Amazonas e marcadora do Westphaliano na do Paraná (Daemon \& França, 1993). 
Comentários/comparações: os exemplares atribuídos a esta espécie se assemelham muito com F. antiquus Schopf, Wilson \& Bentall, 1944; no entanto, o sistema de pregas do corpo central, de forma irregular, impede seu enquadramento nesta espécie.

\begin{tabular}{lccc}
\hline PARÂMETROS & F. occultus & F. guttatus & F. sp \\
\hline EL & $82-100$ & $130-175$ & $150-160$ \\
ET & 64 & $80-130$ & $110-130$ \\
EC & $45-60$ & $55-85$ & 80 \\
CC & $40-65$ & $60-105$ & 70 \\
te & 05 & 08 & 06 \\
\hline
\end{tabular}

EL: medida do eixo longitudinal total do grão; ET: medida total do grão no eixo de simetria; EC: medida do eixo longitudinal do corpo central; CC: comprimento do corpo central; (medidas em $\mu \mathrm{m}$ ); te: total de exemplares medidos.

Tabela 1 - Dimensões das espécies estudadas do gênero Florinites (Schopf, Wilson \& Bentall) Millay \& Taylor, 1974.

Infraturma TRILETESACCITE Leschik, 1955

\section{Gênero Cannanoropollis Potonié \& Sah, 1960}

Espécie-tipo: Cannanoropollis janakii Potonié \& Sah, 1960

Afinidade botânica:CONIFEROPHYTA (Staplin et al., 1967; Archangelsky \& Cuneo, 1987).

Estão incluídos neste gênero todas aquelas formas de grãos de pólen monossacados de simetrial radial com aderência do saco sobre o corpo central de forma equatorial na face proximal e subequatorial na face distal, contorno equatorial circular a subtriangular, desprovidas de pregas exinais sobre a margem externa do corpo central, cuja presença é característica principal do gênero Plicatipollenites Lele, 1964. A forma diferenciada desta aderência, ou inserção do saco, parece ter sido utilizada por alguns autores, principalmente aqueles de origem indiana (e.g. Bharadwaj \& Tiwari, 1964; Bose \& Kar, 1966; Bose \& Maheswari, 1968) para separar este gênero de Parasaccites. Bharadwaj \& Tiwari, 1964, cuja aderência é submarginal em ambas as faces do corpo central. Foster (1975) não encontrou nenhuma diferença entre os holótipos de Cannanoropollis Potonié \& Sah, 1960; Parasaccites 
Bharadwaj \& Tiwari, 1964 e de Virkkipollenites Lele, 1964, citando ter prioridade o gênero mais antigo. No presente trabalho são aceitas as proposições de Foster $(1975,1979)$, respaldadas por Archangelsky \& Gamerro (1979:441) e seguidas por Marques-Toigo (1988) e Dias (1993a).

Cannanoropollis perfectus (Bose \& Maheswari) Dias-Fabrício, 1981

Est. 5, fig. 4

Diagnose: Dias-Fabrício (1981. Pesquisas, Porto Alegre, 14: 69-130; p. 84, est. VII, fig. 4)

Locus/stratum typicus: camadas de carvão próximo ao lago Tanganyka, sul de Albertville, Luanda e Kabangu, Congo.

Descrição: grão de pólen monossacado de simetria radial, contorno equatorial convexamente subtriangular. Corpo central subarredondado a subtriangular, intramicroreticulado. Marca trilete fina e discreta, não ultrapassando $1 / 3$ do raio do corpo central. Saco relativamente largo, cobrindo pouco mais de $1 / 3$ do raio do corpo central, finamente intrareticulado, radialmente "plinsado" ou enrugado, ligado subequatorialmente em ambas as faces do corpo central.

Dimensões: ver Tabela 2.

Ocorrência: 14; 26,5; 41; 45; 77; 83; 98; 148; 152,5; 182; 195; 206 e 209 m (poço).

Distribuição biocronoestratigráfica: espécie assinalada no Subgrupo Itararé ( Dias, 1993a) e Formação Rio Bonito (Dias-Fabrício, 1981) no sul do país.

Comentários/comparações: as formas aqui descritas assemelham-se muito com aquelas da descrição original de Parasaccites perfectus Bose \& Maheswari, 1968, excedendo ligeiramente nas dimensões. Aqueles exemplares ilustrados por Dias-Fabrício (1981: est. VII, fig. 4) e Dias (1993a: est. 7, fig. 1) parecem ter corpo central pouco nítido e saco escuro, o que pode representar variação na preservação do material. Apesar de Daemon \& Quadros (1970) não terem descrito a sua forma P501, as formas aqui atribuídas assemelham-se muito com aquela, tendo então distribuição mais longeva na Bacia do Paraná, não só apenas no intervalo $\mathrm{G}$, devido ao seu registro também na Formação Rio Bonito. 


\section{Cannanoropollis densus (Lele) Bose \& Maheswari, 1968}

Est. 5, fig. 7

Dianose: Bose \& Maheswari (1968. Annales du Musée Royal de L'Áfrique Centrale, Tervuren, Sciences Geológiques, 60, p. 1-116, 26 est.; p. 34, est. V, fig. 3)

Locus/stratum typicus: Flora Talchir, Índia.

Descrição: grão de pólen monossacado de simetria radial, contorno equatorial subcircular a subtriangular. Corpo central nítido, intrareticulado, mais ou menos circular, marcadamente mais denso que o saco, sem pregas exinais. Raios da laesura finos e retos, não alcançando $1 / 3$ do raio do corpo central. Saco com largura mais ou menos uniforme, intrareticulado, de margem lisa, com raiz distal marcada por algumas pregas radiais, aderido ao corpo central equatorialmente na face proximal e subequatorialmente na face distal, onde alcança $1 / 4$ do do raio.

Dimensões: ver Tabela 2.

Ocorrência: 41; 45; 77; 83; 152,5; 167; 171,3; 182; 188,5; 201; 206 e 209 m (poço).

Distribuição biocronoestratigráfica: ocorrente na Palinozona C de Sundaram (1987: est. 6, fig. 5), no Subgrupo Itararé em Santa Catarina (Pons, 1976b: est. I, fig. 6) e Rio Grande do Sul (Dias, 1993a: est. 6, fig. 8); Formação Colorado (Césari, 1984: est. 1, fig. 1), Formação Guadancol e Santa Máxima (Gutierrez, 1993: est. IV, fig. 7), Argentina. Daemon \& Quadros (1970: forma P498) descreveram formas semelhantes, atribuídas a Virkkipollenites densus Lele, 1964, com distribuição nos intervalos G-H a I? J? (sic), correspondente ao Subgrupo Itararé e Formação Rio Bonito.

Comentários/comparações: difere das demais espécies aqui apresentadas, pelo caráter escuro e denso do corpo central.

\section{Cannanoropollis mehtae (Lele) Bose \& Maheswari, 1968}

Est. 5, fig. 59

Diagnose: Bose \& Maheswari (1968. Annales du Musée Royal de L'Áfrique Centrale, Tervuren, Sciences Geológiques, 60, p. 1-116, 26 est.; p. 33, est. IV, fig. 23, est. V, fig. 1)

Locus/stratum typicus: Flora Talchir, Índia.

Descrição: grão de pólen monossacado, de simetria radial, contorno equatorial subcircular a oval, com margem crenulada. Corpo central bem definido, mais escuro que o saco, oval 
a subcircular, intrareticulado a rugoso. Laesura pouco nítida, com raios menores que 1/3 do raio do corpo central. Saco intrareticulado ligado subequatorialmente na face distal e equatorialmente na face proximal; de largura mais ou menos uniforme, com numerosas e marcadas pregas radiais, sobrepondo-se em aproximadamente $1 / 4$ na face distal ao corpo central.

Dimensões: ver Tabela 2.

Ocorrência: 45; 103,5; 155; 167; 168; 182; 195; 201 e 206 m (poço).

Distribuição biocronoestratigráfica: muito comum na Zona Potonieisporites-Lundbladispora e menos comum na Zona Cristatisporites da Bacia Chacoparanaense, conforme Archangelsky \& Gamerro (1979: est. VIII, fig. 7-8).

Comentários/comparações: difere de Cannanoropollis densus (Lele) Bose \& Maheswari, 1968 porque naquela o corpo central é bem mais marcado. Esta espécie já foi noticiada no Subgrupo Itararé no Estado de São Paulo (Sundaram, 1987: est. VI, fig. 8) e Rio Grande do Sul (Dias, 1993a: est. 6, fig. 2).

Cannanoropollis triangularis (Mehtae) Bose \& Maheswari, 1968

Est. 5, fig. 8

Diagnose: Bose \& Maheswari (1968. Annales du Musée Royal de L'Áfrique Centrale, Tervuren, Sciences Geológiques, 60, p. 1-116, 26 est.; p. 32, est. IV, fig. 22)

Locus/stratum typicus: Pali beds, Permiano, South Rewa Gondwana basin, Índia.

Descrição: grão de pólen monossacado, de simetria radial e contorno equatorial subtriangular arredondado, com margem levemente ondulada. Corpo central mais ou menos ovalado, intramicroreticulado, sem pregas exinais; raios da laesura pouco nítidos, atingindo até 1/3 do raio do corpo central. Saco de contorno subtriangular, intrareticulado, largo, aderido ao corpo central equatorialmente na face proximal e subequatorialmente na face distal, onde avança até a metade do raio deste e se desenvolvem inúmeras pregas radiais, que dão aparência crenulada à superfície.

Dimensões: ver Tabela 2.

Ocorrência: 26,5; 41; 45; 77; 152,5; 155; 167; 168; 171,3; 182; 195 e 201 m (poço) e Afloramento km 122,7.

Comentários/comparações: difere de Cannanoropollis trigonalis (Bose \& Maheswari) Bose \& Maheswari, 1968 pela natureza mais nítida do corpo central deste e das demais espécies 
do gênero pelo contorno subtriangular do saco. Gutierrez (1993: est. IV, fig. 2) também registrou esta espécie na Formação Água Colorada, Carbonífero Superior da Argentina.

\section{Cannanoropollis korbaensis (Bharadwaj \& Tiwari) Foster, 1975}

Est. 5, fig. 6

Diagnose: Foster (1975. Palaeontographica, Abt B, Sttutgart, 154: 121-171; p. 140-141)

Locus/stratum typicus: Flora Talchir e Barakar, Permiano Inferior da Índia.

Descrição: grão de pólen monossacado, de simetria radial e contorno equatorial subcircular. Corpo central circular, bem marcado, intramicroreticulado, com aparência esponjosa. Raios da laesura simples, finos e discretos, medindo aproximadamente $1 / 5$ do raio do corpo central. Saco intrareticulado, de largura irregular e contorno liso, aderido ao corpo central equatorialmente na face proximal e subequatorialmente na face distal, onde recobre $1 / 3$ do raio do corpo central se desenvolvem algumas pregas radiais.

Dimensões: ver Tabela 2.

Ocorrência: $14 ; 26,5 ; 41 ; 51 ; 55 ; 57 ; 83 ; 77 ; 83 ; 98 ; 103,5 ; 124 ; 148 ; 152,5 ; 155 ; 170 ; 171,3$; 201 e 206 m (poço).

Distribuição biocronoestraatigráfica: espécie muito comum no Subgrupo Itararé (Dias, 1993a: est. 6, fig. 4) e Formação Rio Bonito (Marques-Toigo, 1988: est. V, fig. 2-3).

\begin{tabular}{lccc}
\hline PARÂMETROS & C.perfectus & C. densus & C. mehtae \\
\hline DG & $94-110$ & $90(100) 105$ & 100 \\
DC & $55-70$ & $58-88$ & $70-74$ \\
LS & $12-35$ & $8-18$ & $12-30$ \\
te & 13 & 09 & 08 \\
\hline PARÂMETROS & C. triangularis & C. korbaensis & \\
\hline DG & $80(94) 100$ & $74-104$ & \\
DC & $50(65) 75$ & $48-78$ & \\
LS & $8(16) 30$ & $10-18$ & \\
te & 08 & 13 & \\
\hline
\end{tabular}

DG: diâmetro total do grão; DC: diâmetro total do corpo central; LS: largura do saco (sem sobreposição no corpo central); (medidas em $\mu \mathrm{m}$ ); te: total de exemplares medidos.

Tabela 2 - Dimensões das espécies estudadas do gênero Cannanoropollis Potonié \& Sah, 1960. 


\title{
Gênero Plicatipollenites Lele, 1964
}

Espécie-tipo: Plicatipollenites indicus Lele, 1964 (=P. malabarensis Potonié \& Sah emend. Foster, 1975)

Afinidade botânica: CONIFEROPHYTA (Bharadwaj, 1975; Clement-Westerhof, 1984).

Conforme a diagnose de Lele (1964:150), estão agrupadas neste gênero as espécies de grãos de pólen monossacados de contorno equatorial subcircular-oval a triangulararredondado, cujo corpo central é variável em forma; marca trilete não muito bem desenvolvida, nítida ou obscura, com raios nunca alcançando a margem do corpo central. Saco intrareticulado, sem ornamentação, unido ao corpo central, proximalmente no equador e distalmente ao longo de uma zona subequatorial, associada a um sistema de dobras ("body infold system"). Este sistema de dobras, comumente chamado de pregueamento circumpolar, relacionado com as características do corpo central e da raiz do saco, é característica diagnóstica do gênero. Comumente encontrado em sedimentos gondvânicos, teve grande distribuição, registrada desde o final do Carbonífero ao início do Permiano.

\section{Plicatipollenites malabarensis (Potonié \& Sah) Foster, 1975}

\author{
Est. 6, fig. 6 e 7
}

Diagnose: Foster (1975. Palaeontographica, Sttutgart, Abt. B, 154: 121-171; p. 141-142, est. 5, fig. 1) Locus/stratum typicus: Cannanore Beach, Índia.

Descrição: grão de pólen monossacado de simetria radial, de contorno equatorial circular a subcircular, com margem lisa, ligeiramente irregular. Corpo central circular a subcircular, intrareticulado, apresentando um pregueamento periférico submarginal do saco, de forma contínua e simples, que marca a raiz do saco na face distal do corpo central. Raios da laesura nem sempre visiveis, atingindo de $1 / 3$ a $2 / 3$ do raio do corpo central, às vezes aberta. Saco de largura mais ou menos uniforme, intrareticulado, com algumas pregas radiais.

Dimensões: ver Tabela 3.

Ocorrência: $14 ; 25,5 ; 26,5 ; 41 ; 41,3 ; 45 ; 66 ; 71 ; 77 ; 83 ; 98 ; 103,5 ; 124 ; 137 ; 148 ; 152,5 ; 167$; $170 ; 171,3 ; 182 ; 188,5 ; 195 ; 201 ; 206$ e 209 m (poço) e Afloramento km 122,7. 
Distribuição biocronoestratigráfica: espécie muito comum entre o Carbonífero Superior e o Permiano Inferior mundial, com maior incidência nas unidades do Carbonífero Superior (Azcuy \& Jelin, 1980: est. II, fig. 2; Lima et al., 1983: est. V, fig. 1). Daemon \& Quadros (1970) assinalaram sua ocorrência entre os intervalos G e K na Bacia do Paraná.

Comentários/comparações: difere das demais espécies do gênero pelo caráter contínuo e simples do sistema de pregas submarginal do corpo central.

\section{Plicatipollenites trigonalis Lele, 1964}

Est. 6, fig. 1 e 2

Diagnose: Lele [1964. The Palaeobotanist, Lucknow, 12(2):147-168; p. 156-157, est. 1, fig. 13-14, textfig. $6 a$ e 12d].

Locus/stratum typicus: Flora Talchir, Índia.

Descrição: grão de pólen monossacado, de simetria radial e contorno circular a subcircular, com margem levemente sinuosa. Corpo central subtriangular, intrareticulado, com sistema de pregas exinais submarginal distalmente de forma triangular e mais raramente poligonal, de contorno geral triangular. Raios da laesura alcançando até $1 / 3$ do raio do corpo central. Saco intrareticulado, de largura variável, sobreposto distalmente no corpo central, recobrindo $1 / 3$ deste.

Dimensões: ver Tabela 3.

Ocorrência: 18; 25,5; 26,5; 41; 41,3; 45; 71; 77; 83; 98; 124; 152,5; 167; 168; 170; 171,3; 182; 188,$5 ; 195 ; 201$ e 209 m (poço).

Distribuição biocronoestratigráfica: espécie já assinalada no Subgrupo Itararé no Estado do Rio Grande do Sul (Dias: 1993a: est. 6, fig. 6), São Paulo (Souza et al., 1993a: est. III, fig. 6), na Formação Água Colorada (Gutierrez, 1993: est. 1, fig. 2), Carbonífero Superior, Bacia Chacoparanaense (Cesari et al., 1995: est. IV, fig. 32), Argentina e Permiano da Austrália (Backhouse, 1991: est. XIII, fig. 10).

Comentários/comparações: difere das demais espécies do gênero pelo contorno triangular do corpo central, cujo pregueamento acompanha em forma. Este sistema pode apresentar 4 lados bem definidos, se enquadrando nesta espécie apenas aquelas formas cujo contorno geral do sistema de pregas seja triangular, como admitido por Lele (1964:154, text-fig. 6b e 6c). 


\section{Plicatipollenites densus Srivastava, 1970}

Est. 6, fig. 3

Diagnose: Srivastava [1970. The Palaeobotanist, Lucknow, 18(2):154-166; p. 159-160, est. I,,fig. 7] Locus/stratum typicus: Flora Talchir-Barakar Inferior, Índia.

Descrição: grão de pólen monossacado de simetria radial, contorno subcircular a oval, com margem crenulada. Corpo central distinto, circular, sempre mais denso que o saco, intrareticulado, com um sistema de pregas submarginal constante e fino na face distal. Raios da laesura atingindo menos que $1 / 3$ do raio do corpo central, nem sempre nítidos. Saco intrareticulado, de largura variável, aderido ao corpo central equatorialmente na face proximal e subequatorialmente na face distal, de onde saem algumas pregas radiais.

Dimensões: ver Tabela 3.

Ocorrência: 25,5; 26,5; 41; 124; 182; 188,5; 195; 206 e 209 m (poço).

Distribuição biocronoestratigráfica: espécie assinalada nas zonas PotonieisporitesLundbladispora, Cristatisporites e Striatites da Bacia Chacoparanaense (Archangelsky \& Gamerro, 1979: est. IV, fig. 5), Subgrupo Itararé no Estado de São Paulo (Kemp, 1975: est. 29, fig. 31) e Rio Grande do Sul (Dias, 1993a: est 7, fig. 3) e muito comum no Permiano da Índia (e.g. Lele \& Karim, 1971: est. 1, fig. 6-7).

Comentários/comparações: difere das outras espécies do gênero pela natureza densa do corpo central e de Cannanoropollis densus (Lele) Bose \& Maheswari, 1968, que possui corpo central semelhante, pela ausência de pregas exinais naquela espécie.

\section{Plicatipollenites gondwanensis (Balme \& Hennelly) Lele, 1964}

Est. 6, fig. 4 e 8

Diagnose: Lele [1964. The Palaeobotanist, Lucknow, 12(2): 147-168; p. 154-156, est. 2, fig. 11]

Locus/stratum typicus: Big Ben Seam, Permiano, Austrália.

Descrição: grão de pólen monossacado de simetrial radial, contorno circular e margem lisa. Corpo central intrareticulado, circular a subcircular, com sistema de pregas submarginal na face distal, de forma triangular a poligonal, de largura regular. Raios da laesura nem sempre visíveis, alcançando até $2 / 3$ do raio do corpo central. Saco de largura constante, às vezes mais densamente intrareticulado na margem externa. A forma ilustrada na Est. 6 e fig. 8 tem dimensões proporcionalmente mais elevadas e saco mais desenvolvido. 
Dimensões: ver Tabela 3.

Ocorrência: 25,$5 ; 26,5 ; 41 ; 41,3 ; 45 ; 77 ; 98 ; 124 ; 152,5 ; 167 ; 168 ; 195 ; 201 ; 206$ e 209 m (poço).

Distribuição biocronoestratigráfica: espécie muito comum no Paleozóico Superior da América do Sul (e.g. Césari, 1984: est. 1, fig. 3; Marques-Toigo, 1988: est. V, fig. 6; Gutierrez, 1993: est. I, fig. 1).

Comentários/observações: difere de $P$. trigonalis Lele, 1964 por este último apresentar contorno do corpo central triangular. Como salientado por Gutierrez (1993:171), $P$. paranaensis Cauduro, 1970, descrito na Formação Rio Bonito, possui as mesmas caracteristicas de $P$. gondwanensis (Balme \& Hennelly) Lele, 1964, podendo se tratar de sinonímia.

Plicatipollenites cf. P. malabarensis (Potonié \& Sah) Foster, 1975

Est. 8, fig. 5

Descrição: grão de pólen monossacado, de simetria radial, contorno equatorial subtriangular, margem lisa a levemente irregular. Corpo central distinto, circular, intramicroreticulado, com pregueamento subequatorial na face distal, fino a contínuo que marca a raiz do saco. Raios da laesura nem sempre visiveis, atingindo de $1 / 3$ a 2/3 do raio do corpo central; às vezes aberta. Saco intrareticulado, de largura variável, preso no corpo central equatorialmente na face proximal e subequatorialmente na face distal de onde saem algumas pregas radiais.

Dimensões: ver Tabela 3.

Ocorrência: 26,$5 ; 45 ; 188,5 ; 201 ; 206$ e 209 m (poço).

Distribuição biocronoestratigráfica: forma semelhante, descrita por Daemon \& Quadros (1970: forma P490), é restrita ao intervalo G, correspondente ao Subgrupo Itararé na Bacia do Paraná.

Comentários/comparações: os exemplares aqui atribuidos assemelham-se muito a $P$. malabarensis (Potonié \& Sah) Foster, 1975, possuindo somente o contorno subtriangular e largura variável do saco em desacordo. Dentre os caracteres diagnósticos distintivos das espécies deste gênero, Azcuy \& Gutierrez (1985) e Gutierrez (1993) não mencionaram o contorno do saco. Espécies de contorno circular a subcircular e ovalado são comumente atribuídas a esta espécie (e.g. Bose \& Maheswari, 1968: est. V, fig. 7). Ottone \& Azcuy (1990: est. III, fig. 4) reconheceram no Carbonifero da Argentina 
exemplarem semelhantes aos aqui descritos. Várias formas de contorno triangular foram atribuidas ao gênero Cordaitina Samoilovich, 1953, que seriam, conforme Gutierrez (1993:171) sinonímias desta espécie (e.g. Marques-Toigo \& Pons, 1974: est. 2, fig. 2; Ybert, 1975: est. 4, fig. 86; Dellazzana, 1976: est. V, fig. 2). A forma P490 descrita por Daemon \& Quadros (1970), que se referem ao sistema de pregas da inserção do saco no corpo central como "dobras de plicação" (p. 382), se assemelha muito com as aqui registradas, sobretudo pelo contorno equatorial "triangular arredondado" (p. 382).

\begin{tabular}{lccccc}
\hline PARÂMETROS & $P$. & $P$. & $P$. & $P$. & $P . c f . P$ \\
& trigonalis & densus & gondwanensis & malabarensis & malabarensis \\
\hline DG & $78(94) 130$ & $93(108) 138$ & $105(124) 195$ & $84(115) 135$ & $102-145$ \\
DC & $46(60) 86$ & $62(70) 86$ & $76(98) 117$ & $55(88) 95$ & $72(94) 102$ \\
LS & $6(14) 35$ & $12(18) 30$ & $14(16) 24$ & $10(20) 35$ & $8(14) 29$ \\
RL & $8-(10)$ & $5-10$ & $5-20$ & $10-13$ & $16-19$ \\
LP & $4(6) 12$ & $3-(5)$ & $4(8) 14$ & $4(8) 10$ & $3(4) 10$ \\
te & 10 & 07 & 11 & 12 & 06 \\
\hline
\end{tabular}

DG: diâmetro total do grăo; DC: diametro total do corpo central; LS: largura do saco (sem sobreposiçâo no corpo central); RL: raios da laesura; LP: largura das pregas exinais; (medidas em $\mu \mathrm{m}$ ); te: total de exemplares medidos.

Tabela 3 - Dimensões das espécies estudadas de Plicatipollenites Lele, 1964

Infraturma VESICULOMONORADITI Pant, 1954

\section{Gênero Potonieisporites (Bharadwaj) Bharadwaj, 1964}

Espécie-tipo: Potonieisporites novicus Bharadwaj 1954

Afinidade botânica: CONIFEROPHYTA ( Nygreem \& Bourm, 1967; Staplin et al., 1967; Rothwell, 1982; Taylor, 1982; Clement-Westhof, 1984).

Este gênero inclui grãos de pólen monossacados, de simetria bilateral e saco com inserção equatorial sobre a face proximal e subequatorial na face distal do corpo central. Sobre essa última é desenvolvido, associado às raizes do saco, um sistema de pregas de forma e distribuição variável. Os caracteres básicos para a distinção de suas espécies ou "morfotipos" (Gutierrez, 1993:172) têm sido a forma e o tamanho do corpo central e a natureza do sistema 
de pregas exinais do corpo central, além do contorno geral do grão e a natureza da laesura. A não observação precisa destes caracteres tem levado a atribuições indevidas de algumas espécies a este gênero. Alguns fatores como a corrosão diferencial, a deformação e o grau de preservação afetam esses traços diagnósticos, como apontado por alguns autores (e.g. Archangelsky \& Gamerro, 1979). De modo que as dificuldades de seu tratamento sistemático têm se agravado, demonstrando a necessidade de uma reavaliação dos táxons atribuídos às várias espécies deste gênero, pelo menos, no âmbito da Bacia do Paraná no Brasil.

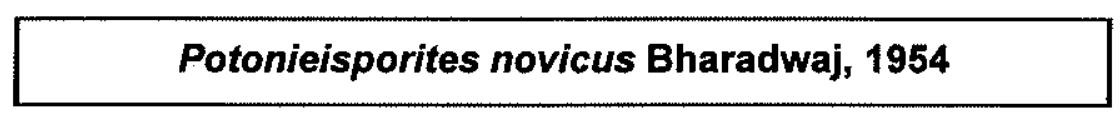

Est. 7, fig. 1 e 2

Diagnose: Bharadwaj (1954. Fortschritte der Geologie Reheiland und Wesfalen, Kreffeld, 12: 45-54)

Locus/stratum typicus: Pfalz, Labachgrube, Grenkohlenflox, Alemanha.

Descrição: grão de pólen monossacado de simetria bilateral e contorno ovalado longitudinalmente. Corpo central subcircular com um sistema de pregas periférico distal retangular, sendo maiores aqueles transversais ao eixo maior do grão. Saco intrareticulado, de margem lisa, com algumas raras pregas radiais.

Dimensões: ver Tabela 4.

Ocorrência: 167; 170; 195 e 201 m (poço) e Afloramento km 122,7.

Distribuição biocronoestratigráfica: apesar de ser comum o registro desta espécie na Bacia do Paraná no Brasil (Pons, 1976b: est. I, fig. 1), ela é mais comumente assinalada na Argentina (Archangelsky \& Gamerro, 1979: est. VIII, fig. 5; Ottone, 1989: est. 1, fig. 2; Ottone \& Azcuy, 1989: est. III, fig. 1; Gutierrez, 1993: est. 2, fig. 5) e Europa (e.g. Doubinger \& Broutin, 1976: est. II, fig. 17).

Comentários/comparações: as formas atribuídas a esta espécie neste trabalho possuem corpo central com sistema de pregas retangular bem desenvolvido transversalmente. Entretanto, comporta uma variação morfológica significativa, como observado nas formas ilustradas.

Potonieisporites brasiliensis (Nahuys, Alpern \& Ybert) Archangelsky \& Gamerro, 1979

Est. 7 , fig. 3 e 4

Diagnose: Archangelsky \& Gamerro [1979. Rev. Esp. de Microp., Madrid, XI(3): 417-478; p. 445446 , est. VII, fig. 10, est. VIII, fig. 1-4] 
Locus/stratum typicus: Permiano Inferior da Bacia do Paraná, Brasil.

Descrição: grão de pólen monossacado de simetria bilateral e contorno equatorial longitudinalmente ovalado. Corpo central circular distinto, com 4 pregas cruzadas, sendo maiores aquelas normais ao eixo maior do grão. Marca monolete distinta, alcançando $1 / 2$ do raio do corpo central. Saco intrareticulado, com inserção subequatorial na face distal e equatorial na face proximal. Pregas radiais mais prolongadas são comuns no saco a partir da inserção no corpo central.

Dimensões: ver Tabela 4.

Ocorrência: 45; 137; 152,5; 182; 195 e 206 m (poço).

Distribuição biocronoestratigráfica: espécie muito comum na Bacia do Paraná (Ybert, 1975: est. 5, fig. 103; Dias, 1993a: est. 7, fig. 7) e na Argentina (Ottone, 1989: est. 10, fig. 4; Ottone \& Azcuy, 1989: est. III, fig. 8), ocorrendo nas zonas PotonieisporitesLundbladispora, Cristatisporites e Striatites da Bacia Chacoparanaense (Archangelsky \& Gamerro, 1979) e na Zona Ancistrospora na Formação Guadancol (Ottone \& Azcuy, 1989).

Comentários/comparações: esta espécie distingue-se das demais pela natureza mais circular do corpo central, sistema de pregas e, principalmente, pelas pregas radiais no saco, mais alongadas transversalmente. Estas pregas, no sentido de menor extensão do saco, dão aparência de biconstrução lateral ao grão, lembrando as espécies de Caheniasaccites (Bose \& Kar) Archangelsky \& Gamerro, 1979. Esta particularidade, que parece ser comum à espécie, já foi observada por Archangelsky \& Gamerro (1979: est. 7, fig. 8) e Ottone \& Azcuy (1989: est. 3, fig. 8).

Potonieisporites magnus Lele \& Karim, 1971

Est. 8, fig. 1

Diagnose: Lele \& Karim [1971. The Palaeobotanist, Lucknow, 19(1): 52-69; p. 58-59, est. 2, fig. 16]

Locus/stratum typicus: Patharjore Nala, Flora Talchir, Jayanti Coalfield, Bihar, India.

Descrição: grão de pólen monossacado, de simetria bilateral e contorno equatorial ovalado longitudinalmente. Corpo central distinto, subcircular a ovalado, transversalmente maior que longitudinalmente. Na face distal a inserção do saco é associada a um sistema de pregas composto por um dois elementos semilunares, que se unem no eixo menor do corpo central. Marca monolete proximal, nem sempre nítida. 
Dimensões: ver Tabela 4.

Ocorrência: 152,$5 ; 171,3 ; 182 ; 188,5 ; 201 ; 206$ e 209 m (poço).

Distribuição biocronoestratigráfica: comum entre o Carbonífero Superior e Permiano Inferior das bacias gondvânicas, representando elemento importante da Palinozona de Potonieisporites (Azcuy \& Jelin, 1980). Esta espécie tem sido comumente assinalada no Westphaliano (Ottone \& Azcuy, 1989: est. III, fig. 1) e Stephaniano (Azcuy \& Jelin, 1980: est. III, fig. 1; Ottone, 1989: est. 9, fig. 1; Ottone \& Azcuy, 1990: est. II, fig. 1; Gutierrez, 1993: est. VII, fig. 8) da Argentina. Na Bacia do Paraná seu registro é mais raro, tendo sido somente assinalada por Souza et al. (1993a: est. 3, fig. 8) na Bacia do Paraná, em material proveniente do carvão de Buri, Estado de São Paulo, os quais a designaram indevidamente como Potonieisporites brasiliensis.

Comentários/observações: os caracteres diagnósticos desta espécie são o elongamento contínuo transversal do corpo central e o desenvolvimento do sistema de pregas único ou por duas pregas semilunares que se unem nos extremos, como aqui observado. Difere de $P$. barrelis Tiwari, 1965, que também possui o eixo transversal do corpo central mais alongado, pela forma característica do corpo central naquela espécie.

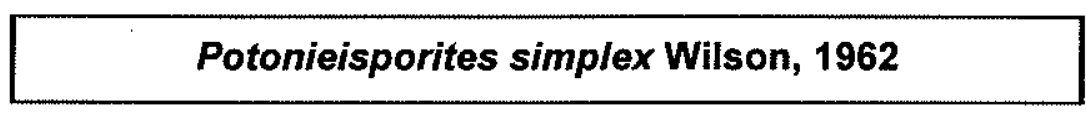

Est. 8, fig. 3

Diagnose: Wilson (1962. Oklahoma Geological Survey Circular, Norman, 49, 47 p.; p. 14-15, est. III, fig. 1-3)

Locus/stratum typicus: Folhelho Flowerport, Grupo El Reno, Permiano, Oklahoma, EUA.

descrição: grão de pólen monossacado, de simetria bilateral, contorno equatorial ovalado, alongado longitudinalmente. Saco finamente intrareticulado, de margem lisa. Corpo central circular, finamente intrareticulado. Inserção do saco submarginal na face distal do corpo central, onde se desenvolve um sistema de pregueamento circular contínuo e mais uniforme.

Dimensões: ver Tabela 4.

Ocorrência: 26,5 e $195 \mathrm{~m}$ (poço).

Comentários/observações: os exemplares aqui registrados se encaixam na descrição de Wilson (1962) cujo caráter diagnóstico principal é o sistema de pregas contínuo e uniforme, como destacado por Gutierrez (1993:173). 


\section{Potonieisporites neglectus Potonié \& Lele, 1961}

Est. 8, fig. 4

Diagnose: Potonié \& Lele [1961. The Paleobotanist, Lucknow, 8(1-2):22-37; p. 30, fig. 60-62 e 64-65]

Locus/stratum typicus: Goraia, South Rewa Basin, India.

Descrição: grão de pólen monossacado, de simetria bilateral, com contorno equatorial longitudinalmente ovalado. Corpo central alongado longitudinalmente, de forma ovalada a trapezoidal. Marca monolete alongada, ocupando 1/3 do corpo central. Raízes do saco subequatoriais na face distal, associada a 4 pregas cruzadas, com área livre retangular.

Dimensões: ver Tabela 4.

Ocorrência: 152,5; 167 e $170 \mathrm{~m}$ (poço).

Distribuição biocronoestratigráfica: espécie comum no Carbonifero da Argentina, Formação Água Colorada (Gutierrez, 1993: est. 2, fig. 1), Formação Santa Máxima (Ottone, 1989: est. 9, fig. 8) e Formação Guadancol (Ottone \& Azcuy, 1989: est. II, fig. 3), também assinalada por Dias (1993a: est. 7, fig. 5) no Subgrupo Itararé do Rio Grande do Sul.

Comentários/observações: Dias (1993a: 163) teceu importantes comentários a respeito das dificuldades de sepação desta espécie de Potonieisporites novicus Bharadwaj, 1954. Os exemplares aqui descritos têm muita semelhança com os registrados na Argentina, principalmente com aquele ilustrado por Gutierrez (1993: est. 2, fig. 1) e Ottone (1989: est. 9, fig. 8), principalmente, pela disposição cruzada do sistema de pegas e forma trapezoidal do corpo central.

\section{Potonieisporites congoensis Bose \& Maheswari, 1968}

Est. 8, fig. 2

Diagnose: Bose \& Maheswari (1968. Annales du Musée Royal de L'Africa Centrale, Tervuren, Serie IN- $8^{0}$, Sciences Geologiques $n^{0} 60$, p. 1-116; p. 52-53, est. XV, fig.6, est. XII, fig. 2-3, text-fig. 11)

Locus/stratum typicus: sul de Albertiville, Luanda, África.

Descrição: grão de pólen monossacado, de simetria bilateral, contorno longitudinalmente ovalado a subretangular. Corpo central distinto, subretangular, com marca monolete proximal. Raizes do saco na face distal, subequtoriais, associadas a 4 pregas grossas 
cruzadas, paralelas ao contorno do corpo central, delimitando área quadrada a retangular. Saco intramicroretulado, com margens lisas.

Ocorrência: 168 e $182 \mathrm{~m}$ (poço).

Dimensões: ver Tabela 4.

Distribuição biocronoestratigráfica: espécie assinalada na Formação Água Colorada, Argentina (Gutierrez, 1993: est. 2, fig. 3), inédita na Bacia do Paraná.

Comentários/comparações: a forma predominantemente retangular do corpo central e do saco permite separar esta espécie de $P$. neglectus Potonié \& Lele, 1961, com caracteres diagnósticos mais próximos.

\section{Potonieisporites cf. P. triangulatus Tiwari, 1965}

Est. 9, fig. 1

Diagnose: Tiwari [1965. The Palaeobotanist, Lucknow, 13(2):168-214; est. 4, fig. 83]

Locus/stratum typicus: Korba Coalfield, Bihar, India.

Descrição: grão de pólen monossacado, de simetria bilateral e contorno equtorial longitudinalmente ovalado. Corpo central subtriangular, mais desenvolvido no eixo transversal do grão. Raíz distal do saco subequatorial no corpo central, associada a um sistema de pregas subtriangular, acompanhando a forma do corpo central. Saco intrareticulado, de margem lisa.

Ocorrência: 152,5 e 168 m (poço) e Afloramento km 122,7.

Dimensões: ver Tabela 4.

Distribuição biocronoestratigráfica: espécie inédita na Bacia do Paraná, reconhecida na Formação Guadancol (Ottone \& Azcuy, 1989: est. III, fig. 3), Formação San Juan (Ottone \& Azcuy, 1990: est. II, fig. 3) e Formação Água Colorada (Gutierrez, 1993: est. 2, fig. 2), Argentina.

Comentários/comparações: a forma subtriangular do corpo central das formas aqui estudadas lembra muito a espécie em alusão, cujo corpo central é mais nitidamente triangular. 


\section{Potonieisporites sp. 1}

Est. 9, fig. 2

Descrição: grão de pólen monossacado, de contorno radial a bilateral e margem lisa. Corpo central distinto, bem definido, proporcionalmente bem desenvolvido, com marca monolete/trilete proximal. Saco intramicroreticulado, com inserção equatorial/proximal e subequatorial/distal no corpo central, onde se desenvolve um sistema de pregas que caracteriza uma área retangular, mais alongado transversalmente ao eixo maior do grão.

Dimensões: ver Tabela 4.

Ocorrência: 26,$5 ; 41 ; 66 ; 98 ; 168 ; 182 ; 195$ e 209 m (poço).

Comentários/comparações: estas formas distinguem-se das demais atribuidas ao gênero pelo contorno não amplamente bilateral e maior desenvolvimento do corpo central.

\begin{tabular}{lccc}
\hline Parâmetros & $P$. novicus & $P$. magnus & $P$. brasiliensis \\
\hline EL & $165-200$ & $175(195) 200$ & $165-175$ \\
ET & $95-130$ & $130-140$ & $95-105$ \\
EC & $90-105$ & $100-110$ & $85-95$ \\
CC & $90-100$ & $115-130$ & $90-95$ \\
te & 15 & 07 & 06 \\
\hline Parâmetros & $P$. sp.1 & $P$. sp. 2 & $P$. simplex \\
\hline EL & $130-135$ & $100-160$ & $150-160$ \\
ET & $115-130$ & $75-115$ & $110-125$ \\
EC & $90-106$ & $44-70$ & $75-95$ \\
CC & $90-110$ & $56-90$ & $75-95$ \\
te & 05 & 05 & 04 \\
\hline Parâmetros & $P$. congoensis & $P$. neglectus & $P$. cf. $P$. triangulatus \\
\hline EL & $150-215$ & $130-205$ & $120-150$ \\
ET & $135-160$ & $100(110) 135$ & $90-140$ \\
EC & $75-100$ & $(100)-130$ & $60-85$ \\
CC & $70-85$ & $80-105$ & $70-115$ \\
te & 04 & 06 & 06 \\
\hline
\end{tabular}

EL: medida do eixo longitudinal total do grão; ET: medida total do grão no eixo de simetria; EC: medida do eixo longitudinal do corpo central; $\mathrm{CC}$ : comprimento do corpo central; (medidas em $\mu \mathrm{m}$ ); te: total de exemplares medidos.

Tabela 4 - Dimensões das espécies estudadas de Potonieisporites (Bharadwaj) Bharadwaj, 1964 


\section{Potonieisporites sp. 2}

Est. 9 , fig. 3

Descrição: grão de pólen monossacado, de simetria bilateral e contorno lontigudinalmente ovalado. Corpo central subcircular, ligeiramente alongado transversalmente, grosseiramente intrareticulado, com marca trilete atingindo $2 / 3$ do raio do corpo central. Saco intrareticulado, de contorno não uniforme, com inserção equatorial na face proximal do corpo central e subequatorial na face distal, onde se desenvolve um sistema de pregas submarginal.

Dimensões: ver Tabela 4.

Ocorrência: 152,$5 ; 171,3 ; 201 ; 206$ e 209 m (poço).

Comentários/comparações: o contorno geral do grão se assemelha muito com aquele da espécie $P$. lelei Maheswari, 1967 , muito comum no Carbonífero Superior (Gutierrez, 1993: est. 1, fig. 6) e Permiano Inferior (Bose \& Maheswari, 1968: est. XI, fig. 4-5) das bacias gondvânicas.

\section{Gênero Caheaniasaccites (Bose \& Kar) Archangelsky \& Gamerro, 1979}

Espécie-tipo: Caheaniasaccites flavatus Bose \& Kar, 1966

Afinidade botânica: CONIFEROPHYTA (Archangelsky \& Cuneo, 1987).

Estão agrupados neste gênero os grãos de pólen monossacados de simetria bilateral, biconscritos lateralmente, de corpo central circular a ovalado, com várias pregas na face distal junto à raiz do saco, delimitando um leptoma de forma variável; saco bem desenvolvido lateralmente, com pregas radiais e com aparência bissacada.

A inserção do saco no corpo central parece variar de espécie para espécie. $\mathrm{Na}$ emenda efetuada por Archangelsky \& Gamerro (1979) esta inserção seria, em geral, equatorial em ambas as faces do corpo central. Já Gutierrez (1993) relaciona ao gênero formas com aderência subequatorial; enquanto que Lele \& Karim (1971) na descrição de C. densus, a refere como mais difusa e mais próxima à periferia do corpo central na face proximal do que na distal. Gutierrez (1993) utilizou o alongamento longitudinal do corpo central para separar estas duas espécies, sendo aquelas de corpo central mais alongado referiveis a $C$. densus (Lele \& 
Karim) Gutierrez, 1993 e as de corpo central mais subarredondados referiveis a $C$. ovatus (Bose \& Kar) Gutierrez, 1993.

A observação das feições diagnósticas principais permite o enquadramento de vários "morfotipos" neste gênero. A biconstrlção lateral do saco é um caráter de transição nos grãos de pólen monossacados, refletindo um "trending" de maior desenvolvimento lateral dos sacos até sua individualização, já notado em algumas espécies atribuídas a Potonieisporites brasiliensis (Nahuys, Apern \& Ybert) Archangelsky \& Gamerro, 1979.

Importante notar que o gênero Constatascyclus Felix \& Burbridge, 1967, descrito no Torunaisiano-Westphaliano B de Oklahoma, EUA (Felix \& Burbrigge, 1967), possui algumas das principais caracteristicas diagnósticas do gênero Caheniasaccites; porém, com pregas radiais mais desenvolvidas no saco, como verificado nas espécies aqui atribuidas a Caheniasaccites sp. 2.

\section{Cahenisaccites ovatus (Bose \& Kar) Gutierrez, 1993}

\section{Est. 9 , fig. 4,5 e 6}

Diagnose: Gutierrez [1993. Ameghiniana, Buenos Aires, 30(2):163-212]

Locus/stratum typicus: Mabuita, região de Walikale, África.

Descrição: grão de pólen monossacado de simetria bilateral e contorno longitudinalmente ovalado, com aparência bissacada pelo caráter de biconstrução lateral. Corpo central circular a subcircular a oval, intramicroreticulado, geralmente com marca monolete (1/3 do raio) na face proximal. Saco intrareticulado, de inserção equatorial/proximal e subequatorial/distal no corpo central, amplamente expandido em suas partes terminais, com pregas radiais na raiz distal, onde desenvolve um leptoma da mesma forma que o corpo central.

Dimensões: ver Tabela 5.

Ocorrência: $14 ; 25,5 ; 26,5 ; 41 ; 41,3 ; 45 ; 51 ; 55 ; 57 ; 66 ; 77 ; 83 ; 98 ; 103,5 ; 127 ; 148 ; 152,5$; $167 ; 168 ; 171,3 ; 182 ; 188,5 ; 195 ; 201 ; 206$ e 209 m (poço) e Afloramento km 118,6.

Distribuição biocronoestratigráfica: assinalada na Palinozona C de Sundaram (1987) correspondente, grosso modo, à parte superior do Subgrupo Itararé. Daemon \& Quadros (1970) ilustraram exemplares semelhantes, atribuidos a Vestigisporites cf. V. diffusus Maithy, 1965 que se enquadram perfeitamente em Caheniasaccites ovatus (Bose \& Kar) 
Gutierrez, 1993, com distribuição ampla, correspondente aos intervalos G a L na Bacia do Paraná.

Comentários/comparações: espécie muito comum e abundante no Permiano Inferior das bacias gondvânicas, mostrando, contudo, um grau de variação morfológica muito grande, sobretudo na forma do saco. Formas semelhantes foram assinaladas no Subgrupo Itararé como Potonieisporites triradialis Marques-Toigo, 1974 ( Lima et al., 1983: est. V, fig. 1; Marques-Toigo, 1988: est. III, fig. 2-3), também referiveis a esta espécie, conforme Gutierrez (1993).

\section{Caheniasaccites densus (Lele \& Karim) Gutierrez, 1993}

Est. 9, fig. 7

Diagnose: Gutierrez [1993. Ameghiniana, Buenos Aires, 30(2):163-212; p. 189, est. II, fig. 7]

Locus/stratum typicus: Pathar Jore Nala, Jayanti Coalfield, Flora Talchir, Índia.

Descrição: grão de pólen monossacado, de simetria bilateral e contorno longitudinalmente alongado. Corpo central ovalado longitudinalmente, denso. Saco intrareticulado, com inserção equatorial/proximal e subequatorial/distal, de onde se desenvolvem pregas e ondulações radiais.

Dimensões: ver Tabela 5.

Ocorrência: 25,$5 ; 26,5 ; 41 ; 41,3 ; 45 ; 83 ; 98 ; 124 ; 137 ; 148 ; 152,5 ; 155 ; 167 ; 168 ; 170 ; 171,3$; 195 e $209 \mathrm{~m}$ (poço).

Comentários/comparações: o caráter denso do corpo central a distingue das demais espécies do gênero. Conforme destacou Gutierrez (1993), esta espécie é referível a uma das ilustrações de Potonieisporites triradialis Marques-Toigo, 1974 (est. 3, fig. 1), descrita na Formação San Gregório, Uruguai.

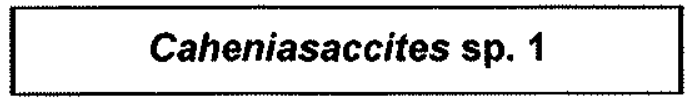

Est. 10 , fig. 1 e 2

Descrição: grão de pólen monossacado, longitudinalmente alongado, de aparência trissacada. Corpo central subcircular, apresentando marca monolete. Saco intramicroreticulado, com inserção equatorial/proximal e subequatorial/distal, onde, nesta última face, desenvolve 
um sistema de pregas exinais delimitando uma área subretangular a subcircular, com algumas dobras de plicamento radiais.

Dimensões: ver Tabela 5.

Ocorrência: 167; 182 e 209 m (poço).

Distribuição biocronoestratigráfica: distribui-se na Bacia do Paraná entre os intervalos G-11 de Daemon \& Quadros (1970), ocorrentes no Subgrupo Itararé e Formação Rio Bonito.

Comentários/comparações: a aparência trissacada separa esta espécie das demais do gênero. Daemon \& Quadros (1970) descreveram a mesma forma (P489), mencionando-a como "forma abortiva", em função da aparência trissacada, porém com valor bioestratigráfico significativo.

\section{Caheniasaccites sp. 2}

Est. 10 , fig. 3 e 4

Descrição: grão de pólen monossacado de simetria bilateral e contorno diploxilonóide. Corpo central subcircular a ovalado, nítido, intramicroreticulado, com marca monolete na face proximal de até $1 / 2$ do raio. Saco intramicroreticulado, bem desenvolvido lateralmente, com forte aparência bissacada; raiz subequatorial em ambas as faces do corpo central onde, distalmente, desenvolve-se um sistema de pregas retangular e nítidas dobras/pregas radiais.

Dimensões: ver Tabela 5.

Ocorrência: 124 e $167 \mathrm{~m}$ (poço).

Comentários/comparações: difere das demais espécies do gênero pelo forte contorno bissacado, com maior desenvolvimento lateral dos sacos e expressivas pregas/dobras radiais. Césari (1984: est. 1, fig. 2) descreveu um exemplar muito semelhante na Formação Tupé, Carbonifero Superior da Argentina, com saco proporcionalmente menos desenvolvido, atribuido a Cannanoropollis densus Lele \& Karim, 1971. Costatascyclus crenatus Felix \& Burbrdige, 1967 possui os mesmos caracteres morfológicos destas formas, sobretudo as pregas/dobras radiais bem desenvolvidas, sendo que naquela espécie são ausentes pregas sobre o corpo central, relativas à inserção do saco, como aqui verificado. 


\section{Caheniasaccites sp .3}

Est. 10, fig. 5

Descrição: grão de pólen monossacado de simetria bilateral e contorno longitudinalmente ovalado. Corpo central subcircular, ligeiramente alongado transversalmente ao eixo maior do grão. Laesura não visível. Inserção do saco equatorial na face proximal do corpo central e subequatorial na face distal, até $1 / 3$ do raio do corpo central, de onde se desenvolvem algumas pregas ou plicas radiais.

Dimensões: ver Tabela 5.

Ocorrência: 45; 167 e $201 \mathrm{~m}$ (poço).

Comentários/comparações: os exemplares aqui verificados assemelham-se muito a Caheniasaccites verrucosus (González-Amicon) Gutierrez, 1993 pela aparência de ornamentação verrucosa no corpo central, dada pelo denso sitema de pregas radiais que se distribuem a partir do corpo central até às porções médias do saco.

\begin{tabular}{lccccc}
\hline PARÂMETROS & C. ovatus & C. densus & C. sp.1 & C. sp. 2 & C. sp. 3 \\
\hline EL & $110-165$ & $125(135) 167$ & $170-200$ & $150-160$ & $130-185$ \\
ET & $75(90) 105$ & $65(70) 95$ & $75-90$ & $100-105$ & $85-135$ \\
EC & $50(65) 95$ & $55-90$ & 75 & 70 & $70-90$ \\
CC & $40-95$ & $45-97$ & 65 & $65-70$ & $55-95$ \\
te & 12 & 07 & 09 & 05 & 06 \\
\hline
\end{tabular}

EL: medida do eixo longitudinal total do grão; ET: medida total do grão no eixo de simetria; EC: medida do eixo longitudinal do corpo central; $\mathrm{CC}$ : comprimento do corpo central; (medidas em $\mu \mathrm{m}$ ); te: total de exemplares medidos.

Tabela 5 - Dimensões das espécies estudadas do gênero Caheniasaccites (Bose \& Kar) Archangelsky \& Gamerro, 1979

Infraturma STRIASACCITI Bharadwaj, 1962

Gênero Striomonosaccites (Bharadwaj) Hart, 1965

Espécie-tipo: Striomonosaccites ovatus Bharadwaj, 1962

Afinidade botânica: desconhecida. 


\section{Striomonosaccites cf. S. ovatus Bharadwaj, 1962}

Est. 11, fig. 1

Diagnose: Bharadwaj [1962. The Palaeobotanist, Lucknow, 9(1-2): 68-106; p. 88, est. 7, fig. 107-114]

Locus/stratum typicus: Poniati Seam, East Raniganj Coalfield, Índia.

Descrição: grão de pólen monossacado de simetria radial, com contorno equatorial subcircular a subovalado. Corpo central subcircular, $\operatorname{com} 6$ estrias longitudinais. Saco intramicroreticulado, com bordas lisas.

Dimensões: ver Tabela 6.

Ocorrência: 4,6; 103,5 e 170 m (poço) e Afloramento km 123,7.

Comentários/comparações: os exemplares aqui verificados, embora sejam ligeiramente menores que o holótipo descrito por Bharadwaj (1962), possuem as principais características diagnósticas da espécie, seja o contorno do saco e corpo central, o número de estrias e a exina do corpo central na face distal não pregada ao saco ("distal exine face free from saccus in a circular area" -Bharadwaj, 1962:88). Leipnitz (1981: est. V, fig. 2) descreveu forma semeihante na Formação Palermo no Estado de Santa Catarina.

\section{Striomonosaccites sp. 1}

Est. 11, fig. 2

Descrição: grão de pólen monossacado de simetria bilateral, alongado longitudinalmente. Corpo central circular a subcircular, ligeiramente alongado transversalmente, com 9 a 12 estrias longitudinais, às vezes anastomosadas. Saco intrareticulado, com inserção proximal equatorial e distal subequatorial, associada a 2 pregas semilunares distintas.

Dimensões: ver Tabela 6.

Ocorrência: 4,$6 ; 25,5 ; 41 ; 77 ; 168$ e 170 m ( poço) e Afloramento km 123,7.

Comentários/comparações: a ocorrência de estrias longitudinais separa esta espécie daquelas do gênero Potonieisporites (Bharadwaj) Bharadwaj, 1964, assim como o caráter monossacado a separa do gênero Protohaploxypinus (Samoilovich) Hart, 1964. Difere de Striomonosaccites ovatus Bharadwaj, 1962 visto que aquela espécie possui simetria radial, não possui pregas no corpo central e o número de estrias longitudinais é inferior a 7. É muito semelhante à forma descrita como S. cf. S. ovatus Bharadwaj, 1964 por Dias- 
Fabrício (1981: est. 8, fig. 6) na Formação Rio Bonito. Porém, o número de estrias daquele e o seu tipo do contorno não permitem o enquadramento da forma descrita por Dias-Fabrício (1981) e as aqui verificadas naquela espécie.

\begin{tabular}{lccc}
\hline Parâmetros & S. cf. S. ovatus & S. sp. 1 & S. sp. 2 \\
\hline EL & $66-84$ & $94-104$ & $104-125$ \\
ET & 78 & $66-85$ & $75-90$ \\
EC & $55-60$ & $50-60$ & $44-64$ \\
CC & 56 & $42-76$ & $62-76$ \\
te & 02 & 06 & 04 \\
\hline
\end{tabular}

EL: medida do eixo longitudinal total do grăo; ET: medida total do grăo no eixo de simetria; EC: medida do eixo longitudinal do corpo central; $\mathrm{CC}$ : comprimento do corpo central; (medidas em $\mu \mathrm{m}$ ); te: total de exemplares medidos.

Tabela 6 - Dimensões das espécies estudadas de Striomonosaccites (Bharadwaj) Hart, 1965

\section{Striomonosaccites sp. 2}

Est. 11, fig. 3

Descrição: grão de pólen monossacado, de simetria bilateral e contorno longitudinalmente alongado. Corpo central subcircular, alongado transversalmente, com 8 a 12 estrias longitudinais e algumas (2-3) perpendiculares, fracamente delineadas. Saco intrareticulado, com raiz proximal equatorial e distal subequatorial, associada a um sistema de pregas contínuo, acompanhando a forma do corpo central.

Dimensões: ver Tabela 6.

Ocorrência: $14 ; 41 ; 124$ e $168 \mathrm{~m}$ (poço).

Comentários/comparações: difere de Striomonosaccites sp. 1, registrada neste trabalho, pela natureza mais contínua do sistema de pregas associado à raiz distal do saco e das demais do gênero pelo contorno mais alongado longitudinalmente. S. crucistriatus Ybert, 1975 e S. cicatricosus Archangelsky \& Gamerro, 1979 possuem sacos menos desenvolvidos e maior número de estrias. Os exemplares aqui registrados assemelhamse muito a ?Striomonosaccites sp. ilustrado por Ottone \& Azcuy (1989: est. II, fig. 4), sendo aquela constituida de um maior número de estriais longitudinais. Com relação a ?Striomonosaccites sp. A e B, ilustradas por Ottone (1989: est. 15 e 13, respectivamente), embora muito semelhantes em forma, aquelas possuem corpo central 
alongado longitudinalmente. Barss (1967: est. XXXVII, fig. 11) e Lima et al. (1983: est. V, fig. 6) também reconheceram formas semelhantes, sendo no entanto dificil uma melhor associação pela ausência de descrições naqueles trabalhos.

Subturma DISACCITES Cookson, 1947

Infraturma DisACCITRILETE (Leschik) Potonié, 1958

\section{Gênero Limitisporites (Leschik) Schaarschmidt, 1963}

Espécie-tipo: Limitisporites rectus Leschik, 1956

Afinidade botânica: PTERIDOSPERMOPHYTA-GLOSSOPTERIDALES (Gould \& Delevoryas, 1977).

Estão incluídos neste gênero os grãos de pólen bissacados com marca monolete/trilete, pregas transversais à maior elongação do grão associadas à inserção distal do saco no corpo central. Os caracteres distintivos entre as suas espécies são a forma do corpo central, o contorno e o desenvolvimento lateral dos sacos, como destacado nos esquemas realizados por Schaarschmidt (1963:49) e Bose \& Maheswari (1968:62). O contorno é, no entanto, desde haploxilonóide a diploxilonóide, com o desenvolvimento, por vezes, de uma fina ligação exinal ("puente exinal", conforme Gutierrez, 1993:199) que, neste sentido, dá aparência semelhante a outros gêneros de monossacados, como Caheniasaccites (Bose \& Kar) Archangelsky \& Gametro, 1979, diferenciando-se destes, no entanto, pela natureza bissacada e por possuir, associadas à raiz distal do saco, pregas somente transversalmente ao eixo maior do grão.

\section{Limitisporites Iuandensis Bose \& Maheswari, 1968}

Est. 11, fig. 4

Diagnose: Bose \& Maheswari (1968. Annales du Musée Royal de L'Afrique Centrale, Tervuren, Série IN $-8^{0}$, Sciences Geológiques 60 , p. 1-116; p. 63, est. XVI, fig. 1-2, text-fig. 15) 
Locus/stratum typicus: camadas de carvão próximo ao lago Tanganyika, sul de Albertville, Luanda, Congo.

Descrição: grão de pólen bissacado, diploxilonóide, alongado longitudinalmente. Corpo central denso, circular a subovalado ("roundly hexagonal" in Bose \& Maheswari, 1968:63), com marca monolete na face proximal, alongada longitudinalmente. Sacos intramicroreticulados, subesféricos, bem desenvolvidos e unidos lateralmente por fina ligação exinal. Inserção distal associada a 2 pregas semilunares, transversais, com pregas/dobras radiais pouco desenvolvidas.

Dimensões: ver Tabela 7.

Ocorrência: 152,$5 ; 155 ; 167 ; 182 ; 201 ; 206$ e 209 m (poço).

Comentários/comparações: os exemplares assemelham-se muito aos descritos por Bose \& Maheswari (1968), sobretudo com o holótipo, ilustrado na sua fig. 1, estampa XVI.

\section{Limitisporites delasaucei (Potonié \& Klaus) Schaarschmidt, 1963}

\section{Est. 11, fig. 6}

Diagnose: Schaarschmidt (1963. Palaeontographica, Sttutgart, Abt B, 113: 38-91; p. 47, est. 11, fig. 14-17)

Descrição: grão de pólen bissacado, fracamente diploxilonóide, alongado longitudinalmente. Corpo central distinto, subcircular a circular, intramicroreticulado, alongado transversaimente ao eixo maior no grão. Saco intrareticulado, unido lateralmente por fina ligação exinal, recobrindo distamente $1 / 3$ do raio do corpo central, onde se desenvolve, na raiz distal, 2 pregas semilunares.

Dimensões: ver Tabela 7.

Ocorrência: $155 \mathrm{~m}, 171,3 \mathrm{~m}$ e 188,5 m (poço).

Distribuição biocronoestratigráfica: também assinalada no Subgrupo Itararé do Rio Grande do Sul (Dias, 1993a: est. 9, fig. 7).

Comentários/comparações: os exemplares aqui registrados, assemelham-se muito àqueles descritos por Schaarschmidt (1963), sobretudo pelo caráter fracamente diploxilonóide, como observado na sua fig. 3 (p. 48). 


\section{Limitisporites vesiculosus Schaarschmidt, 1963}

Est. 11, fig. 5

Diagnose: Schaarschmidt (1963. Palaeontographica, Sttutgart, Abt B, 113:38-91; p. 48-49, est. 12 , fig. 5-7)

Locus/stratum typicus: Büdinger Tunnels, Permiano (ver Schaarschmidt, 1963:48).

Descrição: grão de pólen bissacado, de contorno fortemente diploxilonóide, alongado longitudinalmente. Corpo central denso, circular a subcircular, intramicroreticulado. Raiz distal do saco associada a 2 pregas distais semilunares, transversais ao eixo maior do grão. Sacos intrareticulados, subesféricos, unidos lateralmente por fina ligação exinal, com o desenvolvimento, próximo à margem equatorial do corpo central, de algumas pregas/dobras radiais no saco.

Dimensões: ver Tabela 7.

Ocorrência: 41,$3 ; 83 ; 98 ; 103,5 ; 124 ; 152,5 ; 155 ; 167 ; 168 ; 170 ; 171,3 ; 201 ; 206$ e 209 m (poço).

Distribuição biocronoestratigráfica: Marques-Toigo (1988) assinalou sua ocorrência a partir da parte médio-superior da Formação Rio Bonito nos estados de Santa Catarina e Rio Grande do Sul, correspondente à Subzona Caheniasaccites ovatus. Entretanto, Dias (1993a: est. 9, fig. 11) registrou sua presença no Subgrupo Itararé no Rio Grande do Sul, o que confirma sua maior antiguidade na Bacia do Paraná.

Comentários/comparações: os exemplares aqui registrados são muito semelhantes àqueles descritos originalmente. O desenvolvimento bilateral dos sacos e sua forma são os seus principais caracteres diagnósticos.

\section{Limitisporites sp. 1}

Est. 11, fig. 7

Descrição: grão de pólen bissacado, ligeiramente diploxilonóide, alongado longitudinalmente. Corpo central distinto, subretangular a subhexagonal-arredondado. Sacos subesféricos, intramicroreticulados; inserção distal associada a 2 pregas transversais, que se desenvolvem até a borda equatorial do corpo central, com recobrimento na face distal em quase $1 / 2$ do raio deste. 
Dimensões: ver Tabela 7.

Ocorrência: 26,$5 ; 41 ; 182 ; 188,5 ; 195$ e 201 m (poço).

Comentários/comparações: os exemplares aqui registrados assemelham-se muito àquele descrito por Ottone (1989: est. 10, fig. 2), exceto pelas dimensões menores daquele. Difere de L. hexagonalis Bose \& Maheswari, 1968 e L. luandensis Bose \& Maheswari, 1968 pelo contorno mais haploxilonóide destes últimos.

\begin{tabular}{|c|c|c|c|}
\hline Parâmetros & L. luandensis & & L. delasaucei \\
\hline $\mathrm{EL}$ & $135-(160)$ & & $145-185$ \\
\hline LS & $55-80$ & & $56-(64)$ \\
\hline ET & $65-(80)$ & & $95-(100)$ \\
\hline LC & $55-95$ & & $80-100$ \\
\hline $\mathrm{CC}$ & $60-80$ & & $85-(95)$ \\
\hline te & 06 & & 04 \\
\hline Parâmetros & L. vesiculosus & L.sp. 1 & L. sp. 2 \\
\hline $\mathrm{EL}$ & $135-170$ & $170-225$ & $110-215$ \\
\hline LS & $65(75) 100$ & $60-84$ & $40(56) 84$ \\
\hline ET & $65(75) 100$ & $70-115$ & $60(115) 125$ \\
\hline LC & $70-75$ & $95-110$ & $95(100) 115$ \\
\hline $\mathrm{CC}$ & $55(60) 70$ & $50-105$ & $95(100) 125$ \\
\hline te & 06 & 04 & 08 \\
\hline
\end{tabular}

EL: medida do eixo longitudinal total do grão; LS: largura dos sacos; ET: comprimento do grão na sua maior expansão; LC: largura do corpo central; CC: comprimento do corpo central; (medidas em $\mu \mathrm{m}$ ); te: total de exemplares medidos.

Tabela 7 - Dimensões das espécies estudadas de Limitisporites (Leschik) Schaarschmidt, 1963

\section{Limitisporites sp. 2}

Est. 11, fig. 8

Descrição: grão de pólen bissacado, diploxilonóide, alongado longitudinalmente. Corpo central subcircular a sub-hexagonal arredondado, intramicroreticulado, com marca monolete proximal, que se extende até próximo à margem equatorial deste. Saco 
intramicroreticulado, unido lateralmente por fina ligação exinal; inserção distal no corpo central associada a 2 pregas semilunares, que recobrem a periferia do corpo central no sentido transversal, de onde se desenvolvem algumas dobras radiais no saco.

Dimensões: ver Tabela 7.

Ocorrência: $14 ; 25,5 ; 26,5 ; 98 ; 103,5 ; 137 ; 148 ; 152,5 ; 168 ; 170 ; 171,3$ e 206 m (poço) e Afloramentos $\mathrm{km} 118,6$ e $\mathrm{km} 122,7$.

Distribuição biocronoestratigráfica: os exemplares aqui descritos se assemeiham muito aos descritos por Daemon \& Quadros (1970) como Sahnites sp. (forma P451), cuja distribuição bioestratigráfica inclui os intervalos $\mathrm{G}$ a J, ocorrentes no Subgrupo Itararé e Formação Rio Bonito.

Comentários/comparações: a dimensão da marca monolete no corpo central distingue os exemplares aqui atribuidos às demais espécies do gênero. Zhu Huaicheng (1993: est. VIII, fig. 1-4) ilustra algumas espécies do gênero muito semelhantes às aqui descritas. No entanto, a falta de descrição naquele trabalho não permite melhor associação. $L$. diversus Lele \& Karim, 1971 possui dimensões muito menores, não ultrapassando $95 \mu \mathrm{m}$ de comprimento no eixo longitudinal, o mesmo ocorrendo com Limitisporites plicatus Bose \& Kar, 1966 in Bharadwaj et al. (1976: est. 5, fig. 58 e 60).

Infraturma STRIATITI Pant, 1954

\section{Gênero Protohaploxypinus (Samoilovich) Hart, 1964}

Espécie-tipo: Protohaploxypinus latissimus (Lüber \& Waltz) Samoilovich, 1953

Afinidade botânica: PTERIDOSPERMOPHYTA-GLOSSOPTERIDALES (Gould \& Delevoryas, 1977).

Conforme emenda realizada por Hart (1964:1177), são atribuídos a este gênero os grãos de pólen bissacados, de contorno haploxilonóide ou levemente diploxilonóide, com corpo central circular a ovalado, alongado transversalmente ou longitudinalmente, com estrias longitudinais em número variado; sacos intrareticulados, semi-circulares. Apesar do grande número de éspécies do gênero assinaladas na Bacia do Paraná no Brasil, ainda é necessária uma melhor avaliação sistemática visto que, como verificado, as diferenças entre as espécies propostas são muito sutis. 


\section{Protohaploxypinus latissimus (Lüber \& Waltz) Samoilovich, 1953}

Est. 12, fig. 1

Diagnose: Samoilovich (1953. Trudy Uses. Neft. Issl. Geol. Razv. Inst., Moscou, v. 75, p. 5-57)

Locus/stratum typicus: região de Solikamsk, Permiano, Western Pré-Urals, ex-URSS.

Descrição: grão de pólen bissacado, de contorno haploxyplonóide, ovalado longitudinalmente. Corpo central subovalado, não muito bem definido, com 10-11 estrias longitudinais, ocasionalmente anastomosadas. Sacos semicirculares, intrareticulado. Cappula retangular a ovalada.

Dimensões: ver Tabela 8.

Ocorrência: Afloramento km 118,6.

Distribuição biocronoestratigráfica: espécie muito comum no Permiano do hemisfério norte (e.g. Utting, 1994: est. 6, fig. 27-29), rara nas bacias gondvânicas.

Comentários/comparações: esta forma, espécie-tipo do gênero, ocorre somente no nível do afloramento do $\mathrm{km} 118,6$. Seu contorno e a presença de um ligamento transversal na porção média da face distal lembra Vittatina costabilis Wilson, 1962. No entanto, as espécies daquele gênero possuem plicas/estrias/taenias com terminações afinadas em direçäo aos sacos, diferentemente do observado aqui; além de que os sacos, naquele gênero, são bem menos desenvolvidos. As espécies do gênero Lunatisporites (Leschik) Scheuring, 1970, com aparência geral semelhante, possuem o corpo central dividido em 2 faixas individuais, cada uma com finas estrias longitudinais.

\section{Protohaploxypinus samoilovich (Jansonius) Hart, 1964}

Est. 12, fig. 2

Diagnose: Hart (1964. Congrès INTERnATIONAL de STRATIGRAPHIE ET GÉologie du CARBonifére, 5 , Paris, 1963. Compte Rendu, 4:1171-1199; p. 1181, text-fig. 19)

Locus/stratum typicus: Triássico Inferior do oeste do Canadá.

Descrição: grão de pólen bissacado, de contorno diploxilonóide. Corpo central circular, levemente alongado longitudinalmente, com 9 a 10 estrias neste sentido na face 
proximal. Sacos semicirculares, intrareticulados, menores que o corpo central, ligados distalmente, com pregas semilunares bem marcardas na raiz distal.

Dimensões: ver Tabela 8.

Ocorrência: $14 ; 26,5 ; 45 ; 77 ; 98$ e 124 m (poço).

Distribuição biocronoestratigráfica: muito semelhante à forma P486 descrita por Daemon \& Quadros (1970), com distribuição entre os intervalos $G$ e $H$, correspondentes ao Subgrupo Itararé e Formação Rio Bonito. Também registrada no sul do país por Marques-Toigo (1988: est. VII, fig. 4) e Dias (1993a: est. 10, fig. 8).

Comentários/comparações: a natureza diploxilonóide e o número reduzido de estrias separam esta espécie das demais do gênero. $P$. sewardi (Virkki) Hart, 1964, de forma semelhante, possuindo recobrimento do saco na face distal do corpo central com maior área.

Protohaploxypinus amplus (Balme \& Hennelly) Hart, 1964

Est. 12, fig. 3

Diagnose: Hart (1964. Congrès INTERnational de Stratigraphie et Gélogie du Carbonifere, 5, Paris, 1963. Compte Rendu, 4:1171-1199; p. 1179-1180, text-fig. 10)

Locus/stratum typicus: South Wallarah Borehole, New South Wales, Austrália.

Descrição: grão de pólen bissacado, diploxilonóide, de contorno alongado longitudinalmente. Corpo central circular a ovalado transversalmente, com 9 a 12 estrias longitudinais. Sacos intrareticulados, semicirculares, unidos lateralmente, com raiz distal associada a 2 pregas no corpo central, normais ao eixo de maior elongação.

Dimensões: ver Tabela 8.

Ocorrência: 103,5;137 e 167 m (poço).

Distribuição biocronoestratigráfica: outros autores já noticiaram esta espécie no Carbonifero Superior (Lima et al. 1983: est. V, fig. 7) e Permiano Inferior (MarquesToigo, 1988: est. VII, fig. 6; Dias, 1993a: est. 9, fig. 12) da Bacia do Paraná.

Comentários/comparações: difere de P. sewardi (Virkki) Hart, 1964, cujo contorno é semelhante, pelo maior número de estrias longitudinais destes exemplares. 


\section{Protohaploxypinus dvinensis (Sedova) Hart, 1964}

Est. 12, fig. 5

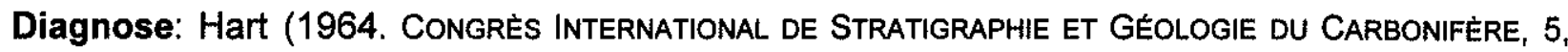
Paris, 1963. Compte Rendu, 4:1171-1199; p. 1179, text-fig. 9)

Locus/stratum typicus: norte da Bacia de Dvina, Toima, ex-URSS.

Descrição: grão de pólen bissacado, haploxilonóide, de contorno longitudinalmente ovalado. Corpo central circular, ligeiramente alongado transversalmente, com 10 a 12 estrias longitudinais. Sacos semicirculares, intrareticulados, menores que o corpo central, com raiz distal associada a 2 pregas semilunares, normais ao eixo maior, subequatorial no corpo central.

Dimensões: ver Tabela 8.

Ocorrência: $77 ; 137$ e 171,3 m (poço).

Comentários/comparações: difere de $P$. perfectus (Naumova) Samoilovich, 1953 porque naquela espécie o número de estrias longitudinais é menor e de $P$. pennatulus (Andreyeva) Hart, 1964 por aquela possuir sacos maiores que o corpo central.

\section{Protohaploxypinus chaloneri Clarke, 1965}

Est. 12, fig. 4

Diagnose: Clarke [1965. Palaeontology, Londres, 8(2):322-354; p. 337-338, est. 42, fig. 3-5, text-fig. 11).

Locus/stratum typicus: Hilton Plant Bed, Permiano Superior, Westmorland, Reino Unido.

Descrição: grão de pólen bissacado, haploxilonóide, de contorno longitudinalmente ovalado. Corpo central ligeiramente alongado no sentido longitudinal, nítido, finamente granulado, com 10 a 12 estrias longitudinais subpararelas, às vezes anastomosadas. Sacos bem desenvolvidos, intrareticulados, com pregueamento na raiz distal subequatorial no corpo central, normal ao eixo maior.

Dimensões: ver Tabela 8.

Ocorrência: 168; 170; 171,3; 201; 206 e 209 m (poço). 
Distribuição biocronoestratigráfica: também registrada no Subgrupo Itararé (Dias, 1993a: est. 9, fig. 9) e Formação Rio Bonito (Dias-Fabrício, 1981: est. 10, fig. 3) no Rio Grande do Sul.

Comentários/comparações: difere das demais espécies do gênero pelo alongamento longitudinal do corpo central e maior desenvolvimento lateral dos sacos.

\begin{tabular}{lcccccc}
\hline Parâmetros & $P$. & $P$. & $P$. & $P$. & $P$. & $P$. \\
& samoilovichi & amplus & dvinensis & chaloneri & latissimus & sp. \\
\hline EL & $115-140$ & $115-145$ & $135-185$ & $84(110) 135$ & 90 & $100-140$ \\
LS & $44-52$ & $42-60$ & $50-55$ & $25(43) 50$ & 20 & $40(50) 54$ \\
CS & $64-83$ & $80-102$ & $85-110$ & $50-80$ & 54 & $55-92$ \\
LC & $60-80$ & 60 & $84-100$ & $52(72) 76$ & 52 & $46-71$ \\
CC & $62-80$ & $80-90$ & $32-50$ & $23(34) 44$ & 64 & $26(30) 38$ \\
cappula & $20-30$ & $25-35$ & $32-50$ & $23(34) 44$ & 56 & $26(30) 38$ \\
te & 05 & 03 & 03 & 07 & 01 & 06 \\
\hline
\end{tabular}

EL: medida do eixo longitudinal total do grăo; LS: largura dos sacos; CS: comprimento dos sacos; LC: largura do corpo central; CC: comprimento do corpo central; cappula: "área-livre" entre os sacos no corpo central sensu Erdtmann (1957) e Segroves (1969); (medidas em $\mu \mathrm{m}$ ); te: total de exemplares medidos.

Tabela 8 - Dimensões das espécies estudadas de Protohaploxypinus (Samoilovich) Hart, 1964

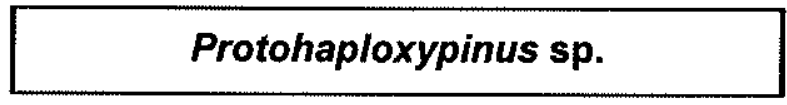

Est. 12, fig. 6

Descrição: grão de pólen bissacado, haploxilonóide, de contorno alongado longitudinalmente. Corpo central nítido, circular a subcircular, finamente ponteado, com marca monolete não ultrapassando $1 / 3$ do raio do corpo central; com 9 a 12 estrias longitudinais, às vezes anastomosadas e mais de 4 estrias transversais, dando aspecto de "malha" na face proximal do corpo central. Sacos bem desenvolvidos, semicirculares, com raiz distal associada a pregas semilunares normais ao eixo maior, bem marcadas, subequatoriais no corpo central.

Dimensões: ver Tabela 8.

Ocorrência: $41 ; 167 ; 195 ; 206$ e 209 m (poço).

Comentários/comparações: assemelha-se muito a $P$. dvinensis (Sedova) Hart, 1964 e a $P$. perfectus (Naumova) Samoilovich, 1953 pela natureza haploxilonóide e contorno, 
diferenciando-se da primeira espécie pelo maior desenvolvimento dos sacos, que naquela espécie são menores e do segundo, pelo seu maior número de estrias longitudinais. Além disso, a presença de estrias transversais, associadas às longitudinais no corpo central, a separa de todas as outras espécies atribuídas no gênero.

\section{Gênero Striatoabieites (Sedova) Hart, 1964}

Espécie-tipo: Striatoabieites bricki Sedova, 1956

Afinidade botânica: CONIFEROPHYTA (Azcuy, 1978).

As formas aqui atribuidas a este gênero se caracterizam pela elongação longitudinal do corpo central, pelas menores dimensões dos sacos em relação ao corpo central e pelo distanciamento de suas raizes distais, com área livre no corpo central usualmente maior do que metade deste.

\section{Striatoabieites sp.}

Est. 12, fig. 7

Descrição: grão de pólen bissacado, de contorno diploxilonóide. Corpo central alongado longitudinalmente, com cerca de 8 estrias longitudinais. Sacos intrareticulados, semicirculares, ligeiramente alongados transversalmente. Raizes distais laterais no corpo central, com zona distal livre, atingindo metade do raio deste.

Dimensões: ver Tabela 9.

Ocorrência: $14 ; 41,3 ; 124 ; 137 ; 152,5$ e $155 \mathrm{~m}$ (poço).

Comentários/comparações: as formas aqui atribuídas a este gênero diferem de $S$. bricki Sedova, 1956 pela forma circular do corpo central daquele e de $S$. elongatus (Lüber \& Waltz) Hart, 1964 e S. sedovai Polukhina, 1960 por aquelas possuirem raizes distais mais lateralmente no corpo central, com área livre bem mais desenvolvida. Por último, diferem de S. giganteus (Samoilovichi) Hart, 1964, de S. richteri (Klaus) Hart, 1964 e de S. duiveni (Jansonius) Hart, 1964 pelo maior número de estrias daquelas espécies. Césari (1984: est. 3, fig. 3 e 5) descreveu forma semelhante na Formação Tupé, Carbonífero Superior da Argentina, atribuida a Striatoabieites sp. 


\begin{tabular}{lc}
\hline Parâmetros & Striatoabieites sp. \\
\hline EL & $95-106$ \\
LS & $30-46$ \\
CS & $44-56$ \\
LC & $50-54$ \\
CC & $48-55$ \\
te & 06 \\
\hline
\end{tabular}

EL: medida do eixo longitudinal total do grăo; LS: largura dos sacos; CS: comprimento dos sacos; LC: largura do corpo central; $\mathrm{CC}$ : comprimento do corpo central; (medidas em $\mu \mathrm{m}$ ); te: total de exemplares medidos.

Tabela 9 - Dimensões das espécies estudadas de Striatoabieites (Sedova) Hart, 1964

\section{GRUPO ACRITARCHA EVITT, 1963}

Com relação ao Grupo Acritarcha Evitt, 1963, atualmente, a sua classificação sistemática é realizada conforme 3 escolas distintas. Alguns autores consideram os acritarcas como um grupo altamente polifilético, incluindo plantas e animais, seguindo a classificação de Downie et al. (1963) que os divide em subgrupos, cujos gêneros são referidos como "gênerosforma", não tendo status nos Códigos Internacionais de Nomenclatura Zoológica e Botânica. Outros autores acreditam que os acritarcas constituem um grupo homogêneo de algas, seguindo a proposição de Madler (1963) que incluiu o grupo na classe Hystrichophyta. Por último, alguns autores acreditam que os acritarcas constituem várias divisões e classes algáceas, reunindo-os com as Chrysophyceae, Dinophyceae, Clorophycea, Phaeophyceae e as Prasinophyceas. Neste trabalho não será adotada nenhuma dessas concepções, como também trataram Playford \& McGregor (1993), em virtude do seu não estabelecimento e aceitação geral na comunidade científica, procurando-se evitar qualquer atribuição indevida. Informações adicionais sobre a problemática envolvida podem ser obtidas no trabaho de Oliveira (1991:36-42).

A grande maioria dos táxons deste grupo aqui observados, constitui-se em organismos naviformes com extremidades sub-arredondadas, sem apêndices, com membrana longitudinalmente estriada, atribuidos ao gênero Navifusa Combaz, Lange \& Pansart, 1967, que ocorre com maior freqüência, na Bacia do Paraná, no Subgrupo Itararé nos estados do sul 
do pais. Formas semelhantes, observadas na literatura, são separadas do gênero por possuírem extremidade ponteaguda e superfície coberta por processos claviformes, atribuidas ao gênero Dactylofusa (Brito \& Santos) Combaz, Lange \& Pansart, 1967 e por possuírem apêndices em cada extremidade, neste caso atribuídas ao gênero Leiofusa (Eisenack) Combaz, Lange \& Pansart, 1967. Uma outra forma, atribuída ao gênero Gorgonisphaeridium Staplin, Jansonius \& Pocock, 1965 não tem expressão quantitativa nem distribuição estratigráfica significativa no material estudado, não tendo sido registrada no Paleozóico Superior da Bacia do Paraná até o momento.

Gênero Navifusa Combaz, Lange \& Pansart, 1967

Espécie-tipo: Navifusa navis Eisenack, 1938

Navifusa bacillum (Deunff) Playford, 1977

Est. 12 fig. 8

Diagnose: Playford (1977. Geological Survey of Canada, Ottawa, Bull. 279, 46 p., 20 est.; est. 12, fig. 1-6).

Locus/stratum typicus: Devoniano da América do Norte.

Descrição: organismo de forma elipsóide, alongado, com extremidades arredondadas, desprovido de apêndices. Superfície finamente granulada, que em vista sob pequenos aumentos, produz um efeito pseudossacado. ou elementos esculturais, com estrias longitudinais subpararelas a paralelas.

Dimensões: $65(130) 130 \mu \mathrm{m}$ de compr. $\times 32(65) 70 \mu \mathrm{m}$ de larg. (12 exemplares).

Ocorrência: 26,$5 ; 45$ e 103,5 m.

Distribuição bicronoestratigráfica: assim como Navifusa sp., esta espécie parece ter distribuição biocronoestratigráfica bem mais ampla do que a até agora reconhecida. Foi registrada também na Formação Cortaderas, Carbonifero Inferior da Argentina (Cesari \& Limarino, 1992: est. I, fig. 14), juntamente com uma associação tipicamente marinha, com quitinozoários e Duvernaysphaera cf. tessela Deunff, 1980.

Comentários/comparações: as formas registradas por Oliveira (1991: est. IX, fig. 9, 11 e 12) na Formação Ponta Grossa, atribuídas a esta espécie, têm comprimento 
proporcionalmente maior que a largura, como também verificado em algumas ilustrações da descrição original (Playford, 1977: est. 12, fig. 1 a 4). No entanto, este último autor também ilustrou formas semelhantes às aqui descritas (est. 12, fig. 5 e 6), com relação às dimensões $e$ ao aspecto pseudoestriado produzido pelos grânulos, mais ou menos distintamente alinhados.

\section{Navifusa sp.}

Est. 12, fig. 9 e 10

Descrição: organismo de forma elipsóide, alongado, como um "bastonete", com extremidade arredondada, desprovida de apêndices ou elementos esculturais, com membrana estriada longitudinalmente, cujas estrias, em número variável (geralmente maior que 14), organizam-se paralelamente.

Dimensões: 90(145)200 $\mu \mathrm{m}$ de compr. $\times 26(45) 60 \mu \mathrm{m}$ de larg. (25 exemplares).

Ocorrência: 25,$5 ; 26,5 ; 41 ; 41,3 ; 45 ; 51 ; 55 ; 148 ; 167 ; 182 ; 188,5 ; 195 ; 201,206$ e 209 m (poço) e Afloramentos dos km 118,6; 122,7; 123,7 e 125,8.

Comentários/comparações: Ottone (1989: est. 12, fig. 7) e Dias (1993a: est. 12, fig. 1 e ?3) descreveram espécies atribuídas a este gênero, sem no entanto, possuírem estrias longitudinais, como aqui observado. Dias (1993a: est. 12, fig. 2) atribuiu a Dactylofusa sp. uma espécie com características semelhantes. Ottone (1989) mencionou que a ocorrência de Navifusa na Formação Santa Máxima, Argentina, seria seu primeiro registro no Paleozóico Superior, o que confirma a raridade destas formas nos demais materiais da Bacia do Paraná. Navifusa sp. ilustrada por Daemon (1974b: est. I, fig. 6), descrita na Bacia do Amazonas (Frasniano a Fameniano) é notadamente mais alongada longitudinalmente. As espécies aqui descritas são muito semelhantes àquela ilustrada por Kemp (1975: est. I, fig. 32), assinalada na rodovia Sorocaba-Itapetininga como Cf. Deusilites sp. É possivel que Deusilites Hemer \& Nygreen, 1967 seja sinonimia deste gênero, pois possui as mesmas características diagnósticas, necessitando, por isso, estudos mais detalhados. 


\section{Gênero Gorgonisphaeridium Staplin, Jansonius \& Pocock, 1965}

Espécie-tipo: Gorgonisphaeridium winslowiae Staplin, Jansonius \& Pocock, 1965

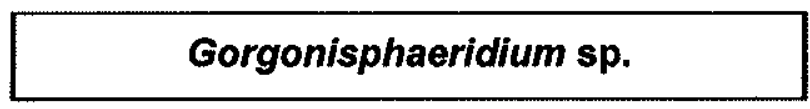

Est. 12, fig. 11

Descrição: vesícula de contorno circular a esférica, de parede fina, lisa e fina $(\sim 2 \mu \mathrm{m})$, com numerosos e sólidos processos, retos ou curvos, de base circular (1-1,5 $\mu \mathrm{m})$, de terminação distal heteromórfica, na grande maioria furcados (bifurcados a multifurcados). Estrutura de desencistamento consistindo em uma fenda simples, rasgada na parede da vesícula.

Dimensões: deq: $42 \times 48 \mu \mathrm{m}$; processos: $10-15 \mu \mathrm{m}$ de alt.

Ocorrência: 167 m (poço).

Distribuição biocronoestratigráfica: formas muito semelhantes, atribuídas a $G$. winslowiae Staplin, Jansonius \& Pocock, 1965, foram assinaladas desde o Devoniano ao Carbonifero Inferior do Canadá (Playford \& McGregor, 1993: est. 5, fig. 8-11, est. 6, fig. 5, 11-12) e do Saara algeriano (Coquel \& Latreche, 1989: est. 4, fig. 21).

Comentários/comparações: espécie considerada como retrabalhada. Difere de G. crenulatum Playford, 1977 e de G. pterispinosum Wicander, 1974 pela maior densidade e pelo caráter mais homomórfico dos processos naquelas espécies. G. ohioense (Winslow) Wicander, 1974 possui processos mais compridos e terminações mais simples. G. reticulatum Oliveira, 1991, descrita na Formação Ponta Grossa da Bacia do Paraná, possui parede reticulada. G. disparatum Playford, 1977 e G. granatum Playford, 1977 possuem processos com terminações de formas distintas. Na figura 5 de Playford \& McGregor (1993:15) estão ilustrados os tipos de terminações dos processos em G. winslowiae Staplin, Jansonius \& Pocock, 1965, notadamente bifurcada a multifurcada, como aqui observado. Somente um exemplar foi verificado, o que impede uma atribuição mais precisa nesta última espécie, tipo do gênero. 


\section{ANÁLISE PALINOESTRATIGRÁFICA}

\section{VIII.1 Considerações gerais}

De modo geral, os zoneamentos palinoestratigráficos propostos para o Paleozóico Superior são baseados nas mudanças ocorridas na sucessão dos táxons do grupo dos grãos de pólen sacados. De acordo com vários autores, como também menciona Marques-Toigo (1988:51), estas mudanças são lentas e comuns a quase todas as áreas gondvânicas, estando sujeitas, no entanto, às variações no comportamento geral, em função de controles paleoclimáticos, paleoecológicos ou paleoambientais mais locais.

Se por um lado, os esquemas palinoestratigráficos das bacias gondvânicas são relativamente escassos e carentes de marcadores cronoestratigráficos mais seguros, por outro, os esquemas estabelecidos na Europa, América do Norte e Ásia apresentam algumas divergências de grande significado.

De acordo com o esquema europeu elaborado por Clayton et al. (1977), espécies do gênero Potonieisporites e outros grãos de pólen monossacados de simetria radial têm seu registro a partir do Westphaliano $C$, quando também surgem os primeiros bissacados estriados, enquanto que os bissacados não estriados já ocorrem desde o Westphaliano A. No entanto, Kmiecik (1986) e Zhou (1994) indicaram o aparecimento de Potonieisporites no Westphaliano A da Polônia e no Namuriano da China, respectivamente.

Nesse aspecto corrobora-se a observação de Kemp et al. (1977), também destacada por Césari (1986) e Sundaram (1987), segundo a qual as zonas palinológicas devem ser usadas com grande precaução nas correlações, uma vez que fatores locais podem influir na composição quantitativa e qualitativa das microfloras, podendo controlar a presença ou a ausência de formas-guias. 
Barreiras de ordem paleoclimática são tidas como responsáveis pela presença, na Bacia de Amazonas e não em sedimentos de mesma idade de outras bacias brasileiras, de grãos de pólen bissacados estriados em sedimentos de idade namuriana, noticiados por Picarelli et al. (1993) e Marques-Toigo et al. (1995). Da mesma forma, Neves \& McLean (1995) identificaram grãos de pólen estriados dos gêneros Complexysporites, Lunatisporites, Protohaploxypinus e Striatoabieites, em associação com espécies do gênero Potonieisporites no Westphaliano D da Inglaterra e da Escócia.

Se estes estratos se encontram "bem amarrados" cronoestratigraficamente, tornase clara a necessidade de extrema cautela no uso das palinozonas e até sobre a validade de algumas formas-índice, como os grãos de pólen estriados são para o Carbonifero Superior e Permiano em âmbito mundial.

Por estas razões, na metodologia de análise e determinação bioestratigráfica utilizada neste trabalho, procurou-se observar alguns aspectos julgados importantes neste intervalo de tempo do Carbonifero:

- quanto ao comportamento ou sucessão dos táxons, com relação à presença/ausência de formas palinológicas marcantes nos principais zoneamentos da Bacia do Paraná, foi considerada a inexistência da caracterização de intervalos mais antigos que aqueles do intervalo G de Daemon \& Quadros (1970), em âmbito geral na bacia;

- alguns esporos mecereram especial atenção, tendo em vista seu registro inédito na Bacia do Paraná e representarem, em outras bacias, formas de significativo valor bioestratigráfico no Carbonifero;

- o padrão de representação de algumas formas, em termos de freqüência, foi devidamente observado por, a despeito de se tratar de variações paleoecológicas e paleoambientais locais, estar ligado a caracteres morfológicos vinculados à evolução dos palinomorfos neste intervalo de tempo, como verificaram Venkatachala et al. (1995). 


\section{VIII.2 Análise bioestratigráfica do poço Geomater}

Os zoneamentos bioestratigráficos mais importantes e abrangentes da Bacia do Paraná (Daemon \& Quadros, 1970; Daemon \& Marques-Toigo, 1991) foram realizados com base na distribuição de grãos de pólen e constituem em intervalos de associação cujos limites são marcados pelo aparecimento e desaparecimento de diversos táxons deste grupo.

Os intervalos estratigráficos envolvidos por estes zoneamentos não se caracterizam pela presença de esporos com valor bioestratigráfico significativo, como aqueles que são utilizados em zoneamentos de seqüências mais antigas do Carbonifero de outras bacias (e.g. Azcuy \& Jelin, 1980; Kemp et al., 1977).

Somente recentemente é que alguns autores utilizaram assembléias de esporos na correlação de niveis do Subgrupo Itararé com outros niveis eogondvânicos mais antigos, como a ocorrência marinha de Araçoiaba da Serra (Lima et al., 1983) e o carvão de Buri (Souza et al., 1990, 1993a). Estas assembléias, se correlacionadas apenas com base no conteúdo de grãos de pólen, grosso modo, seriam enquadradas no intervalo G de Daemon \& Quadros (1970). No entanto, várias são as formas que the indicam maior antiguidade, como exposto adiante.

Muitos esporos e grãos de pólen estão presentes, em percentagens variáveis, em todo o poço ou na sua grande parte, como é o caso de Punctatisporites gretensis, Calamospora hartungiana, Calamospora sp., Retusotriletes simplex, R. golatensis, Verrucosisporites cf. V. morulatus, Granulatisporites varigranifer, Vallatisporites vallatus, V. banffensis, Cristatisporites inconstans, C. inconstans, Lycospora sp. 1, Florinites occultus e de uma forma mais geral, as espécies dos gêneros Cannanoropollis, Plicatipollenites, Caheniasaccites, Potonieisporites e Limitisporites.

Dentre estas espécies, as únicas consideradas significativas, em termos bioestratigráficos, são Granulatisporites varigranifer e Florinities occultus, uma vez que as outras são assinaladas em sedimentos de idades carboniferas e permianas.

Contudo, é necessário destacar a sua presença, bem como de outras formas com grande valor bioestratigráfico, mesmo que não tão abundantes e longevas: 
- Granulatisporites varigranifer Menéndez \& Azcuy, 1969: descrita na Formação Lagares (Namuriano), também assinalada na Formação Malazan (NamurianoWestphaliano), Bacia de Paganzo, Argentina (Azcuy, 1975a), constitui importante elemento da Palinozona de Ancistrospora (Azcuy \& Jelin, 1980);

-Raistrickia rotunda Azcuy, 1975: descrita na Formação Malazan, Bacia de Paganzo, Argentina, também importante na Palinozona de Ancistrospora;

-Ahrensisporites cristatus Playford \& Powis, 1979: espécie inédita na Bacia do Paraná, descrita no Namuriano/Westphaliano da Bacia de Canning, Austrália, também registrada nas formações Agua Colorada e Santa Máxima, Argentina;

- Stenozonotriletes perforatus Playford, 1962: espécie inédita na Bacia do Paraná, descrita no Carbonifero Inferior de Spitsbergen, possui distribuição representativa no poço Geomater. Vale ressaltar que Stenozonotriletes clarus Ischenko, 1956, também comum no Carbonífero Inferior, foi registrada no carvão de Buri (Souza et al., 1993a), onde as possibilidades de retrabalhamento são mais remotas;

- Vallatisporites ciliaris (Lüber) Sullivan, 1964: apesar dos problemas envolvendo sua classificação sistemática, como apontaram Playford \& McGregor (1993), esta espécie constitui importante elemento da Palinozona de Ancistrospora, tendo sido assinalada, na Bacia do Paraná, em Araçoiaba da Serra e em Buri (SP).

-Ancistrospora verrucosa Menéndez \& Azcuy, 1972: espécie de expressivo valor bioestratigráfico, inédita na Bacia do Paraná, com distribuição até o limite superior da Palinozona de Ancistrospora na Bacia de Paganzo;

-Ancistrospora inordinata Menéndez \& Azcuy, 1972: espécie menos comum, porém importante na Palinozona de Ancistrospora;

-Dictyotriletes muricatus (Kosanke) Smith \& Butterworth, 1967: espécie descrita entre o Westphaliano A-C de Illimois, EUA.

-Florinites guttatus Felix \& Burbridge, 1967: espécie inédita na Bacia do Paraná, descrita em sedimentos do Tournaisiano-Westphaliano B de Oklahoma, EUA.

-Florinites occultus Habib, 1966: espécie inédita na Bacia do Paraná, descrita no Westphaliano D da Pensilvânia, EUA. 
-Florinites sp. ( $F$. antiquus): espécie comum no Carbonífero Superior da Bacia do Amazonas (Daemon, R.F. \& Marques-Toigo, M. 1995 -comunicação pessoal).

\section{VIII.2.1 Caracterização de intervalos}

$\mathrm{Na}$ análise preliminar da seqüência do poço Geomater é possível observar a ocorrência de 3 intervalos ou associações palinológicas distintas, com limites nas profundidades de 152,5 e $171,3 \mathrm{~m}$. A distribuição vertical de alguns táxons desta seqüência está expressa na tabela 10.

O intervalo inferior, delimitado entre 171,3 e $209 \mathrm{~m}$ de profundidade, é caracterizado pela presença restrita de Florinites guttatus, Dictyotriletes $\mathrm{sp}$. e Convolutispora sp. As espécies mais comuns são Apiculiretusispora, Cristatisporites rolerii, Ancistrospora inordinata e Caheniasaccites $\mathrm{sp}$. 1, além da grande freqüência de grãos de pólen dos gêneros Plicatipollenites e Potonieisporites.

O intervalo intermediário, delimitado entre 152,5 e 171,3 m de profundidade, é caracterizado, na base, pelo aparecimento de Verrucosisporites cf. $V$. morulatus e Protohaploxypinus dvinensis, além de Raistrickia rotunda e das espécies do gênero Striomonosaccites, que ocorrem a partir de $170 \mathrm{~m}$. Seu limite superior é marcado pelo desaparecimento de Vallatisporites ciliaris, Potonieisporites magnus, Potonieisporites sp. 2, Apiculiretusispora sp., Potonieisporites cf. P. triangulatus e Raistrickia sp.

São característiços deste intervalo as espécies Potonieisporites neglectus, Spelaeotriletes triangulus e a quase maioria dos táxons considerados como retrabalhados, como Punctatisporites solidus, Retusotriletes sp. 2, Stenozonotriletes sp., Spinozonotriletes conspicuus, Emphanisporites rotatus e Grandispora brevispinosa. Esta grande concentração de formas retrabalhada reflete mudanças significativas nos processos geológicos geradores da seqüência, denotada também pela ocorrência de um diastema em sua base.

O intervalo superior, com maior expressão na vertical, é delimitado entre os níveis de 4,6 e $152,5 \mathrm{~m}$, sendo caracterizado pelo aparecimento de Verrucosisporites verrucosus, Vallatisporites punctatus, Cyclogranisporites parvigranulosus, 
Densosporites triangularis, Murospora sp., Esporo Indeterminado 1, Protohaploxypinus samoilovich e Retusotriletes sp. 1, além da maior freqüência de Striatoabieites e das espécies do gênero Striomonosaccites, já presentes no topo do intervalo intermediário.

Como verificado na tabela 10 , muito desses táxons comuns no intervalo superior são encontrados em sedimentos de associações mais antigas em outras bacias, como Raistrickia rotunda, Ahrensisporites cristatus e Stenozonotriletes perforatus.

Pelas razões paleoambientais relacionadas ao favorecimento do estabelecimento das plantas-mães de muitos desses táxons, principalmente de esporos, os limites estabelecidos aqui não são entendidos como bio-horizontes. A não disponibilidade de correlação desta seqüência com outros poços impede qualquer afirmativa mais conclusiva sobre esses limites.

Os intervalos verificados são caracterizados pela concorrência de alguns táxons e associação daqueles mais característicos. No entanto, a impossibilidade de melhores correlações não permite seu estabelecimento formal, de acordo com o Código Estratigráfico, podendo ser melhor estudado nesse aspecto em trabalhos futuros. 


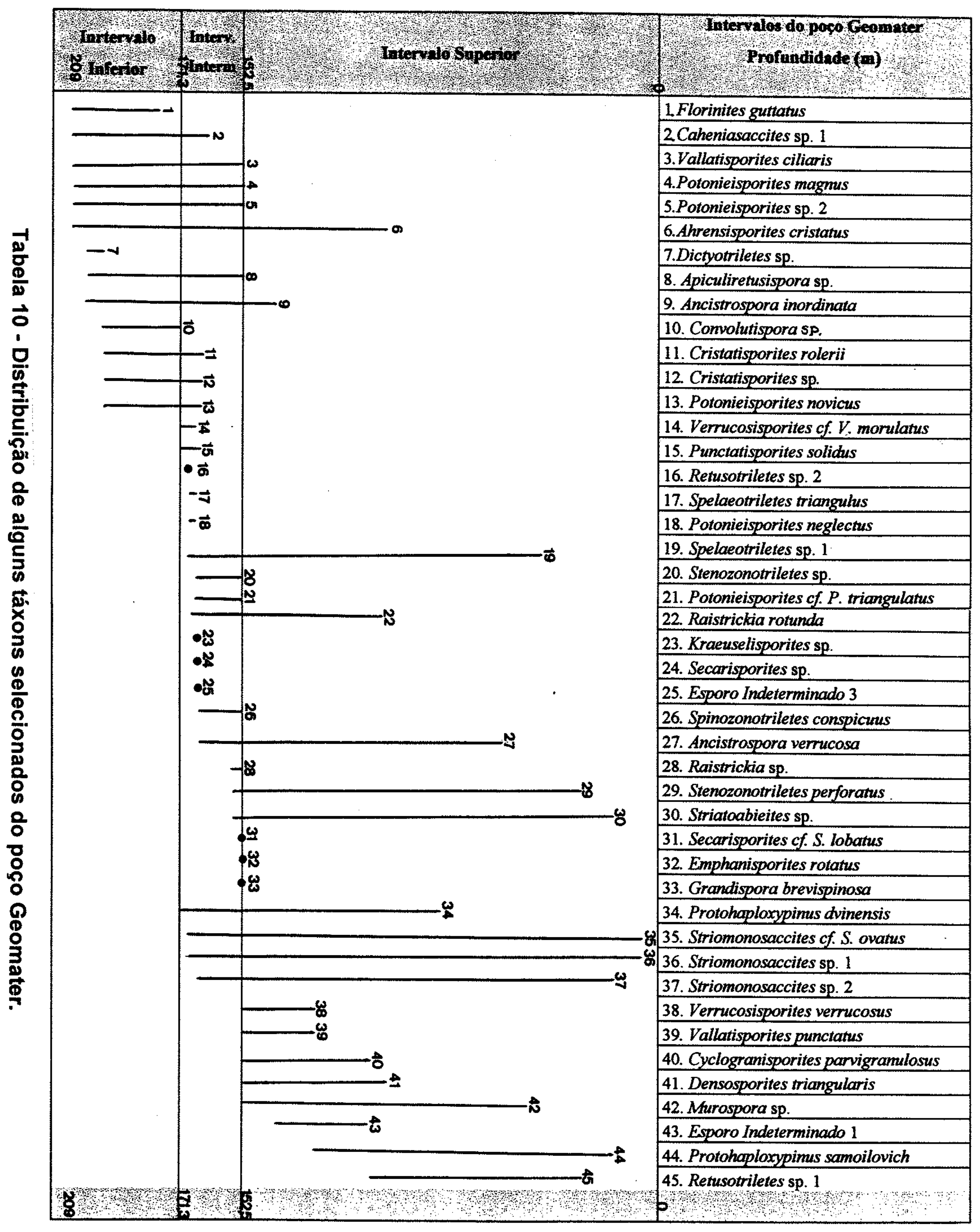




\section{VIII.2.2 Comparações com esquemas da Bacia do Paraná no Brasil}

Alguns dos táxons referentes aos grãos de pólen aqui verificados foram utilizados por Daemon \& Quadros (1970) e Marques-Toigo (1988) na caracterização dos intervalos bioestratigráficos mais antigos do Paleozóico Superior da Bacia do Paraná.

Com relação ao trabalho dos primeiros autores, pode-se destacar a ocorrência de Cannanoropollis perfectus (forma P501) e Plicatipollenites cf. P. malabarensis (forma P490) por serem restritas ao intervalo $G$, assinaladas apenas no Subgrupo Itararé. Outras formas ocorreriam também na Formação Rio Bonito, abrangendo os intervalos G-H: Protohaploxypinus samoilovich (forma P486); intervalo G-I $\mathrm{I}_{1}$ : Caheniasaccites sp.

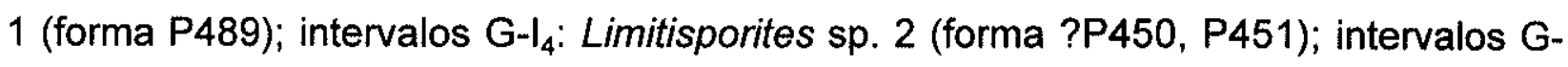
?l-?J (sic): Cannanoropollis densus (forma P489). Formas com distribuição mais longeva também estão presentes, abrangendo os intervalos G-K: Plicatipollenites malabarensis (forma P450) e o intervalo G-L: Caheniasaccites ovatus (forma P479).

Deste modo, seria possivel correlacionar a seqüência aqui estudada com 0 intervalo $G$, já que contém formas restritas a este intervalo e as restantes já se distribuem a partir deste. No entanto, o conjunto de táxons aqui verificado, notadamente com relação aos esporos, não permite tal correlação. Além de que, os intervalos caracterizados por Daemon \& Quadros (1970) não incluem esporos, o que torna as comparações mais difíceis de serem estabelecidas.

Com relação ao zoneamento apresentado por Marques-Toigo (1988), é menos numerosa a quantidade de táxons comuns. Os mais significativos, com distribuição vertical menos longeva, são aqueles restritos à Zona Cananoropollis korbaensis, correspondendo ao Subgrupo Itararé e Formação Rio Bonito naquela parte da bacia. As espécies Plicatipollenites gondwanensis, Caheniasaccites ovatus e Protohaploxypinus samoilovich teriam distribuição restrita nesta zona, nas subzonas Protohaploxypinus goraiensis e Caheniasaccites ovatus, enquanto que Potonieisporites simplex alcançaria porções mais jovens, correspondendo a Subzona Hamiapollenites karroensis. Assim, seria possível a correlação com a Zona Cannanoropollis korbaensis, com divergência apenas com relação à distribuição de Limitisporites vesiculosus, que 
ocorreria, segundo aquela autora, a partir do topo da Formação Rio Bonito até a Formação Irati, Subzona Caheniasaccites ovatus à Zona Lueckisporites virkkiae.

Entrentanto, Dias (1993a) verificou o registro desta espécie também no Subgrupo Itararé no Rio Grande do Sul, o que corrobora a ampliação do limite inferior em sua distribuição, pelo menos para a Bacia do Paraná.

Como já ressaltado nos trabalhos de Daemon \& Quadros (1970) e Daemon (1981), a sedimentação do Grupo Tubarão nas partes mais meridionais da bacia só ocorreu a partir do intervalo $\mathrm{H}$. Seus registros mais antigos estariam assinalados na parte setentrional, equivalendo ao intervalo $G$, quando a parte meridional da bacia estava soerguida. É de se esperar, portanto, que as espécies aqui correlacionadas com as do trabalho de Marques-Toigo (1988) teriam maior longevidade, com aparecimento em idades mais antigas, onde estes sedimentos tenham ocorrido, o que não é o caso da área estudada por esta última autora.

Mais recentemente, Milani et al. (1994) publicaram uma coluna estratigráfica da Bacia do Paraná, correlacionando as unidades lito e bioestratigráficas e utilizando a proposta informal da zona Florinites cf. antiquus, correspondente à base do Subgrupo Itararé, Formação Lagoa Azul (sensu França \& Potter, 1988), correspondente ao Westphaliano. Esta zona é correlacionável, em termos de idade, aos níveis do carvão de Buri e ao afloramento de Araçoiaba da Serra.

São ausentes informações sobre a caracterização palinológica dessa zona, bem como de sua correlação com outros dados já existentes na literatura, tanto da Bacia do Paraná, como de outras bacias gondvânicas, não podendo então ser utilizada como padrão de correlação.

Lima et al. (1983) já haviam notado a necessidade da ampliação do limite inferior do zoneamento bioestratigráfico da Bacia do Paraná, sugerindo informalmente, o intervalo "Pré-G". Mais tarde, Souza et al. $(1990,1993 a)$ indicaram idade westphaliana ao nivel de carvão de Buri, tendo por base um conjunto microflorístico atípico da Bacia do Paraná, composto, entre outras formas, por Foveosporites hortonensis, Anapiculatisporites argentinensis, Ancistrospora verrucosa, Raistrickia rotunda, $R$. paganciana e Stenozonotriletes clarus, confirmando então a existência de depósitos mais antigos que o intervalo $G$. 
É provável que a proposição da zona informal Florinites cf. antiquus esteja relacionada com 0 registro de alguns palinomorfos considerados típicos do Westphaliano por Daemon \& França (1993), que assinalaram a presença de Florinites cf. F. antiquus, F. cf. F. eremus, F. sp., Spelaeotriletes balteatus e Columnispora heyleri em poços da PETROBRÁS S.A. nos estados de São Paulo e Paraná. Este conjunto estaria associado a forma retrabalhadas comuns do Devoniano e Carbonífero Inferior: Retispora lepidophita, Knoxisporites sp., Duvernaysphaera tessela e Veryachium sp.

Embora amplie o arcabouço bioestratigráfico da Bacia do Paraná, sobretudo por também confirmar a maior antiguidade da parte basal do Subgrupo Itararé, como já suspeitava Sundaram (1980) e demonstraram Lima et al. (1983), Souza et al. (1990, 1993a) e Daemon \& França (1993), ainda há ausência de uma caracterização palinológica sistemática adequada e formal destes intervalos ou zonas.

A correlação bioestratigráfica da seqüência estudada com outros zoneamentos efetuados na Bacia do Paraná é mais difícil, por diversas razões, principalmente porque nas outras áreas da bacia os estratos não são tão antigos mais antigos.

Com relação ao proposto por Daemon (1966) a comparação das formas é impossivel, uma vez que este autor não as ilustrou e, como também verificado no trabalho de Daemon \& Quadros (1970), os aspectos sistemáticos devam ser melhor avaliados, embora do ponto de vista de idade não haja nenhuma modificação substancial a ser feita (Marques-Toigo, M. 1995 - com. pessoal).

Comparando as formas aqui estudadas com os conjuntos microflorísticos propostos por Saad (1977), em especial com a distribuição dos palinomorfos reconhecidos (sua fig. 9), alguns aspectos devem ser destacados. Este autor classifcou os táxons em nível apenas genérico, o que dificulta correlação mais detalhada. É importante notar a distribuição dos grãos de pólen, os monossacados de simetria radial e bilateral dominam as microfloras mais antigas. Já os grãos de pólen bissacados estriados têm expressão quantitativa somente a partir da Microflora II, embora o gênero Striomonosaccites tenha sido verificado já na Microflora I. Este padrão encontra-se de acordo com o observado aqui, embora nenhuma correlação clara possa ser efetuada. 
Considerando que os níveis de superfície da Rodovia Raposo Tavares no trecho entre os quilômetros 120 e 129 foram englobados nas microfloras I e II, correspondentes aos conjuntos litoestratigráficos $\mathrm{B}$ e $\mathrm{C}$ e que estes estão acima do poço Geomater, é de se esperar que a correlação mais segura dos sedimentos do poço fosse com a Microflora I, conjunto litoestratigráfico A.

As assembléias provenientes de Buri e Cesário Lange caracterizariam, conforme Sundaram (1980), sua Palinozona A, mais antiga da Bacia do Paraná. A conseguinte, Palinozona $B$, ocorrente na Formação Rio Bonito. Apesar do nivel sistemático precário utilizado, é possível destacar que aquele autor já ressaltava a não correspondência das assembléias microflorísticas da Bacia do Paraná, mais notadamente do Subgrupo Itararé, com aquelas da Índia e África, reconhecendo alguma similaridade com as bacias vizinhas, Chacoparanaense e Paganzo, na Argentina.

Da mesma forma que em Saad (1977), as correlações com o esquema de Sundaram (1987) não são muito claras, embora este último autor tenha verificado um grande número de formas. Face as divergências verificadas, é possível concluir, com relação ao trabalho de Sundaram (1987), que as correlações efetuadas não foram bem estabelecidas e a ausência de grãos de pólen nas palinozonas $A$ e $B$ não deve refletir significativo valor bioestratigráfico, tendo em vista que Saad (1977) já havia registrado grãos de pólen monossacados e estriados nos conjuntos basais da unidade, onde também trabalhou Sundaram (1987).

\section{VIII.2.3 Comparações com esquemas de outras regiões gondvânicas}

\section{Argentina}

Vários autores já propuseram a correlação de alguns níveis do Carbonífero Superior da Bacia do Paraná com aqueles das bacias vizinhas da Argentina, com base na similaridade das associações microflorísticas (Lima et al., 1983; Souza et al., 1990, 1993a) ou pelo aspecto quantitativo (Sundaram, 1980). Conforme Marques-Toigo (1988:64), "é importante salientar que existe uma similitude extraordinária entre as espécies que compöem as associações microfloristicas das seqüências estratigráficas 
estudadas nas Bacias do Paraná e Paganzo.", com relação somente à seqüência a partir da Palinozona III de Azcuy \& Jelin (1980), equivalente aos intervalos $\mathrm{H}_{2}$ e $\mathrm{H}_{3}$ de Daemon \& Quadros (1970).

Dentre as várias ocorrências de estratos carboniferos argentinos, destacam-se aqueles que compõem as bacias de Paganzo e Chacoparanaense, cujos arcabouços bioestratigráficos encontram-se melhor estabelecidos que o da Bacia do Paraná.

Com relação à Bacia de Paganzo, Azcuy \& Jelin (1980), a partir do trabalho de Azcuy (1975c, 1979), estabeleceram 3 palinozonas do tipo "zonas-de-assembléia", da mais antiga para a mais nova: Palinozona de Ancistrospora, dividida em Associação de Ancistrospora verrucosa e Associação de Florinites; Palinozona de Potonieisporites e Palinozona III, com estratotipos nas formações Lagares, Jejenes e Bajo de Veliz, respectivamente. Apenas a partir da parte superior da Palinozona de Potonieisporites é que haveria correlação, conforme aqueles autores, com a Bacia do Paraná, intervalos G-H e a Palinozona III com os intervalos $\mathrm{H}_{2}-\mathrm{H}_{3}$.

A Associação de Ancistrospora verrucosa, cujo elemento mais característico é aquele que the dá o nome, estaria posicionada no Namuriano "tardio", enquanto que a Associação de Florinites verrucosus, entre o Namuriano "tardio" e o Westphaliano "temprano". Já no Stephaniano estaria posicionada a Palinozona de Potonieisporites, marcada pelo desaparecimento de Ancistrospora verrucosa. A Palinozona II, de idade autuno-sakmariana, estaria marcada pelo aparecimento de Vittatina latericostata.

Césari (1986) propôs a reunião das palinozonas de Ancistropora e Potonieisporites, correlacionando-as com a Palinozona de PotonieisporitesLundabladispora estabelecida na Bacia Chacoparanaense. Esta autora se baseou na observação de Azcuy \& Gutierrez (1985) de que a Palinozona de Potonieisporites corresponderia a uma "ecofacies" da Palinozona de Ancistropora e ainda na relocação do gênero Ancistrospora a Cristatisporites por Playford (1978), cuja manutenção, como originalmente proposto, geraria problemas nomenclaturais, já que na Bacia Chacoparanaense fôra estabelecida a Zona de Cristatisporites.

No entanto, Azcuy (1986) não aceitou a proposição de Césari (1985) argumentando que a palizonona de Ancistrospora não teria representante na Bacia Chacoparanaense, reunindo, as 3 palinozonas propostas (Azcuy \& Jelin, 1980), na 
Superzona Plicatipollenites, com posicionamento temporal ligeiramente modificado, relativas, da base para o topo, ao Carbonífero Superior "temprano", Carbonífero Superior "cuspidal" (mais superior/novo) e Permiano Inferior.

Com relação à Bacia Chacoparanaense, Russo et al. (1980) estabeleceram, a partir de testemunhagem contínua atravessando as formações Ordoñez e Victoriano Rodríguez, 3 palinozonas, da mais antiga para a mais nova, Zona PotonieisporitesLundbladispora (Carbonífero Superior), Zona Cristatisporites (Permiano) e Zona Striatites (Permiano), posteriormente subdividida por Césari (1986). Recentemente, Vergel (1993), com base em um conjunto de dados mais significativo de várias unidades daquela bacia, caracterizou melhor estas 3 palinozonas, além de dividir a Zona Cristatisporites em três subzonas, Inferior, Média e Superior, destacando que a Palinozona de Potonieisporities-Lundbladispora teria limite inferior coincidente com parte da Zona de Ancistrospora e Potonieisporites.

Alguns dos elementos que compõem a Palinozona de Ancistrospora, como Granulatisporites varigranifer, Ancistrospora inordinata, A. verrucosa e Vallatisporites ciliaris estão presentes na seqüência aqui estudada. Entretanto, Plicatipollenites malabarensis e Potonieisporites magnus, que marcam o limite inferior da Palinozona de Potonieisporites também estão presentes. Vale ressaltar que esta última palinozona é também marcada pelo desaparecimento de Ancistrospora verrucosa. É possivel, por esses motivos, efetuar a correlação da seqüência estudada com ambas palinozonas, sendo clara a sua maior antiguidade com relação à Palinozona 3 e maior coincidência de táxons com a Palinozona de Ancistrospora.

Ainda com relação à Bacia Chacoparanaense, a correlação mais provável seria com a base da Palizonona Potonieisporites-Lundbladispora, caracterizada, entre outros elementos, por Ancistropora verrucosa, Vallatisporites ciliaris, Potonieisporites neglectus, Plicatipollenites malabarensis e Cannanoropollis dendus, já que em seu topo Vittatina latericostata estaria presente (Vergel, 1993). 
África

São poucos os zoneamentos efetuados nas bacia gondvânicas africanas que têm correlação com aqueles da Bacia do Paraná e com outras bacias vizinhas da Argentina, por apresentarem significativas divergências ou, mais particularmente, por não possuírem zonas tão antigas como as aqui verificadas.

Quanto ao esquema de Bose (1971), realizado na Série Lukuga, Zaire, se se levar em consideração somente a genese dos depósitos que comportam as zonas, teria correspondência, na Bacia do Paraná, em sua parte inferior, o intervalo "Assisses glaciairs et périglaciaires", posicionado no Carbonifero Superior/Permiano Inferior. No entanto, suas características palinológicas não são verificadas nos estratos da Bacia do Paraná, nesse intervalo de tempo, seja com relação aos percentuais quantitativos, quando os triletes começam a decrescer em freqüência, padrão também confirmado por Cahen \& Lepersone (1978), seja pela pouca similaridade dos conjuntos palinológicos.

Jardiné (1974) apresentou a distribuição bioestratigráfica dos esporomorfos das unidades pré-cretáceas da Bacia Oriental do Gabão, estabelecendo até 5 palinozonas, da qual a mais antiga seria referente ao Pemiano Inferior, Sakmariano.

Se por um lado há convergência de alguns dados, como a distribuição de Lueckisporites virkkiae a partir de partes mais altas do Permiano Inferior, há divergências que impedem uma correlação adequada. A espécie Punctatisporites gretensis, comum em todo os niveis correspondentes aos intervalos G-J, ainda que sem valor bioestratigráfico expressivo, só foi verificada juntamente com o aparecimento de Lueckisporites virkkiae. Ou ainda, a distribuição de Potonieisporites novicus, assinalada a partir do topo do Sakmariano, enquanto que na Bacia do Paraná é registrado em niveis correspondentes ao intervalo $\mathrm{G}$.

Anderson (1977) revisou os dados palinológicos do Permiano do norte da Bacia do Karroo, analisando, juntamente a estes, os dados disponíveis das biozonas com base em macroflora, vertebrados e invertebrados marinhos e não marinhos, abrangendo as séries Dwyca, Ecca e Beaufort. Como já ressaltado por Marques-Toigo (1988:70), as microfloras propostas, divididas em 7 zonas, são de difícil comparação devido aos critérios taxonômicos utilizados, com formas que apresentam semelhanças 
com algumas ocorrentes nas associações brasileiras mas não encontram correspondência sistemática ou com a sinonímia clara.

Divergências também foram verificadas com relação ao trabalho de Falcon (1975), realizado na Bacia do Karroo no Zinbabwe (ex-Rodésia). Nesse trabalho, o aparecimento de Caheniasaccites ovatus e Protohaploxypinus é posicionado no Permiano Médio, na unidade "Upper Wankie Sandstone", aproximadamente, $300 \mathrm{~m}$ acima da Série Dwyca, permocarbonifera, de origem glacial.

O esquema de Hart (1971), no qual estão sintetizadas as principais características palinológicas dos esquemas propostos anteriormente na África, não se ajusta, de forma detalhada, com aqueles das bacias gonvânicas sul-americanas, pelos menos para aquelas com unidades mais antigas.

Índia

A maior parte das assembléias palinológicas do Paleozóico Supeior descritas na Índia são referentes a níveis de carvão, que comportam, geralmente macrofloras diversificadas. Estas associações são relativas aos estágios Talchir, Karharbari, Barakar, Barren Measures e Raniganj (Srivastava, 1973). Marques-Toigo (1988) efetuou correlação preliminar entre a Subzona Protohaploxypinus goraiensis e o Estágio Karharbari Superior, pela similaridade de alguns táxons, ressalvando, contudo, algumas dificuldades no que se refere à nomenclatura palinológica e as diferenças nas composições florísticas locais das diferentes regiōes.

É possivel, no entanto, tentar a correlação prelimilar com base em táxons comuns da seqüência aqui analisada e aqueles estágios indianos. Dentre aqueles, o Estágio Talchir, com idade apontada já no Carbonifero Superior (Truswell, 1980), é o que apresenta maior similaridade de táxons: Caheniasaccites densus, Cannanoropollis mehtae, C. densus, Plicatipollenites densus, P. trigonalis e Potonieisporites magnus.

Entretanto, todos esses táxons estão presentes já desde a base do Carbonifero Superior, não sendo possível correlação mais segura. 


\section{Austrália}

A Austrália é uma das regiões cujas informações palinológicas gondvânicas são bastante numerosas. Conforme Balme (1980), grande espessura de sedimentos ocorre naquelas bacias, sendo as mais completas, as bacias de Canning, Bonapart Gulf e Sydney, onde aqueles de origem glacial e periglacial estão depositados sobre unidades de idade namuriana.

Os esquemas palinoestratigráficos alí existentes foram estabelecidos separadamente, para o oeste (Balme, 1964; Segroves, 1970) e para o leste (Evans, 1969), tendo Kemp et al. (1977) realizado uma extensa revisão, reunindo todas as informações disponíveis.

Estes autores dividiram a seqüência palinoestratigráfica em "Pré glacial Carboniferous palynofloral sequence" e "Latest Carboniferous and Permian palynofloral sequence", assinalando a ocorrência das assembléias que as constituem, suas características palinológicas e idades.

Em sua figura 12, os autores sumarizam as informações discutidas, correlacionando o esquema palinoestratigráfico proposto para o oeste australiano com aquele de Evans (1969), este último complementado, em sua base, com a inclusão de assembléias mais antigas.

As correlações daqueles esquemas com o conjunto microfloristico aqui verificado não são muito claras, embora alguns táxons sejam comuns. São mais seguras as correlações com as unidades da "Latest Carboniferous and Permian palynofloral sequence", tendo em vista que a anterior é ocorrente em sedimentos pré-glaciais, embora muitos elementos persistam em ambas, refletindo grandes adaptações climáticas e ambientais. Este é o caso de Ahrensisporites cristatus, espécie descrita na Bacia de Canning, em estratos da Assembléia de Spelaeotriletes yberti.

A correlação mais provável é com as unidades I e ll do oeste (Kemp et al., 1977) e/ou com o Stage 1-2 do leste autraliano (Evans, 1969). O Stage 1 caracteriza-se pela alta diversificação de grãos de pólen monossacados, associados a conjuntos de esporos triletes dos gêneros Retusotriletes, Punctatisporites, Verrucosisporites, Vallatisporites e Dictyotriletes, ocorrente em depósitos de origem glacial. Localmente é 
sucedido por niveis contendo formas mais primitivas de grãos de pólen bissacados estriados ou não, grande variedade de grãos de pólen monossacados e um significativo número de grãos de pólen monocolpados, sendo por isso mais estreitamente relacionado com o conjunto aqui descrito.

Por outro lado, com relação às unidades propostas por Kemp et al. (1977), a mais antiga, Unidade I, se caracteriza pela alta freqüência de grãos de pólen radialmente simétricos, com presença ocasional do gênero Potonieisporites e de outros grãos de pólen bissacados, não estriados. Estes últimos têm freqüência rara na Unidade II, enquanto que na Unidade III estão presente em grandes proporções.

Apesar das dificuldades de correlação, Marques-Toigo (1988) também efetuou comparações entre as zonas estabelecidas e aquelas da Austrália, sendo encontrado similaridade entre a Subzona Protohaploxypinus goraiensis, mais antiga, com a parte superior do Stage 2 de Evans (1969) e com a Unidade III de Kemp et al. (1977).

A Tabela 11 representa a correlação do material estudado com relação aos principais zoneamentos da Bacia do Paraná e os mais importantes e mais completos do Eogondvana. 


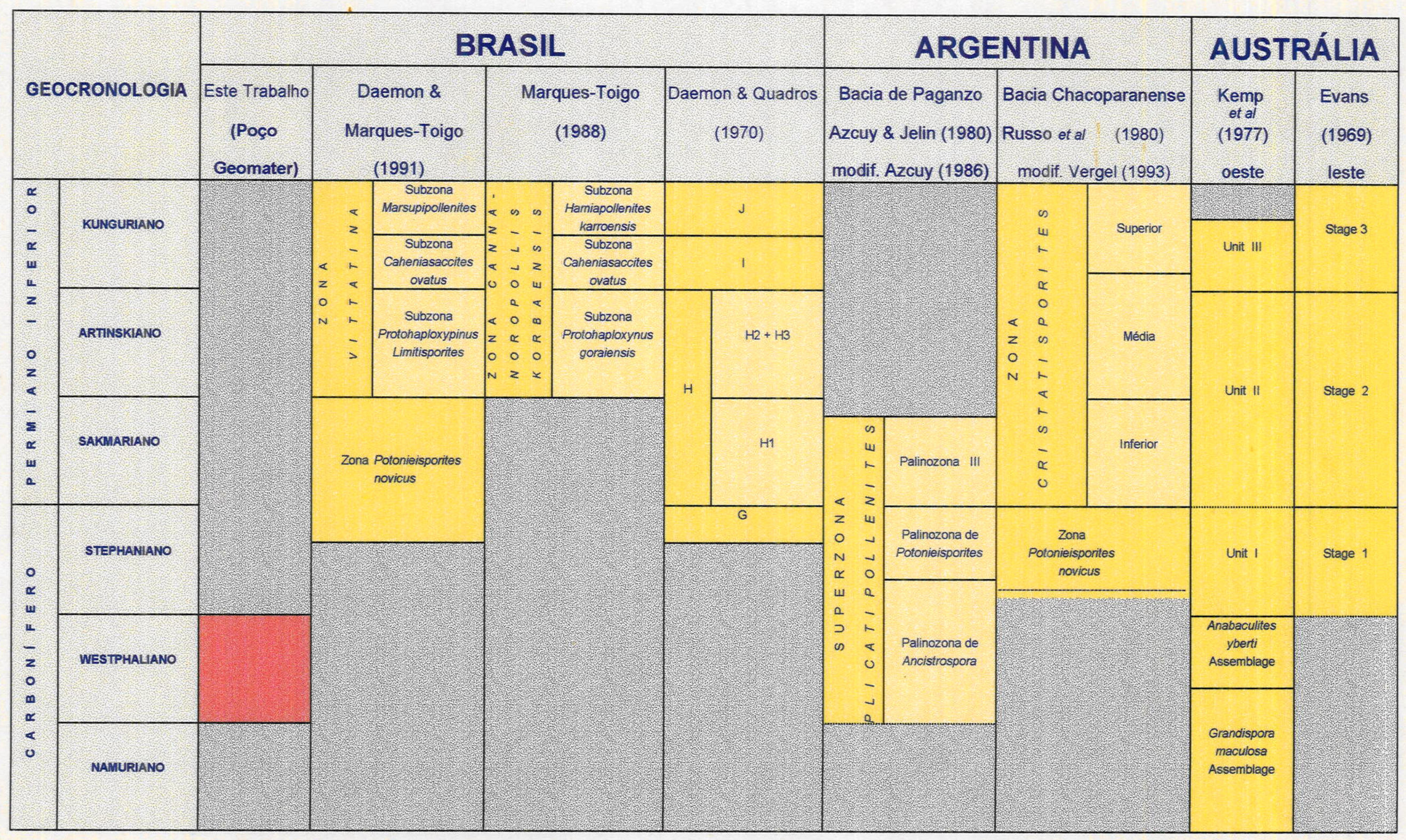

TABELA 11 - Correlação da seqüência estudada com os principais zoneamentos do Paleozóico Superior da bacia do Paraná e de outras áreas gondvânicas. 


\section{VIII.3 Idade}

A indicação de idades às microfloras do Paleozóico Superior da Bacia do Paraná é, por vezes, muito difícil e não recomendada, face à verificação das modificações sofridas nos zoneamentos estabelecidos. Por outro lado, a sucessão bioestratigráfica está cada vez melhor definida, à medida que novos dados são gerados e integrados àqueles já existentes.

Dessa forma, será possível conciliar alguns dados divergentes com relação à macro e microflora, como por exemplo o carvão de Cerquilho no Estado de São Paulo. Embora a macroflora tenha posicionado aquela assembléia no Sakmariano (Rösler, 1978; Millan, 1987) a microflora sugeriu idade kunguriana por Souza et al. (1993b), com base no zoneamento de Daemon \& Quadros (1970).

Wagner (1980) sugeriu o uso da divisão tripartite do Carbonifero, pelo menos para as bacias gondvânicas sul-americanas. Mais recentemente, Wagner \& WinklerPrins (1994) realizaram um profundo trabalho sobre as tabelas estratigráficas do Carbonífero, propondo a utilização dos termos "Lower Subsystem", correspondente ao Tournaisiano-parte do Namuriano e "Upper Subsystem", relativo a parte do NamurianoStephaniano. No presente trabalho é utilizada a divisão da Europa Ocidental para o Carbonífero, amplamente conhecida.

Nesse contexto, a seqüência estudada em subsuperfície é posicionada no Westphaliano, que equivale ao Bashkiriano/Moscoviano no esquema russo, ou ainda ao Carbonífero Médio, conforme Wagner (1980).

Este posicionamento é indicado pelas idades de ocorrências das principais espécies selecionadas apresentadas no capítiulo VIII.2. 


\section{ANÁLISE DOS DADOS DE SUPERFÍCIE}

\section{IX.1 Descrição dos afloramentos}

O afloramento do $\mathrm{km} \mathrm{118,6} \mathrm{(Fotos} 1$ e 2) é constituído por uma seqüência arenosa muito fina e maciça na base $(\sim 0,5 \mathrm{~m})$, que grada para um arenito muito fino a fino, com estratificação cruzada, sugestiva de acanalada, na porção médio-superior $(\sim 2,5 \mathrm{~m})$. Clastos facetados e subarredondados de quartzito, além de "pellets" e intraclastos de argila, ocorrem dispersos na matriz arenosa e concentrados na base e na porção média da seqüência (Figura 05). A amostragem palinológica desse afloramento é proveniente de um desses intraclastos de argila, localizado na porção médio-superior da seqüência (Foto 2).

Esta amostragem é portanto, relativa a sedimentos inconsolidados ou recém depositados, próximos ao sítio deposicional, retrabalhados na deposição do pacote sedimentar mais arenoso.

No $\mathrm{km}$ 122,7 (Foto 3) está exposta uma seqüência síltica de aproximadamente $15 \mathrm{~m}$ de altura, de cor cinza-clara, maciça, muito compactada, ligeiramente carbonática. Nesta seqüência, destacam-se 2 níveis de concreções carbonáticas, de aproximadamente $20 \mathrm{~cm}$ de espessura, com orientação N70E/4NW, conforme Massoli (1991:56). As amostras provenientes deste afloramento são dos niveis de concreção (S23b e S23d -codificação de campo) e do siltito compacto dentre os mesmos ( $\mathrm{S} 23 \mathrm{c}$ ), sendo esta última a mais rica palinologicamente (Foto 4).

O afloramento do $\mathrm{km} \mathrm{123,7} \mathrm{(Foto} \mathrm{5)} \mathrm{é} \mathrm{constituído} \mathrm{de} \mathrm{um} \mathrm{diamictito} \mathrm{cinza,} \mathrm{de}$ aproximadamente $10 \mathrm{~m}$ de altura, maciço, de matriz silto-arenosa, com clastos subarredondados e facetados de quartzito, quartzo e siltito carbonático (Foto 6), de até $15 \mathrm{~cm}$ de comprimento (eixo maior), mais concentrados no topo. A amostragem palinológica é proveniente da matriz silto-arenosa.

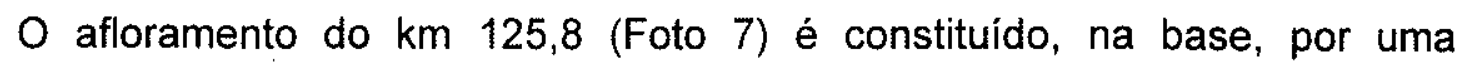
seqüência predominantemente síltica-arenosa com laminação plano-paralela, com aproximadamente $2 \mathrm{~m}$ de espessura, cores cinza-escuras e alaranjadas. Associam-se 
a esta litologia, concreções decimétricas elipsoidais de pirita (Foto 8). Para o topo seguem $4 \mathrm{~m}$ de um siltito arenoso alaranjado, intemperizado.

\section{IX.2 Dados e resultados palinológicos}

O trabalho de cunho palinológico mais detalhado realizado nos niveis aflorantes na Rodovia Raposo Tavares, no trecho entre Sorocaba e Itapetininga é, sem dúvida, o de Lima et al. (1983), referente ao nivel marinho do $\mathrm{km} \mathrm{122,5}$ ao sul de Araçoiaba da Serra.

O trabalho de Kemp (1975), realizado com algumas amostras da mesma área, embora também tenha apresentado uma visão de correlação global, é de difícil análise, já que não há especificação dos conjuntos palinológicos de cada afloramento estudado. Dessa forma, é muito arriscada qualquer análise mais detalhada em nível de afloramentos com base nesse trabalho.

As formas reconhecidas e os dados palinológicos já existentes na literatura sobre esse trecho da rodovia, estão suscintamente apresentados na Tabela 12 . Os dados referentes ao trabalho de Saad (1977) são relativos ao empilhamento estratigráfico e a correlação com as microfloras estabelecidas pelo autor, não podendo-se representar, necessariamente, os dados palinológicos de cada afloramento citado na referida tabela.

É importante salientar que toda a seqüência estudada no poço Geomater está, litoestratigraficamente, abaixo dos níveis afloramentes na rodovia, posicionado por Massoli (1991) na parte superior do seu conjunto litoestratigráfico 2, parte superior do poço.

Em termos bioestratigráficos, as amostras dos quilômetros 122,7, 123,7 e 125,8 correspondem ao intervalo superior do poço Geomater. Isto pode significar, embora sejam poucos os elementos de correlação, na extensão em superfície deste intervalo.

A microflora registrada no $\mathrm{km} \mathrm{122,5,} \mathrm{estudada} \mathrm{por} \mathrm{Lima} \mathrm{et} \mathrm{al.} \mathrm{(1983),} \mathrm{possui}$ alguns elementos comuns com o material aqui estudado, tanto em superficie como em subsuperfície. No entanto, ela parece ser ainda mais jovem do que este, dada a sua maior abundância e'diversificação de grãos de pólen bissacados estriados. Contudo, 
sua composição reflete características de assembléias também posicionadas no Westphaliano e Stephaniano (Lima et al., 1976).

\begin{tabular}{|c|c|c|c|}
\hline & ESTE TRABALHO & Lima et al. (1983) & $\begin{array}{c}\text { Saad (1977) } \\
\text { perfil } 7\end{array}$ \\
\hline $\mathrm{km} \mathrm{118,6}$ & $\begin{array}{c}\text { Punctatisporites gretensis, Calamospora } \\
\text { sp. Vallatisporites arcuatus, } \\
\text { Caheniasaccites ovatus, Limitisporites sp. } \\
\text { 2, Protohaploxypinus } \\
\text { latissimus }\end{array}$ & - & $\begin{array}{l}\text { Conjunto B } \\
\text { Microflora I }\end{array}$ \\
\hline $\mathrm{km} \mathrm{122,5}$ & & $\begin{array}{c}\text { domínio de esporos triletes } \\
\text { zonados, subordinadamente } \\
\text { grãos de pólen } \\
\text { monossacados e } \\
\text { participação conspícua } \\
\text { ( 3\%) de estriados (dados } \\
\text { extraídos de Lima et al., } \\
1983 \text { ) } \\
\end{array}$ & $\begin{array}{l}\text { Conjunto B } \\
\text { Microflora I }\end{array}$ \\
\hline $\mathrm{km} \mathrm{122,7}$ & $\begin{array}{c}\text { Punctatisporites gretensis; Calamospora } \\
\text { sp.; Dictyotriletes pseudopalliatus; } \\
\text { Lycospora sp., Vallatisporites sp. } 2 \text {; } \\
\text { Ancistrospora verrucosa; Lycospora sp. 1; } \\
\text { Cannanoropollis triangularis; } \\
\text { Plicatipollenites malabarensis; } \\
\text { Potonieisporites novicus; Potonieisporites } \\
\text { cf. P. triangulus, Limitisporites } \\
\text { hexagonalis; Limitisporites sp. 2, Navifusa } \\
\text { sp. }\end{array}$ & 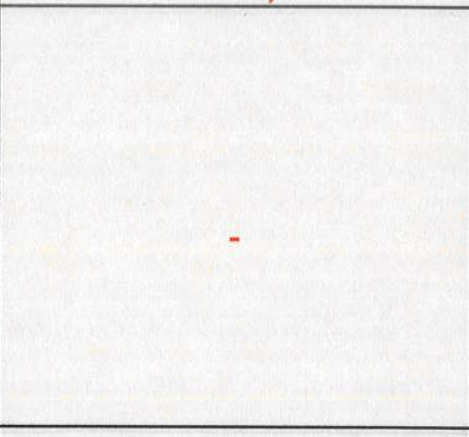 & $\begin{array}{l}\text { Conjunto B } \\
\text { Microflora I }\end{array}$ \\
\hline $\mathrm{km} \mathrm{123,7}$ & $\begin{array}{c}\text { Punctatisporites gretensis; Calamospora } \\
\text { sp. 1; Lundbladispora riobonitensis; } \\
\text { Striomonosaccites cf. S. ovatus; } \\
\text { Striomonosaccites sp. 1, Navifusa sp. }\end{array}$ & - & $\begin{array}{l}\text { Conjunto C } \\
\text { Microflora II }\end{array}$ \\
\hline $\mathrm{km} \mathrm{125,8}$ & $\begin{array}{c}\text { Punctatisporites gretensis; Esporo } \\
\text { indeterminado 1; Calamospora sp. 1; } \\
\text { Retusotriletes sp.1; Stenozonotriletes } \\
\text { perforatus; Caheniasaccites sp. 1; } \\
\text { Navifusa sp. }\end{array}$ & - & $\begin{array}{l}\text { Conjunto C } \\
\text { Microflora II }\end{array}$ \\
\hline
\end{tabular}

Tabela 12 - Dados palinológicos dos afloramentos do trecho entre os quilômetros 118,6 e 125,8 da Rodovia Raposo Tavares. 
A assembléia do km 118,6 é muito pobre palinologicamente. O elemento de valor bioestratigráfico mais significativo é Protohaploxypinus latissimus. Essa espécie, espécie-tipo do gênero, é descrita comumente em níveis permianos do Hemisfério Norte. Suas características morfológicas são bem distintas das apresentadas pelas outras espécies do gênero aqui reconhecidas, seja pela melhor individualização ou pelo tamanho mais reduzido dos sacos. Estes caracteres permitem supor tratar-se de uma espécie mais jovem do que as outras espécies do gênero, conforme também consideram, de modo geral, Venkatachala et al. (1995), tendo por base o maior comprimento da área-livre ("Safra" -saccus free area).

Diante do discutido neste capítulo, as microfloras estudadas e conhecidas no trecho entre os quilômetros 118,6 e 125,8 da Rodovia Raposo Tavares são aqui ordenadas em 3 categorias:

- aquelas bioestratigraficamente correlacionáveis com o intervalo superior do poço Geomater, mas litoestratigraficamente mais altas ( $\mathrm{km} 122,7 ; 123,7$ e 125,8);

- níveis com elementos comuns com o intervalo superior do poço, porém evidenciando idade ligeiramente mais jovem (km 122,5); e,

- amostra' notadamente mais jovem pela ocorrência de Protohaploxypinus latissimus ( $\mathrm{km} \mathrm{118,6),} \mathrm{com} \mathrm{idade} \mathrm{?Eopermiana.}$

\section{IX.3 Relações com Informações Litofaciológicas Prévias}

As relações litoestratigráficas entre os afloramentos da Rodovia Raposo Tavares, no trecho ora enfocado, foram detalhadamente estudadas por Frakes \& Figueiredo-Filho (1967), Saad (1977) e, mais recentemente, por Massoli (1991), com resultados divergentes entre sí. A seguinte análise objetiva apenas confrontar estas informações com os dados palinológicos aqui obtidos dos afloramentos estudados.

$\mathrm{Na}$ seqüência litoestratigráfica proposta por Frakes \& Figueiredo-Filho (1967) os afloramentos deste trecho da rodovia estão empilhados da base para o topo, em ordem crescente de quilometragem (ver sua fig. 2). É possivel, portanto, que algumas das "morenas basais", interpretadas como eventos distintos e repetidos no tempo, do avanço da frente glacial, sejam correlacionáveis entre sí. 
Ainda durante a década de 70 , muitos autores posicionaram os níveis aflorantes do Subgrupo Itararé, seguindo um empilhamento, da base para o topo, generalizadamente, da borda da bacia para o centro desta, em direção ao contato com as unidades sobrejacentes, como verificado, por exemplo, nos trabalhos de Frakes \& Figueiredo-Filho (1967) e Saad (1977).

Massoli (1991) chamou a atenção para as irregularidades da superfície do embasamento e que a espessura sedimentar do Subgrupo Itararé não aumenta gradativamente para oeste, em direção ao centro da bacia, discordando assim dos trabalhos de Frakes \& Figueiredo-Filho (1967), Saad (1977), Santos (1979) e DAEE/UNESP (1979, apud Massoli, 1991).

Segundo este autor, as camadas que compõem a seqüência sedimentar do Subgrupo Itararé na área não se superpõem, necessariamente, a partir da borda da bacia para o seu interior, no caso, na rodovia, de Sorocaba para Itapetininga.

Com base nos dados palinológicos, parte da seqüência aflorante mais próxima à borda da bacia é mais nova que aquela mais para oeste, que envolve os afloramentos entre os $\mathrm{km} \mathrm{122,7} \mathrm{e} \mathrm{125,8.} \mathrm{Dessa} \mathrm{forma,} \mathrm{os} \mathrm{niveis} \mathrm{correlatos} \mathrm{ao}$ afloramento do km 118,6 configurariam uma situação local típica de "onlap" costeiro.

Outra hipótese é com relação a algum rebaixamento tectônico relativo, tendo em vista que a intrusão de Ipanema/Araçoiaba da Serra afetou o Subgrupo Itararé em suas proximidades (Saad, A.R. \& Santos, P.R. 1995, com. pessoal).

$O$ diamictito do afloramento do $\mathrm{km} 123,7$ foi posicionado na base do conjunto 3 de Massoli (1991), pelo referido autor, sendo correlacionável aos niveis entre os km 118-119,5, acima dos níveis aflorantes dos km 122,5, 122,7 e 125,8. Essa situação, aparentemente contrastante, não foi verificada em termos palinoestratigráficos, provavelmente, devido à pouca abundância palinológica da amostra analisada deste afloramento. Torna-se, portanto, arriscada qualquer conclusão mais definitiva a esse respeito.

Os vários posicionamentos litoestratigráficos admitidos por diversos autores e a síntese dos resultados bioestratigráficos dos afloramentos estudados estão ilustrados na Tabela 13.

Em termos paleoambientais, as evidências de influência marinha nas camadas da seqüência aflorante estudada são bem marcada pela presença de macro 
e microfósseis, além dos elementos microplanctônicos aqui noticiados. É possível, portanto, admitir que estes sedimentos representem depósitos marinhos de plataforma rasa proximal, com condições ambientais estressantes, dada a não variedade do microplâncton palinológico.

O afloramento do $\mathrm{km} 125,8$ apresenta indicações sedimentares de pouca energia e ambiente redutor, pela a ocorrência de concreções piritosas, representando facies relativamente mais distais, embora palinologicamente não tenha sido verificada nenhuma modificação paleoambiental.

\begin{tabular}{|c|c|c|c|c|c|c|}
\hline & \multicolumn{5}{|c|}{ 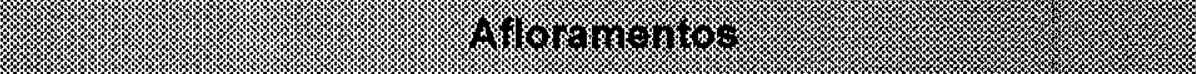 } \\
\hline & & (163. 1258 & kn $128, ?$ & $\ln 122 \pi$ & $1.7 .122,5$ & $\ln .18 .6$ \\
\hline & $\begin{array}{c}\text { Saga } \\
(1972)\end{array}$ & Conj. Lit. C & Conj. Lit. C & Conj. Lit. C & Conj. Lit. C & Conj. Lit B \\
\hline 98 & 14 assoli & Conj. Lit. 2 & Conj. Lit. 3 & Conj. Lit. 2 & Conj. Lit. 2 & Conj Lit 3 \\
\hline 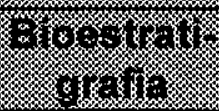 & ististio & $\begin{array}{l}\text { Correlatos } \\
\text { intervalo }\end{array}$ & $\begin{array}{l}\text { entre si e } \\
\text { sup. do poço }\end{array}$ & $\begin{array}{c}\text { como } \\
\text { (Westphaliano) }\end{array}$ & $\begin{array}{l}\text { ?Westphaliano } \\
\text { /Stephaniano }\end{array}$ & ?Eopermiano \\
\hline
\end{tabular}

Tabela 13 - Síntese dos dados litoestratigráficos dos afloramentos estudados na Rodovia Tavares segundo vários autores e dos resultados bioestratigráficos obtidos no presente trabalho.

A análise e as comparações aqui efetuadas permitem levantar as seguintes observaçōes:

1) o posicionamento litoestratigráfico anteriormente proposto de alguns níveis não são corroborados pelos dados bioestratigráficos aqui obtidos;

2) dados sobre a superfície do embasamento dos sedimentos do Subgrupo Itararé e sobre os fenômenos pós-deposicionais que afetaram a unidade (elementos tectônicos), devem ser devidamente considerados no estabelecimento da sequiência litoestratigráfica e mapeamentos de superficie desta unidade;

3) as idéias de que os sedimentos do Subgrupo Itararé estão registrados, em ordem estratigráfica, do mais antigo para o mais jovem, ou seja, da margem da bacia em direção ao seu centro (como se baseou Saad, 1977) ou do centro da bacia 
em direção à margem (França \& Potter, 1988), não podem ser aplicadas generalizadamente. Isto se dá face ao reconhecimento da existência de estratos mais antigos situados em subsuperficie em região mais afastada da borda (Daemon \& França, 1993) e, em superfície, em região próxima à borda da bacia, em Monte Mor por Souza et al. (1993c);

4) a integração dos dados litoestratigráficos com os bioestratigráficos se faz necessária para o entendimento da dos eventos geológicos e dos processos sedimentares envolvidos na geração dos depósitos desta unidade; embora nem sempre se possa correlacionar os dados lito e bioestratigráficas, tendo em vista estes últimos serem, muitas vezes, transgressivos nas litologias. 


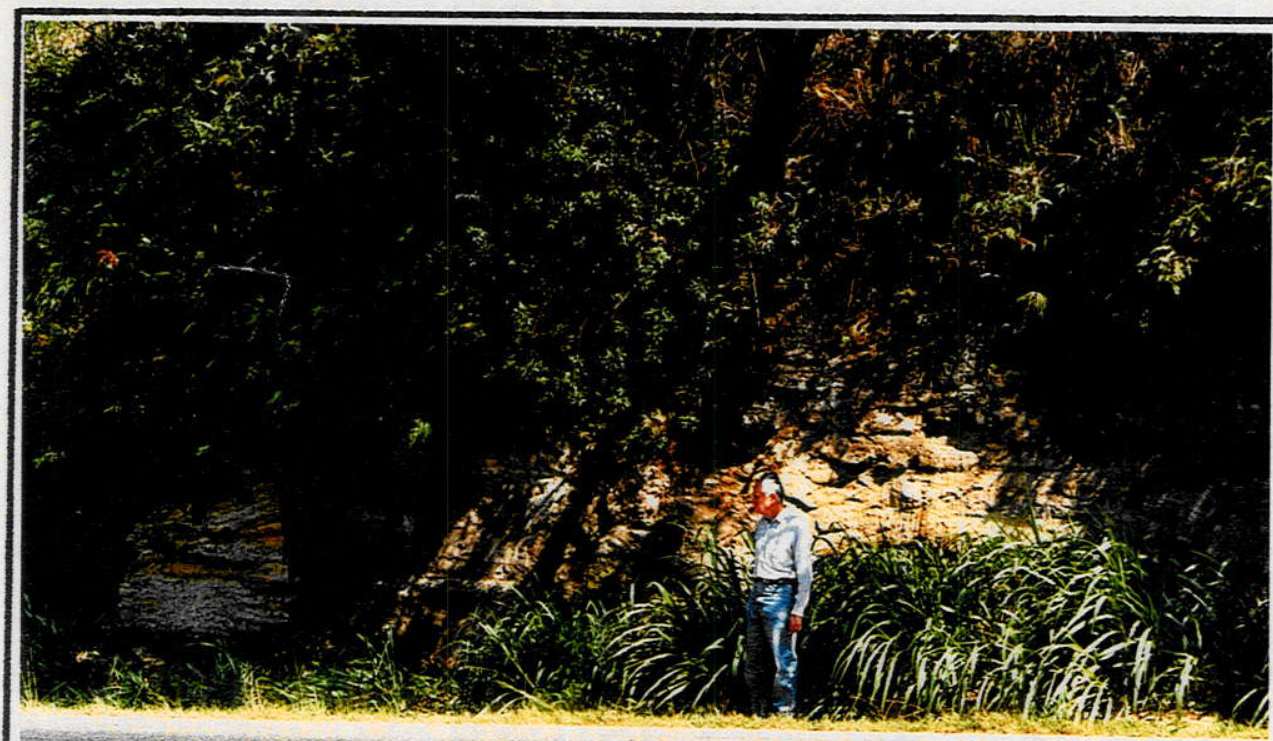

Foto 1 - Vista geral do afloramento do $\mathrm{km} \mathrm{118,6} \mathrm{da} \mathrm{Rod.}$ Raposo Tavares.

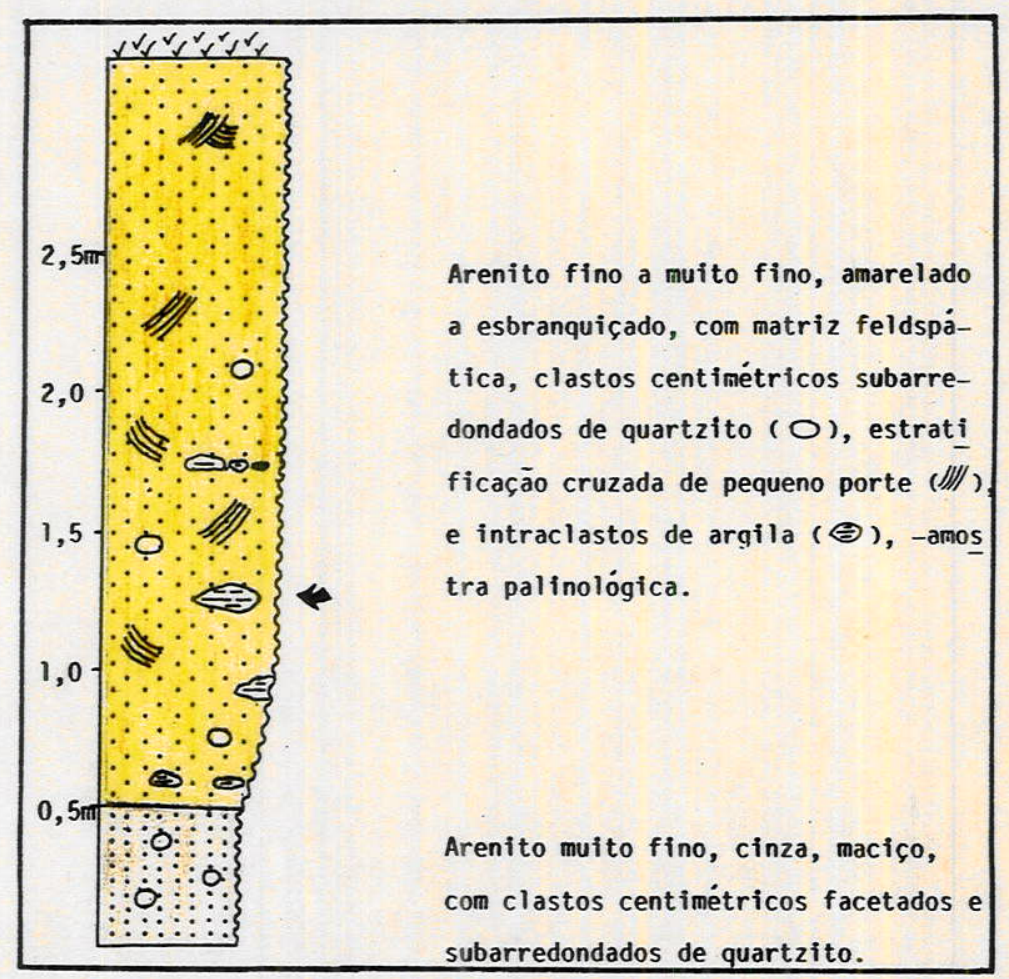

Figura 06 - Perfil esquemático do afloramento do km 118,6 da Rodovia Raposo Tavares, com indicação do nível amostrado palinologicamente.

Foto 2 - Detalhe do afloramento do km 118,6 da Rod. Raposo Tavares, com indicação da amostragem palinológica. 


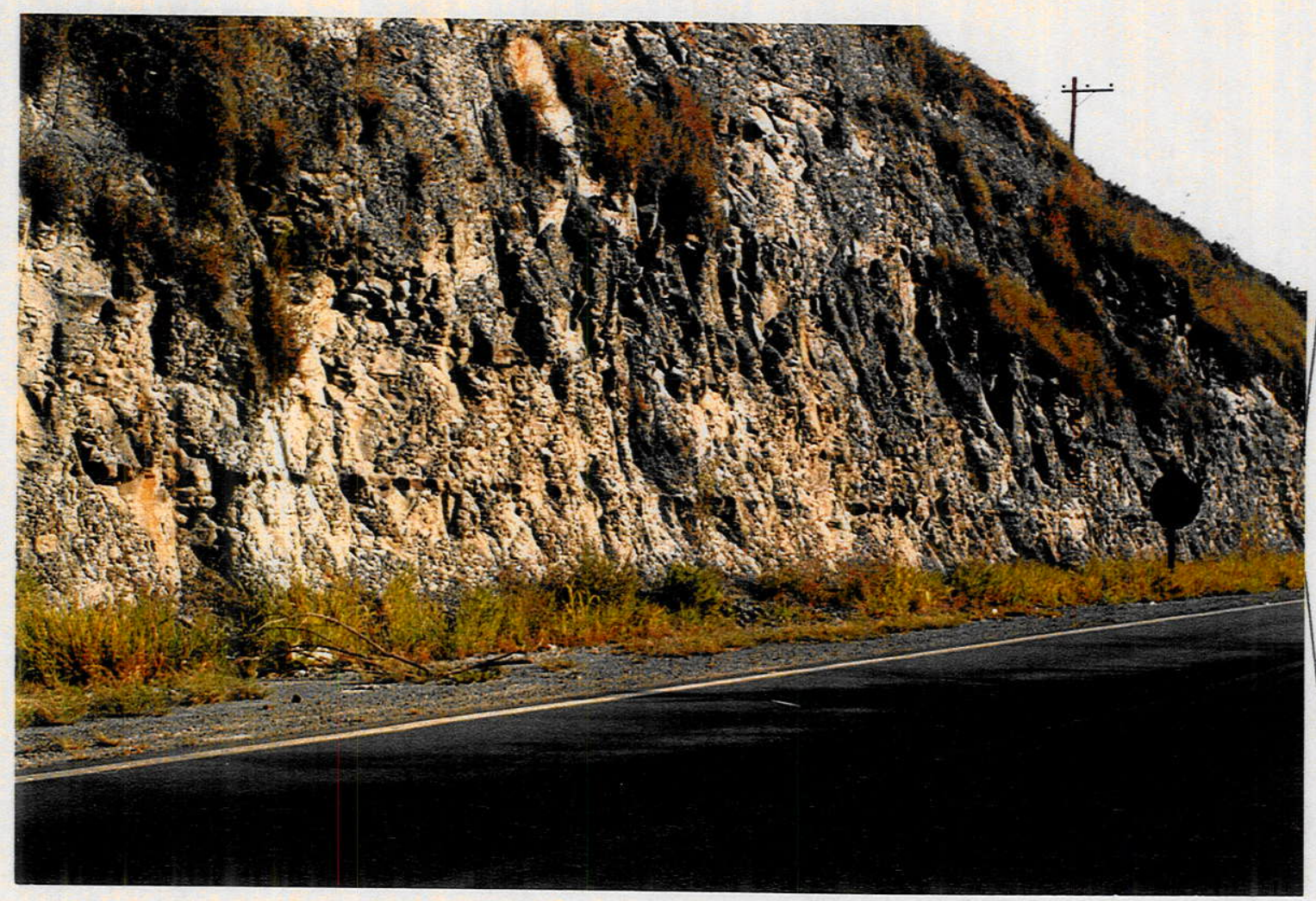

Foto 3 - Vista geral do afloramento do km 122,7 da Rodovia Raposo Tavares.

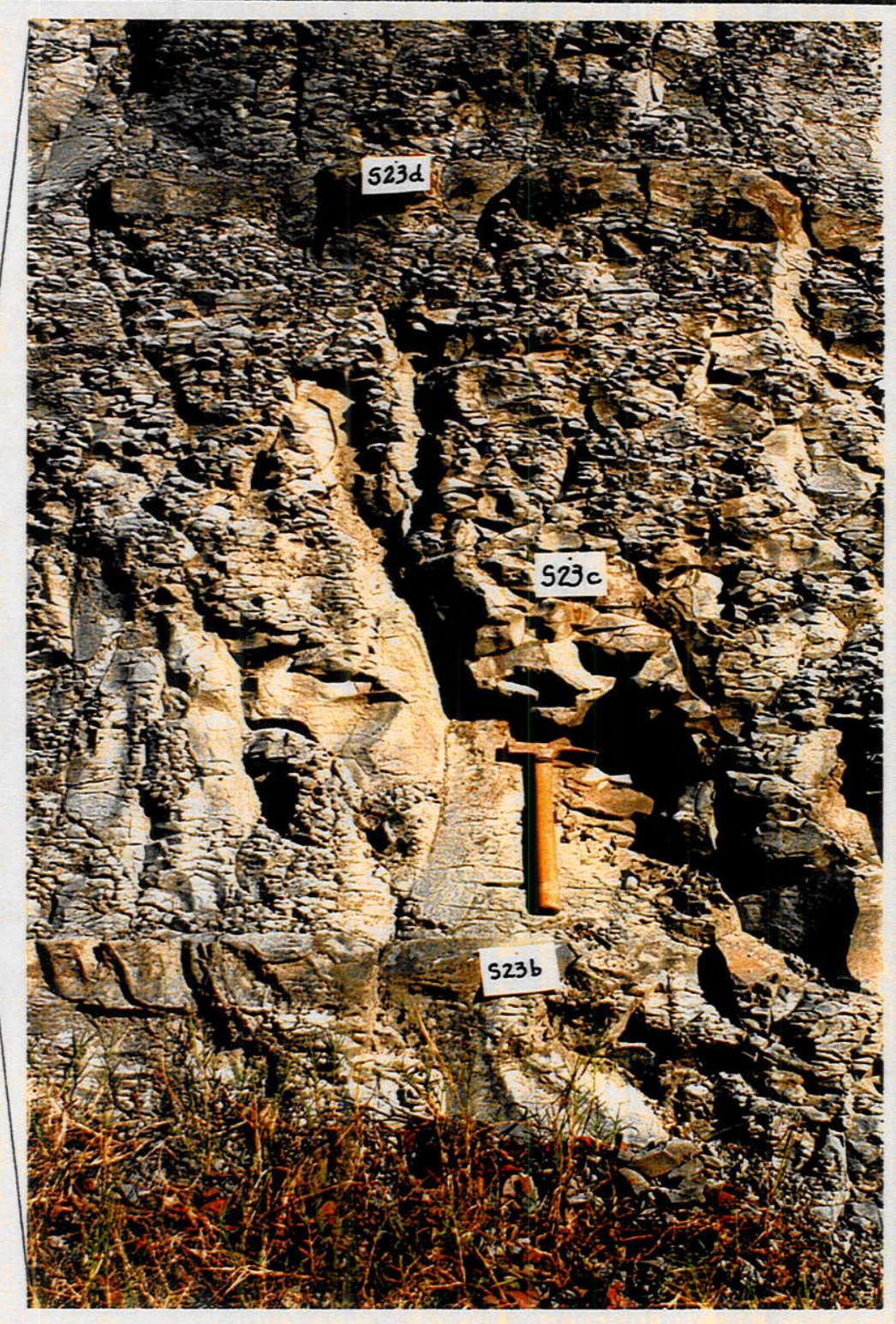

Foto 4 - Detalhe dos níveis de concreção e amostragem palinológica do afloramento do km 122,7 da Rodovia Raposo Tavares. 

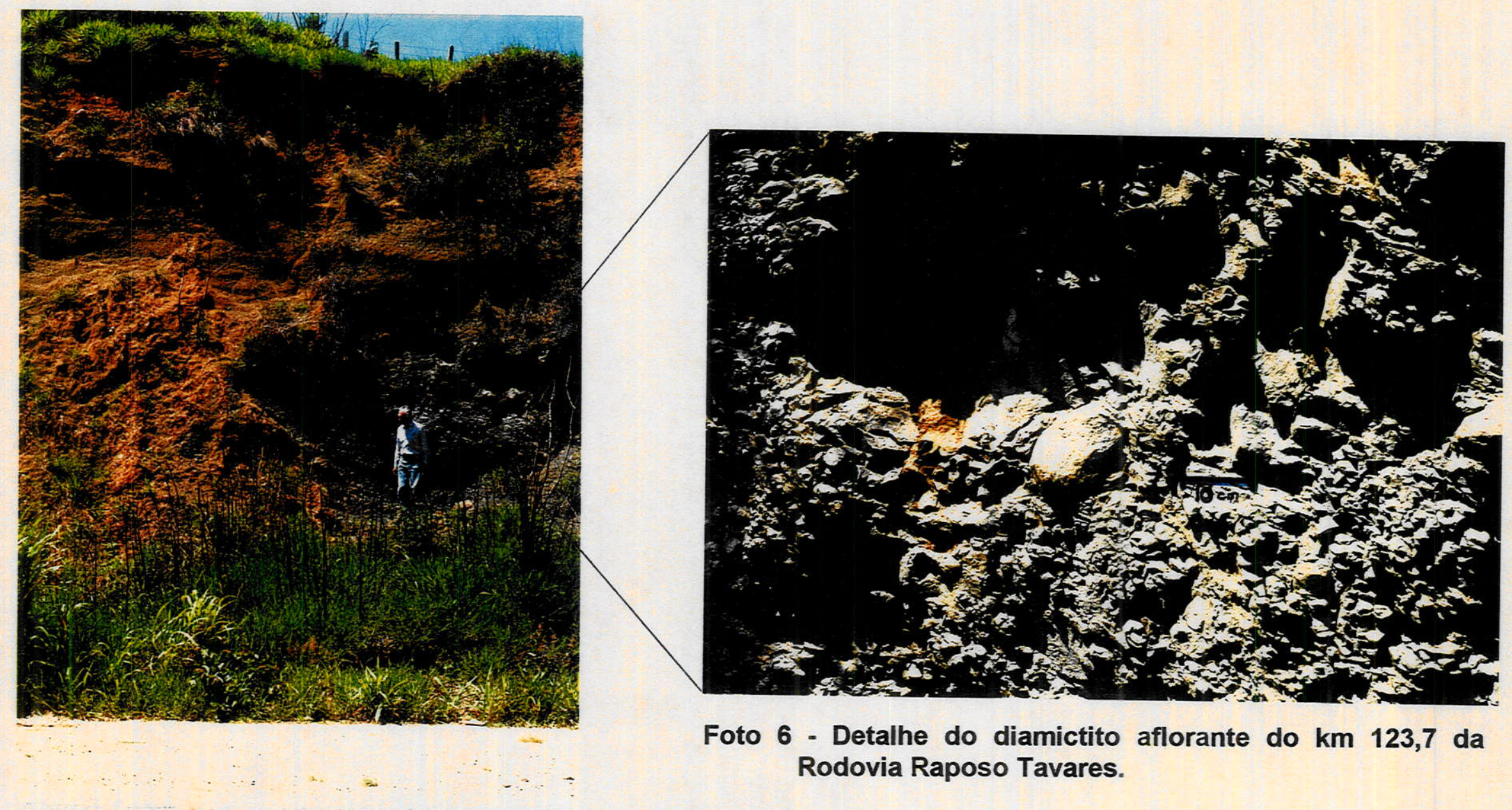

Foto 6 - Detalhe do diamictito aflorante do $\mathrm{km} \mathrm{123,7}$ da Rodovia Raposo Tavares.

Foto 5 - Vista geral do afloramento do $\mathrm{km}$ 123,7 da Rodovia Raposo Tavares. 


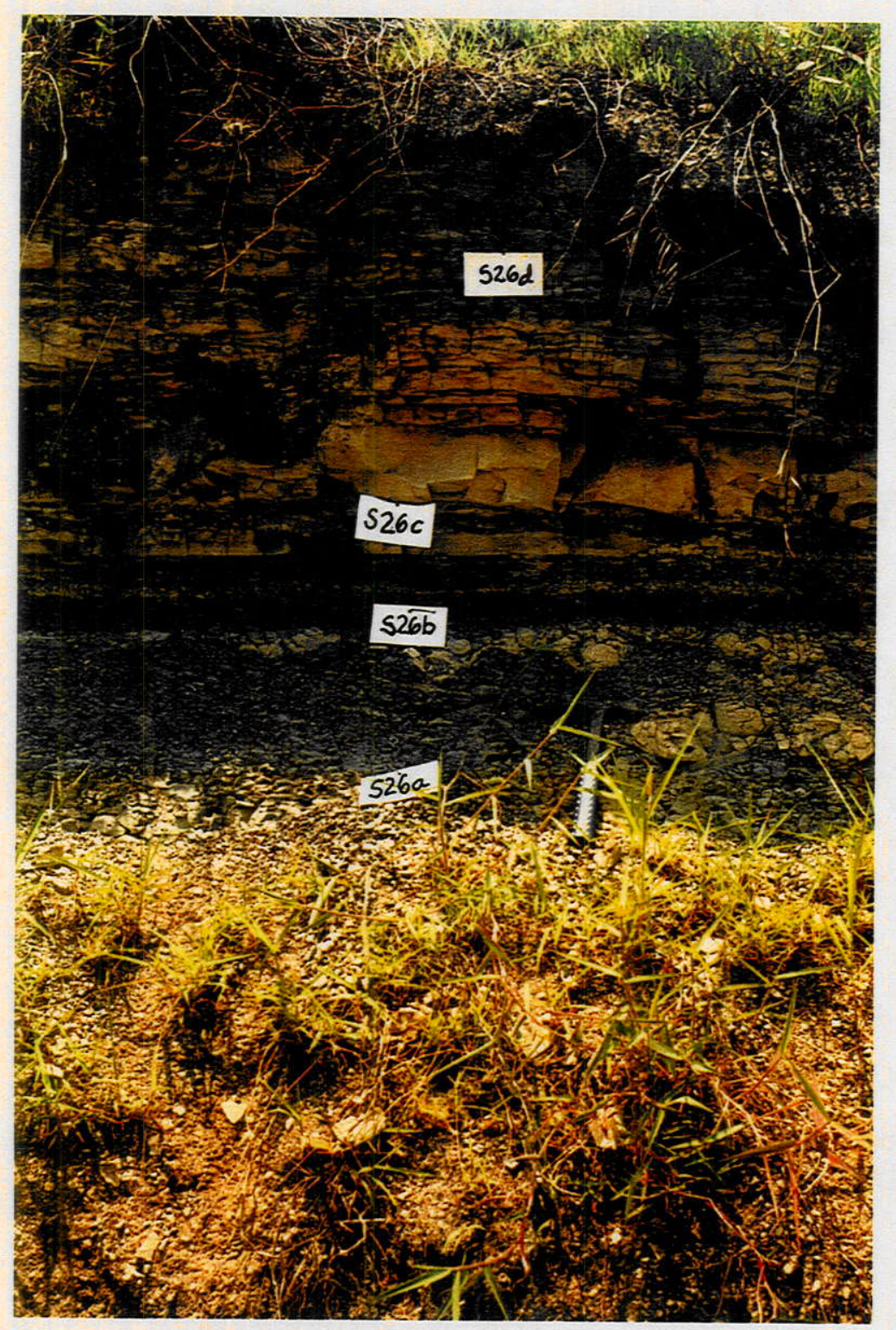

Foto 7 - Afloramento do km 125,8 da Rodovia Raposo Tavares, com indicação dos niveis amostrados palinologicamente.

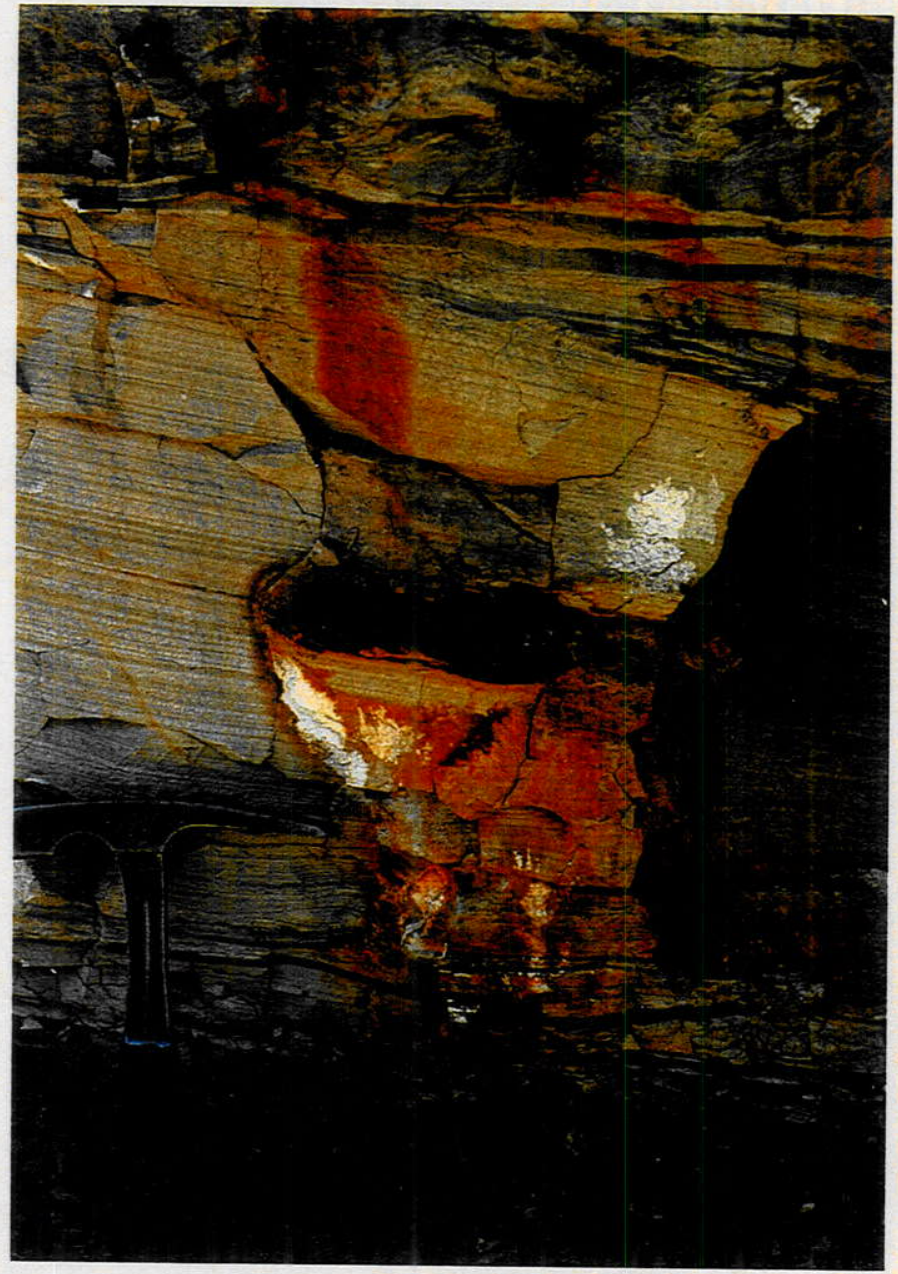

Foto 8 - Detalhe do afloramento do $\mathrm{km}$ 125,8 da Rodovia Raposo Tavares, com concreções piritosas. 


\section{EVIDÊNCIAS DE RETRABALHAMENTO}

\section{X.1 Considerações gerais}

Em alguns niveis do poço Geomater foram verificadas ocorrências de alguns táxons inéditos na Bacia do Paraná, por outro lado, conhecidos e comuns em estratos mais antigos de outras bacias, como apresentado na Tabela 14. Estas formas, relativas a diversas espécies de esporos e a um acritarca, foram identificadas, em sua maioria, entre os níveis 152,5 a $171,3 \mathrm{~m}$ de profundidade.

\begin{tabular}{|c|c|c|c|}
\hline TÁXON & OCORRENCIA* & REGISTRO PRÉVIO & REFERÊNCIA \\
\hline \multirow{2}{*}{$\begin{array}{c}\text { Punctatisporites solidus Hacquebard, } \\
1957\end{array}$} & \multirow{2}{*}{$\begin{array}{c}167 \mathrm{~m} \\
171,3 \mathrm{~m}\end{array}$} & DM do Canadá & Hacquebard (1957) \\
\hline & & DS ao Cl do Canadá & Playford \& McGregor (1993) \\
\hline \multirow{3}{*}{ Retusotriletes sp. 3} & \multirow{3}{*}{$45 \mathrm{~m}$} & $\mathrm{D}$ ao $\mathrm{Cl}$ da Irlanda & Higgs (1975) \\
\hline & & DS ao Cl da Europa & Clayton et al. (1977) \\
\hline & & Cl do Peru & $\begin{array}{l}\text { Azcuy, C.L. (1995, -com. } \\
\text { pessoal) }\end{array}$ \\
\hline $\begin{array}{c}\text { Spinozonotriletes conspicuus } \\
\text { Playford, } 1964\end{array}$ & $\begin{array}{l}152,5 ; 155 \\
\text { e } 167 \mathrm{~m}\end{array}$ & Cl do Canadá & Playford (1964) \\
\hline Stenozonotriletes sp. & $152,5 / 168 \mathrm{~m}$ & Cl do Canadá & Playford (1964) \\
\hline \multirow{4}{*}{$\begin{array}{l}\text { Emphanisponites rotatus McGregor, } \\
\qquad 1961\end{array}$} & \multirow{4}{*}{$152,5 \mathrm{~m}$} & DS do Canadá & McGregor (1961) \\
\hline & & DS do Saara & Jardiné \& Yapaudjian (1968) \\
\hline & & Cl da Argentina & Cesari \& Limarino (1992) \\
\hline & & $\begin{array}{c}\text { DS do Brasil (Bc. do } \\
\text { Paraná) }\end{array}$ & Dino \& Rodrigues (1995) \\
\hline $\begin{array}{c}\text { Grandispora brevispinosa Menéndez } \\
\text { \& Pöthe de Baldis, } 1967\end{array}$ & $152,5 \mathrm{~m}$ & D do Paraguai & $\begin{array}{c}\text { Menéndez \& Pöthe de Baldis } \\
\text { (1967) }\end{array}$ \\
\hline \multirow[t]{2}{*}{ Gorgonisphaeridium sp. } & \multirow[t]{2}{*}{$167 \mathrm{~m}$} & $\mathrm{D}$ ao Cl do Saara algeriano & Coquel \& Latreche (1989) \\
\hline & & D ao Cl do Canadá & Playford \& McGregor (1993) \\
\hline
\end{tabular}

Tabela 14 - Táxons retrabalhados e registros prévios ( $D=$ Devoniano; $D M=$ Devoniano Médio; $\mathrm{DS}=$ Devoniano Superior; $\mathrm{Cl}=$ Carbonifero Inferior; "no poço Geomater).

É possivel que, além dos táxons relacionados na tabela, alguns outros também sejam retrabalhados, como a espécie Retusotriletes sp. 2 e o Esporo Indeterminado 3. 


\section{X.2 Critérios de reconhecimento das formas retrabalhadas}

Contrariamente ao observado na literatura sobre palinomorfos retrabalhados, os espécimens retrabalhados aqui verificados apresentam execelente estado de preservação, sem nenhuma modificação considerável na cor. Isto, por vezes, dificultou seu reconhecimento como forma retrabalhada. Por isso, vale aqui comentar os aspectos gerais sobre as ocorrências de formas retrabalhadas em nivel mundial e os critérios comumente utilizados para a sua distinção.

Com relação à literatura estrangeira, de uma maneira geral, verifica-se que são muitas as citações de retrabalhamento de assembléias palinológicas, incluindo acritarcas, quitinozoários, tasmanitídeos, esporos e grãos de pólen (e.g. Bless \& Streel, 1976; Windle, 1979; Azcuy \& Laffitte, 1981; Legault \& Norris, 1982; OliwkiewiczMiklasinska, 1995).

Stanley $(1965 ; 1966)$ tentou estabelecer critérios para a distinção de esporomorfos retrabalhados dentre aqueles considerados in situ. Esses critérios seriam baseados, essencialmente, no grau de escurecimento da exina dos grãos de pólen e esporos.

Posteriormente, Gray \& Boucot (1975) analisando detalhamente os aspectos físico-químicos que influenciam na cor dos microfósseis e partículas de matéria orgânica, consideram a (1) oxidação pré-litificação, (2) o intemperismo pós-diagenético e a (3) ação de agentes térmicos (pela atuação de atividades tectônicas, corpos ígneos ou calor geotérmico) como os principais fatores que influenciam na cor dos organismos e partículas fósseis, podendo culminar com a sua total destruição.

Apesar de não demonstrarem um padrão geral de alteração na cor, face a combinação e a intensidade dos diferentes agentes envolvidos, os palinomorfos apresentariam uma "maturação" natural, com o passar do tempo.

Embora seja um padrão que se repete em seqüências de diferentes idades, inclusive na Bacia do Paraná, o grau de maturação ou escurecimento da exina das 
formas aqui estudadas não apresentou variação, não tendo sido este o critério utilizado na sua distinção.

Azcuy \& Laffitte (1981) teceram algumas considerações sobre as possibilidades alternativas para explicar $\circ$ retrabalhamento de alguns táxons devonianos e carboníferos inferior no Carbonífero Médio-Superior da Argentina:

-o material ter sido contaminado;

-a distribuição vertical das formas deveria ser estendida até o Carbonifero Médio e Superior;

-a distribuição verticial das formas do Carbonífero Médio e Superior, incluindo grãos de pólen monossacados e raros bissacados, deveria ser estendida até, pelo menos, o limite Fameniano-Tournaisiano;

-que não haveria retrabalhamento, mas algumas formas características das associações estariam mal assinaladas sistematicamente;

-que não haveria retrabalhamento, mas igualdade morfológica de espécies de idades diferentes, resultado de convergências evolutivas.

Estas hipóteses não são aqui consideradas, como também não o foram por Azcuy \& Laffitte (1981) já que outras evidências tornam, no presente estudo, a hipótese de retrabalhamento mais segura, constituindo-se nos critérios utilizados para a sua distinção como formas retrabalhadas:

a) é confiável o posicionamento sistemático da maioria dessas espécies, principalmente por se tratar de material muito bem preservado, opostamente ao padrão geralmente verificado, como exposto por Stanley $(1965,1966)$;

b) em geral, as formas não têm expressão quantitativa nos niveis onde ocorrem, sendo representadas, com raras exceções, por um único espécime;

c) sua ocorrência, com uma exceção, se dá em um intervalo bem delimitado na seqüência do poço Geomater, entre os niveis $152,5 \mathrm{~m}$ e $171,3 \mathrm{~m}$ de profundidade, denotando alguma relação com o contexto geológico-sedimentar.

Particularmente em relação ao Subgrupo Itararé, o clima relativamente frio durante a época de sua deposição, talvez tenha sido o responsável pela boa 
preservação do material orgânico fóssil, impedindo sua oxidação e decomposição na pré-diagênese, pelo menos com referência aos palinomorfos.

\section{X.3 Aspectos geológicos/sedimentares}

Apesar dos problemas bioestratigráficos gerados pela ocorrência de palinomorfos retrabalhados, estes são utilizados na caracterização de alguns aspectos geológicos, sejam de ordem sedimentar ou paleogeográfica.

Stanley (1966) teceu importantes comentários a respeito das relações entre as formas retrabalhadas $e$ as áreas fontes dos sedimentos, com ensaios sobre as indicações de distâncias entre estas e o sítio deposicional.

Uma assembléia palinológica retrabalhada do Carbonifero Superior, com alta diversificação de esporos, incluindo Lycospora, Punctatisporites, Triquitrites e Verrucosisporites, entre outros elementos, foi utilizada por Needham et al. (1969) para determinar o modelo de disperção dos sedimentos depositados durante o Pleistoceno no sudeste do Canadá, como também fizeram Eshet et al. (1988) no Permiano e Triássico de Israel.

Ainda segundo Stanley (1966), com base no seu trabalho preliminar (Stanley, 1965), as altas percentagens de grãos de pólen e esporos ocorrentes em sedimentos depositados durante períodos de glaciação continental são resultantes do aumento da erosão no nível de base durante os periodos glaciais. Movimentos orogênicos que afetariam os niveis de base poderiam, portanto, serem reconhecidos no Pleistoceno e em sedimentos pré-pleistocênicos pelo aumento das percentagens de palinomorfos retrabalhados nas assembléias.

Eshet et al. (1988) verificaram uma perfeita relação entre os níveis com altas percentagens de palinomorfos retrabalhados com os intervalos regressivos e aqueles de baixas percentagens com intervalos transgressivos, que caracterizam a evolução paleogeográfica de parte de Israel na margem do Cráton da Arábia. Segundo esses autores, durante a regressão as áreas expostas seriam submetidas a processos de 
erosão, enquanto que em fases transgressivas ocorreria decréscimo na distância entre as áreas fontes e o sítio deposicional.

Estas constatações parecem corroborar o modelo de palinofácies proposto por Gregory \& Hart (1992), discutido mais adiante, pelo menos com relação ao "Lowstand Systems Tract (LST)", no qual seriam características altas percentagens de palinomorfos retrabalhados. Este modelo encontra-se discutido no capítulo seguinte.

\section{X.4 Registros prévios de retrabalhamento no Subgrupo Itararé}

Apesar de não terem sido objeto de estudos mais profundos, algumas ocorrências de formas do Devoniano e do Carbonifero Inferior foram registradas na literatura como retrabalhadas.

Caetano-Chang (1984) mencionou, baseando-se em relatório PAULIPETRO do poço 2-PN-1-SP, a existência de sedimentos de idade eocarbonifera na Bacia do Paraná, tratados, informalmente, por unidade "pré-Itararé", em contato direto com efusivas ácidas do embasamento. A autora não teceu, contudo, nenhum comentário conclusivo, tendo argumentado que o exame dos testemunhos amostrados naquele pacote sedimentar nada revelaria de diagnóstico que permitisse a distinção entre aqueles sedimentos e os restantes do Subgrupo Itararé e que estes poderiam ser considerados como resultado de "deposições molássicas em calhas tectônicas localizadas" (sic), por sua idade e deposição direta sobre o embasamento.

Esses sedimentos, caracterizados pela ocorrência de palinomorfos retrabalhados, ocorreriam, segundo Santos (1987), baseado nos dados de relatório PAULIPETRO (1983), em seqüências basais do Subgrupo Itararé.

Por outro lado, Diniz (1985) verificou que o topo da Formação Ponta Grossa no poço 2-CS-1-PR (PAULIPETRO, 1983) seria demarcado por uma quebra nos perfis de raio gama e resistividade, atípica para a base do Subgrupo Itararé. Acima deste limite, estariam depositados lamitos e ritmitos característicos dessa unidade, com correspondência litológica em subsuperfície apenas no poço 1-PO-1-PR, $55 \mathrm{~km}$ a noroeste do poço 2-CS-1-PR. Esse intervalo litológico, com $103 \mathrm{~m}$ de espessura e 
delimitado no seu topo por diamictitos, foi datado, pela sua associação palinológica, no Carbonífero Superior e denominado de "unidade basal permo-carbonifera", segundo Diniz (1985).

Observa-se que a totalidade dos dados sobre retrabalhamento de formas antigas na Bacia do Paraná é proveniente de testemunhos de sondagens de poços localizados em partes mais centrais da bacia, relativos aos trabalhos da PETROBRÁS e do Consórcio PAULIPETRO/CESP/IPT.

Tornam-se impossiveis melhores análises face a não disponibilidade desses dados, contidos em relatórios internos daqueles órgãos de pesquisa e exploração. Mesmo em muitos daqueles disponiveis não há referências mais completas sobre a sistemática dessas formas, carentes inclusive de descrições e ilustrações.

Grande parte dos palinomorfos retrabalhados do Devoniano são acritarcas, como aqueles dos gêneros Veryachium, Leiofusa, Navifusa, Michrystridium, Baltisphaeridium, entre outros, sendo mais raras as ocorrências de esporos, destes, o gênero Knoxisporites é o mais comumente registrado.

Em termos de distribuição geográfica na bacia, os sedimentos retrabalhados parecem estar restritos às partes mais setentrionais da bacia, seja na Formação Aquidauana no Mato Grosso do Sul ou no Subgrupo Itararé em São Paulo e Paraná, como constatado no Relatório PAULIPETRO (1983).

\section{X.5 Principais conclusões}

Embora se possa extrair diversos dados a partir do registro de palinomorfos retrabalhados, nenhum trabalho mais profundo a respeito foi realizado na Bacia do Paraná, havendo, inclusive, ausência de informações mais detalhadas sobre esses elementos. O presente trabalho não objetiva realizar uma análise pormenorizada sobre o tema, dada sua abrangência geográfica. Entretanto, algumas considerações devem ser feitas. 
Vários argumentos já levaram alguns autores a inferirem a proveniência dos sedimentos do Subgrupo Itararé a partir de sedimentos devonianos, das formações Furnas e Ponta Grossa, sobre as quais o Subgrupo Itararé repousa, com limites caracterizados por discordâncias erosivas.

A extensão e intensidade da erosão desses sedimentos devem estar ligadas ao soerguimento generalizado ocorrido durante o Carbonífero Inferior, como ressaltou Caetano-Chang (1984), gerando intenso diastrofismo e falhamentos, provocando profunda erosão da coluna sedimentar.

No entanto, a presença de palinomorfos típicos do Carbonífero Inferior permite supor a existência de um pacote sedimentar desta idade na Bacia do Paraná, ou em áreas próximas a ela, que atuaram como fonte de sedimentos. Possivelmente, a instabilidade tectônica a que estava submetida a bacia e a erosão a que se submeteram os sedimentos, impediram o registro desses sedimentos na coluna sedimentar, pelo menos pelo que se conhece até agora. Pequenas calhas do embasamento poderiam servir de centro de acúmulo de sedimentos, não estando excluída a possibilidade de que esses sedimentos tenham sido depositados diretamente sobre as unidades devonianas da bacia. Entretanto, a abrangência mais local deste trabalho impede a formulação de modelos paleogeográficos pré-Itararé.

Assim, é possível distinguir 2 intervalos cronoestratigráficos de retrabalhamento: (1) do Devoniano Superior e (2) do Carbonífero Inferior. Deve-se notar que também na Holanda, Van de Laar \& Fermont (1990) reconheceram, grosso modo, os mesmos intervalos de retrabalhamento em sedimentos do Westphaliano, podendo refletir fenômenos tectônicos mais globais.

A maioria das formas aqui reconhecidas como retrabalhadas a partir de sedimentos do Devoniano e Carbonífero Inferior é registrada em várias partes do mundo, principalmente nas bacias euro-americanas, de características "nórdicas", especialmente da Grã-bretanha, América do Norte e resto da Europa. Não há, nesse contexto, grandes semelhanças com as microfloras gondvânicas. Isto se dá mesmo se considerando o grande volume de dados disponiveis naquelas regiões com relação ao proveniente das regiões gondvânicas, mesmo porque assembléias pré-carboniferas superiores são mais raras nestas últimas regiöes. 
Como já havia ressaltado Azcuy (1975c), estas semelhanças corroborariam a proposição de Jongmans (1952 apud Azcuy 1975c), seguida por Chaloner \& Lacey (1973, apud Azcuy, 1975c) a respeito da existência de uma flora cosmopolita durante o Carbonífero Inferior (Lepidodendropsis-Rhacopteris-Triphyllopteris), que teria se desenvolvido na Bacia do Paganzo, pelo menos, até o Westphaliano. Recentemente, em confirmação, Abdesselam-Rouighi et al. (1995) também destacaram as influências gondvânicas e euroamericanas no Carbonífero Inferior do Saara algeriano.

Sundaram (1987) também ressaltou que os esporos das 3 palinozonas por ele estabelecidas no Subgrupo Itararé do Estado de São Paulo sugeririam um cosmopolitismo, guardando parentesco com aqueles das floras euro-americanas, enquanto que as formas relacionadas às gimnospermas, na maioria grãos de pólen, evidenciariam endemismo gondvânico. 


\section{CONSIDERAÇÕES PALEOAMBIENTAIS}

\section{Considerações gerais}

Os grãos de pólen e esporos, originados quase que exclusivamente de plantas de ambientes continentais, são comumente utilizados na determinação de paleoambientes e paleoclimas. Constituem-se em organismos isolados que integram o aparelho de reprodução das plantas. Seu uso na determinação das informações geológicas está diretamente relacionado às atribuiçōes de suas afinidades aos grupos botânicos conhecidos do passado.

Neste sentido, vários autores têm estabelecido suas afinidades, seja a partir de seu registro em frutificações vinculadas a megafósseis vegetais, ou por possuírem peculiaridades morfológicas exclusivas de certos grupos vegetais. No entanto, a maioria dos gêneros de esporomorfos ainda tem sua afinidade botânica duvidosa. Isto é verificado pela observação das diferentes proposições que constam na literatura. Vale salientar que muitos gêneros ainda têm a afinidade botânica desconhecida.

Entre os vários trabalhos que tratam mais diretamente sobre o assunto, pode-se citar os de Potonié \& Kremp (1956), Azcuy (1978) e Arai \& Rösler (1980).

Muitos autores têm se dedicado a estudos mais profundos sobre o significado paleoecológico dos conjuntos palinológicos do Paleozóico Superior da América do Sul (e.g. Vergel, 1986; Azcuy, 1975c; Daemon et al., 1992; Dias, 1993b).

De um modo geral, os palinomorfos aqui registrados são agrupados em 3 categorias, em função de sua afinidade botânica e de seus caracteres morfológicos, que refletem o modo de dispersão:

1) esporos: produzidos por vegetais inferiores, são vinculados, conforme a maioria dos autores, ao grupo das Pteridophyta; 
2) grãos de pólen anemófilos: constituem-se em grãos portadores de 1 ou mais sacos aeríferos, permitindo sua dispersão pelo vento, além da água. São vinculados ao grupo das Gymnospermae;

3) microplâncton: constituem-se em organismos com afinidade algálica, de ambiente marinho, representado, neste trabalho pelas espécies dos gêneros Navifusa e Gorgonisphaeridium, atribuídos ao Grupo Acritarcha.

Um importante trabalho de cunho paleontológico foi realizado por Remy (1975) que, a partir da observação dos dados microflorísticos do Carbonífero e Permiano da Europa, sugeriu a distinção das floras dos diferentes ambientes de acordo com a profundidade do lençol freático, definindo, deste modo, 4 associações:

1) associações hidrófilas: representadas por organismos aquáticos, englobando os acritarcas, algas e alguns incertae sedis;

2) associações higrófilas: representadas por plantas de porte herbáceo, arbustivo até arbóreo, cujo sistema de raizes seria continuação da parte aérea, com o desenvolvimento de um amplo sistema de sustentação. Estas características refletiriam vegetais associados a solos frouxos, em ambientes costeiros e pantanosos. Nestas associações estão incluídos alguns esporos triletes zonados, lisos, relacionados às Pteridophytas (licófitas e esfenófitas);

3) associações higrófilas-mesófilas: representadas por plantas de porte herbáceo, com necessidade de clima úmido e de vegetação arborescente que lhes forneça sombra. Aí foram incluidos alguns gêneros de filicófitas, relacionadas a alguns triletes lisos, triletes apiculados e muronados. Nestas associações, características de locais um pouco mais afastados do corpo d'água, estariam vinculadas as Glossopteridophytas, às quais se relacionam os grãos de pólen monossacados, bissacados e estriados;

4) associações mesófilas-xerófilas: estas associações são caracterizadas pelo predomínio de plantas associadas às Pteridospermophyta, Cordaitophyta e Coniferophyta, de hábito arbustivo ou arborescente, com raizes fortes e ramificadas. Distribuiam-se em ambientes terrestes mais variados, como planicies 
deltáicas, regiões marginais a terras baixas, até regiöes montanhosas. Estão vinculados a essas associações alguns grãos de pólen monossacados e estriados.

Marques-Toigo \& Correa-da-Silva (1984 apud Marques-Toigo, 1988) identificaram 3 tipos de associações microflorísticas características e marcantes nos carvões gondvânicos do sul do Brasil:

1) associação Lundbladispora-Punctatisporites-Portalites: características de ambientes límnicos, em condições hidrófilas a higrófilas, representadas por plantas associadas às Lycophyta e organismos incertae sedis;

2) associação Vallatisporites-Cristatisporites: típica de ambientes de terras baixas e úmidas, higrófila tendendo a mesófila, de ambientes pantanos;

3) associação Scheringipollenites-Caheniasaccites: representadas por vegetação do tipo gimnospérmicos, que caracterizariam zonas mais secas, de ambiente mesófilo.

Por outro lado, para se compreender o significado dessas associações é necessário notar que algumas variaçōes na composição das microfloras estão diretamente relacionadas ao tipo de sedimento onde ocorre. Nesse contexto, Daemon et al. (1992) utilizaram o modelo litofaciológico de Eyles \& Eyles (1992 apud Daemon et al., 1992) na definição do padrão de distribuição quantitativa dos palinomorfos do Subgrupo Itararé em subsuperfície. Dentre os litotipos estudados por Daemon et al. (1992), os diamictitos apresentaram certa homogeneização no conteúdo palinológico, embora com predomínio de esporos e de grãos de pólen monossacados. Os arenitos, resultados de fluxos gravitacionais em turbiditos ou "slumps" em borda de talude, apresentaram domínio de esporos, com associação menos homogênea. Os folhelhos apresentaram amplo domínio de microplâncton com acentuado declínio de esporos e aumento relativo de grãos de pólen.

De maneira geral, Daemon et al. (1992) concluíram que a sedimentação do Subgrupo Itararé seria marinha, com influência continental, marcada nos pacotes mais arenosos. 
Gregory \& Hart (1992) propuseram 3 modelos de respostas do conteúdo palinológico às variações do nível do mar. Nos eventos regressivos (Lowstand System Tract - LST), o rebaixamento do nível do mar, a migração da base da sedimentação em direção à bacia e a formação de vales incisos na plataforma e deltas, propiciariam o registro de conjuntos palinológicos com domínio de formas terrestres, com componentes marinhos associados. Neste regime são esperadas altas percentagens de palinomorfos retrabalhados, provenientes, principalmente, dos vales incisos.

Nos eventos transgressivos (Transgressive Systems Tract - TST), caracterizados pela subida do nivel do mar, haveria uma diminuição no transporte sedimentar e as assembléias palinológicas seriam pobres em quantidade e diversidade, com poucos elementos terrígenos, destes, têm maior participação, os gãos de pólen de ambientes mesófilos e xerófilos.

Os eventos de mar alto (Highstand Systems Tract - HST) seriam caracterizados pela estabilização da transgressão, com a progradação de sistemas deltaicos na plataforma e altas percentagens das associações hidrófilas e higrófilas.

Estes modelos, testados e formulados em 3 diferentes áreas (Novo México, Alabama e Louisiana), embora já corroborados pelos dados de geoquímica orgânica, devem ser detalhadamente estudados para a sua aplicação na Bacia do Paraná. Os dados aqui disponiveis são insuficientes para qualquer assertativa, haja vista a espessura do pacote analisado.

\section{XI.2 Análise dos dados}

A partir da observação das tabelas 15 e 16 e aplicando-se o modelo paleoecológico de Remy (1975), verifica-se maior influência dos grãos de pólen

monossacados sobre os esporos no intervalo inferior e principalmente no intervalo intermediário do poço Geomater. Tal influência reflete maior participação de plantas de porte arbustivo e arborescente (Pteridospermophyta/Cordaitophyta/Coniferophyta), relativas a associações mesófilas-xerófilas, típicas de terras baixas a montanhosas, representadas pelos gêneros Caheniasaccites, Potonieisporites, Cannanoropollis e 
Plicatipollenites. Somente no topo do intervalo superior é que ocorre decréscimo desse grupo.

\begin{tabular}{|c|c|c|c|c|c|c|c|c|c|}
\hline \multirow[b]{2}{*}{$\begin{array}{l}\text { Profun } \\
\text { didade } \\
\text { (m) }\end{array}$} & \multicolumn{4}{|c|}{ ESPOROS TRILETES } & \multicolumn{4}{|c|}{ GRÃOS DE PÓLEN } & \multirow[b]{2}{*}{$\begin{array}{c}\text { Micro } \\
\text { plâncton } \\
(\%)\end{array}$} \\
\hline & $\underset{(\%)}{\mathbf{T L}}$ & $\underset{(\%)}{\text { TA }}$ & $\begin{array}{c}\text { TC/TZ } \\
\text { TCZ } \\
(\%)\end{array}$ & $\begin{array}{c}\text { TM/TA } \\
\text { /TMS } \\
(\%) .\end{array}$ & $\begin{array}{l}\text { ML } \\
(\%)\end{array}$ & $\begin{array}{l}\text { ME } \\
(\%)\end{array}$ & $\begin{array}{c}\text { BL } \\
(\%)\end{array}$ & $\begin{array}{c}\text { BE } \\
(\%)\end{array}$ & \\
\hline 25,5 & 32,0 & - & 26,5 & - & 29,0 & 1,0 & 1,0 & 1,0 & 9,5 \\
\hline 26,5 & 22,0 & - & 38,0 & - & 30,5 & 1,0 & 3,0 & 1,0 & 4,5 \\
\hline 41,0 & 23,0 & - & 27,5 & 0,5 & 40,5 & 2,5 & 2,0 & 1,0 & 3,0 \\
\hline 41,3 & 23,5 & 2,5 & 18,5 & 1,0 & 41,5 & 1,5 & 2,0 & 2,5 & 7,0 \\
\hline 45,0 & 23,0 & 5,5 & 48,0 & 0,5 & 18,0 & 1,0 & 2,0 & 0,5 & 1,5 \\
\hline 66,0 & 28,0 & 3,0 & 40,0 & 2,5 & 19,0 & 3,0 & 3,0 & 1,5 & - \\
\hline 71,0 & 45,0 & 1,0 & 40,0 & 1,5 & 10,0 & 1,0 & 1,0 & 0,5 & - \\
\hline 77,0 & 52,0 & 1,0 & 14,5 & 1,0 & 26,0 & 2,5 & 2,5 & 0,5 & - \\
\hline 83,0 & 22,5 & 1,0 & 34,0 & 1,0 & 38,0 & 1,0 & 2,0 & 0,5 & - \\
\hline 98,0 & 25,0 & 1,5 & 22,0 & 5,0 & 41,5 & 1,0 & 3,5 & 0,5 & - \\
\hline 103,5 & 24,0 & 1,5 & 26,0 & 2,5 & 40,0 & 2,5 & 2,0 & 0,5 & 1,0 \\
\hline 124,0 & 16,5 & 2,0 & 16,5 & 3,0 & 9,0 & 0,5 & 2,0 & 0,5 & - \\
\hline 137,0 & 28,5 & 2,0 & 23.5 & 1,5 & 37,5 & 1,0 & 5,0 & 1,0 & - \\
\hline 148,0 & 15,0 & 1,5 & 37,0 & 2,5 & 37,0 & 1,0 & 3,5 & 1,0 & 1,5 \\
\hline $\mathbf{1 5 2 , 5}$ & 17,0 & 2,0 & 31,0 & 3,5 & 41,5 & 0,5 & 3,5 & 1,0 & - \\
\hline 155,0 & 28,5 & 2,0 & 33.5 & 2,5 & 28,5 & 0,5 & 4,0 & 0,5 & - \\
\hline 167,0 & 16,5 & 2,5 & 34,5 & 4,5 & 36,5 & 0,5 & 2,5 & 1,5 & 1,0 \\
\hline 168,0 & 25,5 & 2,5 & 12,0 & 4,5 & 42,5 & 1,0 & 1,0 & 1,0 & - \\
\hline 170,0 & 32,5 & 1,5 & 27,5 & 2,5 & 32,0 & 1,5 & 1,5 & 1,0 & - \\
\hline 171,3 & 20,0 & 3,0 & 13,5 & 4,5 & 54,0 & - & 4,0 & 1,0 & - \\
\hline 182,0 & 14,5 & 2,0 & 11,5 & 4,0 & 64,0 & - & 2,0 & 1,0 & 1,0 \\
\hline 188,5 & 25,0 & 3,5 & 25,5 & 3,5 & 35,5 & - & 2,0 & 0,5 & 4,5 \\
\hline 195,0 & 28,0 & 1,5 & 14,5 & 1,5 & 43,5 & - & 5,0 & 0,5 & 5,5 \\
\hline 201,0 & 17,0 & 2,0 & 9,5 & 2,5 & 61,0 & - & 5,0 & 0,5 & 2,5 \\
\hline 206,0 & 27,5 & 1,0 & 15,5 & 2,0 & 43,5 & - & 3,5 & 1,0 & 6,0 \\
\hline 209,0 & 24,5 & - & 8,5 & 1,0 & 55,0 & - & 3,5 & 0,5 & 7,0 \\
\hline
\end{tabular}

TL: triletes lisos; TA: triletes apiculados; TC: triletes cingulados; TZ: triletes zonados; TCZ: triletes cingulizonados; TM: triletes muronados; TR: triletes auriculados; TMS: triletes monopseudossacados; ML: monossacados lisos; ME: monossacados estriados; BL: bissacados lisos; BE: bissacados estriados

Tab. 15 - Freqüência dos principais morfogrupos presentes no poço Geomater. 
Os esporos triletes lisos, apiculados, zonados, cingulados e cingulizonados, representativos das associações higrófilas/mesófilas, têm maior freqüência nos intervalos intermediários e superior, denotando maior influência de plantas de clima úmido, de porte herbáceo/arbustivo (Lycophyta/Psilophyta/Sphenophyta/Filicophyta), comuns em ambientes costeiros e pantanosos, representadas por esporos dos gêneros Punctatisporites, Raistrickia, Cyclogranisporites, Granulatisporites, Verrucosisporites (Filicophyta), Retusotriletes (Psilophyta), Calamospora (Sphenophyta), Lundbladispora, Cristatisporites e Vallatisporites (Lycophyta). 


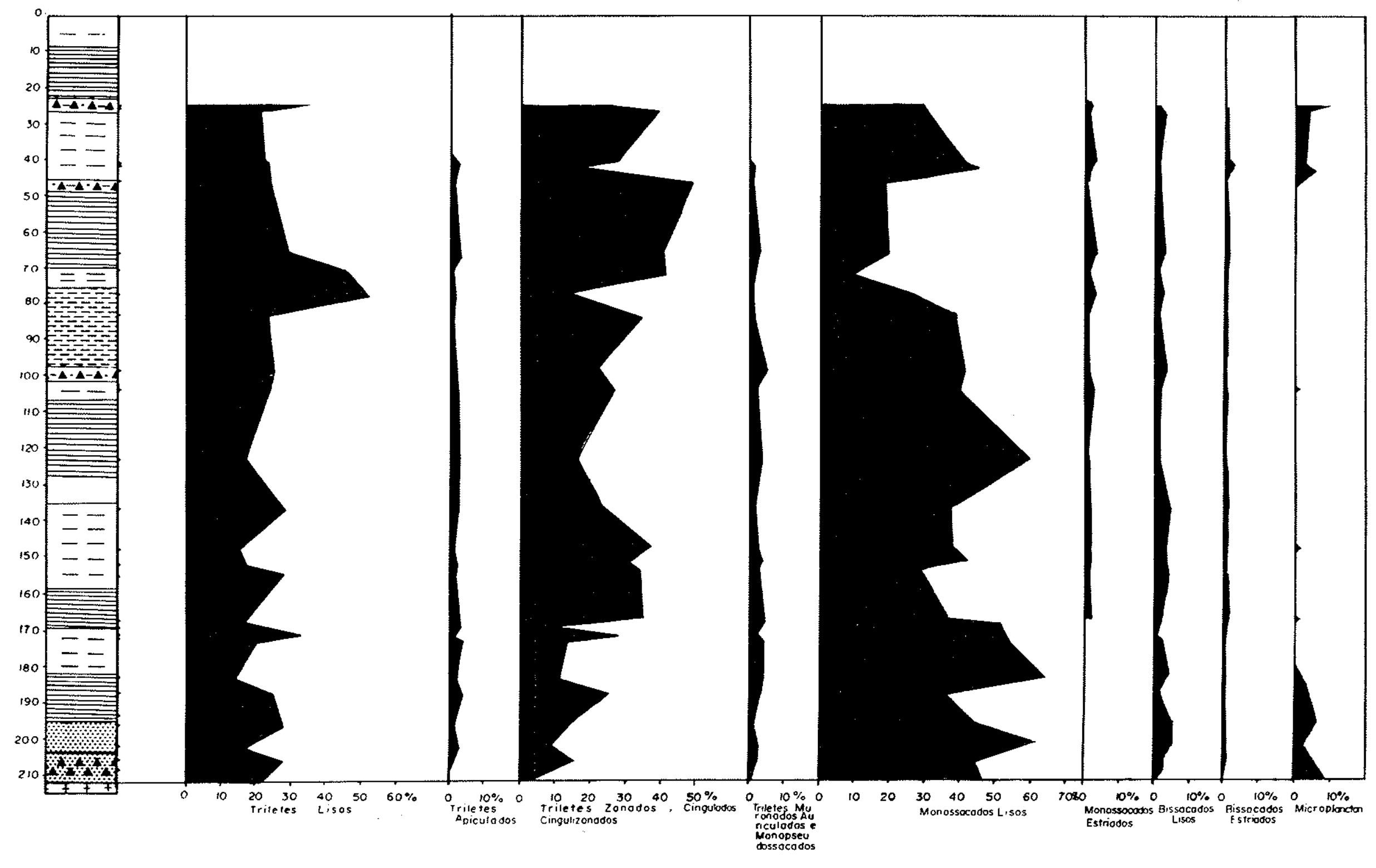

Tabela 16 - Representação quantitativa dos principais morfogrupos no poço Geomater. 
No nível de $77 \mathrm{~m}$ de profundidade é ressaltada uma brusca queda na freqüência de grãos de pólens monossacados e triletes zonados/cingulizonados e, opostamente, aumento de esporos triletes lisos, principalmente aqueles do gênero Calamospora (Sphenophyta), Punctatisporites (Filicophyta) e Retusotriletes (Psilophyta), denotando maior contribuição de plantas relativas às terras baixas e mais úmidas.

Os triletes muronados, auriculados e monopseudossacados não possuem participação expressiva na seqüência.

As informações sobre as afinidades botânicas e das condições paleoambientais indicativas dos principais táxons estudados estão sintetizadas na tabela 17.

\begin{tabular}{|c|c|c|c|c|c|c|c|c|c|c|c|}
\hline & \multicolumn{7}{|c|}{ 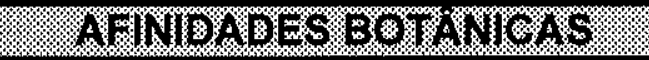 } & \multicolumn{4}{|c|}{ 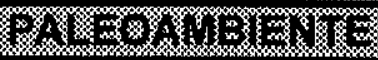 } \\
\hline \multirow{3}{*}{ 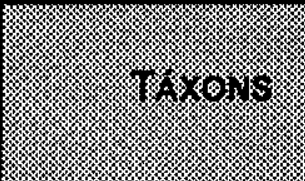 } & \multicolumn{4}{|c|}{ 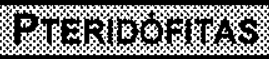 } & \multicolumn{3}{|c|}{ 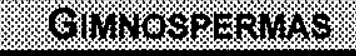 } & \multirow{2}{*}{\multicolumn{2}{|c|}{ 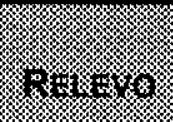 }} & \multirow{2}{*}{\multicolumn{2}{|c|}{ 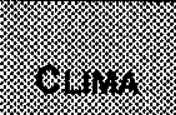 }} \\
\hline & (2) & P.1. & (3) & Iil: & & & Ftang & & & & \\
\hline & & & & & $6 \%$ & 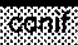 & 20 & \% & 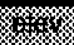 & 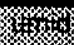 & 4 \\
\hline Punctatisporites & & & & - & & & & - & & - & \\
\hline Calamospora & & & - & & & & & - & & - & \\
\hline Retusotriletes & - & & & & & & & - & & - & \\
\hline Granulatisporites & & & & - & & & & - & & - & \\
\hline Cyclogranisporites & & & & - & & & & - & & - & \\
\hline Verrucosisporites & & & & - & & & & - & & - & \\
\hline Raistrickia & & & & - & & & & - & & - & \\
\hline Dictyotriletes & & & & • & & & & - & & - & \\
\hline Convolutispora & & & & - & & & & - & & - & \\
\hline Lundbladispora & & - & & & & & & $\bullet$ & & - & \\
\hline Lycospora & & - & & & & & & - & & - & \\
\hline Densosporites & & - & & & & & & - & & - & \\
\hline Vallatisporites & & - & & & & & & - & & - & \\
\hline Cristatisporites & & - & & & & & & - & & - & \\
\hline Ancistrospora & & - & & & & & & - & & - & \\
\hline Florinites & & & & & - & - & & & - & & \\
\hline Cannanoropollis & & & & & & - & & - & - & & \\
\hline Plicatipollenites & & & & & & - & & - & - & & \\
\hline Potonieisporites & & & & & & $\bullet$ & & - & - & & \\
\hline Caheniasaccites & & & & & & - & & $\bullet$ & - & & \\
\hline Striomonosaccites & & & & & & & - & & & & - \\
\hline Limitisporites & & & & & & & - & & & & - \\
\hline Protohaploxypinus & & & & & & & - & & & & - \\
\hline Striatoabietites & & & & & & - & & & & & - \\
\hline
\end{tabular}

Tabela 17 - Afinidades botânicas e dados paleoambientais (conforme Azcuy, 1978) dos principais gêneros de esporomorfos estudados. 
Em termos paleoclimáticos, é maior a representatividade, em toda a seqüência do poço, de vegetação associada a clima úmido. Aquela típica de maior aridez, representada pelos grãos de pólen bissacados lisos e estriados, está presente em participação relativamente constante em todo o poço. Isto é indicativo da existência de terras mais altas, mais afastadas dos corpos d'água, sem, contudo, denotar significativa modificação climática.

Embora a natureza paleoecológica dos acritarcas ainda não esteja devidamente estabelecida, a grande maioria dos autores, como Staplin (1961), Evitt (1963) e Wall (1965), consideram esses microfósseis como tipicamente marinhos, especialmente aqueles atribuídos aos gêneros Michrystridium, Veryhachium, Navifusa, Leiofusa e Dactylofusa. Assim também consideram alguns autores brasileiros (e.g. Picarelli et al., 1987; Dias, 1993b).

É importante salientar a influência marinha nos sedimentos do poço Geomater, representada pela ocorrência do gênero Navifusa. Este gênero tem participação mais significativa no intervalo inferior e no topo do intervalo superior, chegando a alcançar até $9,5 \%$ na assembléia do nível de $25,5 \mathrm{~m}$.

Ocorre, menos significativamente, nos intervalos intermediário e superior (exceção do topo), onde a participação dos esporos é maior.

A maior representatividade de formas marinhas e grãos de pólen dos ambientes mesófilo/xerófilo permite supor que a deposição do intervalo inferior se deu em ambiente aquoso com forte influência marinha. Em contraste com o intervalo intermediário e superior (parte), onde a presença de associações de ambiente higrófilo/mesófilo é bem mais marcante, denotanto maior influência continental na deposição.

Embora não possa ser devidamente testado no presente trabalho, o modelo de Gregory \& Hart (1992) corrobora as observações paleoambientais aqui inferidas. A pouca influência marinha verificada no intervalo intermediário pode ter sido reflexo do gradual rebaixamento do nivel do mar, quanto então são dominantes as formas continentais, com altas percentagens de formas retrabalhadas, como verificado. Essa constatação sugere que nessa fase as áreas expostas foram submetidas a processos de erosão. 
Entretanto, no topo do intervalo superior, a representatividade dos esporos diminui, em oposição ao aumento da freqüência das formas microplanctônicas, denotando, outra vez, maior influência marinha. Esta influência é corroborada pelos dados dos afloramentos dos quilômetros 122,5 (Lima et al., 1976, 1983) e 122,7 (este trabalho).

Contudo, os dados aqui tratados são insuficientes para a reconstituição detalhada do cenário paleogeográfico e a aplicação de qualquer modelo de sedimentação. São claras, entretanto, as variações paleoambientais aqui expressas.

Geralmente, a caracterização dos paleoambientes marinhos nos depósitos sedimentares é feita com base em diversos táxons, visto que a diversidade e abundância aumenta proporcionalmente ao gradual estabelecimento das ingressões marinhas, como verificado nos conjuntos palinológicos registradas na Formação Palermo (Leipnitz, 1981; Picarelli et al., 1987).

Segundo Wall (1965), as assembléias de acritarcas com dominância monoespecífica e grande número de espécimens caracterizariam ambientes mais restritos, como os mares internos ("inshore").

A presença abundante do paleomicroplâncton marinho, representado pelas espécies do gênero Navifusa, é forte indicativa de ambiente marinho nos níveis onde ocorre.

Isto é corroborado pelos foraminíferos aglutinantes e pelo registro de 1 braquiópode inarticulado (Lima et al., 1976; 1983) no afloramento do km 122,5 da Rodovia Raposo Tavares, estratigraficamente logo acima do poço Geomater. Há que se observar que, em termos palinológicos, o citado afloramento não contém nenhuma evidência marinha.

Tal divergência, entre o conteúdo palinológico e de macrofósseis, também ocorre nas camadas marinhas de Mafra, Santa Catarina (Daemon, 1974a), onde as condições eram bem mais marcadamente marinhas do que em Araçoiaba da Serra.

Quanto aos niveis de superfície, a amostragem foi considerada pobre palinologicamente, não sendo possivel se estabelecer, adequadamente, relações paleoambientais. O gênero Navifusa só foi verificado nos niveis dos afloramentos dos 
km 118,$6 ; 122,7 ; 123,7$ e 125,8 , refletindo também alí influências marinhas na sedimentação.

Deve ser salientado que também o afloramento do $\mathrm{km} 122,7$ possui registro de foraminíferos, como aquele do km 122,5 (Saad, A.R. \& Santos, P.R. dos. 1995, comunicação pessoal). 


\section{CONCLUSÖES}

A execução do presente trabalho permitiu a enumeração de alguns itens que sintetizam a análise dos dados tratados, implementando o conhecimento palinológico, bioestratigráfico e geológico do Subgrupo Itararé.

\section{XII.1 Palinologia}

A sistemática adotada por diversos autores que trabalharam na Bacia do Paraná mostra-se carente de estudos mais detalhados e profundos, principalmente no Estado de São Paulo, onde os dados são bem menos numerosos e a sequêencia sedimentar da unidade é a mais espessa.

Quarenta e oito táxons são reconhecidos pela primeira vez na Bacia do Paraná, refletindo o desconhecimento de parte da seção da unidade, onde, por diversas razões, as floras que contribuíram na produção dos esporomorfos eram distintas daquelas já conhecidas.

\section{XII.2 Bioestratigrafia}

Até o momento, nenhum estrato da Bacia do Paraná, tanto em superficie como em subsuperfície, é correlacionável com os dados da sequêencia do poço Geomater, com relaçâo a, pelo menos, os intervalos inferior e intermediário, lá que os afloramentos dos quilômetros $122,7,123,7$ e 125,8 são correlacionáveis ao intervalo superior.

Embora a ausência de correlação não indique, por si só, a ancestralidade da sequêencia estudada, devido ao não registro na literatura, até o momento, de camadas 
Se, por um lado, alguns autores já haviam levantado essa hipótese (Sundaram, 1980, 1987), por outro, a palinologia dos niveis de Araçoiaba da Serra (Lima et al., 1983, km 122,5) e de Buri (Souza et al., 1990, 1993a) demonstraram a ancestralidade de alguns dos níveis do Subgrupo Itararé com relação aos esquemas palinoestratigráficos mais abrangentes da bacia (Daemon \& Quadros, 1970; MarquesToigo, 1988, 1991; Daemon \& Marques-Toigo, 1991).

Os esquemas palinoestratigráficos estabelecidos na Bacia do Paraná estão sendo progressivamente modificados nos últimos anos, face à inclusão de novos dados, embora ainda haja a necessidade de modificaçōes mais substanciais, unificando as terminologias e caracterizando as palinozonas propostas, de modo mais formal e detalhado. Nesse aspecto, o esquema de Daemon \& Marques-Toigo (1991) é, até o momento, o que melhor representa a sucessão palinológica no Neopaleozóico da bacia, por refletir a integração de dados abrangentes (Daemon \& Quadros, 1970) com outro mais regionalizado (Marques-Toigo, 1988; 1991).

A assembléia palinológica reconhecida na seqüência do poço Geomater é subdividida informalmente em 3 intervalos, inferior, intermediário e superior, que se caracterizam pela concorrência de táxons.

Os niveis de superfície dos quilômetros $122,7,123,7$ e 125,8 são correlacionados com o intervalo superior do poço.

As formas de maior significado bioestratigráfico são Granulatisporites varigranifer, Raistrickia rotunda, Ahrensisporites cristatus, Stenozonotriletes perforatus, Vallatisporites cilliaris, Ancistrospora verrucosa, Ancistrospora inordinata, Dictyotriletes muricatus, Florinities guttatus, Florinites occultus, Florinites sp. e Potonieisporites novicus. A maioria destas formas é inédita na Bacia do Paraná e estão registradas em zonas bioestratigráfica de idades mais antigas, não correlacionáveis com as estabelecidas.

Da análise dos zoneamentos das outras bacias gondvâncias, a assembléia palinológica aqui estudada no poço Geomater é correlacionada com níveis do Carbonifero Médio/Superior da Argentina, relativos à Palinozona de Ancistropora e Palinozona de Potonieisporites e, com menor precisão, com a unidade I (Kemp et al., 1977) e Stage 1 (Azcuy \& Jelin, 1980) da Austrália. 
De maneira geral, o estudo desta seqüência pode gerar, futuramente, com a integração de novos dados, a proposição de uma nova palinozona, mais antiga do Neopaleozóico da Bacia do Paraná, pelas indicaçōes das idades e pela singularidade de sua composição. Para tanto, os dados de Lima et al. (1983), Souza et al. (1990, 1993a) e Daemon \& França (1993) devem ser considerados, por demonstrarem também tratar de associações mais antigas que o intervalo $G$ de Daemon \& Quadros (1970).

\section{XII.3 Idades}

Com relação à idade, a seqüência do poço é posicionada no Westphaliano, pela distribuição estratigráfica das espécies mais significativas em termos bioestratigráficos.

É importante ressaltar, porém, que essa atribuição não significa a correlação desta seção com os outros níveis também posicionados nesta idade, uma vez que as associações são palinologicamente distintas, embora alguns elementos sejam comuns.

Por outro lado, as variações na composição das assembléias podem ser reflexos da natureza litológica distinta dos diferentes niveis, cujas condições paleoambientais relacionadas à sua formação demonstrariam caráter diferenciado.

A presença de Protohaploxypinus latissimus no afloramento do km 118,6 é indicativa de que este seja, bioestratigraficamente mais jovem que os demais, inclusive em relação àquela do $\mathrm{km} \mathrm{122,5} \mathrm{(Lima} \mathrm{et} \mathrm{al.,} \mathrm{1983).}$

O reconhecimento de formas do Devoniano e Carbonífero Inferior no poço, sugere exposição de sedimentos mais antigos destas idades, posteriormente removidos pela erosão. Há a possibilidade também destes sedimentos serem provenientes de bacias africanas, trabalhados pelas geleiras, cujas direções de transporte convergem para a Bacia do Paraná. 


\section{XII.4 Paleoambiente}

A análise paleoecológica indicou a influência de formas marinhas na seção do poço Geomater, bem como dos afloramentos analisados. Embora pobremente diversificada, estas formas ocorrem, mais representativamente, no intervalo inferior e no topo do intervalo superior.

Os intervalos intermediário e superior (exceto o topo), apresentam o domínio de formas tipicamente continentais, com raros e esporádicos elementos microplanctônicos.

Nesse contexto, é possivel detectar pequena variação no regime sedimentar do poço, no qual o intervalo inferior representaria sedimentação marinha, não franca. No intervalo intermediário ocorreria ligeiro recuo do nivel do mar, com exposição e erosão de sedimentos, inclusive aqueles mais antigos do Devoniano e Carbonifero Inferior. Esse recuo é marcado, pelo menos até a profundidade de $55 \mathrm{~m}$, onde então passa a ser registrado, mais significativamente, o microplâncton marinho.

O limite inferior do intervalo intermediário, que se caracteriza pela ocorrência de formas retrabalhadas, é marcado por um diastema que, conforme Massoli (1991), reflete uma paraconformidade. A magnitude desse evento geológico discordante deve ser melhor avaliada, com trabalhos que delimitem sua extensão

\section{XII.5 Litoestratigrafia}

A análise cronológica dos dados de superfície e a comparação com os espilhamentos litoestratigráficos efetuados por alguns autores que se dedicaram mais localmente à área apontaram divergências significativas.

Com relação aos trabalhos de Frakes \& Figueiredo-Filho (1967) e Saad (1977), cujo empilhamento foi realizado, grosso modo, da borda da bacia em direção ao centro, é possivel que muitas das camadas empithadas distintamente sejam 
correlacionáveis entre sí, como no caso das morenas basais do perfil dos primeiros autores.

Sabe-se que o intervalo G de Daemon \& Quadros (1970) não é verificado em todas as regiōes da bacia, estando o Subgrupo ltararé assentado sobre o embasamento pré-cambriano ou sedimentos devonianos, já a partir do intervalo $H$, em muitas partes da bacia. É possível que, analogamente, a seqüência de subsuperfície aqui analisada represente sedimentos de calhas localizadas na bacia, porém ainda não susceptivel de mapeamentos, dada a sua ocorrência localizada.

Esta fase de sedimentação está associada à gradual implantação do regime tectônico da bacia, estabilizada, provavelmente a partir do tempo correlato ao intervalo $\mathrm{G} / \mathrm{H}_{1}$.

Pelo menos localmente, a sedimentação desta seqüência basal do Subgrupo Itararé deu-se sob condições marinhas, com forte evidências de onlap costeiro. 


\section{CONSIDERAÇÕES FINAIS}

A análise dos dados apresentados no presente trabalho constitui uma contribuição ao aprimoramento bioestratigráfico e paleoambiental do Subgrupo Itararé nesta parte da Bacia do Paraná, onde estudos detalhados são mais escassos.

Estes estudos palinológicos na área de afloramento e em subsuperfície são potenciais para a adequada delimitação da área com o registro da sedimentação do Carbonífero Médio na Bacia do Paraná. Com efeito, as correlações bioestratigráficas poderão ser estabelecidas com a formulação de uma nova biozona que implemente o atual arcabouço palinoestratigráfico.

A utilização da Palinologia como ferramenta de trabalho em Geologia mostrou-se, mais uma vez, significativa, seja no ordenamento dos eventos geológicos, na datação, ou por fornecer subsídios para a caracterização paleoambiental e paleogeográfica de uma determinada seqüência sedimentar. 


\section{REFERÊNCIAS BIBLIOGRÁFICAS}

ABDESSELAN-ROUIGHI, F.; BROUTIN, J.; COQUEL, R.; GHOSSARI, A. \& MASSA, D. 1995. Moscovian microflora from the Bordj Nili area (Northern Algerian Sahara). Comparasions with the euramerican microfloras and paleogeographical implications. In: CONGRESS ON CARBONIFEROUSPERMIAN, XIII, Kraków, 1995. Abstracts..., Polish Geological Institute, p. 3-4.

ANDERSON, J.M. 1977. The biostratigraphy of the Permian and Triassic. Part 3: a review of Gondwana permian palynology basin, South Africa. Memoirs of the Botanical Survey of South Africa, $\mathrm{n}^{0} 41$, $67 \mathrm{p}$.

ANDREWS, H.N.; ARNOLD, C.A.; BOUREAU, E.; DOUBINGER, J. \& LECLERQ, S. 1970. Traité de Paléobotanique. Masson \& Cie. (eds), 4(1):1-519.

ARAI, M. 1980. Contribuição dos pólens estriados na bioestratigrafia neopaleozóica da parte nordeste da Bacia do Paraná. Böl. IG-USP, São Paulo, 11:98-105.

ARAI, M. \& RÖSLER, O. 1980. Pólens e esporos associados a megafósseis vegetais em São João do Triunfo, PR, Formação Rio Bonito (Permiano). Bol. IG-USP, Paleobotânica e Áreas Afins na América do Sul, São Paulo, 11:31-189.

ARCHANGELSKY, S. \& GAMERRO, J.C. 1979. Palinologia del Paleozoico Superior en el subsuelo de la Cuenca Chacoparanense, Republica Argentina. I. Estudio sistematico de los palinomorfos de tres perfaciones de la Provincia de Cordoba. Revista Española de Micropaleontología. Madrid, XI(3):417-478.

ARCHANGELSKY, S. \& CUNEO, R. 1987. Ferugliocladeceae, a new family from the Permien of Gondwana. Review of Palaeobotany and Palynology, Amsterdam, 51(1/3):3-30.

ARCHANGELSKY, S.; AZCUY, C.L.; GONZALES, C.; MARQUES-TOIGO, M.; PINTO, I.D.; RÖSLER, O. \& WAGNER, R. 1980. The Carboniferous and Early Permian of South American Gondwana Area: a summary of biostratigraphic information. In: CONGRESO ARGENTINO DE PALEONTOLOGIA Y BIOESTRATIGRAFIA, 2, Y CONGRESO LATINOAMERICANO DE PALEONTOLOGIA, 1, Buenos Aires, 1977. Actas..., IV:257-269.

AZCUY, C.L. 1975a. Miosporas del Namuriano y Westfaliano de la Comarca Malanzan-Loma Larga, Provincia de La Rioja, Argentina. I. localizacion geografica y geologica de la comarca y descripciones sistematicas. Ameghiniana, Buenos Aires, XII(1):1-69.

AZCUY, C.L. 1975b. Miosporas del Namuriano y Westfaliano de la Comarca Malazan-Loma Larga, Provincia de La Rioja, Argentina. Ameghiniana, Buenos Aires, XII(2):113-163.

AZCUY, C.L. 1975c. Las asociaciones palinologicas del Paleozoico Superior de Argentina y sus relaciones. In: CONGRESO ARgENTINO DE PALEONTOlogía Y BIOESTRATIGRAFIA, I, Tucumán, 1975. Actas..., vol. I: 455-477.

AZCUY, C.L. 1978. Posible significado paleoecológico de microfloras gondwânicas del Paleozóico Superior, especialmente argentinas. Ameghiniana, Buenos Aires, 15(1-2):85-95.

AZCUY, C.L. 1979. A review of the early Gondwana palynology of Argentina and South America. In: International Palynological Conference, 4, Lucknow, 1976. Proceedings..., 2:175-185.

AZCUY, C.L. 1986. Algumas precisiones sobre las palinozonas carbonico-permicas de la Cuenca Paganzo. Ameghiniana, Buenos Aires, 23(1-2):97-100. 
AZCUY, C.L. \& JELIN, R. 1980. Las palinozonas e o limite Carbono-Permico en la Cuenca Paganzo. In: Congreso ARgentino DE PAleontologia Y BIOESTRATIGRAFIA, 2, Y Congreso LATINOAMERICANO DE PALEONTOLOGIA, 1,Buenos Aires, 1980. Actas..., 4:51-67.

AZCUY, C.L. \& LAFFITTE, G. 1981. Palinologia de la Cuenca Noroeste Argentina. I. Caracteristicas de las asociaciones carbónicas: problemas y interpretación. In: CONGRESO GEOLóGrCo ARGENTINO, VIII, San Luis, 1981. Actas...., vol. IV:823-838.

AZCUY, C.L. \& GUTIERREZ, P.R. 1985. Palinologia de sedimentitas carbonicas de La Cuenca San Rafael. Ameghiniana, Buenos Aires, 22(1-1):97-109.

AZCUY, C.L.; GUTIERREZ, P.R. \& BARREDA, V.D. 1982. Algunas miosporas carbonicas de la Formacion Agua colorada, Provincia de La Rioja. Ameghiniana, Buenos Aires, XIX(3-4):289-302

BACKHOUSE, J. 1991. Permian palynostratigraphy of the Collie Basin, Western Australia. Review of Palaeobotany and Palynology, Amsterdam, 67:237-314.

BALME, B.E. 1963. Plant microfossils from the Lower Triassic of Western Australia. Palaeontology, Londres, 6(1):12-40.

BALME, B.E. 1964. The palynological record of Australian pré-Tertiary Floras. Ancient Pacific Floras, University of Hawaii Press, p. 48-80.

BALME, B.E. 1980. Palynology and the Carboniferous-Permian boundary in Australia and other Gondwana continents. Palynology, Dallas, 4:43-55.

BARSS, M.S. 1967. Carboniferous and Permian spores of Canada. Geological Survey of Canada, Paper $67-11,18 \mathrm{p} ., 38 \mathrm{pl}$.

BERI, A. 1988. Estudio sistematico del contenido palinológico de una muestra de la Formación Tres Islas (Pérmico Inferior) del Uruguay. Paula-Coutiana, Porto Alegre, 3:27-48.

BHARADWAJ, D.C. 1962. The miospore genera in the coals of Ranignaj Stage (Upper Permian), India. The Palaeobotanist, Lucknow, 9(1-2):68-10.

BHARADWAJ, D.C. 1975. Palynology in biostratigraphy and palaeocology of Indian Lower Gondwana Formations. The Palaeobotanist, Lucknow, 22(2):150-157.

BHARADWAJ, D.C. \& TIWARI, R.S. 1964. On two monosaccate genera from Barakar stage of India. The Palaeobotanist, Lucknow, 12(2):139-146.

BHARADWAJ, D.C; KAR, R.K. \& NAVALE, G.K.B. 1976. Palynostratigraphy of the Lower Gondwana deposits in Paraná and Maranhão basins, Brazil. Biological Memoirs, Paleopalynology Series -3, Lucknow, 1(1-2):53-108.

BLESS, M.J.M. \& STREEL, M. 1976. The occurrence of reworked miospores in a Westphalian C microflora from South Limburg (The Netherlands) and its bearing on paleogeography. Meded. Rijks Geol. Dienst., N.S., 27(1):1-39.

BOSE, M.N. 1971. Palynostratigraphy of the Lukuga Series in Congo. Académie Royale des Sciences D'Outre-Mer, Bulletin des Séances, Bruxellas, 1971-2:234-245.

BOSE, M.N. \& KAR, R.K. 1966. Palaeozoic sporae dispersae from Zaïre (Congo). XI. Assises glaciaires et périglaciaires from the Lukuga Valley. Annales du Musée Royal de l'Afrique Centrale, Tervuren, Série In $8^{\circ}$, Sciences Geologiques, $n^{\circ} 77$, p. 3-11, 3 est.

BOSE, M.N. \& MAHESHWARI, H.K. 1968. Palaezoic sporae dispersae from Congo. VII - Coal measures near lake Tanganyika, South of Albertiville. Annales du Musée Royal de L'Africa Centrale, Tervuren, Série IN $8^{\circ}$, Sciences Geologiques, $\mathrm{n}^{\circ}$ 60, p. 1-116, 26 pl. 
BROUTIN, J.; DOUBINGER, J.; EL HAMET, M.O. \& LANG, J. 1990. Palynologie comparée du Permien nigérien (Afrique occidentale) et Péritéthysien. Implications stratigraphiques et phytogéographiques. Review of Palaeobotany and Palynology, Amsterdam, 66:243-261.

BUTTERWORTH, M.A.; JANSONIUS, J.; SMITH, A.H.V. \& STAPLIN, F.L. 1964. Densosporites (Berry) Potonié \& Kremp and related genera. In: CONGRES STRATIGRAPHIE ET GÉOLOGIE DU CARBONIFĖRE, 5, Paris, 1963. Compte Rendu..., 1:1049-1057.

CAETANO-CHANG, M.R. 1984. Análise ambiental e estratigráfica do Subgrupo Itararé (PC) no sudoeste do Estado de São Paulo. São Paulo, 309 p., inédito (Tese de Doutoramento - Instituto de Geociências da USP).

CAHEN, L. \& LEPERSONNE, J. 1978. Synthèse des connaissances relatives au Groupe (Anciennemente Sériè) de la Lukuga (Permien du Zaire). Annales du Musée Royal de L'Afrique Centrale, Série In- $8^{0}$; Sciences Geologiques, $n^{0} 82$.

CAUDURO, A.D. 1970. Lower Gondwana miospores from São Sepé outcrop (Rio Grande do Sul, Brasil). Escola de Geologia, Porto Alegre, Publ. Esp. n 17, 34 p., 20 pl.

CESARI, S.N. 1984. Palinologia de la formacion Tupe (Paleozoico Superior), Sierra de Maz, Provincia de La Rioja. Parte I. Ameghiniana, Buenos Aires, 21(1):85-102.

CESARI, S.N. 1985. Palinologia de La Formacion Tupe (Paleozoico Superior), Sierra de Maz, Provincia de la Rioja. Parte II. Ameghiniana, Buenos Aires, 22(3-4):197-212.

CESARI, S.N. 1986. Zonación palinologica del Carbonífero Tardio en Argentina. In: CONGRESSo ARgentino de PALEONTOlogia y BIoESTRATIGRAFIA, IV, Mendonza, 1986. Atas..., p. 227-230.

CESARI, S. N. \& GUTIERREZ, P.R. 1984. Microflora de la Localidad de Los Mogotes Colorados (Paleozóico Superior), Provincia de la Rioja, República Argentina. Bol. IG*USP, São Paulo, 15:2031.

CESARI, S.N. \& LIMARINO, C.O. 1992. Palinomorfos eocarboníferos en la Formacion Cortaderas, Provincia de San Juan, Argentina. In: Simpósio ARgentino de PAlEobotânICA E PALINOlogia, VIII, Corrientes, 1991. Actas..., Asociacion Paleontologica Argentina, Publ. Esp. n ${ }^{0}$ 2, p. 45-48.

CESARI, S.N.; ARCHANGELSKY, S. \& SEOANE, L.V. de. 1995. Palinologia del Paleozoico Superior de la perforacion Las Mochas, Provincia de Santa Fé, Argentina. Ameghiniana, Buenos Aires, 32(1):73-106.

CHALONER, W.G. 1962. A sporangiostrobus with Densosporites microspores. Palaeontology, Londres, 5(1):73-85.

CLAYTON, G.; COQUEL, R.; DOUBINGER, J.; GUEINN, K.J.; LOBOZIAK, S. \& OWENS, B. 1977. Carboniferous miospores of Western europe: illustration and zonation. Mededelingen Rijks Geologische Dienst, 29:1-71.

CLEMENT-WESTERHOFF, J.A. 1984. Aspects of Permian Palaeobotany and Palynology. IV. The Conifer Ortiseia Florin from the Val Gardena Formation on the Dolomites and the Vicentinian Alps (Italy) with special reference to a revised concepts of the Walchiaceae (Göppert) Schimper. Review of Palaeobotany and Palynology, Amsterdam, 41(1-2):51-166.

COOKSON, I.C. 1947. Records of the occurrence of Botryococcus braunii and the hystrichosphaeridae in Cainozoic deposits of Australia. Memoir of Natural Museum of Victoria, Queensland, 18:107123.

COQUEL, R. \& LATRECHE, S. 1989. Etude palynologique de la Formation D'Illerene (DevonoCarbonifere) du Bassin D'Illizi (Sahara Algerien Oriental). Palaeontographica, Abt. B, Sttugart, 212:47-70, 4 est. 
COQUEL, R. \& MOREAU-BENOIT, A. 1989. A propos de quelques spores trilètes <chambrées> du Dévonien Terminal-Carbonifère Inférieus d'Afrique du Nord. Revue de Micropaléontologie, Paris, 32(2):87-102.

COURVOISIER, J.M. \& PHILLIPS, T.L. 1975. Correlation of spores from Pennsylvanian coal-ball fructification with dispersed spores. Micropaleontology, New York, 21(1):45-59.

DAEMON, R.F. 1966. Ensaio sobre a distribuição e zoneamento dos esporomorfos do Paleozóico Superior da Bacia do Paraná. Boletim Técnico da Petrobrás, Rio de Janeiro, 9(2):211-218.

DAEMON, R.F. 1974a. Integração dos resultados palinológicos da fauna e flora das camadas fossilíferas da Bacia do Paraná - Implicações estratigráficas e paleogeográficas. Revista Unimar, Maringá, 1:25-40.

DAEMON, R.F. 1974b. Palinomorfos-guias do Devoniano Superior e Carbonífero Inferior das bacias do Amazonas e Paraniba. An. Acad. bras. Ci., Rio de Janeiro, 46(3-4):549-587.

DAEMON, R.F. 1981. Controle litobioestratigráfico preliminar do Devoniano, Carbonífero Superior e Permiano da bacia sedimentar do Paraná. In: Simpósıo Regional dE Geologia, 3, São Paulo, 1981. Atas... SBG, p. 124-132.

DAEMON, R. F. \& QUADROS, L.P. 1970. Bioestratigrafia do Neopaleozóico da Bacia do Paraná. In: CONGRESSO BRASILEIRO DE GEOLOGIA, 24, Brasília, 1970. Anais... SBG, p. 359-412.

DAEMON, R.F. \& MARQUES-TOIGO, M. 1991. An integrated biostratigraphical column for the Paraná Basin, Brazil. In: INTERNATIONAL CONGRESS OF CARBONIFEROUS AND PERMIAN Stratigraphy AND Geology, 12, Buenos Aires, 1991. Abstracts..., p. 25-26.

DAEMON, R.F. \& FRANÇA, A.B. 1993. Sedimentos do Westfaliano (Carbonífero Médio) na Formação Lagoa Azul, Grupo Itararé. In: Simpósio SOBRE Cronoestratigrafia DA BACIA DO PARANÁ, 1 , Rio Claro, 1993. Resumos, p. 36.

DAEMON, R.F.; QUADROS, L.P. de; PICARELLI, A.T.; MARQUES-TOIGO, M.; \& CAZZULOKLEPZIG, M. 1992. Arcabouço bioestratigráfico da Bacia do Paraná - Grupo Itararé. Fase 1: Palinologia quantitativa e a evolução paleoambiental do Grupo Itararé. Rio de Janeiro, 156 p., 9 anexos, Relatório Interno PETROBRÁS, projeto 01.02.41, CENPES-SUPEP-DIVEX-SEBIPE.

DELLAZZANA, J.G. 1976. Contribuição à palinologia da Formação Irati (Permiano) Rio Grande do Sul, Brasil. Ameghiniana, Buenos Aires, XIII(1):1-42.

DETTMAN, M.E. 1963. Upper Mesozoic microfloras from South-Eastern Australia. Proceedings of Royal Society of Victoria, Brisbane, 77:1-148.

DIAS, M.E.R. 1993a. Palinologia do Grupo Itararé no Rio Grande do Sul. Porto Alegre, 277 p., 13 est., inédito (Tese de Doutoramento - Instituto de Geociências da UFRGS).

DIAS, M.E.R. 1993b. Palinologia do Grupo Itararé na porção centro-sul do Rio Grande do Sul, Permiano da Bacia do Paraná, Brasil. Pesquisas, Porto Alegre, 20(2):132-140.

DIAS-FABRÍCIO, M.E. 1981. Palinologia da Formação Rio Bonito na área de Gravataí - Morungava, Rio Grande do Sul. Pesquisas, Porto Alegre, 14:69-130.

DINIZ, M.N. 1985. Interpretação ambiental da Formação Ponta Grossa na parte central da Bacia do Paraná - Um estudo de subsuperfície. São Paulo, 148 p., inédito (Dissertação de Mestrado Instituto de Geociências da USP).

DINO, R. \& RODRIGUES, M.A.C. 1995. Palinomorfos eodevonianos da Formação Furnas - Bacia do Paraná. An. Acad. bras. Ci., Rio de Janeiro, 67(1):107-116.

DOUBINGER, J. \& BROUTIN, J. 1976. Premières études palinologiques dans le bassin autunostéphanien de Guadalcanal (Nord de la Province de Séville, Espagne du Sud). Bull. Soc. géol. France, Paris, XVIII(4): 1033-1040. 
DOWNIE, C.; EVITT, W.R. \& SARJEANT, W.A.S. 1963. Dinoflagelates, hystrichospheres and the classification of the Acritarchs. Geological Sciences, Standford Univ. Publ., 7(3):3-16.

DYBOVÁ, S. \& JACHOWICZ, A. 1957. Microspores of the Upper Silesian Coal Measures. Mikrospory, Wydawnictawa Geologiczne, Warszawa, vol. 28, 328 p., 41 est.

EGGERT, D.A. \& TAYLOR, T.N. 1966. Studies of Paleozoic ferns: on the genus Tedelea gen. nov. Palaeontographica, Abt B, Sttutgart, 118:52-73.

ERDTMAN, G. 1947. Suggestions for the classification of fossil and recente pollen grains and spores. Svensk. Bot. T., Upsala, 41(1):104-114.

ESHET, Y.; DRUCKMAN, Y.; COUSMINER, H.L.; HABIB, D. \& DRUGG, W.S. 1988. Reworked palynomorphs and their use in the determination of sedimentary cycles. Geology, Boulder, 16:662665 .

EVANS, C.R. 1969. Upper Carboniferous and Permian palynological stages and their distribution in Eastern Australia. In: Gondwana STRATIGRAPHY, IUGS SyMPOSIUM, Buenos Aires, 1967. UNESCO, Earth Sciences, 2:41-54.

EVITT, W.R. 1963. A discussion and proposals concerning fossil dinoflagellates, hystrichospheres and acritarchs. I. Natu. Acad. Sci, USA, 49(2):158-164.

FALCON, R.M.S. 1975. Palyno-stratigraphy of the Lower Karroo sequence in the Central Sebungwe District, Mid-Zambezi Basin, Rhodesia. Palaeontologia Africana, Johannesburgo, 18:1-29.

FASOLO, Z. \& VERGEL, M.M. 1993. Palinología de la perforación Fraile Muerto (FM 2), Formacion Tres Islas (Permico Inferior) de la Cuenca Paraná del Uruguay. Acta Geológica Leopoldensia, São Leopoldo, XVII(39/2):679-689.

FELIX, C.J. \& BURBRIDGE, P.P. 1967. Palynology of the Springer Formation of southern Oklahoma, U.S.A. Palaeontology, Londres, 10(3), 349-425.

FOSTER, C.B. 1975. Permian plant microfossils from the Blair Athol Coal Measures, Central Queensland, Australia. Palaeontographica, Abt. B, Sttutgart, 154:121-171.

FOSTER, C.B. 1979. Permian plant microfossils of the Blair Athol Coal Measures, Baralaba Coal Measures, and Basal Rewan Formation of Queensland. Geological Survey of Queensland, Brisbane, 372(45): 1-154.

FRAKES, L.A. \& FIGUEIREDO-FILHO, P.M. de. 1967. Glacial rocks of the Paraná Basin exposed along the Sorocaba Itapetininga Road. In: BIGARELLA, J.J.; BECKER, R.D. \& PINTO, I.D. (edit.). Problems in Brazilian Gondwana Geology. INTERNATIONAL SYMPOSIUM ON THE GONDWANA STRATIGRAPHY AND PALAEONTOLOGY, 1, Curitiba, 1967. p. 103-106.

FRANÇA, A.B. \& POTTER, P.R. 1988. Estratigrafia, ambiente deposicional e análise de reservatório do Grupo Itararé (Permocarbonífero), Bacia do Paraná (Parte I). Boletim de Geociência da Petrobrás, Rio de Janeiro, 2(2/4):447-491.

GÓRECKA, T. \& GÓRECKA-NOWAK, A. 1990. Palynostratigraphic studies of Upper Carboniferous deposits from the Intra-Sudetic Basin, southwestern Poland. Review of Paleobotany and Palynology, Amsterdam, 65:287-292.

GOULD, R.E. \& DELEVORYAS, T. 1977. The biology of Glossopteris: evidence from petrified seedbearing spores. Alcheringa, Sydney, 1(3-4):387-399.

GRAUVOGEL-STAMM, L. \& DOUBINGER, J. 1975. Deux fougères fertiles du Stéphanien du Massif Central (France). Geóbios, Lion, 8(6):37-41.

GRAY, J. \& BOUCOT, A.J. 1975. Color changes in pollen and spores: a review. Geological Society of America Bulletin, Boulder, 86:1019-1033. 
GREGORY, W.A. \& HART, G.F. 1992. Towards a predictive model for the palynologic response to sealevel changes. Palaios, Tulsa, 7(1):3-33.

GUTIERREZ, P.R. 1993. Palinologia de la Formacion Agua Colorada (Carbonifero Superior), Sierra de Famatina, Provincia de La Rioja, Argentina. I. Granos de polen. Ameghiniana, Buenos Aires, 30(2): 163-212.

HACQUEBARD, P.A. 1957. Plant spores in coal from the Horton Group (Mississipian) of Nova Scotia. Micropaleontology, New York, 3(4);301-324.

HAMER, J.J. \& ROTHWELL, G.W. 1983. Philipopteris gen. nov. - Anatomical preserved sporangial fructifications from the Upper Pennsylvanian of the Appalachian Basin. American Journal of Botany, 70(9): 1378-1385.

HART, G.F. 1964. A review of the classification and distribution of the Permian miospore: Dissacate Striatiti. In: CONGRĖs INTERNATIONAL DE STRATIGRAPHIE ET DE GÉOLOGIE DU CARBONIFĖRE, 5, Paris, 1963. Compte Rendú, 4:1171-1199

HART, G.F. 1965. The systematic and distribution of Permian miospores. Johannesburg, 252 p., Witwatersrand University Press.

HART, G.F. 1971. The Gondwana Permian palynofloras. An. Acad. bras. Ci., Rio de Janeiro, 43(suplemento): 145-185.

HIGGS, K.T. 1975. Upper Devonian and Lower Carboniferous miospores assemblages from Hook Head, County Wexford, Ireland. Micropaleontology, Londres, 21(4):393-419.

IANNUZZI, R. \& RÖSLER, O. 1993. Migração florística na América do Sul durante o Carbonífero: uma hipótese de trabalho. In: CONGRESSO BRASILEIRO DE PALEONTOLOGIA, 13, São Leopoldo, 1993. Resumos, p. 198.

INSTITUTO GEOLÓGICO. 1990. Mapeamento geológico da folha de Salto de Pirapora - SP. Escala 1:50.000. Secretaria do Meio Ambiente do Estado de São Paulo, 76 p., 24 fot., 2 anexos, inédito (relatório interno).

JANSONIUS, J. 1962. Palynology of Permian and Triassic sediments, Peace River Area, Western Canada. Palaeontographica, Stuttgart, Abt. B, 110:35-98, pl. 11-16.

JARDINÉ, S. 1974. Microflores des Formations du Gabon attibuées au Karroo. Review of Palaeobotany and Palynology, Amsterdam, 17(1/2):75-112.

JARDINÉ, S. \& YAPAUDJIAN, L. 1968. Lithostratigraphie et palynologie du dévonien-Gothlandien gréseux du Bassin de Polignac (Sahara). Revue de l'Institut Français du Pétrole, Rueil-Malmaison, 23(4):439-469.

KEMP, E.M. 1975. The palynology of Late Paleozoic glacial deposits of Gondwanaland. In: CAMPBELL, K.S.W. (edit.). Gondwana Geology. Papers from the Gondwana Symposium, Camberra. Australian National University Press, p. 397-416.

KEMP, E. M.; BALME, B.E.; HELBY, R.J.; KYLE, R.A.; PLAYFORD, G. \& PRICE, P.L.1977. Carboniferous and Permian palynostratigraphy in Australia and Antarctica: a review. BMR Journal of Australian Geology and Geophisic, Camberra, 2:177-208.

KMIECIK, H. 1986. Palynostratigraphy of the Carboniferous at the margin of the polish part of the EastEuropean Platform. Review of Palaeobotany and Palynology, Amsterdam, 48:327-345.

KOSANKE, R.M. 1950. Pennsynvanian spores of Illinois and their use in correlation. State Geological Survey of Illinois, Urbana, Bull. 74, 128 p.,

LAVEINE, J.P. 1969. Quelques Pécoptéridinées houillères à la lumière de la palynologie. Pollen et Spores, Paris, 11(3):619-688. 
LAVEINE, J.P. 1971. Sporomorphs in situ de quelques Parispermées (Neuroptéridées) du Carbonifère. Ann. Soc. Géol. Nord., 91(2):155-173.

LEGAULT, J.A. \& NORRIS, G. 1982. Palynological evidence for recybling of Upper Devonian into Lower Cretaceus of the Moose River Basin, James Bay Lowland, Ontario. Canadian Journal of Earth Sciences, Ottawa, 19(1):1-7.

LEINZ, V. 1937. Estudos sobre a glaciação permocarbonifera do sul do Brasil. DNPM, Div. Fom. Prod. Miner., Rio de Janeiro, Bol. 21, 47 p.

LEIPNITZ, B. 1981. Estudo palinológico da Formação Palermo, Estado de Santa Catarina, Permiano, Bacia do Paraná, Brasil. Porto Alegre, 141 p., 7 est., inédito (Dissertação de Mestrado, Intituto de Geociências da UFRGS).

LELE, K.M. 1964. Studies in the Talchir flora of India: 2. Resolution of the sporegenus Nuskoisporites Pot. \& Kl. The Palaeobotanist, Lucknow, 12(2):147-168, 2 pl.

LELE, K.M. \& KARIM, R. 1971. Studies in the Talchir flora of India - 6. Palynology of the Talchir Boulder Bed in Jayanti coalfield, Bihar. The Palaeobotanist, Lucknow, 19(1):52-69.

LESCHIK, G. 1955. Die Keuperflora von Neueweit bei Basel. II: Die Iso und Mikrosporen. Schweizerischen Paläontologischen Abhandlungen, Zurich, 72:1-70.

LIMA, M.R. de \& SUNDARAM, D. 1982. Reavaliação dos dados palinológicos do Neopaleozóico brasileiro. Bol. IG-USP, São Paulo, 13:81-99.

LIMA, M.R. de; SAAD, A.R.; CARVALHO, R.G. de \& SANTOS, P.R. dos. 1976. Foraminiferos arenáceos e outros fósseis do Subgrupo Itararé (Neopaleozóico), Bacia do Paraná, Brasil. In: CONGRESSo Brasileiro de Geologia, 29, Ouro Preto, 1976. Anais... SBG, p. 49-64.

LIMA, M.R. de; DINO, R. \& YOKOYA, N.S.1983. Palinologia das concreções calcíferas do Subgrupo Itararé (Neopaleozóico da Bacia do Paraná) na região de Araçoiaba da Serra, Estado de São Paulo. An. Acad. bras. Ci., Rio de Janeiro, 55(2):195-208.

MADLER, K.A. 1963. Die figurierten organischen Besandteile der Posidonienschiefer. Beihefte Zum Geologischen Jahrbuch, Hannover, 58:287-406.

MAHESHWARI, H.K. 1969. Palaeozoic sporae dispersae from Congo. X - Microfossils from a cliff section at the confluence of Lufupa and Mushyashya rivers, South Katanga. Annales du Musée Royal de l'Afrique Centrale, Tervuren, Série IN 80, Sciences Geologiques, $\mathrm{n}^{\circ}$ 63, p. 115-168, 6 pl.

MAHESHWARI, H.K. \& BOSE, M.N. 1969. Palaeozoic sporae dispersae from Congo. VIII - The Kibamba River (Lukuga coalfield area). Annales du Musée Royal de L'Africa Centrale, Tervuren, Série IN $8^{\circ}$, Sciences Geologiques, $n^{\circ} 63$, p. 3-63, 9 pl.

MARQUES-TOIGO, M. 1970. Anabaculites nov. gen., a new miospore genus from San Gregorio Formation of Uruguai. Ameghiniana, Buenos Aires, VII(1):79-82.

MARQUES-TOIGO, M. 1974. Some new species of spores and pollens of Lower Permian age from the Sant Gregorio Formation in Uruguay. An. Acad. bras. Ci.,Rio de Janeiro, 46(3/4):601-616.

MARQUES-TOIGO, M. 1988. Palinologia, bioestratigrafia e paleoecologia do Neopaleozóico da Bacia do Paraná nos estados do Rio Grande do Sul e Santa Catarina, Brasil. Porto Alegre, 259 p., 9 est., inédito (Tese de Doutoramento - Instituto de Geociências da UFRGS).

MARQUES-TOIGO, M. 1991.Palynobiostratigraphy of the southern brazilian neopaleozoic Gondwana sequence. In: INTERNATIONAL GONDWANA SYMPOSIUM, 7, São Paulo, 1988. Proceedings..., p. 503-515.

MARQUES-TOIGO, M. \& PONS, M.E. 1974. Estudo palinológico do furo de sondagem P7 malha oeste da bacia carbonífera de iruí, RS, Brasil. In: CONGRESSO BRASILEIRO DE GEOLOGIA, XXVIII, Porto Alegre, 1974. Anais..., vol. II:277-288. 
MARQUES-TOIGO, M. \& PICARELLI, A.T. 1984. On the morphology and affinities of Lundbladispora Balme 1963, in the Permian of the Paraná Basin, Brazil. Bol. IG-USP, São Paulo, 15:46-52.

MARQUES-TOIGO, M.; CAZZULO-KLEPZIG, M.; PICARELLI, A.T. \& QUADROS, L.P. de.1995. The occurrence of disaccites Striatiti polen grains in the Amazonas Basin Namurian palaeoclimatic and paleogeographic implications. In: INTERNATIONAL CONGRESS ON CARBONIFERous-PERMIAN, XIII, Kraków, 1995. Abstracts... Polish Geological Institute, p. 97.

MASSOLI, M. 1991. Relação entre o embasamento cristalino e os sedimentos basais do Subgrupo Itararé na região de Salto de Pirapora, SP. São Paulo, 94 p., inédito (Dissertação de Mestrado Instituto de Geociências da USP).

McGREGOR, D.C. 1961. Spores with proximal radial pattern. Geological Survey of Canada, Bull. 76, Ottawa, 10 p., 1 est.

MENÉNDEZ, C.A. \& PÖTHE DE BALDIS, E.D. 1967. Devonian spores from Paraguai. Review of Palaeobotany and Palynology, Amsterdam, 1:161-172.

MENÉNDEZ, C.A. \& AZCUY, C.L. 1972. Ancistrospora un nuevo genero de miospora del Carbonico de la Argentina. Revista Española de Micropaleontología, Madrid, IV(2):157-168.

MILANI, J.E.; FRANÇA, A.B. de \& SCHNEIDER, R.L. 1994. Bacia do Paraná. Boletim de Geociências da Petrobrás, Rio de Janeiro, 8(1):69-82.

MILLAN, J.H. 1987. Os pisos florísticos do carvão do Subgrupo Itararé no Estado de São Paulo e suas implicações. In: CONGRESSO BRASIleIRo DE PALEONTOlOGiA, 10, Rio de Janeiro, 1987. Anais... SBP, p. 832-857.

MILLAY, M.A. \& TAYLOR, T.N. 1982. The ultrastructure of Paleozoic fern spores: I Botryopteris. American Journal of Botany, 69(7):1148-1155.

MOORE, P.D. \& WEBB, J.A. 1978. An illustrated guide to pollen analysis. Londres, 133 p., Hodder and Stoughton, Richard Clay Ltd.

NEEDHAM, H.D.; HABIB, D. \& HEEZEN, B.C. 1969. Upper Carboniferous palynomorphs as a tracer of red sediment dispersal patterns in the northwest Atlantic. The Journal of Geology, Chicago, $77(1): 113-120$.

NEVES, R. 1961. Namurian plant spores from the Southern Pennines, England. Palaeontology, Londres, 4(2):247-279.

NEVES, R. \& OWENS, B. 1966. Some namurian camerate miospores from the english Pennines. Pollen et Spores, Paris, 8(1-3):337-359.

NEVES, R. \& McLEAN, D. 1995. Taeniate pollen in the british Westphalian and their stratigraphical significance. In: INTERNATIONAL CONGRESS ON CARBONIFEROUS PERMIAN, XIII, Kraków, 1995. Abstracts... Polish Geological Institute, p. 104.

NYGREEN, P.W. \& BOURN, O.B. 1967. Morphological variation of Potonieisporites in the Late Pennsylvanian florule. Review of Palaeobotany and Palynology, Amsterdam, 1(1-4):115-128.

OLIVEIRA, S. de F. 1991. Acritarcas e prasinofíceas da Formação Ponta Grossa (Devoniano) no flanco noroeste da Bacia do Paraná. São Paulo, 205 p., 11 est. (Dissertação de Mestrado Instituto de Geociências da USP).

OLIWKIEWICZ-MIKLASINSKA, M. 1995. The occurence of rewoked miospores in deposits of the Upper Silesian sandstone Series and mudstone Series in the area of Jaworzno (Upper Silesian Coal Basin). In: Crongress on CARBONIFERous-PERMIAN, XIII, Kraków, 1995. Abstracts... Polish Geological Institute, p. 107. 
OTTONE, E.G. 1989. Palynoflores de la Formation Santa Máxima, paléozoïque Supérieus, République Argentine. Palaeontographica, Stuttgart, Abt. B, 213: 89-148, pl. 1-12.

OTTONE, E.G. 1991. Palynologie du Carbonifère Supérieus de la Coupe de Mina Esperanza, Bassin Paganzo, Argentina. Revue de Micropaléontologie, Paris, 34(2):118-135.

OTTONE, E.G. \& AZCUY, C.L. 1989. Datos palinologicos de la Formacion Guandacol (Carbonifero) en la Quebrada la Delfina, Provincia de San Juan, Argentina. Ameghiniana, Buenos Aires, 26(34):191-208.

OTTONE, E.G. \& AZCUY, C.L. 1990. Palinologia del carbon del Agua Hedionda (Carbonifero). Huaco, Provincia de San Juan, Argentina. Ameghiniana, Buenos Aires, 27(1-2):3-18.

OWENS, B.; GUEINN, K.J. \& CAMERON, J.B. 1977. A tournaisian miospore assemblage from the Altagoan Formation (Upper Calciferous Sandstone), Draperstown, Northern Ireland. Pollen et Spores, Paris, XIX(2):313-324.

PAULIPETRO. 1983. Refinamento do zoneamento bioestratigráfico do Neopaleozóico da Bacia do Paraná. Relatório ${ }^{0}$ 18.142/83, Consório PAULIPETRO/CESP/IPT.

PEPPERS, R.A. 1964. Spores in strata of late Pennsylvanian Cyclothems in the Illinois Basin. State Geological Survey of Illinois, Urbana, Bull. 90, 72 p., 8 pl.

PETRI, S. 1964. Geologia do Estado de São Paulo. Instituto Geográfico e Geológico, São Paulo, Boletim 41, p. 56-63.

PETRI, S. \& SOUZA, P.A. de. 1993. Síntese dos conhecimentos e novas concepções sobre a bioestratigrafia do Subgrupo Itararé, Bacia do Paraná, Brasil. Rev. IG, São Paulo, 14(2):7-18.

PICCARELLI, A.T.; DIAS-FABRÍCIO, M.E. \& CAZZULLO-KLEPZIG, M. 1987. Considerações sobre a paleoecologia e a palinologia da jazida carbonífera de Santa Terezinha, RS, Brasil - Permiano da Bacia do Paraná. In: SimpósIo Sul-BrasileIRo DE GEOloGiA, III, Curitiba, 1987. Atas..., 1:351372.

PICCARELLI, A.T.; MARQUES-TOIGO, M.; QUADROS, L.P. de \& CAZZULLO-KLEPZIG, M. 1993. Ocorrência do gênero Protohaploxypinus no Namuriano da Bacia do Amazonas Implicações paleoclimáticas e paleogeográficas. In: CONGRESSO BRASILEIRO DE PALEONTOLOGIA, 13, São Leopoldo, 1993. Boletim de Resumos... , p. 137.

PLAYFORD, G. 1962. Lower Carboniferous microfloras of Spitsbergen. Palaeontology, Londres, 5(3):550-618.

PLAYFORD, G. 1964. Miospores from the Mississipian Horton Group, Eastern Canada. Geological Survey of Canada, Ottawa, Bull. 107, 47 p., 11 est.

PLAYFORD, G. 1977. Lower to Middle Devonian acritarchs of the Mosse River Basin, Ontario. Geological Survey of Canada, Ottawa, Bull. 279, 46 p., 20 est.

PLAYFORD, G. 1978. Lower Carboniferous spores from the Ducabrook Formation, Drummond Basin, Queensland. Palaeontographica, Sttutgart, Abt. B, 167:195-160.

PLAYFORD, G. \& HELBY, R. 1968. Spores from a carboniferous section in the Hunter Valley, New South Wales. Journal of the Geological Society of Australia, Sydney, 15(1):103-119.

PLAYFORD, G. \& POWIS, G.D. 1979. Taxonomy and distribution of some trilete spores in carboniferous strata of the Canning Basin, Western Australia. Pollen et Spores, Paris, XXI(3):371394.

PLAYFORD, G. \& McGREGOR, D.C. 1993. Miospores and organic-wallered microphytopiankton of Devonian-Carboniferous boundary beds (Bakker Formation), Southern Saskatchewan: a systematic and stratigraphic appraisal. Geological Survey of Canada, Calgary, Bull. 445, 64 p., 21 pl. 
PONS, M.E. 1976b. Estudo palinológico do Sub-grupo Itararé na "Coluna White", Permiano Inferior, Santa Catarina, Brasil. Parte II. Ameghiniana, Buenos Aires, 13(3-4):235-253.

POTONIÉ, R. 1956. Synopsis der Gattungen der Sporae dispersae. Beihefte zum Geologischen Jahrbuch, Heft 23, 103 p., 11 est.

POTONIÉ, R. 1958. Synopsis der Gattugen der Sporae Dispersae. II Teil: Sporites, Saccites, Aletes, Preacolpates, Polyplicates, Monocolpates. Geologischen Jahrbuch, Hannover, 31:1-114.

POTONIÉ, R. 1970. Synopsis der Gattungen der Sporae Dispersae. V Teil: Nachträge zur allen Gruppen (Turmae). Geologischen Jahrbuch, Hannover, 87:1-172.

POTONIÉ, R. \& KREMP, G.O.U. 1954. Die Gattungen der Paläozoischen sporae dispersae und ihre Stratigraphie. Geologischen Jahrbuch, Hannover, 69:111-194.

POTONIÉ, R. \& KREMP, G.O.U. 1956. Die Sporae dispersae des Ruhrkarbons, ihre Morphographie und Stratigraphie mit Ausblicken auf Arten anderer Gebiete und Zeitabschnite. Teil III. Palaeontographica, Abt. B, Stuttgart, 100:85-191.

QUADROS, L.P. \& MELLO, J.H.G. de. 1987. Método prático de preparação palinológica em sedimentos pré-mesozóicos. Boletim de Geociências da Petrobrás, Rio de Janeiro, 1(2):205-214.

REMY, R. 1975. The floral change at the Carboniferous-Permian boundary in Europa and North America. In: Bouriow, A. J. (Edit.), I.C. White Memorial SyMposium - "The AGE OF THE DUNKARD", 1, Morgantown, 1972. Proceedings...., p. 305-343.

RICHARDSON, J.B. 1965. Middle Old Red Sandstone spore assemblages from the Orcadian basin, north-east Scotland. Palaeontology, Londres, 7(4):559-605.

ROCHA-CAMPOS, A.C. 1967. The Tubarão Group in the brazilian portion of the Parana Brasil. In: BIGARELlA, J.J.; BECKER, R.D. \& PINTO, I.D. (edits.). Problems in Brazilian Gondwana Geology, p. 27-102.

ROCHA-CAMPOS, A.C. \& RÖSLER, O. 1978. Late Paleozoic faunal and floral sucessions in the Paraná bașin, southeastern Brazil. Bol. IG-USP, São Paulo, 9:1-15.

ROCHA-CAMPOS, A.C.; SANTOS, P.R.; OLIVEIRA, M.E.C. \& SAAD, P.R. 1976. Boulder pavements and the sense of the movemente of Late paleozoic glaciers in Central Eastern São Paulo State, Paraná Basin, Brazil. Bol. IG-USP, São Paulo, 7:149-160.

RÖSLER, O. 1978. The brazilian eogondwanic floral sucessions. Bol. IG-USP, São Paulo, 9:85-91.

ROTHWELL, G.W. 1982. New interpretations of the earliest conifers. Review of Palaeobotany and Palynology, Amsterdam, 37(1-2):7-28.

RUSSO, A; ARCHANGELSKY, S. \& GAMERRO, J.C. 1980. Los depositos suprapaleozoicos en el subsuelo de la llanura Chaco-pangeana, Argentina. In: CONGREsO ARgENTINA DE Paleontologia y Bioestratrgrafia, II, Buenos Aires, 1980. Atas..., 4:157-173.

SAAD, A.R. 1977. Estratigrafia do Subgrupo Itararé no centro e sul do Estado de São Paulo. São Paulo, 107 p, inédito (Dissertação de Mestrado - Instituto de Geociências da USP).

SANTOS, P.R. dos. 1979. Distribuição estratigráfica, características e fácies de diamictitos e rochas associadas do Subgrupo Itararé no centro e sul do Estado de São Paulo. São Paulo, 135 p., inédito (Dissertação de Mestrado - Instituto de Geociências da USP).

SANTOS, P.R. dos. 1987. Fácies e evolução paleogeográfica do Subgrupo Itararé/Grupo Aquidauana (Neopaleozóico) na Bacia do Paraná, Brasil. São Paulo, 128 p, vol. I, inédito (Tese de Doutoramento - Instituto de Geociências da USP).

SCHAARSCHMIDT, F. 1963. Sporen und hystrichosphaerideen aus dem jechstein von büdingen in der Wetterau. Palaeontographica, Sttutgart, Abt B, 113:38-91. 
SEGROVES, K.L. 1969. Saccate plant microfossils from the Permian of Western Europe. Grana Palynologyca, Uppsala, 9(1-3):174-227.

SEGROVES, K.L. 1970. The sequence of palynological assemblages in the Permian of the Perth Basin, Western Australia. In: GoNDWANA SYMPOSIUM, 2, Pretoria, 1970. Council for Scientific and Industrial Research, p. 511-529.

SMITH, A.V.H. \& BUTHERWORTH, M.A. 1967. Miospores in the coal sequence of the Carboniferous of Great Britain. Special Paper in Palaeontology, Londres, vol. 1, p. 1-342.

SOARES, P.C.; LANDIM, P.M.B.; SINELLI, O.; WERNICK, E.; WU, F.T. \& FIORI, A.P. 1977. Associações litológicas do Subgrupo Itararé e a sua interpretação ambiental. Revista Brasileira de Geociências, São Paulo, 7:131-149.

SOUZA, P.A. de. 1994. Palinoestratigrafia do Subgrupo Itararé na região de Salto de Pirapora, Estado de São Paulo. In: SEMINÁRIO ANUAL Do INSTITUTO GEOLÓGICO, 1, São Paulo, 1994. Resumos... IGSMA, p 59-60.

SOUZA, P.A. de \& LIMA, M.R. de. 1994. Palinologia, bioestratigrafia e paleogeografia do Subgrupo Itararé (Neopaleozóico da Bacia do Paraná) na região de Salto de Pirapora, Estado de São Paulo, Brasil. In: WORKSHOP CIENTÍFICO DE PÓS-GRAdUAÇÃO, I, São Paulo, 1994. Resumos... IG-USP, p. 25 .

SOUZA, P.A. de; LIMA, M.R. de \& SAAD, A.R. 1990. Palinologia dos carvões paleozóicos do Estado de São Paulo. I - O Carvão de Buri. Paleobotânica Latinoamericana, São Paulo, Circular Informativa da ALPP, 9(1):55.

SOUZA, P.A. de; LIMA, M.R. de \& SAAD, A.R. 1993a. Palinologia dos carvões paleozóicos do Estado de São Paulo. I - O Carvão de Buri. Rev. IG, São Paulo, 14(1):5-20.

SOUZA, P.A. de; LIMA, M.R. de \& SAAD, A.R. 1993b. Palinologia dos carvões paleozóicos do Estado de São Paulo. III - O Carvão de Cerquilho. In: CONGRESSo BrasileIro DE PAleontologia, 13, São Leopoldo, 1993. Resumos, p. 62.

SOUZA, P.A. de; LIMA, M.R. de \& SAAD, A.R. 1993c. Palinologia dos carvões paleozóicos do Estado de São Paulo. II - O Carvão de Monte Mor. An. Acad. bras. Ci., Rio de Janeiro, 65(3):327.

SOUZA-FILHO, E. E. de. 1986. Mapeamento faciológico do Subgrupo Itararé na Quadrícula de Campinas (SP). São Paulo, 121 p., inédita (Dissertação de Mestrado - Instituto de Geociências da USP).

SRIVASTAVA, S.C. 1973. Permian Microfloras. Aspects and Appraisal of Indian Palaeobotany, Lucknow, p. 278-284.

STANLEY, E.A. 1965. Use of reworked pollen and spores for determining the Pleistocene-Recent and the Intra-Pleistocene boundaries. Nature, Londres, 206(4981):289-291.

STANLEY, E.A. 1966. The problem of reworked pollen and spores in marine sediments. Marine Geology, Amsterdam, 4:397-408.

STAPLIN, F.L. 1960. Upper Mississippian plant spores from the Golata Formation, Alberta, Canada. Palaeontographica, Sttutgart, Abt. B, 107:1-40, pl. 1-8.

STAPLIN. F.L. 1961. Reef controlled distribution of Devonian microplancton in Alberta, Canada. Palaeontology, Londres, 4(3):392-424.

STAPLIN, F.L. \& JANSONIUS, J. 1964. Elucidation of some Paleozoic Densospores. Palaeontographica, Sttutgart, Abt B,. 114:95-117, pl. 18-21.

STAPLIN, F.L.; POCOCK, S.J. \& JANSONIUS, J. 1967. Relationship among Gimnospernous pollen. Review of Palaeobotany and Palynology, Amsterdam, 3(1-4):297-310. 
STAPLIN, F.L.; POCOCK, S.J. \& JANSONIUS, J. 1967. Relationship among Gimnospernous pollen. Review of Palaeobotany and Palynology, Amsterdam, 3(1-4):297-310.

STEVAUX, J.C.; SOUZA-FILHO, E.E. de; TEIXEIRA, J.A. \& LANDIM, P.M.B. 1987. Sistemas deposicionais do Subgrupo Itararé (P-C) na bacia hidrográfica do baixo rio Capivari, SP: um modelo para prospeç̧ão de água subterrânea. In: SIMPÓSIO REGIONAL DE GEOLOGIA, VI, Rio Claro, 1987. Atas... SBG, 1:355-374.

SULLIVAN, H.J. 1964. Miospores from the Drybrook Sandstone and associated measures in the forest of Dean Basin, Gloucestershire. Palaeontology, Londres, 7(3):351-392.

SUNDARAM, D. 1980. Observações palinológicas sobre alguns sedimentos do Gondwana Inferior da Bacia do Paraná, Brasil. Bol. IG-USP, São Paulo, 11:161-189.

SUNDARAM, D. 1987. Palinologia do Subgrupo Itararé (Neopaleozóico da Bacia do Paraná) no Estado de São Paulo, Brasil. São Paulo, 311 p., 10 est., inédito (Tese de Doutoramento - Instituto de Geociências da USP).

TAYLOR, T.N. 1981. Palaeobotany: an introduction to fossil plant Biology. New York, 589 p., 1979. Edit. McGraw Hill.

TAYLOR, T.N. 1982. Ultraestructural studies of Paleozoic seed fern polien: sporoderm developement. Review of Palaeobotany and Palynology, Amsterdam, 37(1-2):21-53.

TIWARI, R.S. 1964. New miospore genera in the coals of Barakar Stage (Lower Gondwana) of India. The Palaeobotanist, Lucknow, 12(3):250-259.

TRUSWELL, E,M. 1980. Permo-Carboniferous palynology Gondwanaland: progress and problems in the decade to 1980. BMR Journal of Australian Geology and Geophysics, Camberra, 5:95-111.

UTTING, J. 1994. Palynostratigraphy of Permian and Lower Triassic rocks, Sverdup, Canadian Artic Archipelago. Geological Survey of Canadá, Ottawa, Bull. 478, 107 p.

VAN DE LAAR, J.G.M. \& FERMONT, W.J.J. 1990. Westphalian palynology of The Netherlands on six continuosly cored borehole. Review of Palaeobotany and Palynology, Amsterdam, 65:275-285.

VENKATACHALA, B.S.; TIWARI, R.S. \& VIJAYA. 1995. Diversification of sporte-pollen "character states" in the Indian Permian. Review of Palaeobotany and Palynology, Amsterdam, 85:319-340.

VERGEL. M. del. M. 1986. Consideraciones paleoecológicas sobre las palinofloras neopaleozóicas de la Cuenca Chacoparanense, Republica Argentina. In: CONGRESO ARGENTINO DE PALEONTOLOGIA Y BIOESTRATIGRAFIA, IV, Mendoza, 1986. Actas, vol. 1:221-225.

VERGEL. M. del. M. 1987. Palinologia del Paleozoico Superior en la perforation YPF SF J (Josefina), Provincia de Santa Fe, Argentina. II. Anteturma Variegerminantes, Grupo Acritarcha e Incertae Sedis. Ameghiniana, Buenos Aires, 24(1-2):67-80.

VERGEL. M. del. M. 1993. Palinoestratigrafia de la secuencia neopaleozoica en la Cuenca Chacoparanense, Argentina. In: INTERNATIONAL CONGRES ON CARBONIFEROUS-PERMIAN, XII, Buenos Aires, 1993. Comptes Rendus, vol. 1: 201-212.

WAGNER, R.H. 1980. Breve reseña de la labor cumplida por la subcomission internacional sobre la estratigrafia del Carbonifero (IUGS). In: CONGRESO ARGENTINA DE PALEONTOLOGIA Y Bioestratigrafia, Il, y Congreso latinoamericano de Paleontologia, I, Buenos Aires, 1978. Actas..., IV:237-244.

WAGNER, R.H. \& WRINKLER-PRINS, C.F. 1994. General overview of Carboniferous stratigraphy. Annales de la Societé Geologique de Belgique, Bruxelas, 116(1):163-174.

WALL, D. 1965. Modern hystrychospheres and dinoflagelate cysts from the Woods Hole region. Grana Palynologica, Uppsala, 6(2):297-314. 
WINDLE, T.M.F 1979. Reworked carboniferous spores: an example from the Lower Jurassic of northeast Scotland. Review of Palaeobotany and Palynology, Amsterdam, 27:173-184.

YBERT, J-P. 1975. Etude des miospores du bassin houiller de Candiota-Hulha Negra, Rio Grande do Sul, Bresil. Pesquisas, Porto Alegre, 5:181-226.

ZHOU, Y-X. 1994. Earliest pollen-dominated microfloras from the early late Carboniferous of the Tian Shan Mountains, NW China: their significance for the origin of conifers and palaeophytogeography. Review of Palaeobotany and Palynology, Amsterdam, 81:193-211.

ZHU HUAICHENG. 1993. A revised palynological sub-division of the Namurian of Jingyuan, northwest China. Review of Palaeobotany and Palynology, Amsterdam, 77(3/4):273-300. 


\section{ESTAMPAS}

As fotomicrografias apresentadas a seguir foram realizadas, quase que exclusivamente, em vista polar, ressaltando, por isso, os esporomorfos e acritarcas em posição equatorial.

A escala é diferenciada, com indicação de 40 ou $80 \mu \mathrm{m}$ para a mesma barra grafada.

As informações necessárias para a localização das formas nas lâminas e destas na coleção científica do Departamento de Paleontologia do Instituto de Geociências da USP, encontram-se na Tabela 18. 


\begin{tabular}{|c|c|c|c|c|c|c|c|}
\hline TÁXON & EST & FIG & PAG & $\begin{array}{l}\text { NIVEL } \\
(1)\end{array}$ & $\begin{array}{l}\text { LÁMINA } \\
(2)\end{array}$ & $\begin{array}{c}\text { COORD } \\
(3)\end{array}$ & (4) \\
\hline Ahrensisporites cristatus & 2 & 15 & $54-55$ & $171,3 a$ & GP/4E-1406 & $98,9 / 16,3$ & L29 \\
\hline Ancistrospora inordinata & 4 & 2 & $74-75$ & $137,0 \mathrm{a}$ & GP/4E-1392 & $105,0 / 21,0$ & F36 \\
\hline Ancistrospora reticulata & 4 & 3 & $75-76$ & $182,0 \mathrm{~b}$ & GP/4E-1412 & $87,8 / 13,7$ & N17 \\
\hline Ancistrospora reticulata & 4 & 5 & $75-76$ & $195,0 \mathrm{~b}$ & GP/4E-1416 & $110,2 / 18,1$ & $\mathrm{~J} 41$ \\
\hline Ancistrospora verrucosa & 4 & 1 & 74 & $152,5 b$ & GP/4E-1397 & $87,8 / 3,7$ & Y17 \\
\hline Apiculiretusispora sp. & 2 & 1 & 75 & $206,0 \mathrm{~b}$ & GP/4E-1420 & $92,0 / 3,2$ & Y22 \\
\hline Caheniasaccites densus & 9 & 7 & 103 & $209,0 \mathrm{~b}$ & GP/4E-1422 & $116,9 / 22,7$ & D48 \\
\hline Caheniasaccites ovatus & 9 & 6 & $102-103$ & $41,3 \mathrm{a}$ & GP/4E-1363 & $111,5 / 16,5$ & V42 \\
\hline Caheniasaccites ovatus & 9 & 4 & $102-103$ & $195,0 b$ & GP/4E-1416 & $107,0 / 20,0$ & G38 \\
\hline Caheniasaccites ovatus & 9 & 5 & $102-103$ & $206,0 b$ & GP/4E-1420 & $89,0 / 4,2$ & $\mathrm{X} 19$ \\
\hline Caheniasaccites sp. 1 & 10 & 1 & $103-104$ & $167,0 \mathrm{~b}$ & GP/4E-1401 & $119,2 / 8,0$ & U50 \\
\hline Caheniasaccites sp. 1 & 10 & 2 & $103-104$ & $182,0 \mathrm{~b}$ & GP/4E-1412 & $93,2 / 23,8$ & $\mathrm{C} 23$ \\
\hline Caheniasaccites sp. 2 & 10 & 3 & 104 & $167,0 \mathrm{~b}$ & GP/4E-1401 & $101,0 / 19,2$ & $\mathrm{H} 32$ \\
\hline Caheniasaccites sp. 2 & 10 & 4 & 104 & $201,0 \mathrm{~b}$ & GP/4E-1417 & $104,2 / 5,0$ & W35 \\
\hline Caheniasaccites sp. 3 & 10 & 5 & 105 & $45,0 \mathrm{~b}$ & GP/4E-1370 & $94,3 / 11,5$ & Q24 \\
\hline Calamospora hartungiana & 1 & 4 & 36 & $45,0 \mathrm{~b}$ & GP/4E-1371 & $117,2 / 17,1$ & K48 \\
\hline Calamospora liquida & 1 & 5 & 37 & $103,5 a$ & GP/4E-1388 & $114,6 / 2,5$ & $Z 45$ \\
\hline Calamospora sp. & 1 & 6 & 37 & $206,0 a$ & GP/4E-1419 & $109,9 / 7,0$ & U50 \\
\hline Cannanoropollis densus & 5 & 7 & 87 & $209,0 \mathrm{~b}$ & GP/4E-1422 & $93,2 / 23,9$ & $\mathrm{D} 23$ \\
\hline Cannanoropollis mehtae & 5 & 5 & $87-88$ & $45,0 \mathrm{~b}$ & GP/4E-1370 & $109,8 / 25,3$ & B41 \\
\hline Cannanoropollis perfectus & 5 & 4 & 86 & $77,0 \mathrm{a}$ & GP/4E-1382 & $101,1 / 6,9$ & U31 \\
\hline Cannanoropollis triangularis & 5 & 8 & $88-89$ & $206,0 b$ & GP/4E-1420 & $101,4 / 8,8$ & S32 \\
\hline Cannanoropolllis korbaensis & 5 & 6 & 89 & $98,0 b$ & GP/4E-1387 & $92,8 / 13,7$ & N23 \\
\hline Convolutispora sp. & 2 & 10 & 52 & $201,0 a$ & GP/4E-1417 & $112,1 / 14,5$ & $\mathrm{~N} 43$ \\
\hline Cristatisporites inconstans & 3 & 14 & $69-70$ & $195,0 a$ & GP/4E-1415 & $113,2 / 23,0$ & D44 \\
\hline Cristatisporites inconstans & 3 & 15 & $69-70$ & $201,0 \mathrm{~b}$ & GP/4E-1418 & $111,0 / 23,0$ & $\times 34$ \\
\hline Cristatisporites indignabundus & 3 & 13 & 69 & $206,0 \mathrm{a}$ & GP/4E-1419 & $116,7 / 18,1$ & $J 48$ \\
\hline Cristatisporites lestai & 3 & 16 & 71 & $167,0 \mathrm{a}$ & GP/4E-1400 & $128,0 / 7,7$ & U59 \\
\hline Cristatisporites mammillatus & 3 & 18 & $71-72$ & $167,0 \mathrm{~b}$ & GP/4E-1401 & $116,0 / 12,5$ & P47 \\
\hline Cristatisporites rolerii & 3 & 17 & 70 & $167,0 \mathrm{~b}$ & GP/4E-1401 & $95,5 / 9,1$ & $\mathrm{~S} 26$ \\
\hline Cristatisporites sp. & 3 & 19 & 72 & $167,0 \mathrm{a}$ & GP/4E-1400 & $111,2 / 11,5$ & Q42 \\
\hline Cyclogranisporites parvivermiculatus & 1 & 14 & $41-42$ & $152,5 b$ & GP/4E-1397 & $110,1 / 22,3$ & E41 \\
\hline Densosporites sp. & 3 & 4 & $60-61$ & $152,5 b$ & GP/4E-1397 & $109,7 / 11,0$ & Q40 \\
\hline Densosporites triangularis & 3 & 3 & 60 & $103.5 \mathrm{~b}$ & GP/4E-1389 & $105,0 / 11,0$ & Q35 \\
\hline Dentatispora cf. D. indica & 4 & 4 & 61 & $57,0 \mathrm{~b}$ & GP/4E-1377 & $105,8 / 21,4$ & E37 \\
\hline Dictyotriletes muricatus & 2 & 7 & 50 & $167,0 b$ & GP/4E-1401 & $106,2 / 20,2$ & G37 \\
\hline Dictyotriletes pseudopalliatus & 2 & 8 & $50-51$ & $152,5 b$ & GP/4E-1397 & $87,3 / 13,4$ & 017 \\
\hline Dictyotriletes sp. & 2 & 9 & $51-52$ & $206,0 \mathrm{~b}$ & GP/4E-1420 & $107,0 / 6,2$ & V37 \\
\hline Emphanisporites rotatus & 2 & 12 & $53-54$ & $152,5 b$ & GP/4E-1397 & $91,1 / 17,2$ & J21 \\
\hline Esporo Indeterminado 1 & 4 & 11 & 80 & $137,0 \mathrm{a}$ & GP/4E-1392 & $111,0 / 6,5$ & V42 \\
\hline Esporo Indeterminado 2 & 4 & 12 & $80-81$ & $168,0 \mathrm{~b}$ & GP/4E-1403 & $109,0 / 13,1$ & 039 \\
\hline Esporo Indeterminado 3 & 4 & 8 & 81 & $167,0 \mathrm{~b}$ & GP/4E-1401 & $111,4 / 2,4$ & Z42 \\
\hline Florinites guttatus & 5 & 1 & 84 & $206,0 b$ & GP/4E-1420 & $108,9 / 21,8$ & E39 \\
\hline Florinites occultus & 5 & 3 & 83 & $209,0 \mathrm{~b}$ & GP/4E-1422 & $111,2 / 5,1$ & W42 \\
\hline Florinites sp. & 5 & 2 & $84-85$ & $188,5 b$ & GP/4E-1414 & $92,2 / 3,1$ & $\mathrm{X} 22$ \\
\hline Gorgonisphaeridium sp. & 12 & 11 & 121 & $167,0 \mathrm{a}$ & GP/4E-1400 & $119,8 / 3,3$ & $Z 51$ \\
\hline Grandispora brevispinosa & 4 & 10 & $79-80$ & $152,5 b$ & GP/4E-1397 & $98,0 / 2,8$ & Y28 \\
\hline Granulatisporites triconvexus & 1 & 16 & 43 & $77,0 \mathrm{~b}$ & GP/4E-1383 & $118,4 / 16,1$ & L50 \\
\hline Granulatisporites varigranifer & 1 & 15 & $42-43$ & $77,0 \mathrm{~b}$ & GP/4E-1383 & $109,8 / 19,3$ & G41 \\
\hline Kraeuselisporites sp. & 3 & 12 & $67-68$ & $167,0 \mathrm{~b}$ & GP/4E-1401 & $101,8 / 19,4$ & G32 \\
\hline Limitisporites delasaucei & 11 & 6 & 109 & $171,3 \mathrm{c}$ & GP/4E-1408 & $105,2 / 10,2$ & R36 \\
\hline Limitisporites luandensis & 11 & 4 & 108-109 & $167,0 \mathrm{a}$ & GP/4E-1400 & $104,1 / 12,1$ & P35 \\
\hline Limitisporites sp. 1. & 11 & 7 & 110-111 & $195,0 b$ & GP/4E-1416 & $109,8 / 23,1$ & D40 \\
\hline Limitisporites sp. 2 & 11 & 8 & $111-112$ & $25,5 a$ & GP/4E-1357 & $102,0 / 17,1$ & K32 \\
\hline Limitisporites vesiculosus & 11 & 5 & 110 & $152,5 b$ & GP/4E-1397 & $98,1 / 10,5$ & R28 \\
\hline Lundbladispora braziliensis & 2 & 16 & 58 & $155,0 \mathrm{~b}$ & GP/4E-1399 & $102,0 / 7,9$ & T32 \\
\hline Lundbladispora nobonitensis & 2 & 17 & 57 & $152,5 a$ & GP/4E-1396 & $121,1 / 21,1$ & F52 \\
\hline Lundbladispora sp. & 2 & 18 & 58 & $167,0 \mathrm{~b}$ & GP/4E-1401 & $95,9 / 12,1$ & $\mathrm{P} 26$ \\
\hline Lycospora sp. 1 & 3 & 1 & 59 & $26,5 b$ & GP/4E-1360 & $105,0 / 15,0$ & N36 \\
\hline Lycospora sp. 2 & 3 & 2 & 59 & $209,0 \mathrm{~b}$ & GP/4E-1422 & $92,1 / 5,6$ & $\mathrm{X} 22$ \\
\hline Murospora sp. & 2 & 11 & 53 & $152,5 b$ & GP/4E-1397 & $114,1 / 15,0$ & M45 \\
\hline Navifusa bacillum & 12 & 8 & $119-120$ & $43,5 b$ & GP/4E-1368 & $120,0 / 13,0$ & P51 \\
\hline Navifusa sp. & 12 & 10 & 120 & $209,0 a$ & GP/4E-1421 & $99,9 / 17,3$ & $\sqrt{30}$ \\
\hline Navifusa sp. & 12 & 9 & 120 & $41,0 \mathrm{~b}$ & GP/4E-1362 & $92,1 / 15,7$ & M23 \\
\hline
\end{tabular}




\begin{tabular}{|c|c|c|c|c|c|c|c|}
\hline Plicatipollenites cf. P. malabarensis & 6 & 5 & $93-94$ & $206,0 \mathrm{~b}$ & GP/4E-1420 & $112,1 / 3,8$ & Y43 \\
\hline Plicatipollenites densus & 6 & 3 & 92 & $209,0 b$ & GP/4E-1422 & $112,1 / 20,0$ & G43 \\
\hline Plicatipollenites gondwanensis & 6 & 4 & $92-93$ & $41,0 \mathrm{~b}$ & GP/4E-1362 & $116,8 / 12,0$ & P47 \\
\hline Plicatipollenites gondwanensis & 6 & 8 & $92-93$ & $170,0 \mathrm{~b}$ & GP/4E-1405 & $107,2 / 7,5$ & U38 \\
\hline Plicatipollenites malabarensis & 6 & 7 & $90-91$ & $206,0 a$ & GP/4E-1419 & $121,9 / 19,6$ & $\mathrm{H} 53$ \\
\hline Plicatipollenites malabarensis & 6 & 6 & $90-91$ & $41,3 a$ & GP/4E-1363 & $119,0 / 6,5$ & F46 \\
\hline Plicatipollenites trigonalis & 6 & 2 & 91 & $25,5 b$ & GP/4E-1358 & $85,7 / 10,0$ & R15 \\
\hline Plicatipollenites trigonalis & 6 & 1 & 91 & $25,5 a$ & GP/4E-1357 & $103,7 / 4,6$ & $\times 34$ \\
\hline Potonieisporites brasiliensis & 7 & 4 & $95-96$ & $152,5 b$ & GP/4E-1397 & $117,0 / 20,1$ & G48 \\
\hline Potonieisporites brasiliensis & 7 & 3 & $95-96$ & $152,5 b$ & GP/4E-1397 & $89,7 / 10,4$ & R20 \\
\hline Potonieisporites cf. P. triangulatus & 9 & 1 & 99 & $152,5 b$ & GP/4E-1397 & $86,7 / 12,8$ & 016 \\
\hline Potonieisporites congoensis & 8 & 2 & $98-99$ & $168,0 a$ & GP/4E-1402 & $11,2 / 19,2$ & $\mathrm{H} 42$ \\
\hline Potonieisporites magnus & 8 & 1 & $96-97$ & $195,0 \mathrm{a}$ & GP/4E-1415 & $116,9 / 13,0$ & 048 \\
\hline Potonieisporites neglectus & 8 & 4 & 98 & $167,0 \mathrm{a}$ & GP/4E-1400 & $128,8 / 7,8$ & U60 \\
\hline Potonieisporites novicus & 7 & 2 & 95 & $195,0 a$ & GP/4E-1415 & $112,2 / 14,7$ & $\mathrm{~N} 43$ \\
\hline Potonieisporites novicus & 7 & 1 & 95 & $201,0 a$ & GP/4E-1417 & $100,0 / 10,1$ & R30 \\
\hline Potonieisporites simplex & 8 & 3 & 97 & $26,5 b$ & GP/4E-1360 & $100,8 / 5,8$ & W31 \\
\hline Potonieisporites sp. 1 & 9 & 2 & 100 & $182,0 \mathrm{~b}$ & GP/4E-1412 & $92,1 / 18,0$ & $\sqrt{22}$ \\
\hline Potonieisporites sp. 2 & 9 & 3 & 101 & $209,0 \mathrm{~b}$ & GP/4E-1422 & $99,7 / 4,9$ & W30 \\
\hline Protohaploxypinus amplus & 12 & 3 & 114 & $137,0 \mathrm{~b}$ & GP/4E-1393 & $113,3 / 22,8$ & D44 \\
\hline Protohaploxypinus dvinensis & 12 & 5 & 115 & $77,0 \mathrm{~b}$ & GP/4E-1383 & $106,1 / 20,3$ & F37 \\
\hline Protohaploxypinus latissimus & 12 & 1 & 113 & $\mathrm{~km} \mathrm{118,6}$ & GP/4E-1335 & $124,0 / 14,6$ & N55 \\
\hline Protohaploxypinus samoilovich & 12 & 2 & $113-114$ & $98,0 \mathrm{a}$ & GP/4E-1386 & $102,0 / 3,9$ & $\mathrm{X} 32$ \\
\hline Protohaploxypinus sp. & 12 & 6 & $116-117$ & $167,0 \mathrm{~b}$ & GP/4E-1401 & $98,4 / 2,9$ & $Z 29$ \\
\hline Protohaploxypinus chaloneri & 12 & 4 & $115-116$ & $209,0 a$ & GP/4E-1421 & $120,1 / 14,9$ & M51 \\
\hline Punctatisporites foveolatus & 1 & 2 & 34 & $201,0 \mathrm{~b}$ & GP/4E-1418 & $95,0 / 13,3$ & $\mathrm{O} 25$ \\
\hline Punctatisponites gretensis & 1 & 1 & 33-34 & $45,0 \mathrm{~b}$ & GP/4E-1371 & $92,7 / 7,7$ & U23 \\
\hline Punctatisporites solidus & 1 & 3 & 35 & $167,0 \mathrm{a}$ & GP/4E-1400 & $115,9 / 9,3$ & R46 \\
\hline Raistrickia rotunda & 2 & 3 & 47 & $167,0 \mathrm{a}$ & GP/4E-1400 & $117,4 / 18,1$ & $\mathrm{~J} 48$ \\
\hline Raistrickia sp. & 2 & 4 & 48 & $155,0 \mathrm{a}$ & GP/4E-1398 & $113,5 / 5,5$ & W44 \\
\hline Retusotriletes baculiferus & 1 & 9 & 39 & $45,0 \mathrm{~b}$ & GP/4E-1371 & $117,2 / 8,1$ & T48 \\
\hline Retusotriletes golatensis & 1 & 8 & $39-40$ & $137,0 \mathrm{a}$ & GP/4E-1392 & $127,7 / 12,8$ & P59 \\
\hline Retusotriletes nigritellus & 1 & 10 & 38 & $155,0 a$ & GP/4E-1398 & $112,0 / 23,4$ & $\mathrm{C} 43$ \\
\hline Retusotriletes simplex & 1 & 7 & $37-38$ & $201,0 a$ & GP/4E-1417 & $123,8 / 20,9$ & F55 \\
\hline Retusotriletes sp. 1 & 1 & 11 & 40 & $41,0 \mathrm{~b}$ & GP/4E-1362 & $105,0 / 20,2$ & U40 \\
\hline Retusotriletes sp. 2 & 1 & 12 & 40 & $170,0 b$ & GP/4E-1405 & $115,0 / 2,1$ & $\mathrm{Z46}$ \\
\hline Retusotriletes sp. 3 & 1 & 13 & 41 & $45,0 \mathrm{~b}$ & GP/4E-1371 & $98,9 / 23,4$ & D29 \\
\hline Secarisporites cf. S. lobatus & 2 & 5 & $48-49$ & $152,5 b$ & GP/4E-1397 & $89,1 / 10,8$ & R19 \\
\hline Secarisporites sp. & 2 & 6 & 49 & $167,0 \mathrm{~b}$ & GP/4E-1401 & $106,8 / 13,1$ & 037 \\
\hline Spelaeotriletes sp. & 4 & 9 & 79 & $152,5 b$ & GP/4E-1397 & $112,9 / 13,2$ & 044 \\
\hline Spelaeotriletes triangulus & 4 & 7 & $77-78$ & $168,0 \mathrm{a}$ & GP/4E-1402 & $107,7 / 7,4$ & U38 \\
\hline Spelaeotriletes ybertii & 4 & 6 & 78 & $168,0 \mathrm{~b}$ & GP/4E-1403 & $115,0 / 4,6$ & $\mathrm{X} 46$ \\
\hline Spinozonotriletes conspicuus & 2 & 2 & $46-47$ & $167,0 \mathrm{~b}$ & GP/4E-1401 & $115,9 / 5,3$ & W46 \\
\hline Stenozonotriletes perforatus & 2 & 13 & $55-56$ & $137,0 \mathrm{~b}$ & GP/4E-1393 & $105,2 / 23,5$ & $\mathrm{C} 36$ \\
\hline Stenozonotriletes sp. & 2 & 14 & 56 & $152,5 b$ & GP/4E-1397 & $97,8 / 14,2$ & N28 \\
\hline Striatoabieites $s p$ & 12 & 7 & 117 & $155,0 \mathrm{~b}$ & GP/4E-1399 & $108,2 / 24,0$ & C39 \\
\hline Striomonosaccites cf. S. ovatus & 11 & 1 & 106 & $170,0 \mathrm{~b}$ & GP/4E-1405 & $102,0 / 12,5$ & P33 \\
\hline Striomonosaccites sp. 1 & 11 & 2 & 106-107 & $170,0 \mathrm{~b}$ & GP/4E-1405 & $100,8 / 15,9$ & L31 \\
\hline Striomonosaccites sp. 2 & 11 & 3 & $107-108$ & $41,0 \mathrm{~b}$ & GP/4E-1362 & $98,2 / 22,9$ & D29 \\
\hline Vallatisporites arcuatus & 3 & 6 & 63 & $206,0 b$ & GP/4E-1420 & $117,0 / 20,0$ & G48 \\
\hline Vallatisporites banffensis & 3 & 8 & $64-65$ & $26,5 a$ & GP/4E-1359 & $119,5 / 12,2$ & P50 \\
\hline Vallatisporites cf. V. spinosus & 3 & 10 & 66 & $41,0 a$ & GP/4E-1361 & $98,3 / 17,1$ & $\mathrm{~K} 29$ \\
\hline Vallatisporites ciliaris & 3 & 7 & 63-64 & $167,0 \mathrm{~b}$ & GP/4E-1401 & $114,2 / 17,3$ & K45 \\
\hline Vallatisporites punctatus & 3 & 9 & $65-66$ & $124,0 \mathrm{~b}$ & GP/4E-1391 & $117,0 / 7,0$ & U48 \\
\hline Vallatisporites sp. & 3 & 11 & 67 & $124,0 \mathrm{a}$ & GP/4E-1390 & $123,9 / 4,1$ & Y55 \\
\hline Vallatisporites vallatus & 3 & 5 & 62 & $98,0 \mathrm{~b}$ & GP/4E-1387 & $110,0 / 21,8$ & E41 \\
\hline Verrucosisporites cf. V. morulatus & 1 & 18 & $44-45$ & $171,3 \mathrm{a}$ & GP/4E-1406 & $99,0 / 8,0$ & T29 \\
\hline Verrucosisporites sp. & 1 & 19 & 45 & $201,0 \mathrm{a}$ & GP/4E-1417 & $118,2 / 20,0$ & G49 \\
\hline Verrucosisporites verrucosus & 1 & 17 & 44 & $152,5 b$ & GP/4E-1397 & $112,1 / 22,0$ & E43 \\
\hline
\end{tabular}

Tabela 18 - Informações sobre a localização dos táxons e lâminas no texto e na coleção científica do DPE-IG-USP.

1 - Profundidade no poço Geomater ou afloramento ( $\underline{a}$ e $\underline{b}$ são referentes às lâminas)

2 - Codificação da coleção do DPE-IG-USP

3 - Coordenadas do Microscópio Carl Zeiss do DPE-IG-USP

4 - Coordenadas na lâmina England Finder 


\section{ESTAMPA 01}

1- Punctatisporites gretensis Balme \& Hennelly, 1956

2- Punctatisporites foveolatus Maheswari \& Bose, 1969

3- Punctatisporites solidus Hacquebard, 1957

4- Calamospora hartungiana Schopf, Wilson \& Bentall, 1944

5- Calamospora liquida Kosanke, 1950

6- Calamospora sp.

7- Retusotriletes simplex Naumova, 1953

8- Retusotriletes golatensis Staplin, 1953

9- Retusotriletes baculiferus Ybert, 1975

10- Retusotriletes nigritellus (Lüber) Foster, 1979

11- Retusotriletes sp. 1

12- Retusotriletes $\mathrm{sp} .2$

13- Retusotriletes sp. 3

14- Cyclogranisporites parvigranulosus (Leschik) Ybert, 1975

15- Granulatisporites varigranifer Menéndez \& Azcuy, 1969

16- Granulatisporites triconvexus Staplin, 1960

17- Verrucosisporites verrucosus (Ibrahim) Ibrahim, 1933

18- Verrucosisporites cf. V. morulatus (Konx) Smith \&

Butterworth, 1967

19- Verrucosisporites sp. 


\section{ESTAMPA 01}

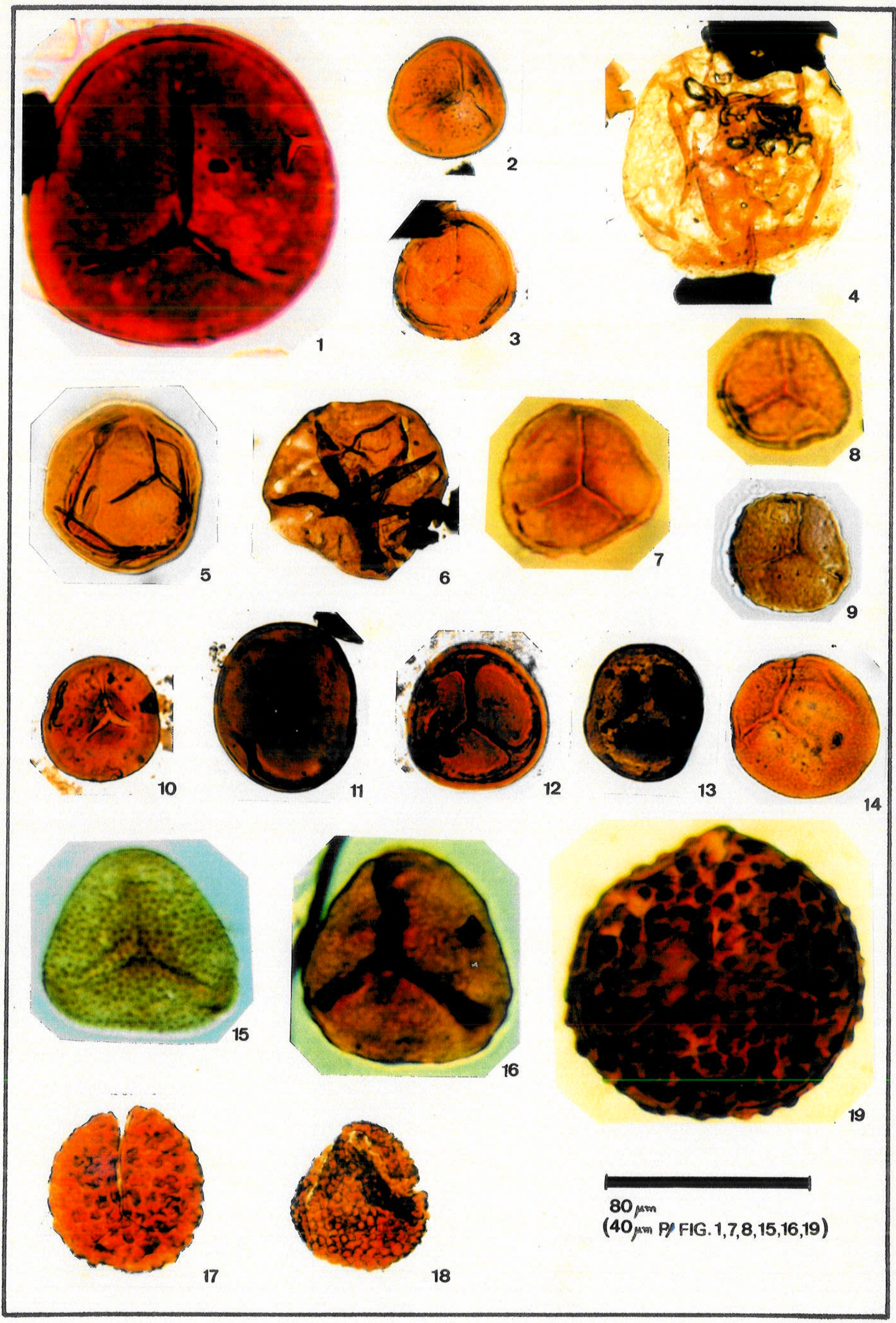




\section{ESTAMPA 02}

1- Apiculiretusispora sp.

2- Spinozonotriletes conspicuus Playford, 1964

3- Raistrickia rotunda Azcuy, 1975

4- Raistrickia sp.

5- Secarisporites of. S. lobatus Neves, 1961

6- Secarisporites sp.

7- Dictyotriletes muricatus (Kosanke) Smith \& Butterworth, 1967

8- Dictyotriletes pseudopalliatus (Stapli) comb. nov.

9- Dictyotriletes sp.

10- Convolutispora sp.

11- Murospora sp.

12- Emphanisporites rotatus McGregor, 1961

13- Stenozonotriletes perforatus Playford, 1962

14- Stenozonotriletes $\mathrm{sp}$.

15- Ahrensisporites cristatus Playford \& Powis, 1979

16- Lundbladispora braziliensis (Marques-Toigo \& Pons)

Marques-Toigo \& Picarelli, 1984

17- Lundbladispora riobonitensis Marques-Toigo \& Picarelli, 1984

18- Lundbladispora sp. 


\section{ESTAMPA 02}

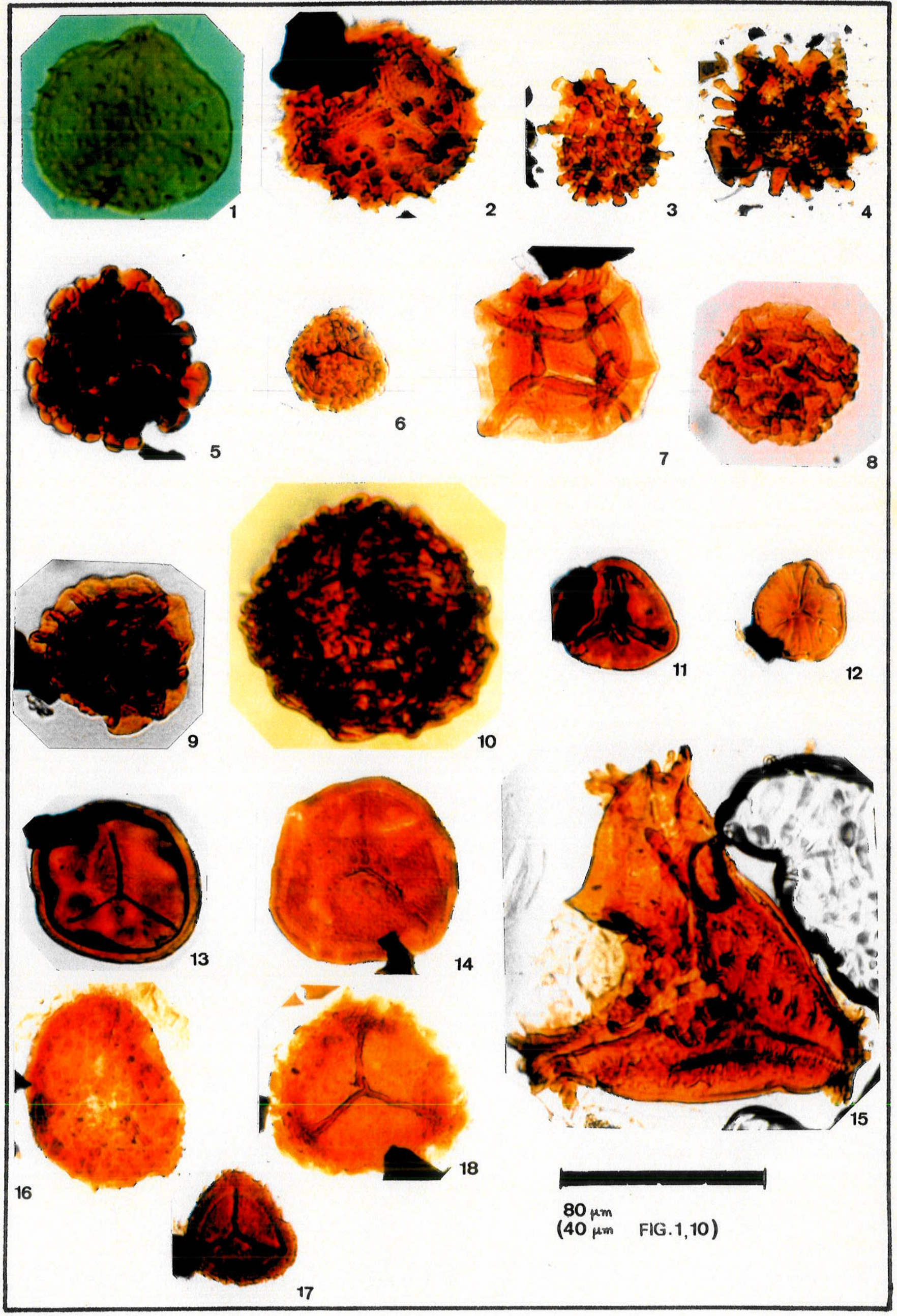




\section{ESTAMPA 03}

1- Lycospora sp.1

2- Lycospora sp. 2

3- Densosporites triangularis Kosanke, 1950

4- Densosporites sp.

5- Vallatisporites vallatus Hacquebard, 1957

6- Vallatisporites arcuatus (Marques-Toigo) Archangelsky \& Gamerro, 1979

7-Vallatisporites ciliaris (Lüber) Sullivan, 1964

8- Vallatisporites banffensis Staplin \& Jansonius, 1964

9- Vallatisporites punctatus (Marques-Toigo) comb. nov.

10- Vallatisporites cf. V. spinosus Cauduro, 1970

11- Vallatisporites sp.

12- Kraeuselisporites sp.

13- Cristatisporites indignabundus (Potonié \& Kremp) Staplin \& Jansonius, 1964

14 e 15- Cristatisporites inconstans Archangelsky \& Gamerro, 1979

16- Cristatisporites lestai Archangelsky \& Gamerro, 1979

17- Cristatisporites rolerii Ottone, 1989

18- Cristatisporites mammillatus Maheswari, 1969

19- Cristatisporites sp. 
ESTAMPA 03

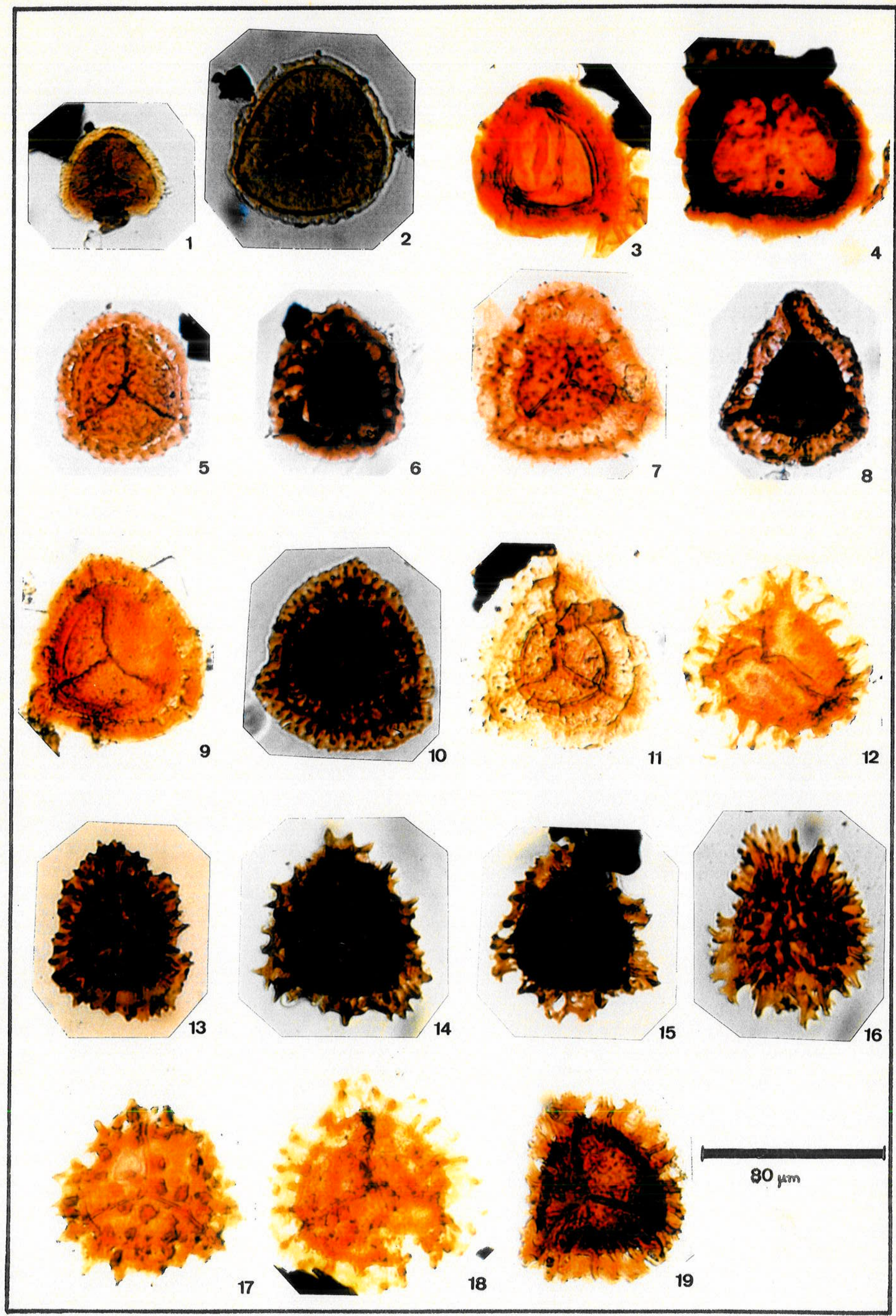




\section{ESTAMPA 04}

1- Ancistrospora verrucosa Menéndez \& Azcuy, 1972

2- Ancistrospora inordinata Menéndez \& Azcuy, 1972

3 e 5- Ancistrospora reticulata sp. $\mathrm{n}$.

4- Dentatispora cf. D. indica Tiwari, 1964

6 - Spelaeotriletes yberti (Marques-Toigo) Playford \& Powis, 1979

7 - Spelaeotriletes triangulus Neves \& Owens, 1966

8 - Esporo Indeterminado 3

9 - Spelaeotriletes sp.

10- Grandispora brevispinosa Menéndez \& Pöthe de Baldis, 1967

11- Esporo Indeterminado 1

12- Esporo Indeterminado 2 
ESTAMPA 04

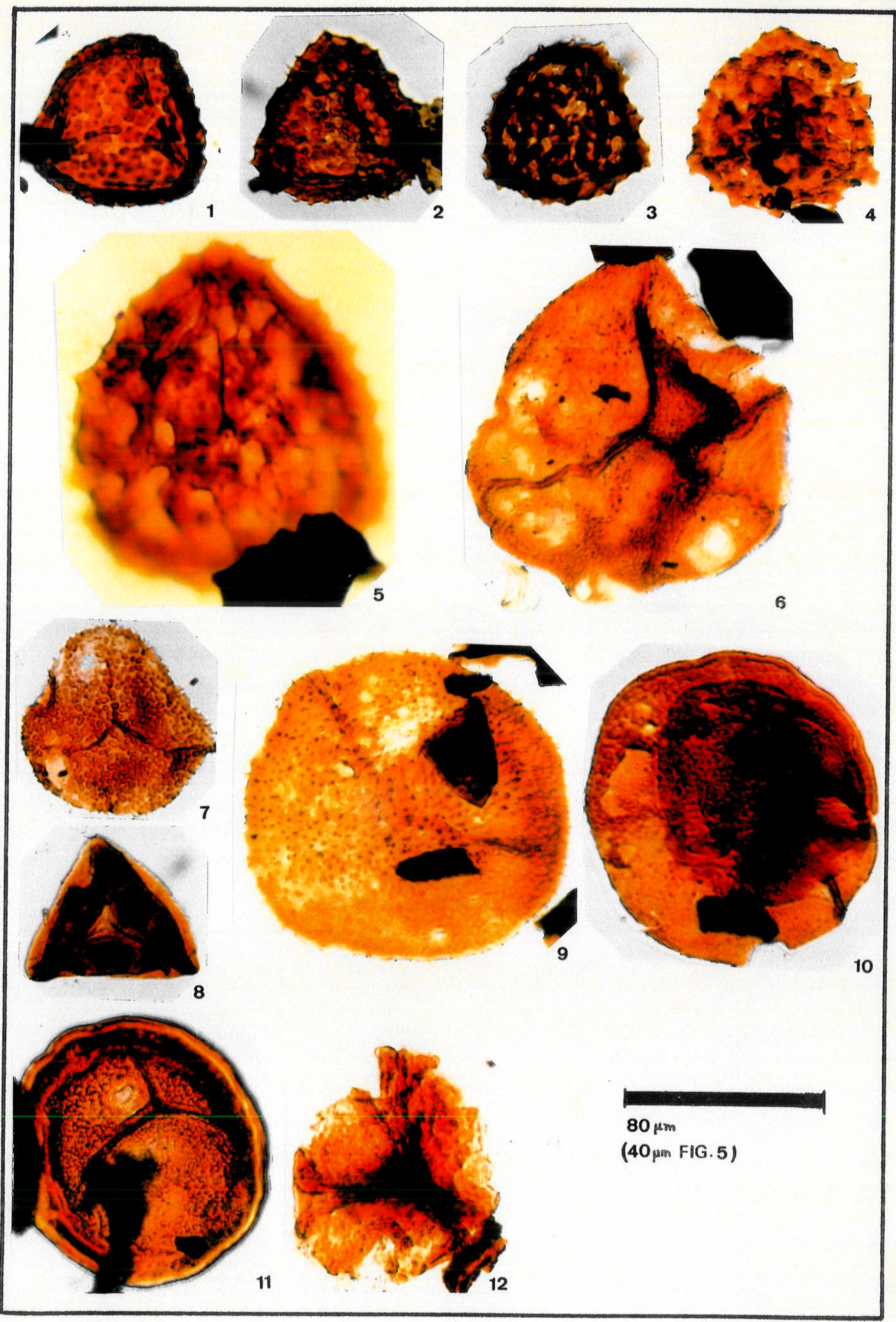




\section{ESTAMPA 05}

1- Florinites guttatus Felix \& Burbridge, 1967

2- Florinites sp.

3- Florinites occultus Habib, 1966

4- Cannanoropollis perfectus (Bose \& Maheswari) DiasFabrício, 1981

5- Cannanoropollis mehtae (Lele) Bose \& Maheswari, 1968

6- Cannanoropollis korbaensis (Bharadwaj \& Tiwari) Foster, 1975

7- Cannanoropollis densus (Lele) Bose \& Maheswari, 1968

8 - Cannanoropollis triangularis (Mehtae) Bose \& Maheswari, 1968 


\section{ESTAMPA 05}

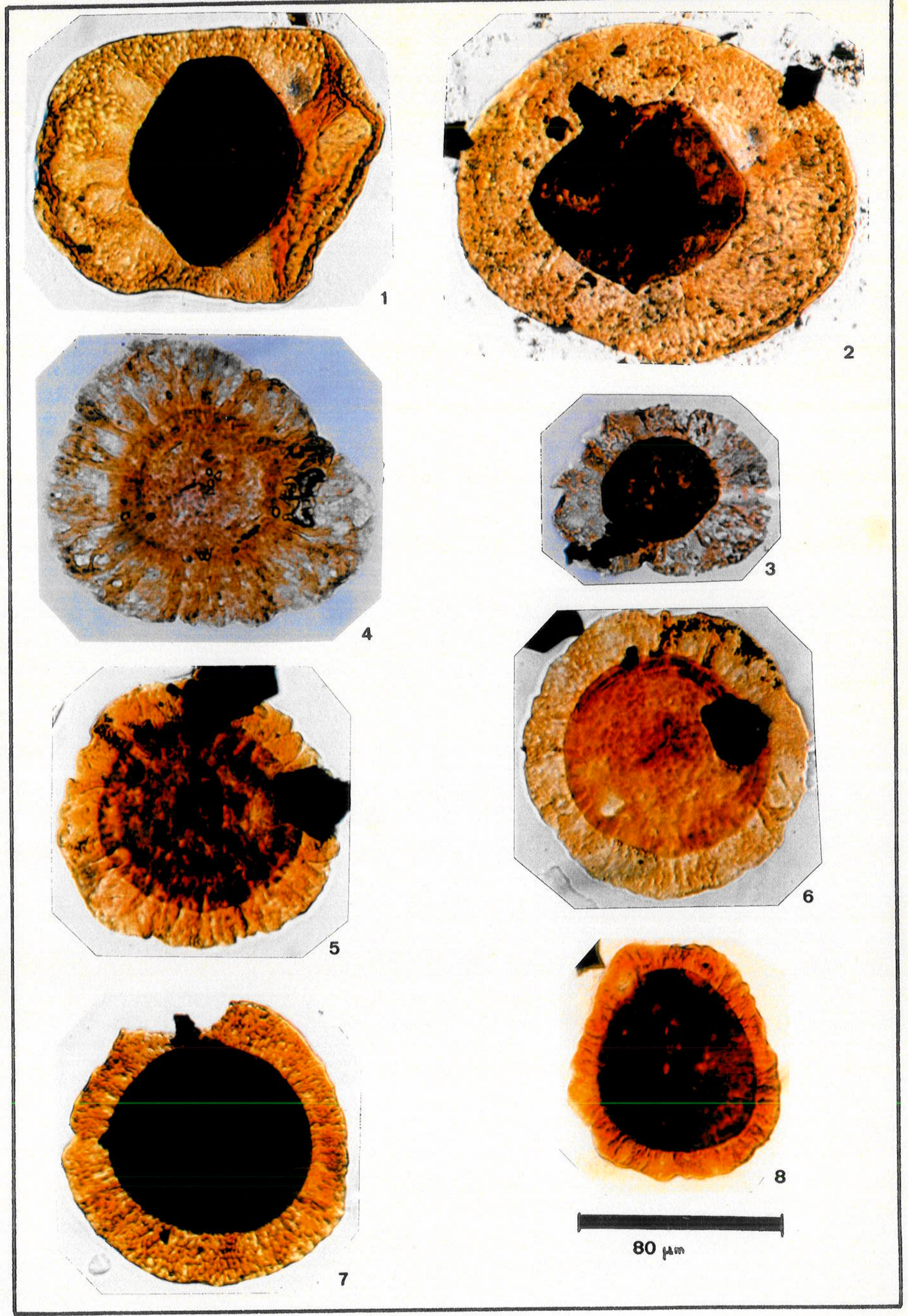




\section{ESTAMPA 06}

1 e 2- Plicatipolenites trigonalis Lele, 1964

3- Plicatipollenites densus Srivastava, 1970

4 e 8- Plicatipollenites gondwanensis (Balme \& Hennelly) Lele, 1964

5- Plicatipollenites cf. P. malabarensis (Potonié \& Sah) Foster, 1975

6 e 7-Plicatipollenites malabarensis (Potonié \& Sah) Foster, 1975 
ESTAMPA 06

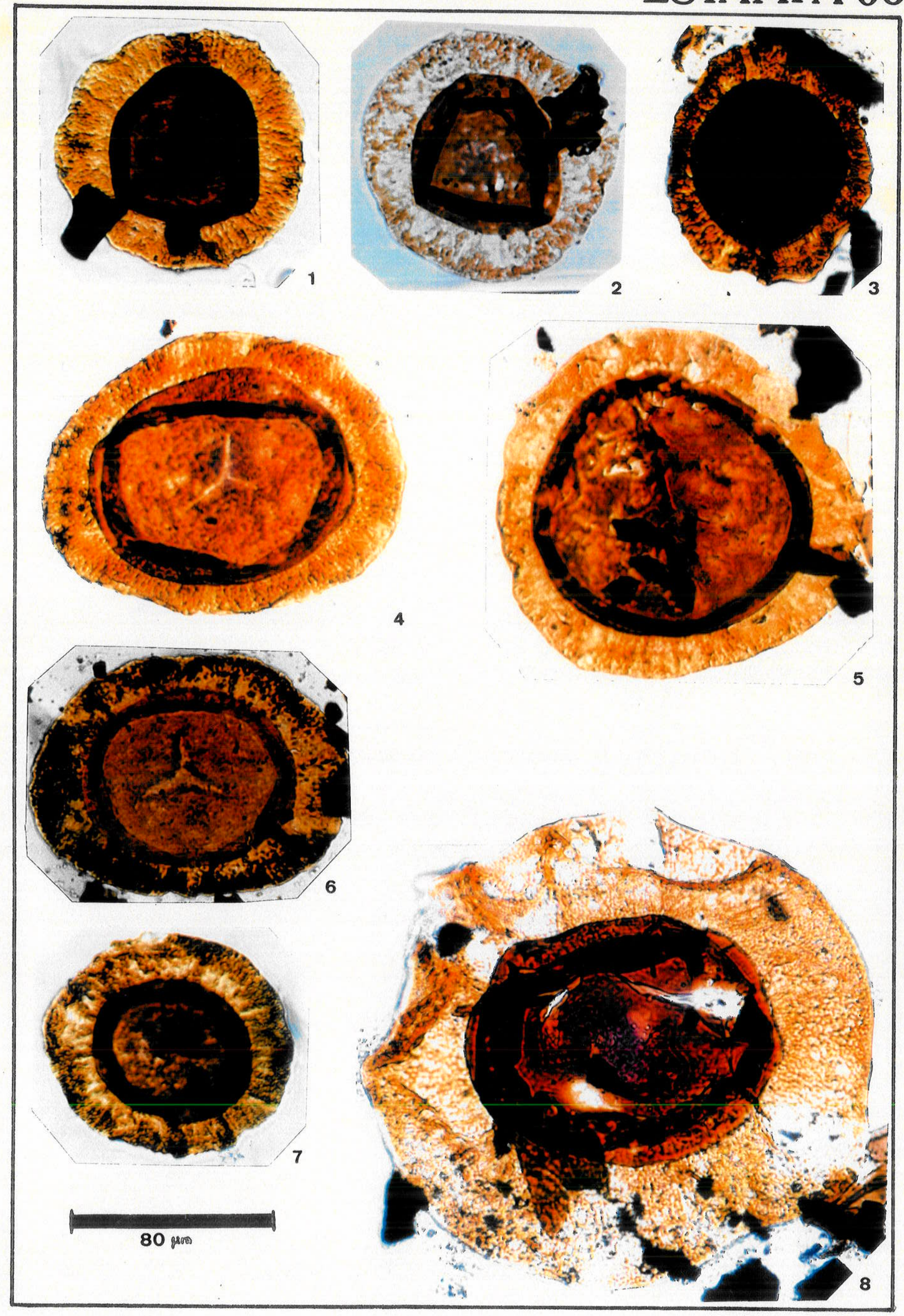




\section{ESTAMPA 07}

1 e 2- Potonieisporites novicus Bharadwaj, 1954

3 e 4- Potonieisporites brasiliensis (Nahuys, Alpern \& Ybert) Archangelsky \& Gamerro, 1979 

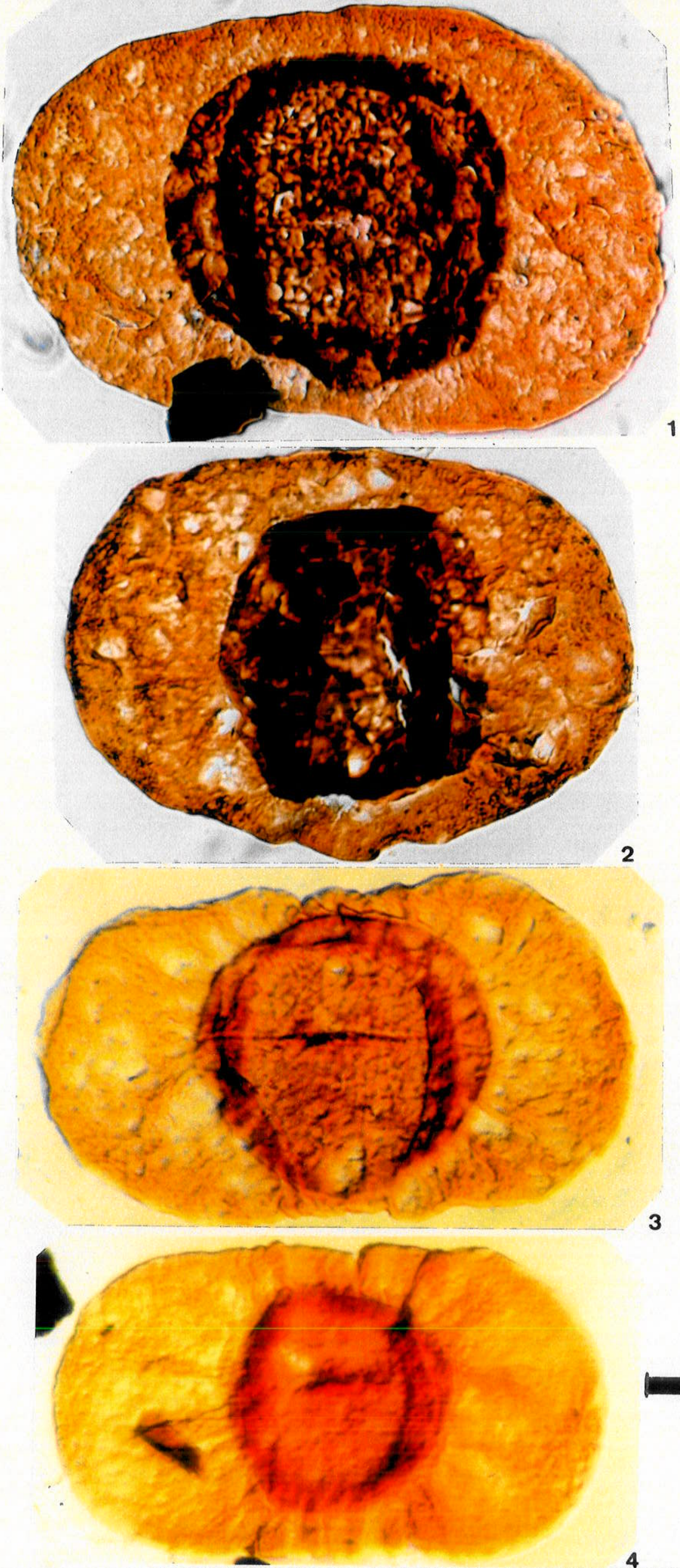


\section{ESTAMPA 08}

1- Potonieisporites magnus Lele \& Karim, 1971

2- Potonieisporites congoensis Bose \& Maheswari, 1968

3- Potonieisporites simplex Wilson, 1962

4- Potonieisporites neglectus Potonié \& Lele, 1961 
ESTAMPA 08

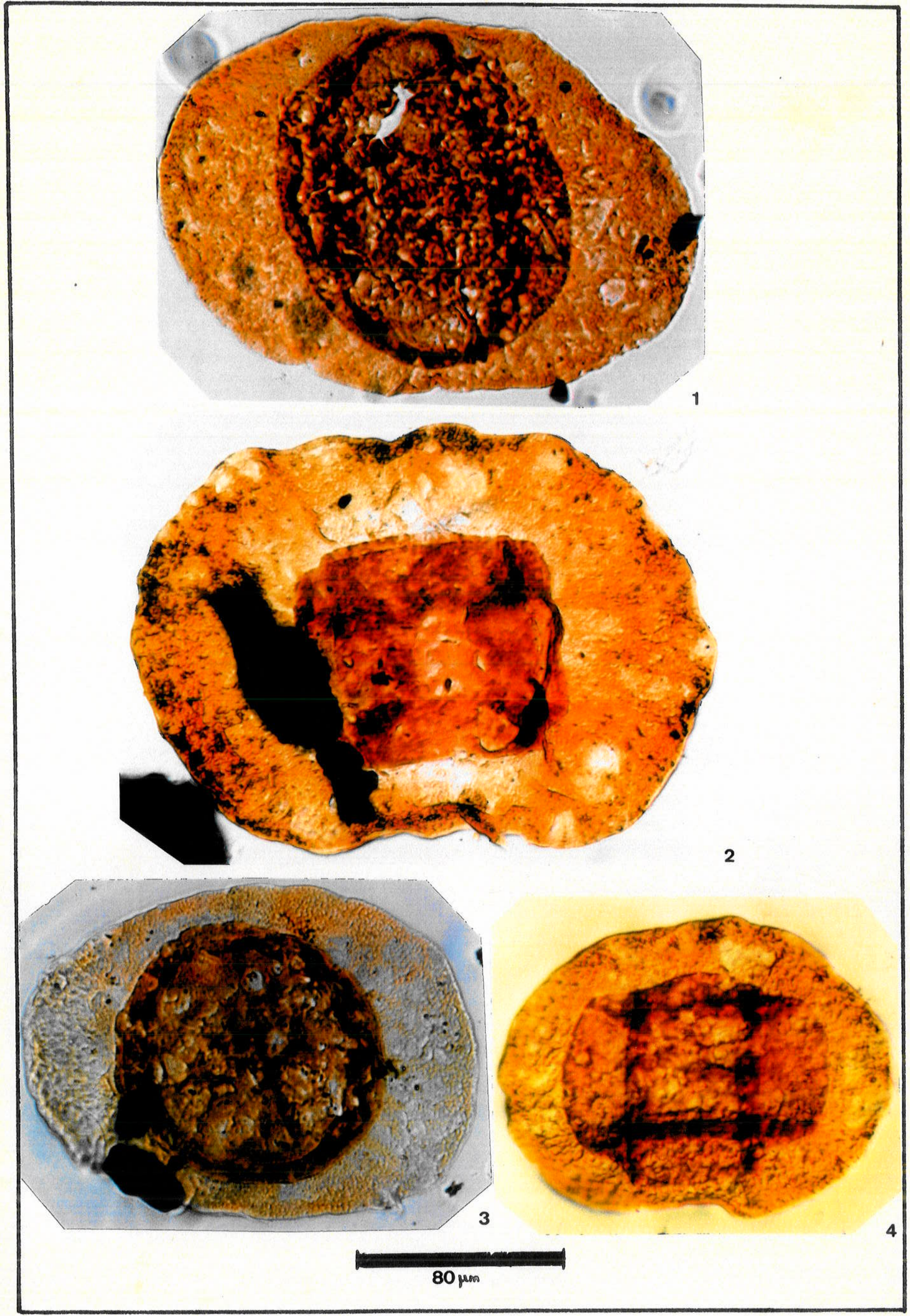




\section{ESTAMPA 09}

1- Potonieisporites cf. P. triangulatus Tiwari, 1965

2- Potonieisporites sp. 1

3- Potonieisporites sp. 2

4, 5 e 6- Caheniasaccites ovatus (Bose \& Kar) Gutierrez, 1993

7- Caheniasaccites densus (Lele \& Karim) Gutierrez, 1993 

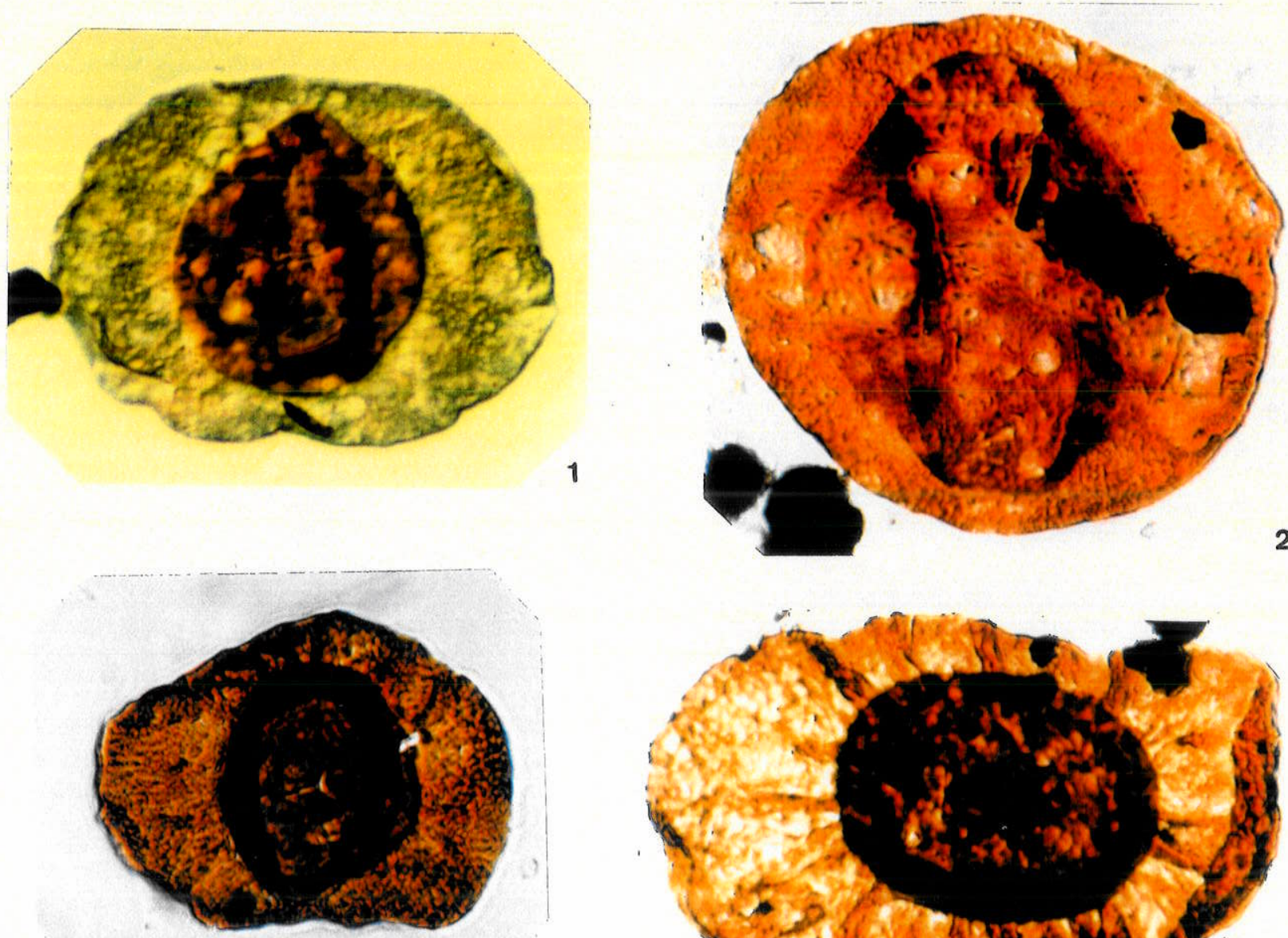

3
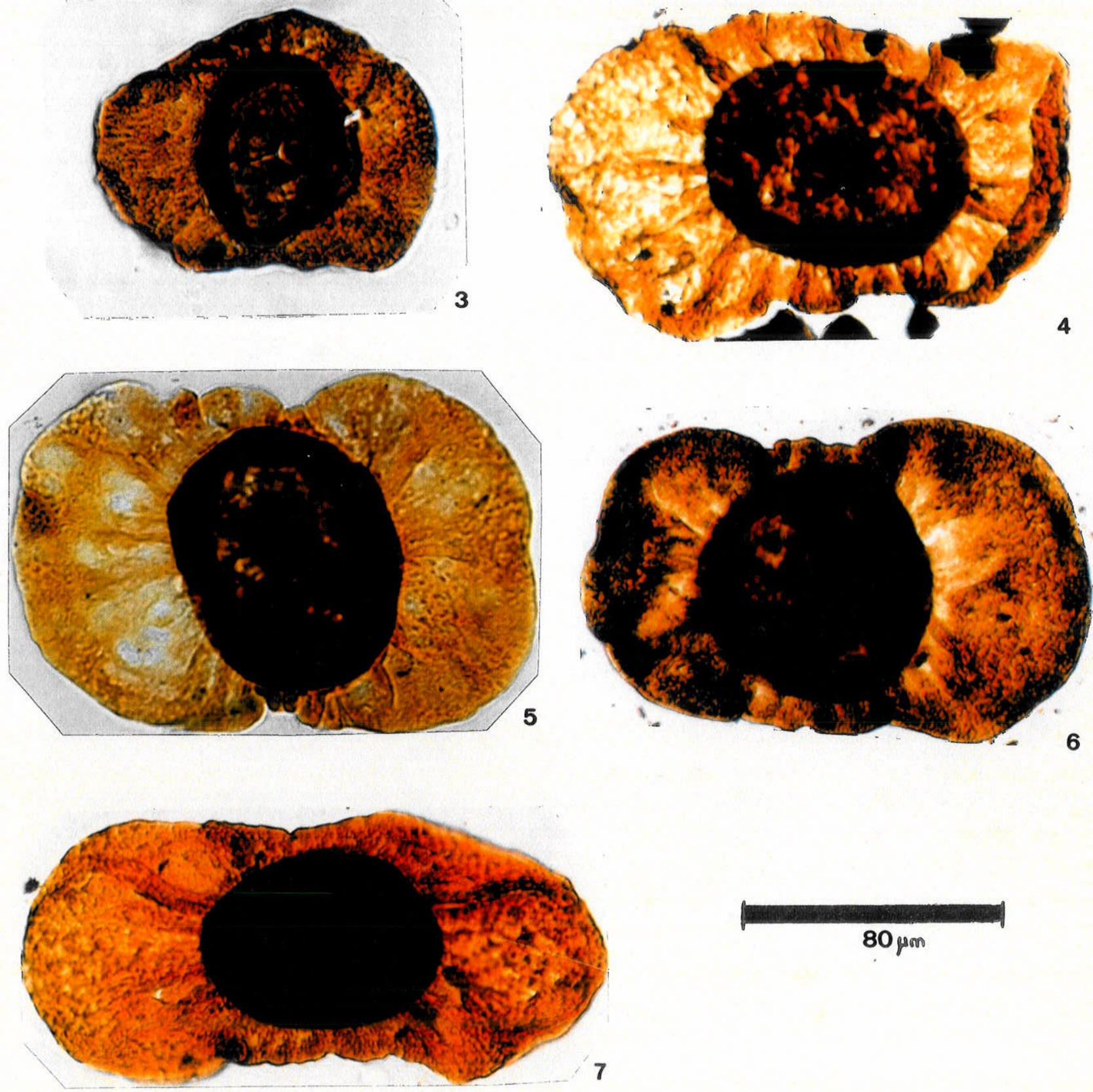

$80 \mu \mathrm{m}$ 


\section{ESTAMPA 10}

1 e 2- Caheniasaccites sp. 1

3 e 4- Caheniasaccites sp. 2

5- Caheniasaccites sp. 3 
ESTAMPA 10

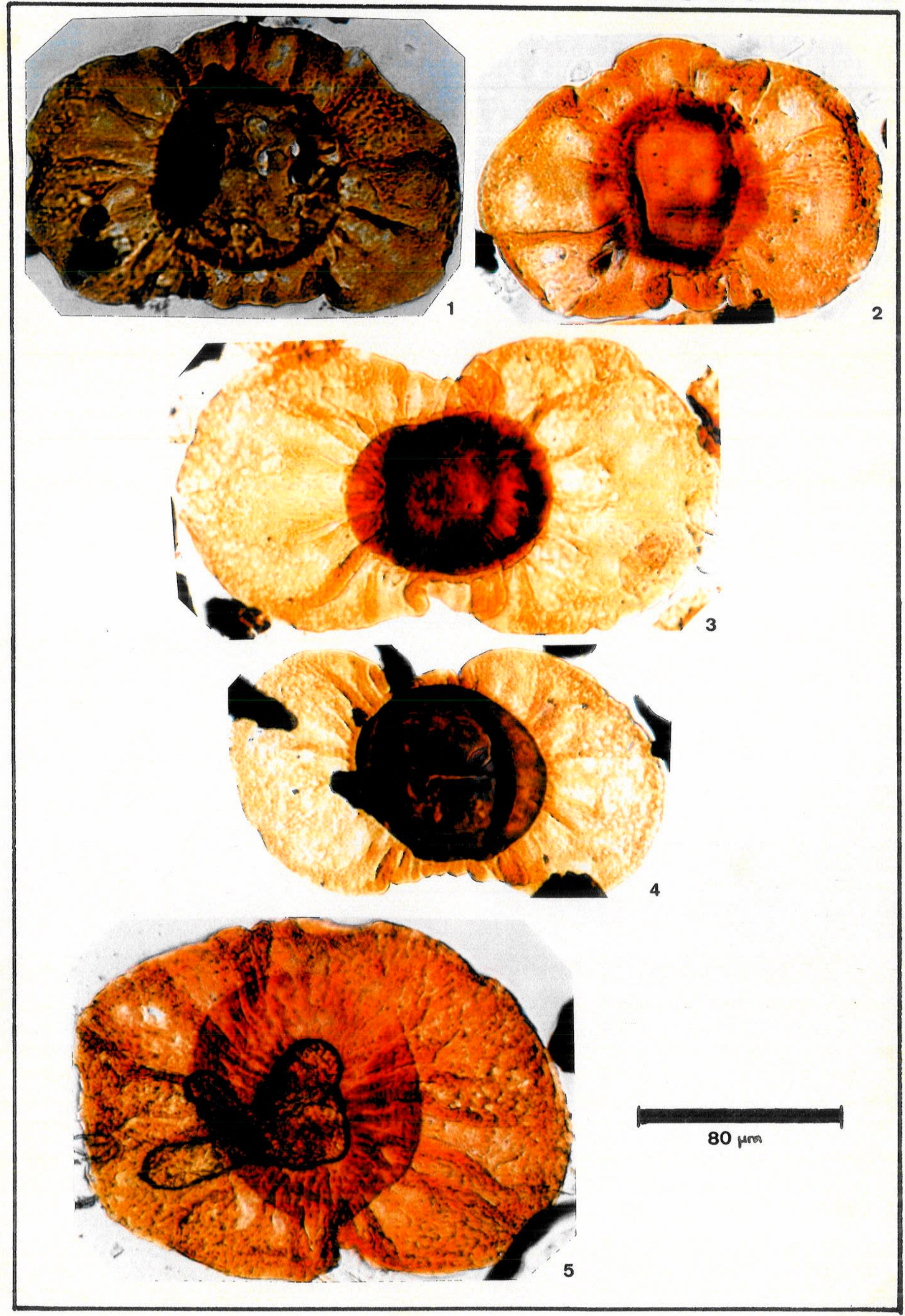




\section{ESTAMPA 11}

1- Striomonosaccites cf. S. ovatus Bharadwaj, 1962

2- Striomonosaccites sp. 1

3- Striomonosaccites $\mathrm{sp} .2$

4- Limitisporites luandensis Bose \& Maheswari, 1968

5- Limitisporites vesiculosus Schaarschmidt, 1963

6- Limitisporites delasaucei (Potonié \& Klaus) Schaarschmidt, 1963

7-Limitisporites sp. 1

8- Limitisporites sp. 2 
ESTAMPA 11

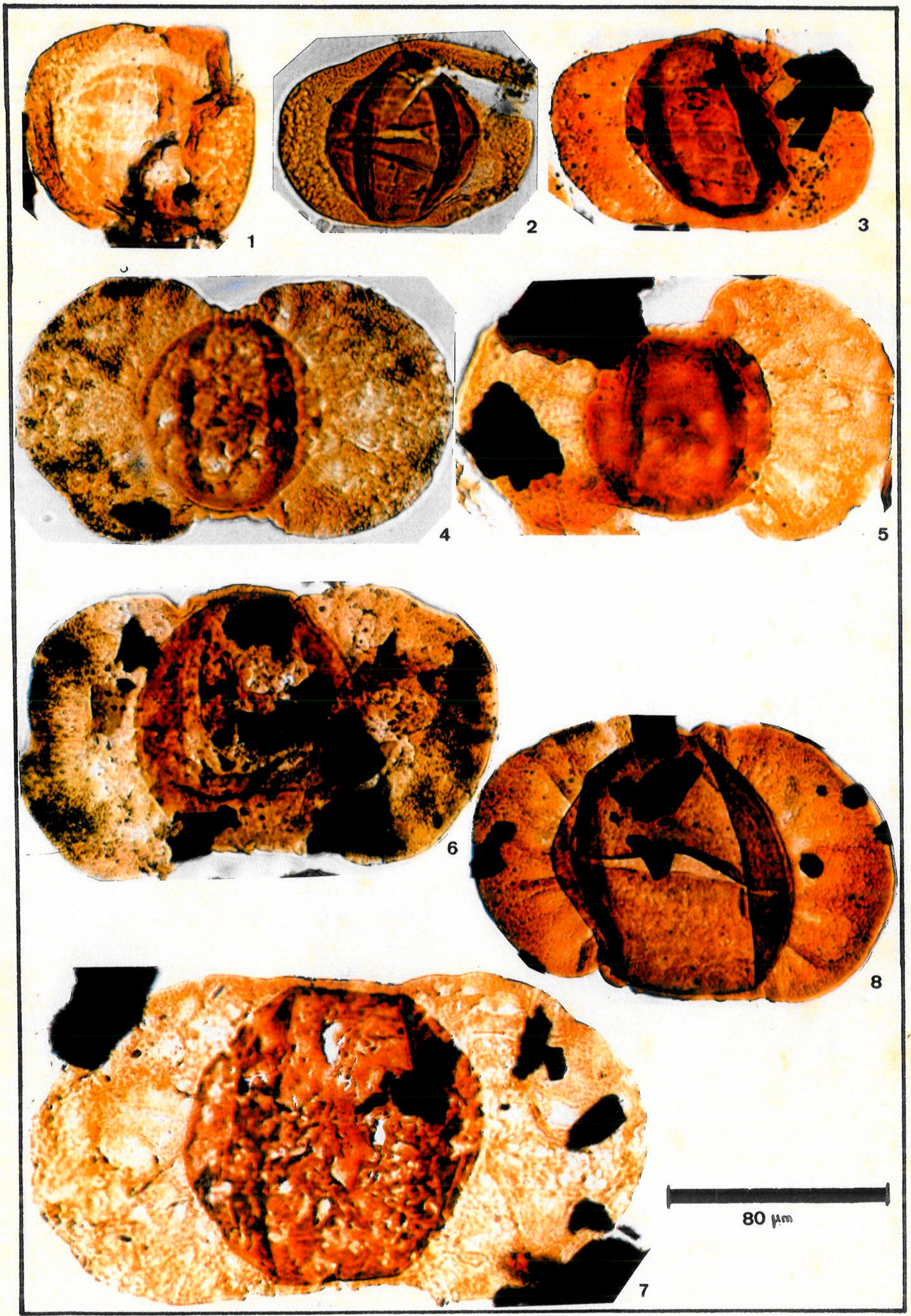




\section{ESTAMPA 12}

1- Protohaploxypinus latissimus (Lüber \& Waltz) Samoilovich, 1953

2- Protohaploxypinus samoilovich (Jansonius) Hart, 1964

3- Protohaploxypinus amplus (Balme \& Hennelly) Hart, 1964

4- Protohaploxypinus chaloneri Clarke, 1965

5- Protohaploxypinus dvinensis (Sedova) Hart, 1964

6- Protohaploxypinus sp.

7- Striatoabieites $\mathrm{sp}$.

8- Navifusa bacillum (Deunf) Playford, 1977

9 e 10- Navifusa sp.

11- Gorgonisphaeridium sp. 
ESTAMPA 12

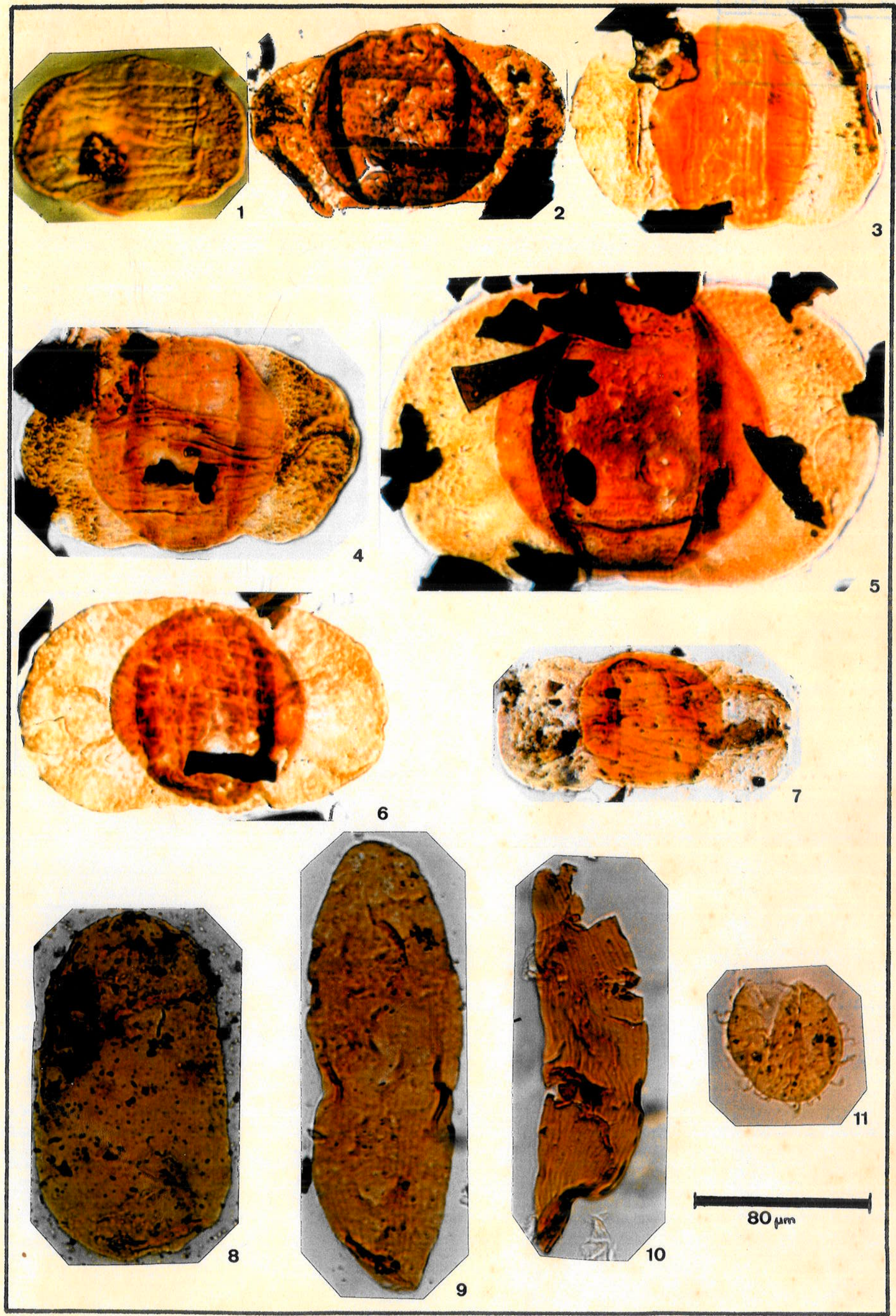

